University of Louisville

ThinkIR: The University of Louisville's Institutional Repository

Electronic Theses and Dissertations

8-1979

\title{
A microprocessor-based mathematics trainer with voice output.
}

Michael Joseph Linnig 1956-

University of Louisville

Follow this and additional works at: https://ir.library.louisville.edu/etd

\section{Recommended Citation}

Linnig, Michael Joseph 1956-, "A microprocessor-based mathematics trainer with voice output." (1979). Electronic Theses and Dissertations. Paper 838.

https://doi.org/10.18297/etd/838

This Master's Thesis is brought to you for free and open access by ThinkIR: The University of Louisville's Institutional Repository. It has been accepted for inclusion in Electronic Theses and Dissertations by an authorized administrator of ThinkIR: The University of Louisville's Institutional Repository. This title appears here courtesy of the author, who has retained all other copyrights. For more information, please contact thinkir@louisville.edu. 


\title{
A MICROPROCESSOR-BASED MATHEMATICS \\ " TRAINER WITH VOICE OUTPUT
}

\author{
By \\ Michael Joseph Linnig \\ B. S., University of Lou'šville, 1978

\begin{abstract}
A Thesis
Submitted to the Faculty of the University of Louisville Speed Scientific School

as Partial Fulfillment of the Requirements

for the Professional Degree
\end{abstract} \\ MASTER OF ENGINEERING
}

Department of Electrical Engineering

August 1979 


\section{A MICROPROCESSOR-BASED MATHEMATIC TRAINER WITH VOICE OUTPUT}

Submitted by:

Michael Joseph Linnig

A Thesis Approved on

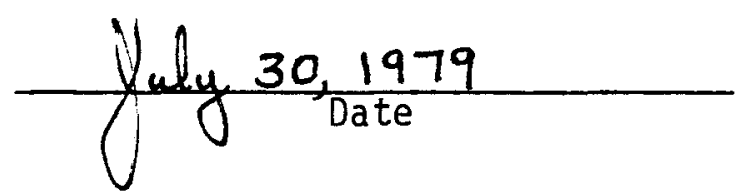

by the Following Reading and Examination Committee:

Thesis director, Barry R. Hordwitz

Donald L. Kalmey

Thomas M. Murray, $8 r$.

Emerson FouTke 


\section{ACKNOWLEDGEMENTS}

The author would like to thank: Dr. Barry R. Horowitz, who first conceived the Mathematics Trainer, for his help and guidance in this project; Dr. Emerson Foulke and Dr. Charles Thompson for their advice in the areas of human factors and education; and the author's associates in The Perceptual Alternatives Lab, especially, Mr. Brian Garvey, Mr. John Kilpatrick, and Mr. Jimmy Ryan. The author would al so like to thank Dr. Peter Aronhime and Mr. Don Fleischer for their help in producing the program Tistings, and Dr. Donald Kalmey and Professor Thomas Murray for serving on his thesis committee. The author is grateful to the Graduate School for their grant that made the device financially possible. Most of all the author would like to thank his parents for their support and encouragement in the past 23 years. 


\section{ABSTRACT}

The design and development of a microprocessor-controlled mathematics trainer is described. The trainer is designed primarily for a blind student, and uses synthetic speech to verbally present mathematics problems in the form of incomplete mathematical sentences. The student responds via numeric keypad. Feedback is given to the student immediately after each problem and after each problem session. Several options give the teacher flexibility in pacing the student. In addition, the teacher can create individualized problem sets or choose from many predefined problem sets, arranged in order of difficulty. 
ACKNOWLEDGEMENTS.$\ldots \ldots \ldots \ldots \ldots \ldots \ldots \ldots \ldots \ldots \ldots \ldots \ldots \ldots \ldots \ldots$

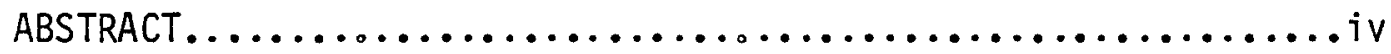

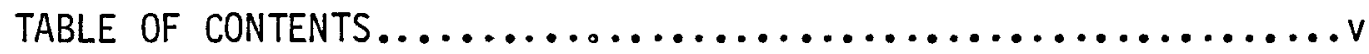

LIST OF TABLES..................................... viii

LIST OF FIGURES $\ldots \ldots \ldots \ldots \ldots \ldots \ldots \ldots \ldots \ldots \ldots \ldots \ldots \ldots \ldots \ldots \ldots$

I. INTRODUCTION.................................

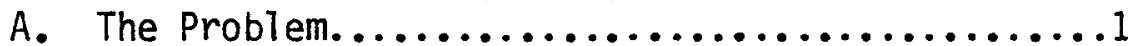

B. Project Motivation........................

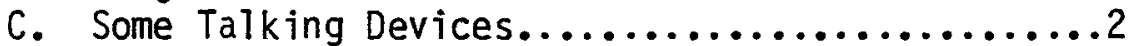

1. Texas Instruments' "Speak and Spell".......2

2. The "Speed Plus" Calculator..................

3. The Votrax............................

II. FUNCTIONAL SPECIFICATIONS AND MAN-MACHINE INTERFACE ...4

A. Device Overview..........................4

B. Problem Generation........................

1. Range Mode.........................

2. Level of Difficulty....................9

C. Problem Presentation........................10

1. Learning Considerations.................10

a. Format...........................

b. Pacing Options.....................15

2. Man-Machine Considerations.................15

D. Teacher Programming.......................

III. SYSTEM DESIGN................................20

A. System Requirements.......................20

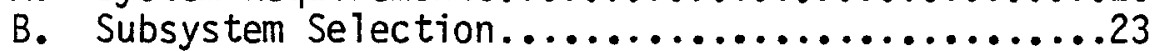

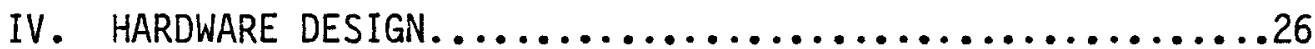

A. The Development System....................26

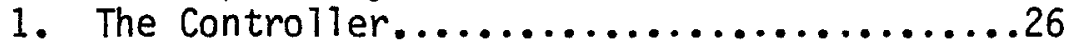

2. Memory Expansion.......................26

B. Final System Design.......................27

1. The Controller.......................27

2. Firmware...........................30

3. Interface Circuitry....................32

a. Overview...........................32

C. Display and Keyboard Circuitry...............35 


\section{TABLE OF CONTENTS (continued)}

1. Seven Segment Displays....................35

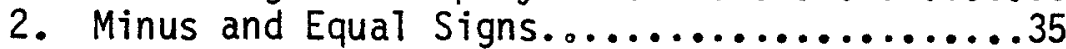

3. Emergency Blanking Circuit.................35

4. Operation Sign.........................37

5. User Prompts.........................37

6. Interface Summary....................41

V. SOFTWARE.................................45

A. Software Development.....................45

B. The Software..........................46

1. Control Subroutines....................48

a. MAIN Program......................48

b. DRILL Subroutine...................53

c. PROGRAM Subroutine...................53

d. REPORT Subroutine....................58

e. TEACH Subroutine.....................58

2. Input/Output Subroutines................62

a. BLANK Subroutine..................62

b. BLANKIT Subroutine..................62

c. DISPLAY Subroutine..................62

d. GETDIS Subroutine....................62

e. GETEM Subroutine....................68

f. PACK Subroutine....................68

g. SAYDISP Subroutine................68

h. SCAN Subroutine.....................68

i. SPKEY Subroutine.....................77

j. SFKWD and LDPAUS Subroutines............77

k. UNPACK Subroutine...................81

1. WAIT Subroutine....................81

3. Arithmetic Subroutines..................81

a. ADDEM Subroutine....................85

b. BCDADD Subroutine....................85

c. BCDINC Subroutine....................85

d. BCDMULT Subroutine...................85

e. BISUB Subroutine....................85

f. COMPARE Subroutine..................89

g. DADD Subroutine....................89

h. GETANS Subroutine..................89

$i$. HI-LO Subroutine....................93

j. RANDOM Subroutine...................93

4. Special Function Subroutines...............93

a. ERROR Subroutine..................97

b. GENERATE Subroutine.................97

c. INTERRUPT Program.................97

d. LINK............................97

e. LOADX Subroutine.......................101

f. MINTOBI Subroutine...................101

g. OPGEN Subroutine.....................101

h. RIGHT Subroutine.....................107

i. RESTART Program......................107

j. SAYNUM Subroutine.....................107

k. TBLOOK Subroutine.....................110

1. 2BEEP Subroutine....................110 
TABLE OF CONTENTS (continued)

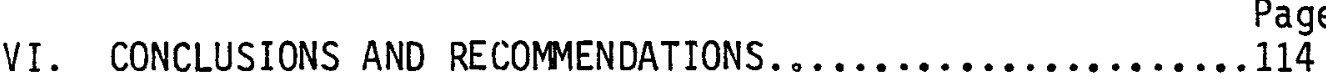

A. Cost Analysis..........................114

B. Device Improvement Recommendations............114

C. Notes on Doing Similar Projects..............116

REFERENCES CITED..............................118

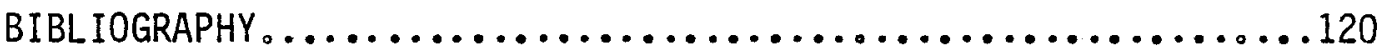

APPENDIX I DEVELOPMENT CIRCUITRY..............................

APPENDIX II DEVICE HARDWARE DOCUMENTATION.................... 128

APPENDIX III DEVICE SOFTWARE DOCUMENTATION.................. 143

APPENDIX IV PROCEDURE FOR BURNING EPROMs.................

APPENDIX $V \quad$ USERS MANUAL...............................200

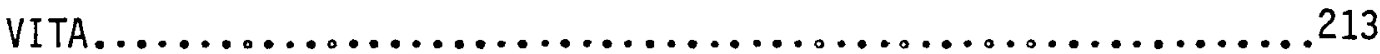




\section{LIST OF TABLES}

TABLE I ADDITION PROBLEM SETS....................... Page

TABLE II SUBTRACTION PROBLEM SETS...................12

TABLE III MULTIPLICATION AND DIVISION PROBLEM SETS $\ldots \ldots \ldots \ldots . .13$

TABLE IV 64 -WORD SYNTHESIZER VOCABULARY.............18

TABLE $V$ DEVICE ADDRESS SUMMARY...................43

TABLE VI DEVICE CONTROL CODES....................44

TABLE VII GLOSSARY OF SUBROUTINES $\ldots \ldots \ldots \ldots \ldots \ldots \ldots \ldots . \ldots 49$

TABLE VIII OPERAND RANGE AS DETERMINED BY A-REGISTER......... 105

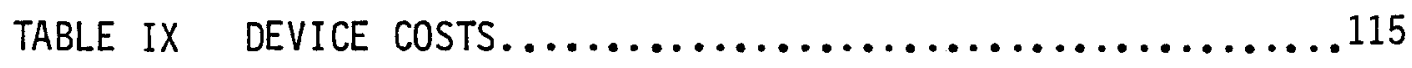

APPENDIX II

TABLE I CONNECTOR INFORMATION...................... 140

APPENDIX III

TABLE I SYMBOL TABLE.............................144

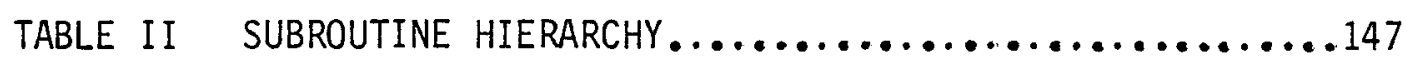

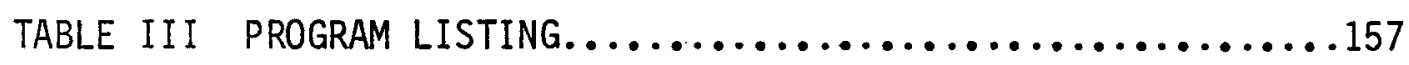

APPENDIX IV

TABLE I ADDITION PROBLEM SETS.................. 206

TABLE II SUBTRACTION PROBLEM SETS.................... 207

TABLE II I MULTIPLICATION AND DIVISION PROBLEM SETS........ 208 


\section{LIST OF FIGURES}

Figure 1 Math Trainer............................. 5

Figure 2 Keyboard Detai1..........................6

Figure 3 Device Flowchart (Users view) $. \ldots \ldots \ldots \ldots \ldots \ldots . .$.

Figure 4 Programming Event Sequence................... 19

Figure 5 System Overview..........................21

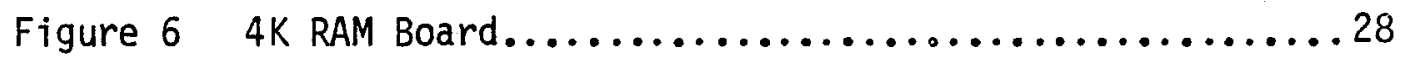

Figure 7 Memory Protect Circuit.....................29

Figure 8 RESET Circuit............................ 31

Figure 9 EPROM Circuit........................... 33

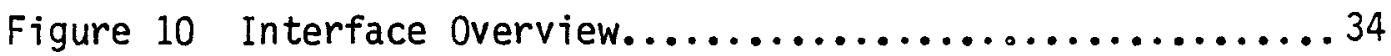

Figure 11 7-Segment Display Circuit...................... 36

Figure 12 Emergency Blanking Circuit..................38

Figure 13 Operation Sign Matrix.......................... 39

Figure 14 0peration Sign Circuitry.....................40

Figure 15 Prompt Circuit...........................42

Figure 16 MAIN Subroutine......................... 52

Figure 17 DRILL Subroutine........................ 54

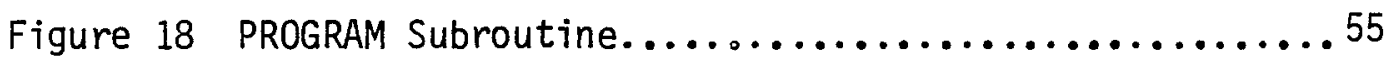

Figure 19 REPORT Subroutine....................... 59

Figure 20 TEACH Subroutine $\ldots \ldots \ldots \ldots \ldots \ldots \ldots \ldots \ldots \ldots . \ldots . \ldots . \ldots$

Figure 21 BLANK Subroutine.........................63

Figure 22 BLANKIT Subroutine.......................6 64

Figure 23 DISPLAY Subroutine $\ldots \ldots \ldots \ldots \ldots \ldots \ldots \ldots \ldots \ldots \ldots$

Figure 24 GETDIG Subroutine.....................66 
Figure 25 GETEM and PACK Subroutines......0.0.0.0.0.0.0.0.69. Page

Figure 25 GETEM and PACK Subroutines....................69

Figure 26 SAYDISP Subroutine..............................

Figure 27 SCAN DISPLAY Subroutine....................72

Figure 28 CHECK SPEECH Subroutine.....................

Figure 29 Circular FIFO (Speech Buffer).................75

Figure 30 CHECK TIME \& KEY DEBOUNCE Subroutine..............78

Figure 31 Finite State Representation of Key Debounce.........79

Figure 32 SPKEY Subroutine..........................80

Figure 33 SPKWD and LDPAUS Subroutines..................82

Figure 34 UNPACK Subroutine.........................83

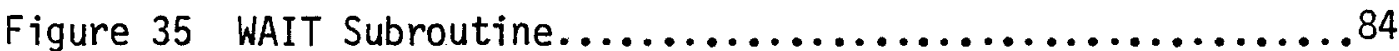

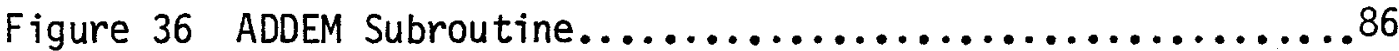

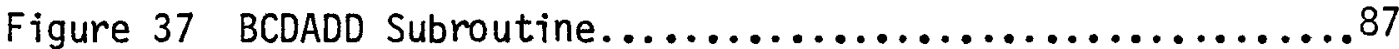

Figure 38 BCDINC Subroutine....................... 87

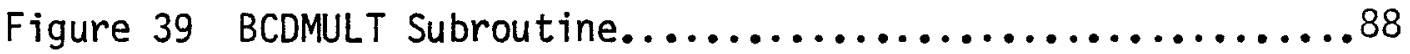

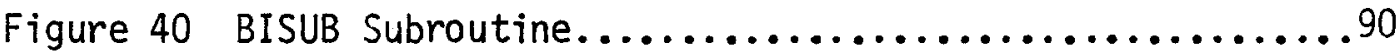

Figure 41 COMPARE Subroutine.........................90

Figure 42 DADD Subroutine........................... 91

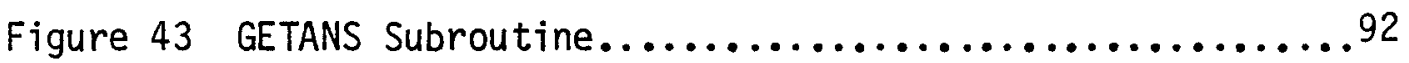

Figure 44 How HI-LO works............................ 94

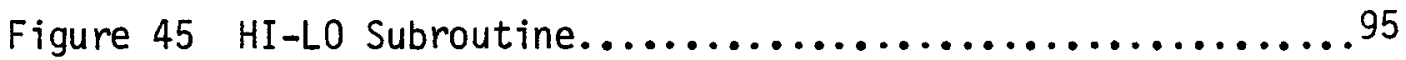

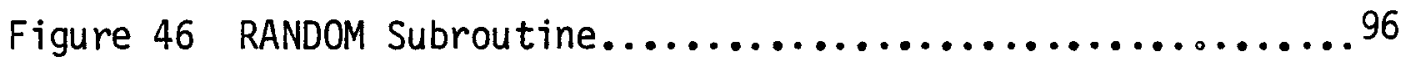

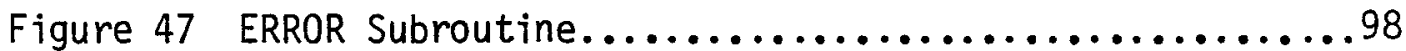

Figure 48 GENERATE Subroutine...........................

Figure 49 INTERRUPT Subroutine........................... 100

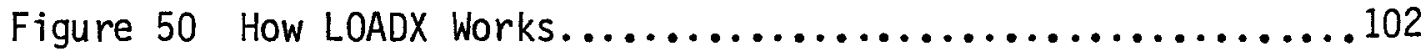


Page

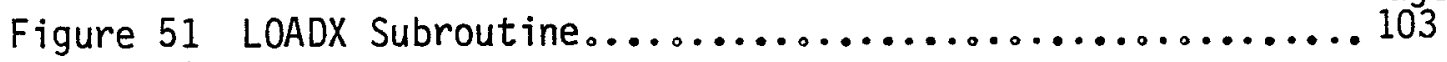

Figure 52 MINTOBI Subroutine........................ 104

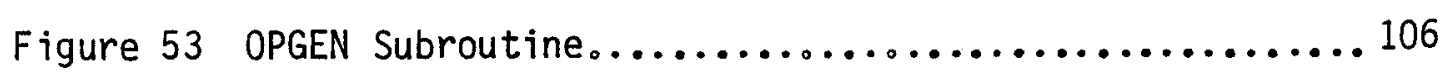

Figure 54 RIGHT Subroutine......................... 108

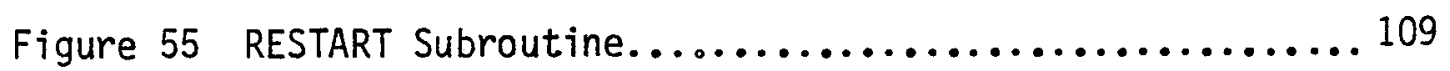

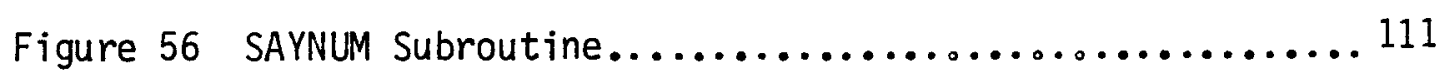

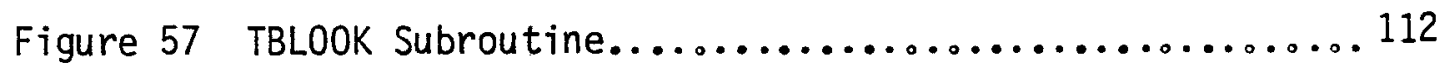

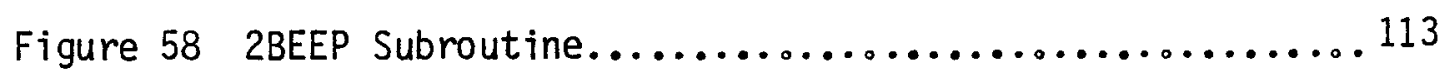

Appendix I

Figure 1 D2 Board Microcomputer Module................. 122

Figure 2 4K RAM Board........................... 126

Figure 3 Memory Protect Circuit..................... 127 Appendix II

Figure $1 \quad D 1$ Board wi th Changes..................... 129

Figure 2 Display Board Circuitry..................... 131

Figure 3 EPROM Board Circuitry.................... 136

Figure 4 Keyboard Circuitry....................... 137

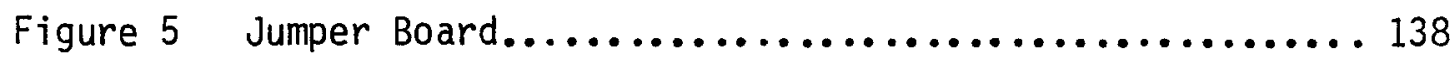

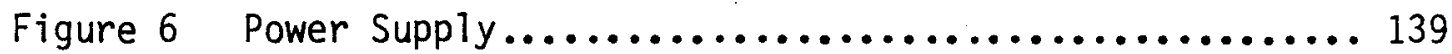
APPENDIX IV

Figure $1 \quad 02$ to Prolog Interface.................... 197 APPENDIX $V$

Figure 1 Math Trainer Layout......................... 201

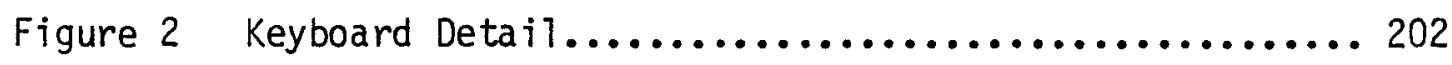




\section{INTRODUCTION}

Research has shown that, on the average, unsighted students score lower than do sighted students on standardized achievement tests,

such as the SAT. ${ }^{1}$ Math skill exhibited a definite deficiency. ${ }^{2}$ The area to which this thesis is aimed is that of mathematics and the blind student.

\section{A. The Problem}

A blind student is at a disadvantage when compared to the sighted student. The manipulative skills (e.g., scratchwork on paper, problem visualization) that the sighted student routinely employs in working mathematics problems are not as easily employed by the blind student.

Nolan and Ashcroft ${ }^{3}$ and, more recently, Brothers ${ }^{4}$ reported that blind students average between eight to fifteen percent lower on SAT scores than do sighted students. Brothers ${ }^{5}$ attributes this deficit to the arithmetic computational ability of the blind student. Mathematics skills, therefore, is an area where assistance in training the blind student is strongly needed.

\section{B. Project Motivation}

The need for assistance in the area of mathematics training of the blind has been demonstrated above. One device that is currentiy in use to aid visually handicapped students is the Speech-Plus talking calculator. Originality developed by Telesensory Systems, Inc., 6 
the talking calculator was later modified by The American Printing House for the Blind to include a speech rate control. A survey of schools using talking calculators ${ }^{7}$ reported the following as frequent applications: teaching number concepts; teaching general and remedial mathematics; and use as a replacement for braille calculators, the abacus, or slide rules for those students who can't or won't use these instruments because they are too cumbersome.

The obvious utility of spoken output prompted the author to pursue the creation of a talking mathematics trainer. Although a braille-output trainer is feasable; only about $21 \%$ of visually handicapped students read braille. 8

\section{Some Talking Devices}

A review of the appropriate literature revealed no references to a talking mathematics trainer. However, some devices incorporating synthesized speech are worth reviewing.

\section{Texas Instruments" "Speak and Spe11}

The "Speak and Spe17", although teaching a different subject, comes remarkably close to what a mass produced talking math trainer would be like. The "Speak and Spe11", selling for only $\$ 48.00$ has a vocabulary of about 200 words. The device verbally presents words to be spelled and the user enters answers via an alphabetic keyboard. The "Speak and Spell also has an alphabetic LED display, used to show the student's entries. The synthesizer used by the "Speak and Spe11" is a monolithic device using an advanced linear predictive coding algorithm. 
2. The "Speech Plus" Calculator 10

The "Speech P1us" calculator has been mentioned previously. It is a small calculator designed for the blind student. It contains a Read Only Memory (ROM) circuit that stores the speech. The contents of the ROM are clocked out under control of a ROM Controller. The digital speech signal is routed to a resistor network which serves as a digital to analog converter. A more advanced version of the "Speech Plus" synthesizer was chosen as the synthesizer for the Math Trainer. 3. The Votrax 11

The Votrax is a phoneme oriented speech synthesizer. With the Votrax, a user can form words by stringing together several basic sounds called phonemes. The use of a phoneme structured device like the Votrax permits an almost unlimited vocabulary. However, each word must be coded by hand, or the phonemes must be chosen by an extremely large program that performs speech synthesis by rule, in order to get a good approximation to human speech.

The aim of the present work is to design and construct a talking mathematics trainer that will assist the visually handicapped student in acquiring basic number skills. 
II. FUNCTIONAL SPECIFICATIONS AND MAN-MACHINE INTERFACE

\section{A. Device Overview}

A proof-of-concept prototype has been designed to tutor a visually handicapped student in the four basic arithmetic operations: addition, subtraction, multiplication, and division. The device uses speech in order to present the student with an incomplete mathematical sentence such as "three plus two equals blank". The student will use a numeric keypad to enter a choice of what should be in the blank. A sketch of the device is shown in Figs.1 and 2 . The device will inform the student of the response's correctness. If the answer is incorrect, the device will repeat the problem. If the student fails to enter the correct response the second time, the device will inform the student of the response's incorrectness and will speak the entire problem with the correct answer in its proper place. If the student's answer is correct, the device will indicate that the response is correct and speak the complete mathematical sentence with the answer in place. After each problem, the device records the correctness of the student's answer and the amount of time that it took the student to respond. After the student has completed $\mathrm{a} 11$ of the problems that the teacher has assigned, the device reports the number of correct answers, the total number of problems attempted, and the tota 1 response time.

The teacher is able to select how the problems will be presented to the student. Problem sets may be setup on the basis of: 1) a maximum 


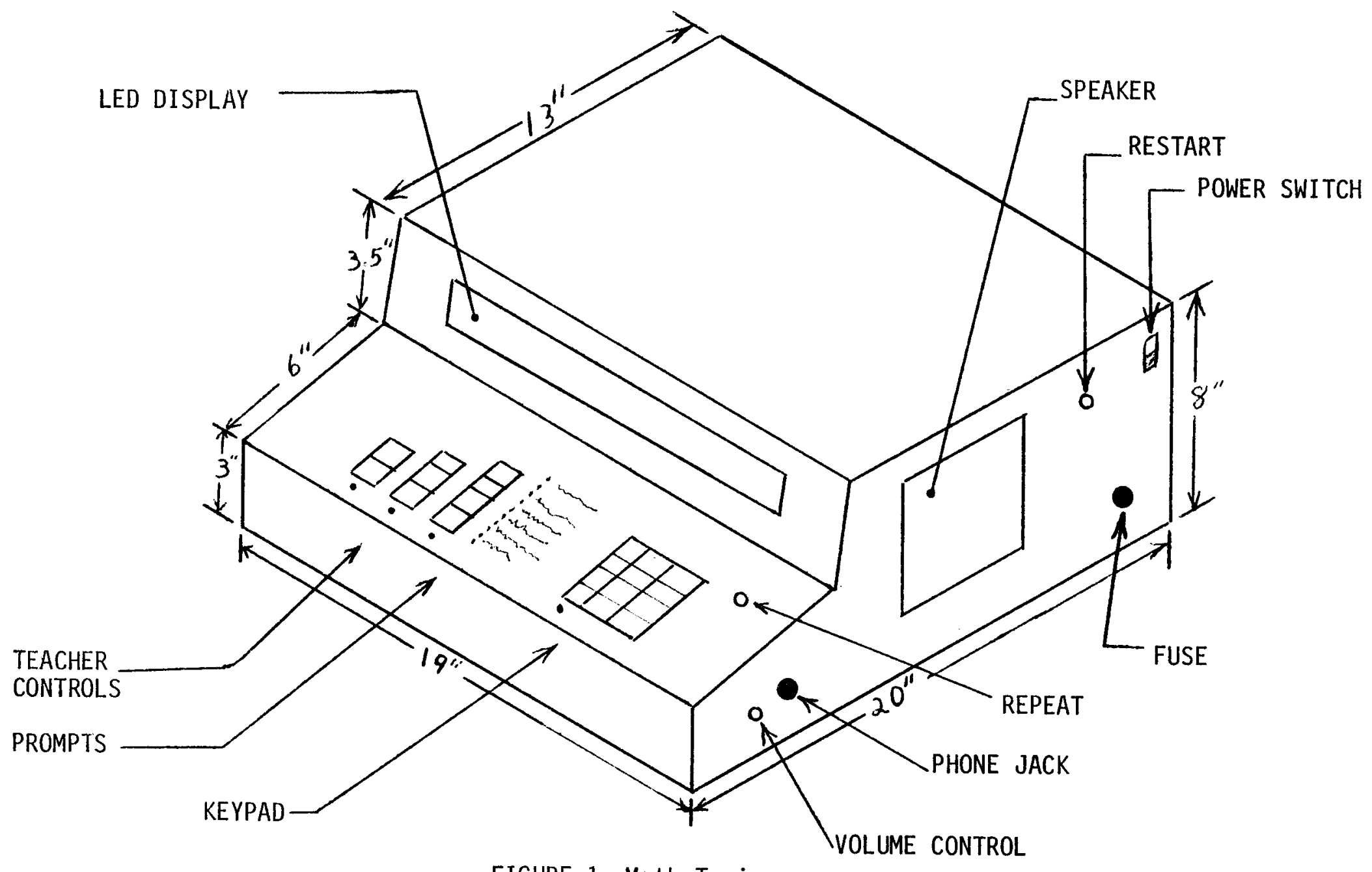

FIGURE 1 Math Trainer 

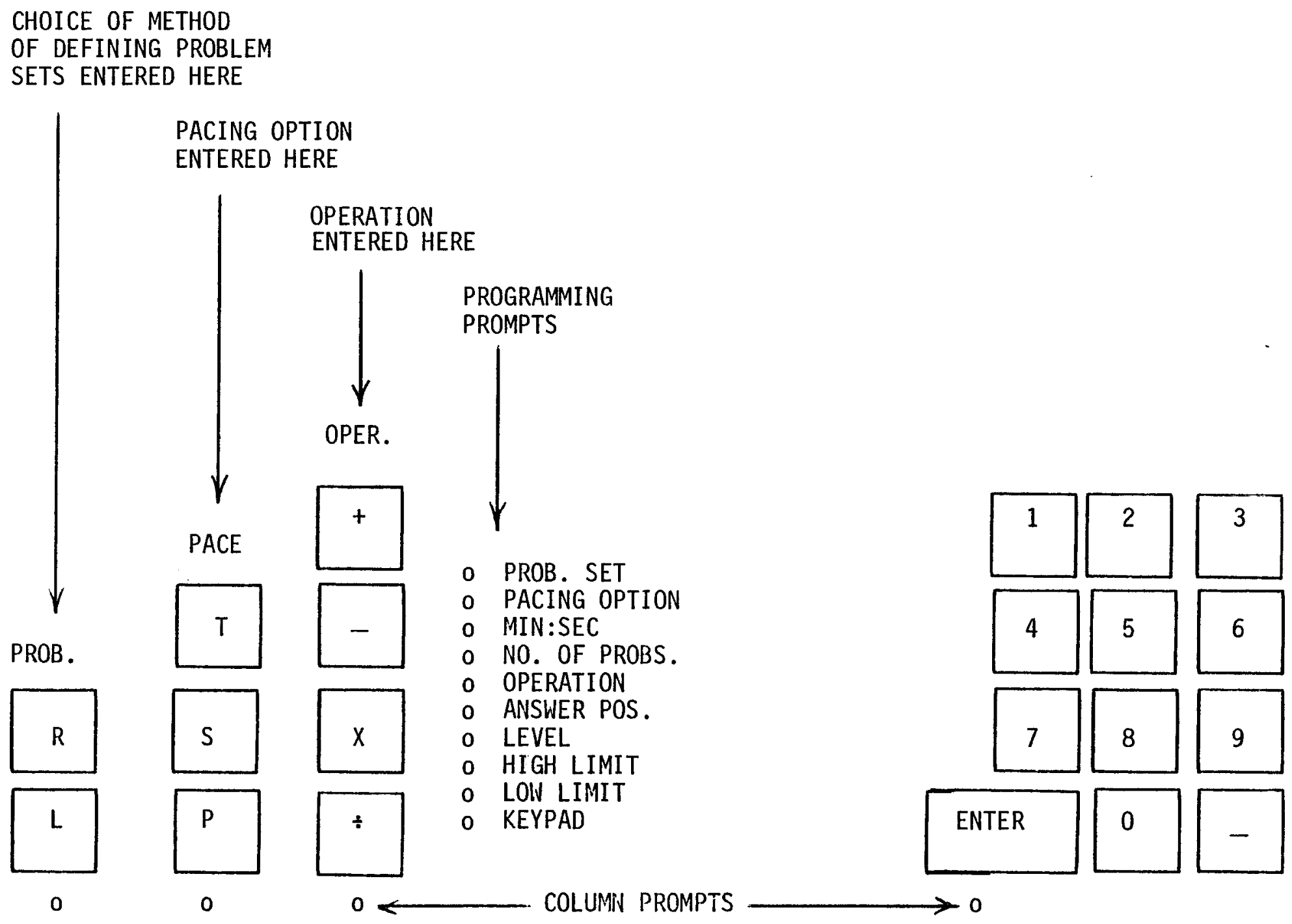

FIGURE 2 - Keyboard Detail. Prompt labels are in both print and braille. 
total response time, 2) a Power mode, with a fixed number of problems and unlimited time, or 3) a Speed mode where the student has a fixed amount of time per problem and a fixed number of problems in the problem set.

The teacher is also able to define the contents of the problem sets. In addition to specifying the operation involved (addition, etc.), the teacher can delimit the problem sets using two different modes. In one mode, the teacher supplies the device with the level of difficulty desired. In the other mode, the teacher supplies the upper and lower bounds on the two operands needed to define the problems. The problems are generated randomly within a given problem set. The overall sequence of events in the operation of the device is shown in Figure 3 . Each problem set is repeatable, so the teacher can determine which type of problem the student finds the most difficult. A discussion of the choices made with regard to problem set generation, as well as learning modes, is presented in the following sections.

\section{B. Problem Generation}

1. Range mode

In the Range mode, the teacher defines the problem set by keying in the upper and lower limits for each of the independent variables (OPERANDS) of the problem. The device generates a random number between or equal to, the higher and lower limits for the first operand. This random number then becomes the actual value of the first operand. This process is repeated for the second operand. Once the two operands have been determined, the device will perform 


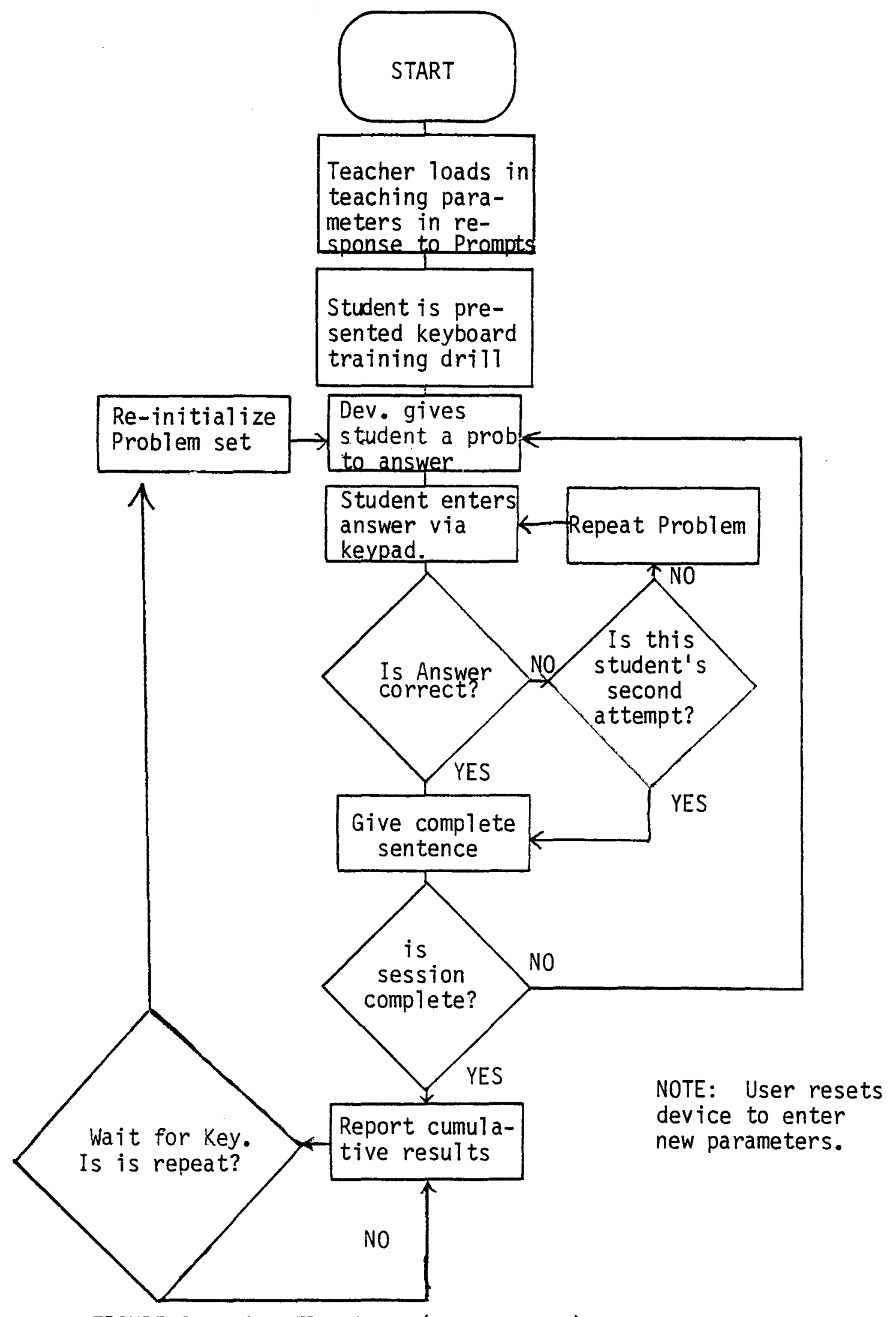

FIGURE 3 Device Flowchart (User's View) 
the mathematical operations necessary to solve for the dependent variable.

This mode allows the teacher to tailor problem sets to a student's specific needs. If, for example, a student is having trouble solving problems involving multiplication by three, the teacher could have the device present only problems that have three as the second operand. This could be accomplished by setting both of the limits of the second operand equal to three. 2. Level of Difficulty Mode

In the level of difficulty mode, the teacher supplies a level number to the device; that number corresponds to a specific predefined problem set. Those problem sets are arranged so that, for a given operation, they are progressively more difficult as the level number increases.

The Level mode forms a fixed learning program for the student. The teacher needs only to increment the level number, after the student becomes proficient in the present level, in order to proceed sequentially to the next more difficult problem set. of course, the teacher must train the student in the mathematical mechanics necessary for each problem set.

In selecting the problem set for each level, every effort was made to present the computational concepts in the same order as is currently employed in the elementary schools. ${ }^{12}$ One of the major determinants of problem set difficulty is the presence of problems that involve regrouping. Regrouping is a term used in education to denote the occurrence of a carry in addition or a borrow in subtraction. 
The device will discriminate between problems that have regrouping for addition and subtraction. (The problem set definitions for addition and subtraction are shown in TABLES I and II.) Because division is normally taught as the conceptual inverse of multiplication, ${ }^{13}$ it was decided that the division problem sets would be the inverses of the multiplication problem sets (see TABLE III).

\section{Problem Presentation}

\section{Learning Considerations}

a. Format. The device is designed to be used by students in elementary school; therefore the problem sets will be limited to integer arithmetic. Generally, non-integer (rational) arithmetic is not introduced to the student until later. ${ }^{14}$ Since the integers are not closed under division, only problems that have integer quotients are generated.

It was decided that a signed three digit display would give the device sufficient capability to present the types of problems that are usually taught at the elementary school level.

Often, problems that are presented in the students' textbooks, have the missing number in positions other than to the right of the equals sign. Because of this, the device will allow the teacher to change the position of the missing number to correspond to any of the three positions in the problem sentence.

In teaching machines, one often finds that a student is given a couple of attempts at each problem before being scored incorrect. A good example of the above is Texas Instrument's Speak and Spe11, which is a spelling trainer. ${ }^{15}$ Given that synthesized speech may be 


\section{TABLE I}

ADDITION PROBLEM SETS

\begin{tabular}{lll}
\hline $\begin{array}{c}\text { Problem Set } \\
\text { Level }\end{array}$ & R a n ge of 0 pe $r$ a n d $s$ \\
\hline 1 & Augend & Addend \\
\hline 2 & 0 to 4 & 0 to 4 \\
3 & 0 to 4 & 5 to 9 \\
4 & 5 to 9 & 0 to 4 \\
5 & 5 to 9 & 5 to 9 \\
6 & 0 to 9 & 0 to 9 \\
7 & $0,10,20, \ldots, 90$ & 0 to 9 \\
8 & 0 to 9 & $0,10,20, \ldots 90$ \\
$9 *$ & $0,10,20, \ldots 90$ & $0,10,20, \ldots 90$ \\
$10^{*}$ & 10 to 99 & 0 to 9 \\
11 & 0 to 9 & 10 to 9 \\
12 & 10 to 99 & 0 to 9 \\
$13^{*}$ & 0 to 99 & 10 to 99 \\
14 & 19 to 99 & 10 to 99 \\
$15^{*}$ & 10 to 99 & 10 to 99 \\
$16^{*}$ & 100 to 499 & 0 to 9 \\
17 & 0 to 9 & 100 to 499 \\
18 & 100 to 499 & 0 to 9 \\
$19^{*}$ & 0 to 9 & 100 to 499 \\
$20 *$ & 100 to 499 & 10 to 99 \\
21 & 10 to 99 & 100 to 499 \\
22 & 100 to 499 & 10 to 99 \\
$23^{*}$ & 10 to 99 & 100 to 499 \\
24 & 100 to 499 & 100 to 499 \\
25 & 199 to 499 & 100 to 499 \\
26 & 100 to 499 & -499 to 499 \\
27 & -499 to 499 & 100 to 499 \\
& -499 to 499 & -499 to 499
\end{tabular}

*NOTE: Indicates that problems containing regrouping are not members of the problem set. 
TABLE II

SUBTRACTION PROBLEM SETS

\begin{tabular}{lll}
\hline $\begin{array}{c}\text { Problem Set } \\
\text { Level }\end{array}$ & Range of 0 p e $r$ a n d $s$ \\
\hline $1^{*}$ & 0 Minuend & Subtrahend \\
$2^{*}$ & 0 to 4 & 0 to 4 \\
$3^{*}$ & 0 to 4 & 5 to 9 \\
$4^{*}$ & 5 to 9 & 0 to 4 \\
$5^{*}$ & 5 to 9 & 5 to 9 \\
$6^{* *}$ & 0 to 9 & 0 to 9 \\
7 & 10 to 99 & 10 to 99 \\
8 & $0,10,20, \ldots, 90$ & 0 to 9 \\
$9 * *$ & 10 to 99 & 0 to 9 \\
$10^{* *}$ & 10 to 99 & 0 to 9 \\
11 & 100 to 499 & 0 to 9 \\
$12^{* *}$ & 100 to 499 & 0 to 9 \\
13 & 100 to 499 & 10 to 99 \\
$14 * *$ & 100 to 499 & 10 to 99 \\
15 & 100 to 499 & 100 to 499 \\
16 & 0 to 9 & 0 to 9 \\
17 & 19 to 99 & 10 to 99 \\
18 & 100 to 499 & 100 to 499 \\
19 & 0 to 9 & -9 to 9 \\
20 & -9 to 9 & 0 to 9 \\
$21^{*}$ & -9 to 9 & -9 to 9 \\
& -499 to 499 & -499 to 499
\end{tabular}

*NOTE: Indicates the given operand ranges are actually those of the augend and addend in the complementary addition problems.

* NOTE: Indicates that problems containing regrouping are not members of the problem set. 
TABLE III

MULTIPLICATION AND DIVISION PROBLEM SETS

\begin{tabular}{cll}
\hline $\begin{array}{c}\text { Problem Sets } \\
\text { Level }\end{array}$ & Range of & Ope ra n $\mathrm{p}^{*}$ \\
\hline 1 & 0 Multiplicand & Multiplier \\
\hline 2 & 0 to 4 & 0 to 4 \\
3 & 0 to 9 & 0 to 9 \\
4 & 0 to 9 & 0 to 4 \\
5 & $0,10,20, \ldots, 90$ & 0 to 9 \\
6 & 0 to 9 & 0 to 9 \\
7 & 0 to 9 & $0,10,20, \ldots, 90$ \\
8 & 10 to 99 & 10 to 99 \\
9 & 10 to 30 & 0 to 9 \\
10 & 0 to 9 & 10 to 30 \\
11 & -9 to 9 & -9 to 9 \\
12 & -30 to 30 & 0 to 9 \\
& & -30 to 30
\end{tabular}

*NOTE: For division the problem is generated by the multiplication of numbers within the ranges in the table. The product is then placed in dividend position. 
difficult to recognize, it was felt that to give the student only one chance per problem would be unduly frustrating. It was decided that the device will give the student two attempts at getting each problem correct.

Without feedback, the student would not be able to learn from making errors. The device provides two forms of feedback. The first is immediate item-by-item feedback. According to Holding, "Separate or item-by-item feedback is very effective in teaching machines" 16 After the student enters an answer, the device immediately informs the student of the answer's correctness. The second type of feedback is what Holding terms "accumulated feedback". In the device, the feedback consists of reporting the number of correct answers, the number of attempted problems, and the total amount of time the student took to answer the problems in the problem set. Holding points out that this type of feedback is especially good for increasing motivation.

One of the skills that is generally taught, alongside the math skills, is the proper speaking of multidigit numbers. Students are taught to pronounce 214 as "two hundred fourteen", and not as "two one four". The decision was made that the device would pronounce its numbers in the proper way.

The device also has the capability to repeat a problem set verbatim. The major use of this feature would be if the teacher noticed that the student had difficulty with the present problem set. The teacher could then cause the problem set to be repeated, and observe the types of problems that give the student the most difficulty. 
b. Pacing Options. The teacher may choose three options that govern how the device limits problem sessions. In the first option (the Timed option), the teacher limits the time the student works on a problem set. When the time runs out, the problem session ends. In the second option (Speed), the teacher is able to limit the amount of time per problem attempt, as well as the total number of problems. If the time per attempt runs out, the device acts as if the student had entered an incorrect answer; if the maximum number of problems has been reached the problem session ends. In the third option (Power) the limiting factor is the number of problems. The teacher limits the number of problems in the session, but the student may take any amount of time in responding to each problem. When the maximum number of problems has been completed the problem session ends. 2. Man-Machine Considerations

The foremost feature of this device is that it has a voice output. The Speech Plus talking calculator has been on the market for a few years. The speech synthesizer that is used in the present device is a more advanced version of the one used in that calculator, and has a 64 word fixed vocabulary, shown in TABLE IV. Using the vocabulary of the synthesizer several standard phrases were created. When a problem has been answered correctly, a string of three low tones (word number $61_{10}$ ) are said by the synthesizer. An incorrect response elicits two high tones (word number $62_{10}$ ). These arbitrary tone sequences were chosen because no semanticly relative true-word combinations could be found. The words "go please", however, served nicely as a general purpose audio prompt. 
If a sighted student forgets the current problem, that student can simply look at the problem again. A blind student listening to a verbal problem should have the same opportunity. For this reason a repeat problem presentation button has been incorporated into the device.

Because many students are familiar with the Speech Plus calculator, the device's keyboard is designed with the numeric keys in the same configuration as the calculator's. The only difference being the presence of an enter key and a minus key (for negative number entry).

It was also decided to incorporate auditory feedback of keyboard entry into the device. As each key is depressed, the device speaks the key's designation. Keys which do not have descriptions in the vocabulary wi11, when depressed, cause a tone to be sounded.

In addition to the keyboard echo feature, the device also has a keyboard training drill. This dri11 will ask the student to depress the keys on the keyboard in a certain order. If the student hits the right key, that key will echo its designation and sound a tone. Wrong keys will only echo their designations. It was decided that the device's display should be as large as possible, so that a low vision student might benefit from the visual input. The main reason for having the display, however, is to aid a sighted teacher in watching the students progress when the student is using headphones.

D. Teacher Programming

Before each problem session, the teacher will have to set up (program) the device in the desired configuration. Parameters such 
as pacing mode, operation to be performed, location of missing number, number of problems, level of difficulty, etc. must be supplied to the device. Verbal asking of the required questions is not possible with the limited vocabulary of the device (see TABLE IV. Therefore, a scheme using a prompt beside a written statement (in both braille and print) of the parameter to be entered was decided upon. The prompt is an illuminated LED next to a print and brailler label. Later, if funds are available, solenoids will replace the LEDs to allow a non-sighted person to program the device. For details of teacher programming see the users manual in Appendix $V$. It was felt that, to eliminate student confusion, the programming controls should be located away from the controls the student will use (see Fig. 2). Fig. 4 illustrates the sequence of events involved in setting up the device by the teacher. 
TABLE IV

64-WORD SYNTHESIZER VOCABULARY

$\begin{array}{cll}\begin{array}{cl}\text { Data Code } \\ \text { (decimal) }\end{array} & \text { Word } \\ 000 & \text { zero } \\ 001 & \text { one } \\ 002 & \text { two } \\ 003 & \text { three } \\ 004 & \text { four } \\ 005 & \text { five } \\ 006 & \text { six } \\ 007 & \text { seven } \\ 008 & \text { eight } \\ 009 & \text { nine } \\ 010 & \text { ten } \\ 011 & \text { eleven } \\ 012 & \text { twelve } \\ 013 & \text { thirteen } \\ 014 & \text { fourteen } \\ 015 & \text { fifteen } \\ 016 & \text { sixteen } \\ 017 & \text { seventeen } \\ 018 & \text { eighteen } \\ 019 & \text { nineteen } \\ 020 & \text { twenty } \\ 021 & \text { thirty } \\ 022 & \text { forty } \\ 023 & \text { fifty } \\ 024 & \text { sixty } \\ 025 & \text { seventy } \\ 026 & \text { eighty } \\ 027 & \text { ninety } \\ 028 & \text { hundred } \\ 029 & \text { thousand } \\ 030 & \text { plus } \\ 031 & \text { minus } \\ & & \end{array}$

\begin{tabular}{|c|c|}
\hline $\begin{array}{l}\text { Data Code } \\
\text { (decimal) }\end{array}$ & Word \\
\hline 032 & times \\
\hline 033 & over \\
\hline 034 & equals \\
\hline 035 & point \\
\hline 036 & overflow \\
\hline 037 & clear \\
\hline 038 & percent \\
\hline 039 & and \\
\hline 040 & seconds \\
\hline 041 & degrees \\
\hline 042 & dollars \\
\hline 043 & cents \\
\hline 044 & pounds \\
\hline 045 & ounces \\
\hline 046 & total \\
\hline 047 & please \\
\hline 048 & feet \\
\hline 049 & meters \\
\hline 050 & centimeters \\
\hline 051 & volts \\
\hline $\begin{array}{l}052 \\
053\end{array}$ & $\begin{array}{l}\text { ohms } \\
\text { amps }\end{array}$ \\
\hline 054 & hertz \\
\hline 055 & $D C$ \\
\hline $\begin{array}{l}056 \\
057\end{array}$ & $\begin{array}{l}\text { AC } \\
\text { down }\end{array}$ \\
\hline 058 & up \\
\hline 059 & go \\
\hline 060 & stop, \\
\hline 061 & $\begin{array}{l}\text { tone(low) } \\
\text { tone(high) }\end{array}$ \\
\hline 063 & oh \\
\hline
\end{tabular}


1) Teacher turns device on.

2) Teacher chooses either Range or Level mode.

3) The Pacing Option (Timed, Speed, Power) is selected.

4) If the Time Option was selected the teacher enters the total time limit (via the keypad) in minutes and seconds (up to 99 minutes and 99 seconds).

5) If the Speed Option was selected the teacher enters in the time limit per attempt in minutes and seconds (up to 20 minutes).

6) If the Timed Option has not been selected the teacher enters the number of problems in the problem session via the keypad.

7) The teacher keys in the operation $(+,-, x$, or $\div)$.

8) If the Level Mode was selected the teacher keys in the level of difficulty number.

9) If the Range Mode was chosen the teacher enters the high and low limits of the first operand followed by the high and low limits of the second operand.

FIGURE 4 - Programming Event Sequence 


\section{SYSTEM DESIGN}

The math trainer, described in Chapter II, consists of a speech synthesizer for voice output, a keyboard for data entry, a visual display for problem presentation, and prompts to aid the teacher in programming problem set information into the device. A11 of these components are tied together through a controller to form a complete system. The system is designed so that the controller can coordinate the actions of each of the components.

\section{A. System Requirements}

The system consists of five basic components; the controller, the keyboard, the LED display, the speech synthesizer, and the prompts. These subsystems are functionally tied together as shown in Fig. 5 .

Specifications for the controller required that it must be able to control the activities of the other components. It must be able to store and manipulate the data received from the keyboard and provide data for the output subsystems (display, synthesizer, and prompts). A microcomputer was the most logical choice for the controller.

The second major component is the keyboard. There are 22 keys on the keyboard; ten digits, minus, enter, repeat, and nine keys dedicated to programming the problem sets. (See Fig. 2 in Chapter II). The controller must be able to determine which, if any, of these keys is depressed. The keys themselves must be debounced (i.e., so that a single key closure is not interpreted as multiple closures). 


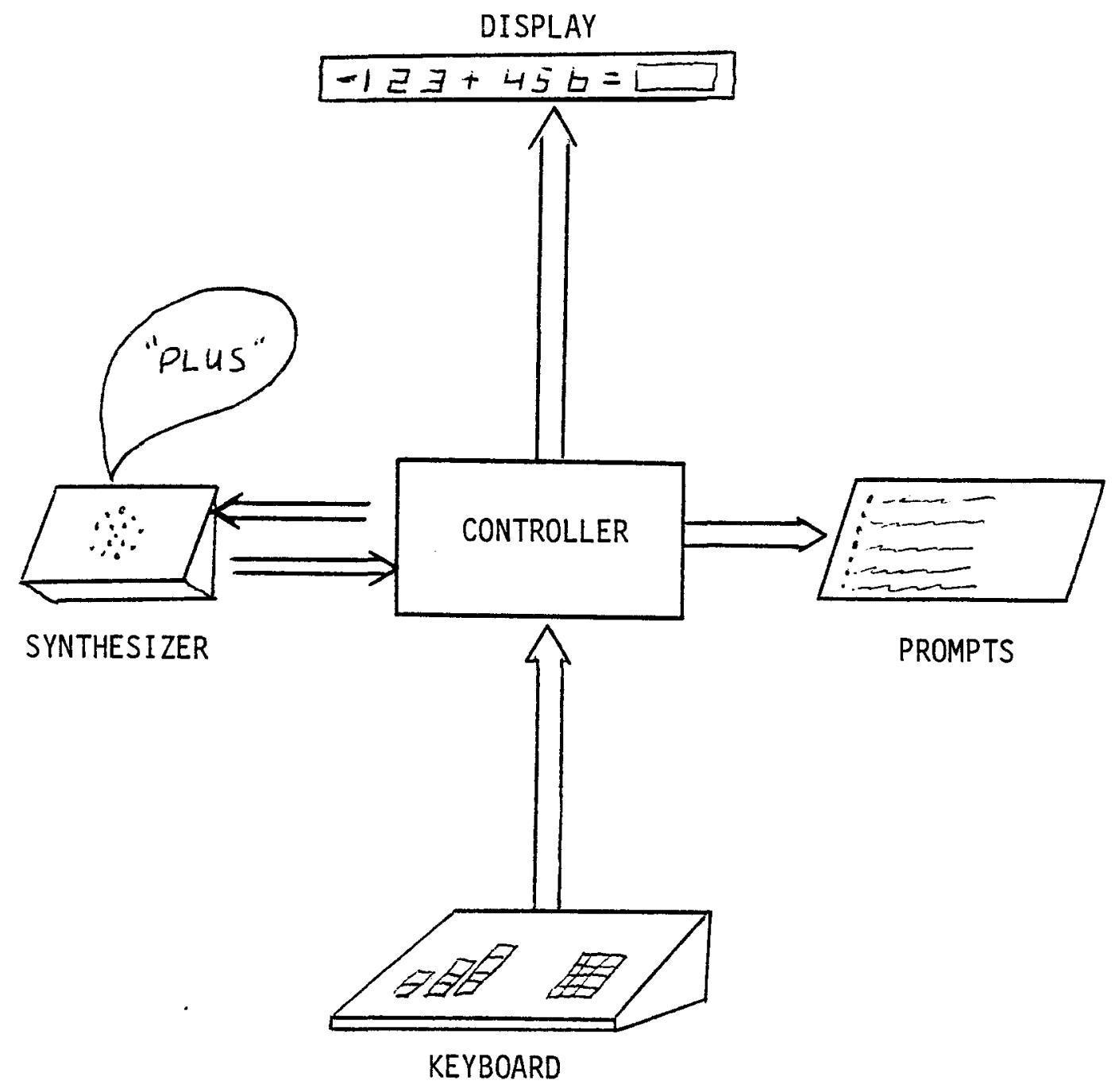

FIGURE 5 - System Overview 
The third major subsystem is the LED display, used to present the problem visually. The display must have three numbers, each consisting of a sign and three digits. In addition, it must have an operation sign $(+,-, x, \div)$ and an equals sign. The display should be as large as possible, as some users will have some useful vision. Moreover, having a large display will allow the teacher to monitor a student's progress from a distance.

The speech synthesizer subsystem is what makes the device unique. The synthesizer must present the problems to the student, echo the keys as they are depressed, provide audio feedback, and report the student's score. The synthesizer must provide intelligible speech at a rate that the user can comprehend.

The last subsystem is the prompt system. This system is designed to say the questions that the synthesizer cannot say, due to its limited vocabulary. If solenoids are eventually used for the prompts, they must be small enough so that if they are placed sideby-side they will not take up too much room in the device. The solenoids must also be rated for continuous duty, low power, and a convenient voltage (five volts would be ideal). At present, small, inexpensive solenoids are not available, so discrete LEDs were substituted. The LEDs must have sufficient brightness to be seen in a normal classroom environment. Use of LEDs instead of solenoids, would not help an unsighted teacher to program the device, but would still allow for proof-of-concept evaluation of the device by blind students.

In addition to the five components described above, the device 
must have a DC power supply that is capable of meeting the current and voltage requirements of the subsystems. Also, the device should be portable; therefore, the physical size and weight of the device should be low enough for easy transportation. Although the device is intended as a proof-of-concept prototype, it should, nontheless, be made as economical as possible.

\section{B. Subsystem Selection}

After considering the microcomputer systems that were available, the Motorola 6800 was chosen to act as the controller. A large amount of software is available for the 6800 . Also, the 6800 is suited for data manipulation of the type required by the device. For example, it has instructions that perform Binary Coded Decimal $(B C D)$ arithmetic; $B C D$ arithmetic is often used in calculators and devices with large amounts of numeric input and output 19 Perhaps the most important reason for using the 6800 is its availability. The Perceptual Alternatives Laboratory supplied the author with a Motorola 6800 based 02 evaluation system. That microcomputer is a program development system that allows the programmer to enter, debug, and single step through programs. After development was in progress, the Electrical Engineering Department offered the use of a 6800 based D1 system. It was decided to continue to use the D2 for program development, and to incorporate the simpler D1 into the device as the controller.

The keyboard requires 22 switches; to cut down on the number of switch inputs to the controller, a multiplexing scheme was used. 
The switches, themselves, had to be made such that they could be touched without being activated. This feature allows a user to tactually localize the position of the various keys without inadvertantly entering incorrect information. Keys that were obtained from a used keyboard satisfy the above condition. These keys were used in the Math Trainer.

For the display, Litronix DL $747^{2}$ Seven-segment displays was chosen. These displays (which are common anode) are easily multiplexed. The decision to multiplex the display reduces the number of components required. In addition to the seven-segment displays, an operation display is required. It was decided to make that display from discrete LEDs, since nothing could be found that was suitable for the task.

The next major subsystem is the speech synthesizer. The decision was made to use the Telesensory Systems Incorporated model S2B 64-word voice synthesizer 21 see TABLE IV). This synthesizer contains a vocabulary rich enough to be able to say any number up to 999,999 properly. It can also say the words required to present problems. The prompts substitute for most of the additional needed words that are not in the speech board's vocabulary. Words can be added to its vocabulary; but, TSI charges about $\$ 200$ to add words available on other models, and considerably more than $\$ 200$ for totally new words. ${ }^{22}$ It was felt that the standard model would be sufficient for a proof-of-concept device. The TSI synthesizer requires 6 wordselect lines and two handshake lines. This last subsystem, together with the previously mentioned ones, use up the control lines available on the D1 and D2 computer boards. 
The last subsystem is the prompt system. Funds for solenoids were not available, so, LEDs were used instead.

To power the device a Godbout multivoltage power supply was selected. Rated to supply four amps at five volts and 0.5 amps at +12 volts and -12 volts, this supply was chosen for its low cost and availability. 


\section{HARDWARE DESIGN}

The development of the hardware for the Math Trainer was done in a stepwise fashion. A11 of the software development was done using a Motorola MEK $6800 \mathrm{D} 2 \mathrm{kit}^{23}$, driving a prototype interface circuit. The prototype interface circuit was constructed on breadboarding sockets. After the majority of the software was completed, the interface circuit was rebuilt in its final form using wire-wrap sockets. Finally, after al1 of the control programs were finished the software was transferred to EPROMs and a MEK 6800 D1 24 board was modified to serve as the controller.

\section{A. The Development System}

\section{The Controller}

The MEK 6800 D2 board (schematic shown in Fig. 1 of Appendix I) was used as the device controller for the Math Trainer during software development. It is we11 suited to program development. The D2 kit can have as many as 512 bytes of user RAM on board, with provisions for up to $16 \mathrm{~K}$ bytes of off-board memory. Programs can be entered and changed via a keypad, and an LED display integral to the D2 kit permits verifying contents. Programs may be stored using an audio type recorder. The D2 kit has Peripheral Interface Adapter (PIA) that was used to interface to the Math Trainer's hardware. 2. Memory Expansion

The 512 bytes of on-board RAM available on the D2 kit was quickly found to be insufficient to contain the expanding software. 
An expansion memory board, designed by Brian Garvey, was added to the 02 board. (See Fig.6). This memory baord can accomodate up to $8 \mathrm{~K}$ bytes (in $1 \mathrm{~K}$ increments), of which only $4 \mathrm{~K}$ bytes were actually installed. The author also designed and installed a memory protect (write disable) circuit to prevent faulty programs from selfdestructing. The protect circuit is shown in Fig. 7. A full schematic of the 4K RAM board is shown in Fig. 2 of Appendix I .

\section{B. Final System Design}

1. The Controller

The D2 kit used for software development was deemed unsuitable for use as the final device controller. Much of D2 would not be needed in the final version (e.g., the cassette interface, the Hex keypad, etc.). A MEK 6800 D1 kit was supplied for the author's use by the Electrical Engineering Department of the University of Louisville and was used as the controller. A schematic of the D1, incorporating the needed changes is shown in Fig. 1 of Appendix II.

Unlike the $D 2$, the $D 1$ is a single board computer. It can hold up to 512 bytes of user RAM (although on $1 y 256$ bytes are required for the controller). Because the user PIA addresses differ for the $D 1$ and D2, the software was changed to reflect that fact before the EPROMs were programmed. The only major changes required to the $D 1$ board involved the RAM select and $\overline{R E S E T}$ circuits. The DI's address decoding for the user's RAM is incomplete. When certain parts of the control program are addressed by the microprocessor, user RAM is also selected. Control program range from $\$ 2000$ to $\$ 2 \mathrm{FFF}$ while user RAM extends from $\$ 0000$ through $\$ 00 \mathrm{FF}$. A $\overline{\text { RAM ENABLE }}$ signals was 


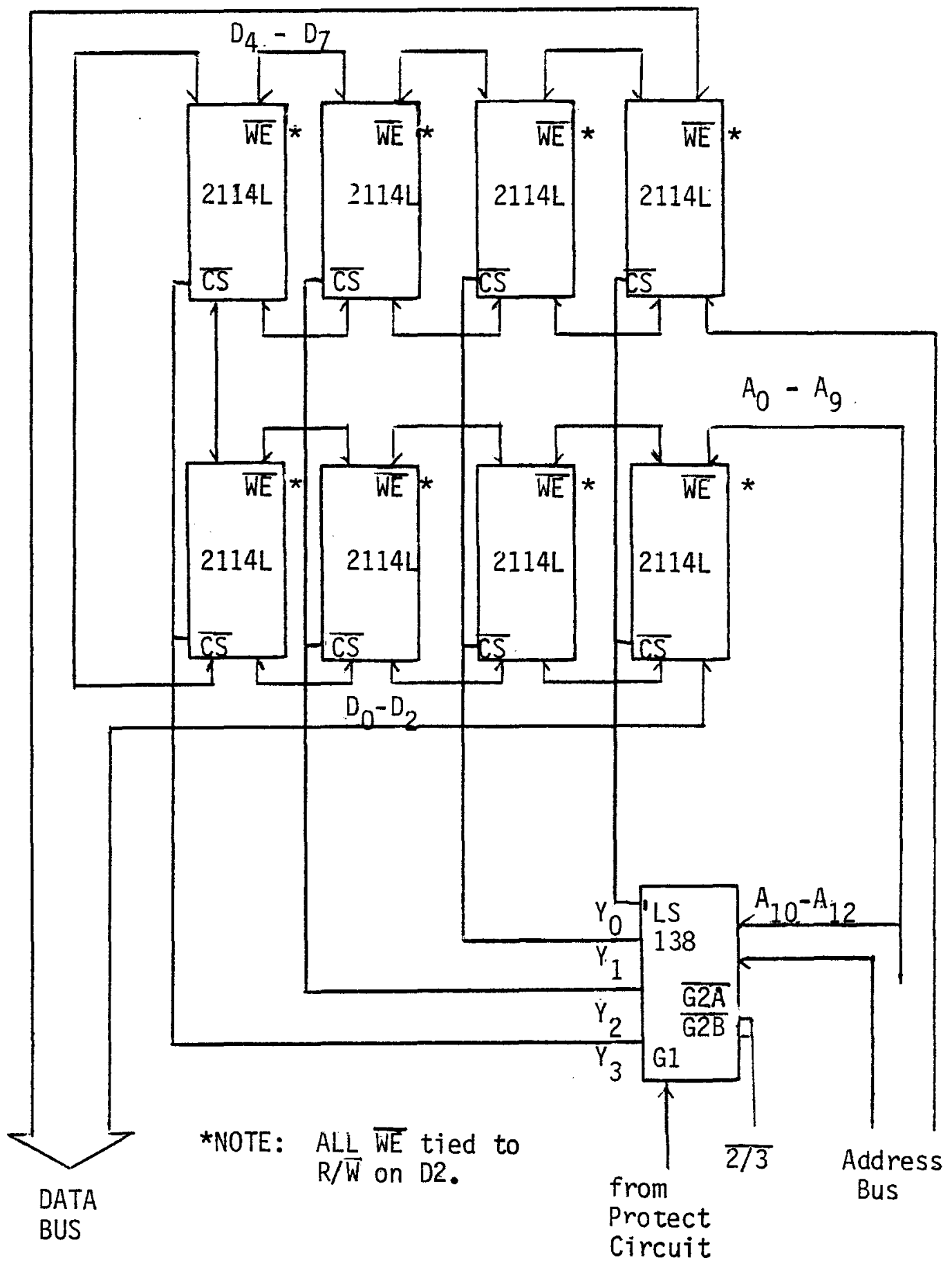

FIGURE 6 -4K RAM Board 


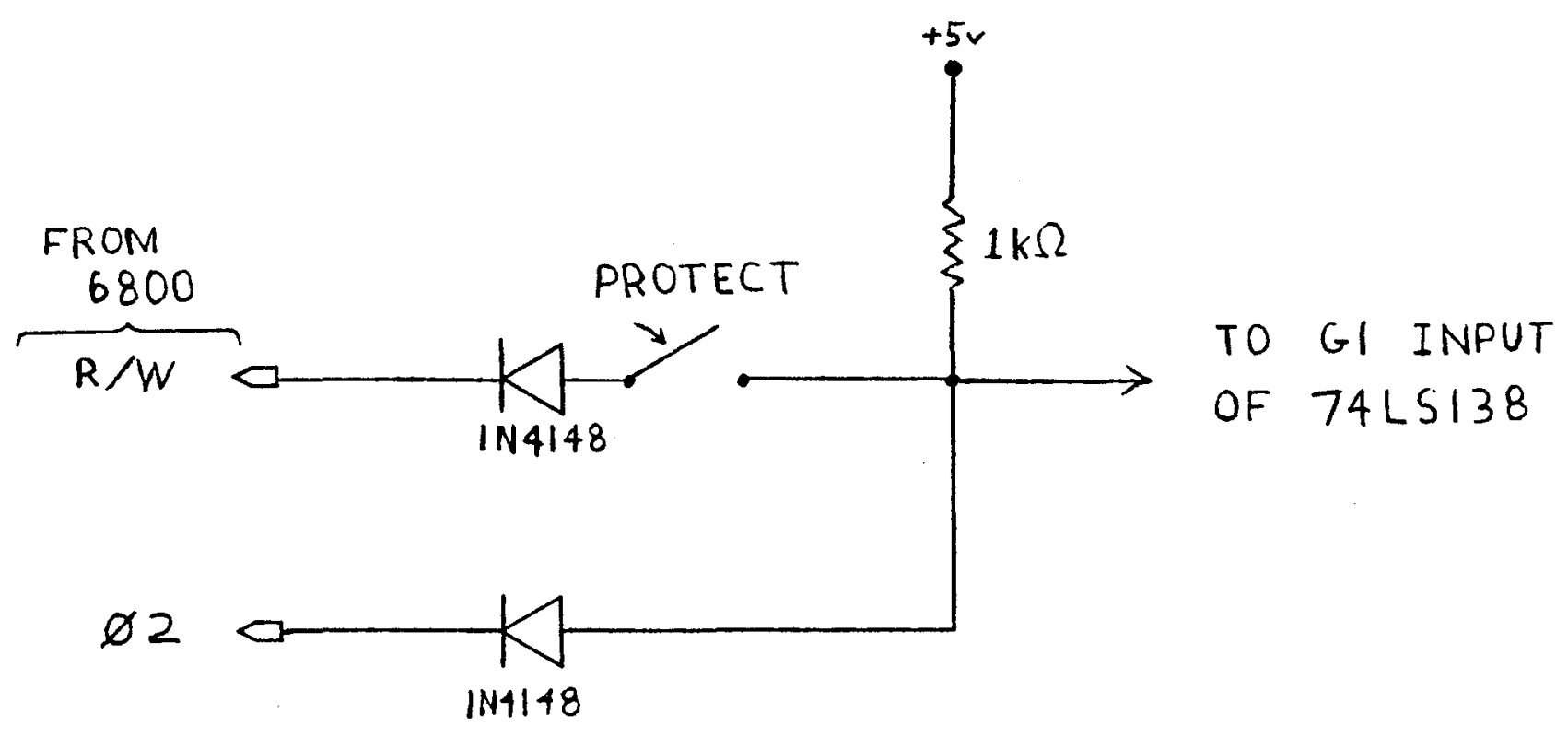

FIGURE 7 - Memory Protect Circuit 
generated by $O R^{\prime}$ ing together $A_{15}, A_{14}, A_{13}$. This signal was generated on the EPROM board and brought onto the D1 through pin $\bar{E}$. Normaliy, $\bar{E}$ contains BUS AVAILABLE (BA) but BA was cut where it leaves the microprocessor. $A_{15}$ was cut before reaching the user RAM's. The $A_{15}$ input to two RAM chips was replaced with $\overline{R A M ~ E N A B L E}$ so the RAMs would only be selected if the three most significant address lines were low. The other major change to the D1 involved cutting the output of the on-board reset circuit so that an external $\overline{R E S E T}$ signal could be brought in from the edge connector. This circuit along with the other Math Trainer circuits can be found in Appendix II .

A power-on reset circuit was built for the controller utilizing a design shown in the Motorola 6800 Applications Manua ${ }^{25}$ The actual circuit used is shown in Fig. 8 . The user can also reset the device by pushing the normally closed momentary switch (RESTART). That switch interrupts the power to the LM555 causing a power-on sequence. 2. Firmware

A working device cannot store its control programs in RAM, as they would be lost every time power were removed. Control programs must be stored in read only memory (ROM). For the Math Trainer, 2708 erasable programmable ROMs (EPROMs) were used. These EPROMs can be erased and reprogrammed many times.

When the control programs were written, they were located in memory from $\$ 2000$ to $\$ 2 F F F$. The 6800 needs some memory at $\$ F F F A$ to \$FFFF for its Reset and Interrupt vectors. It was decided to use incomplete address decoding for the EPROMs, to allow the Restart and Interrupt vectors to be located in the EPROMs. The circuit used 


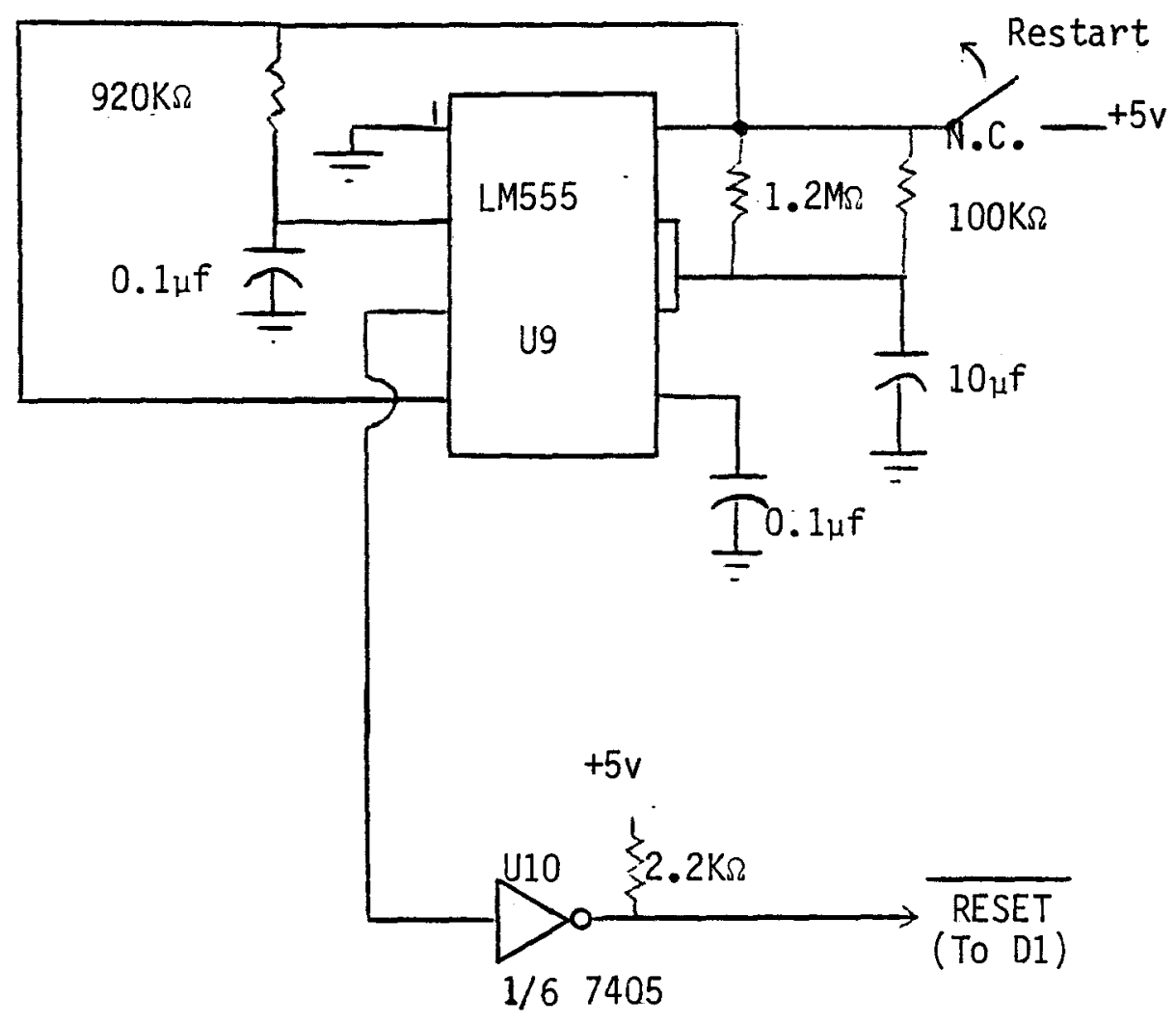

FIGURE 8 - Reset Circuit 
for this is shown in Fig. 9 . When the 6800 addresses \$FFFE and \$FFFF to retrieve the Reset vector, the EPROM at \$2FFE and $\$ 2 F F F$ supplies it. In a like way, the Interrupt vector is retrieved.

The EPROMs were programmed under the control of a 02 computer using a PROLOG EPROM Programmer. ${ }^{26}$ After loading the data to be programmed into the D2's RAM, a program, written by the author and Mr. Jimmy Ryan, was executed. The program sent the data over a RS232 link at 1200 baud to the PROLOG. A diagram showing the circuit used for linking the PROLOG and the D2, and the program appear in Appendix IV .

\section{Interface Circuitry}

a. Overview. The interface circuitry described in this section includes the LED display, the prompts, the keyboard, the speech synthesizer controls, and the circuitry required to connect those devices to the microprocessor controller. The design used for the Math Trainer needs only one PIA and is shown in Fig.10. The PIA is divided into two parts, with one part controlling the speech synthesizer and the other part controlling the remainder of the interface. The connections to the synthesizer are straightforward. The busy line is sensed by CAl and the completion of a word causes an interrupt. The synthesizer is triggered by CA2 (the start line).

The remaining interface is somewhat involved. A four bit device address is sent to a four-to-sixteen-line decoder. The four bit address selects one output device (e.g., 7-segment display, operation sign latch, Prompt latch, etc.) and two input switches. The output data for the displays are contained on the four-bit data 


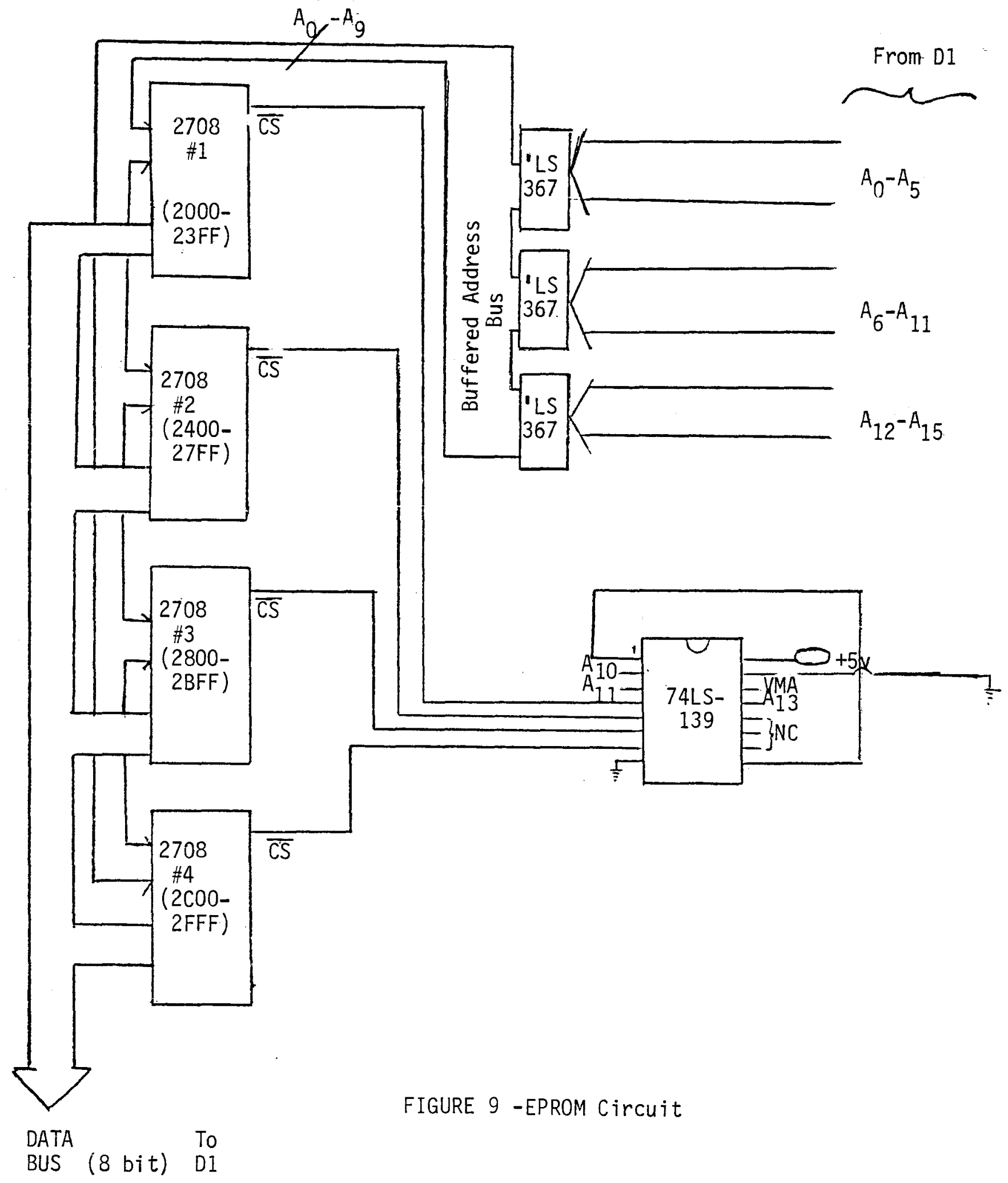




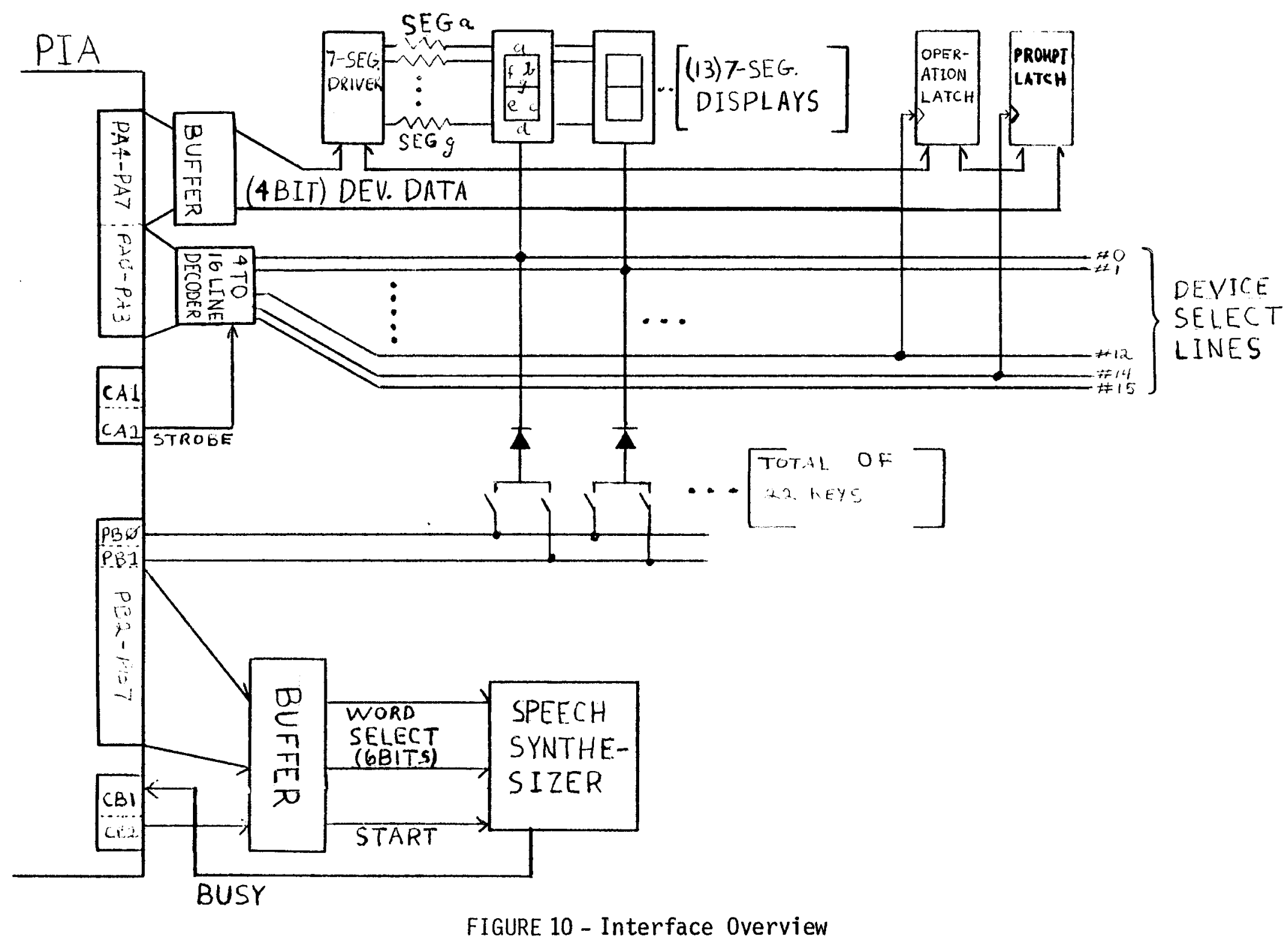


bus. The positions of the selected pair of switches are sensed by $\mathrm{PB} \emptyset$ and $\mathrm{PB} 1$. The microprocessor can sequentially output the device addresses and the data to those devices while simultaneously bringing in switch information.

\section{Display and Keyboard Circuitry}

\section{Seven Segment Displays}

The Math Trainer requires an LED display for visual problem presentation. Litronix DL $747^{27}$ displays were chosen for numeric displays. Multiplexed by the processor, the DL $747 \mathrm{~s}$ were configured as shown in Fig. 11 . The 27 ohm resistors were chosen to allow the 7446 to sink as much current as safely possible (40 ma per segment). The low duty cycle $(1 / 16)$ prevents the average current through the display form exceeding the $30 \mathrm{ma} /$ segment limit. 2. Minus and Equal Signs

The display also contains three minus signs and one equals sign. These signs are constructed using $\mathrm{DL} 747 \mathrm{~s}$ in the circuit shown in Fig.11 with the exception that some of the segments are left unconnected. To make a minus sign only segmentg (the center bar) is connected. For an equals sign segments $\mathrm{a}$ and $\mathrm{g}$ are connected into the circuit and the DL 747 is lowered (with respect to the other 7-segment displays) to line up the equals sign.

\section{Emergency Blanking Circuit}

The average current through the 7 -segment displays is within limits as long as the display is multiplexed by the 6800 . If the microprocessor halts for some reason, one of the LED displays would be on continuously, thus destroying it. To prevent this a circuit using 


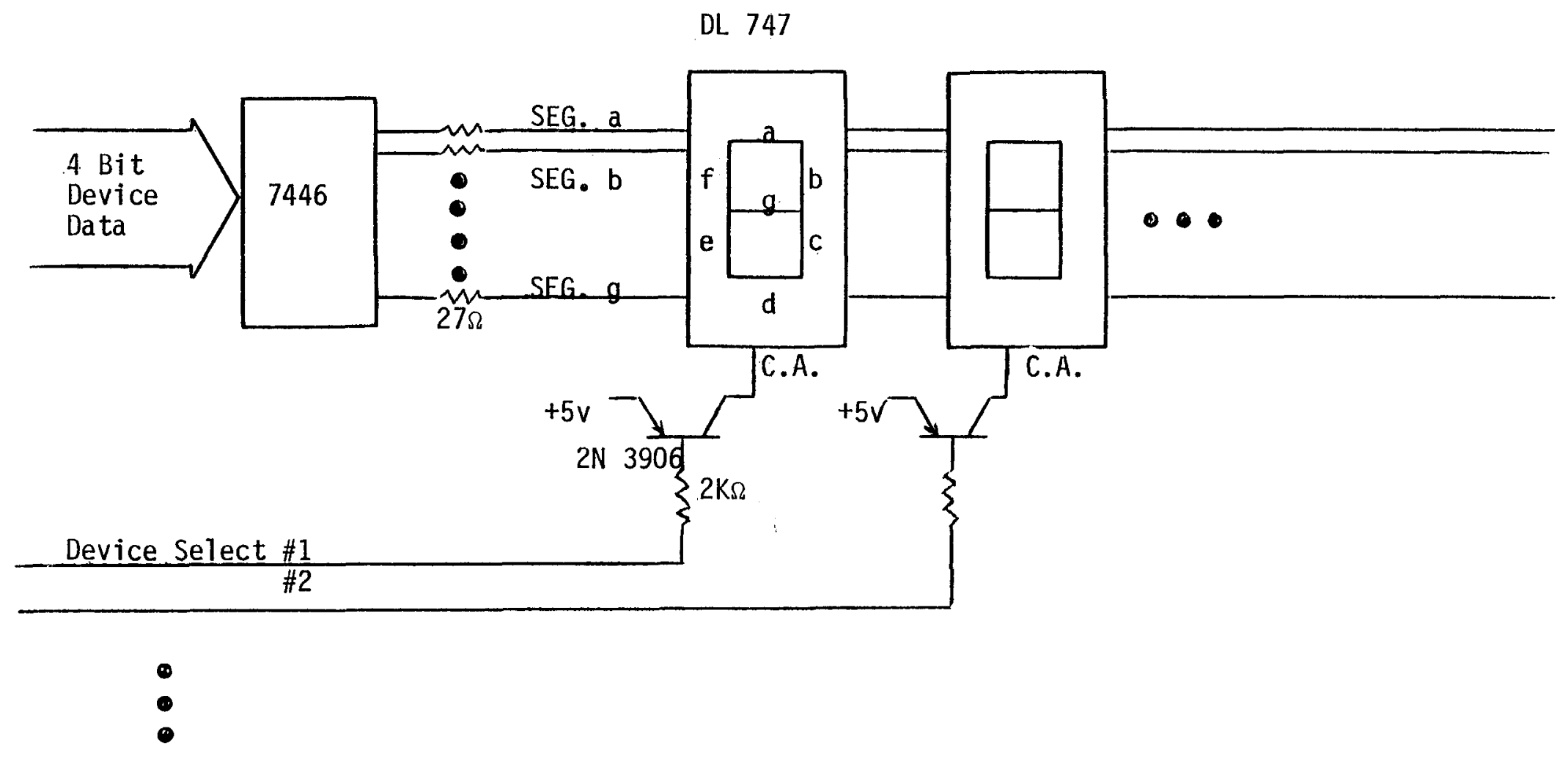

FIGURE 11- 7-Segment Display Circuit 
half of a LM 556 timer was built (see Fig. 12). In this circuit, the timer is set up as a one-shot multivibrator. The 556 triggers when the last device address is selected. The 556's output then goes high, powering the segment driver (7446). The time constant is adjusted so that the 556 times out after 1.5 scan cycles (at 50 cycles/sec). If the display is being multiplexed, the timer is continuously reset and retriggered. If multipliexing stops, the 556 times out and turns off the display driver.

4. Operation Sign

The need for an operation sign (displaying $+,-, x, \div$ ) presented aproblem. No commercialiy available display was both inexpensive and large enough. The author constructed an operation display using discrete LEDs. The LEDs were arranged in a format shown in Fig. 13. The discrete LEDs were divided into five groups. To simplify connections, the LEDs within a group (and their current Timiting resistors) were tied together as a unit. The way the LEDs were grouped, if one member were on, the remainder of the group should be on (even if they had been wired individually) to display the operation sign properly. The data to the operation sign was latched, rather than multiplexed; the driver circuitry is shown in Fig. 14 . Only one LED is in group 5 (the center of the matrix), and that LED is wired on continuously, and also serves as a DC power indicator. 5. User Prompts

The teacher has to answer a string of questions to program the Math Trainer. To aid in knowing which question is being asked, a system of LED prompts is used. When an input is required, an LED lights 


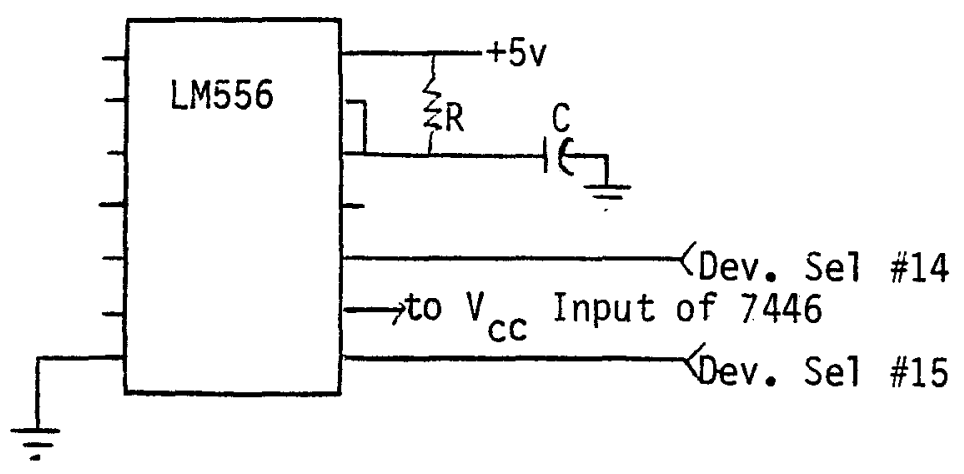

$$
\begin{aligned}
& R=270 \mathrm{k} \Omega \\
& C=0.1 \mu \mathrm{f}
\end{aligned}
$$

FIGURE 12 - Emergency Blanking Circuit 
(1)

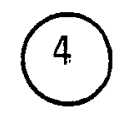

(1)

(1) (2) (1)

(3) (3) (5) (3) (3)

(1) (2) (1)

(1)

(4)

(1)

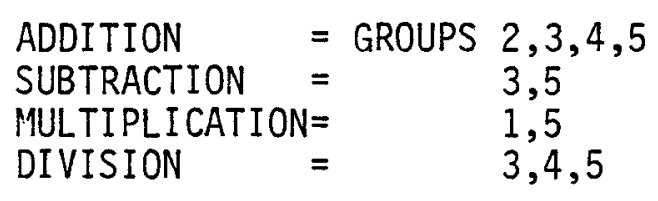

FIGURE 13 -Operation Sign Matrix 

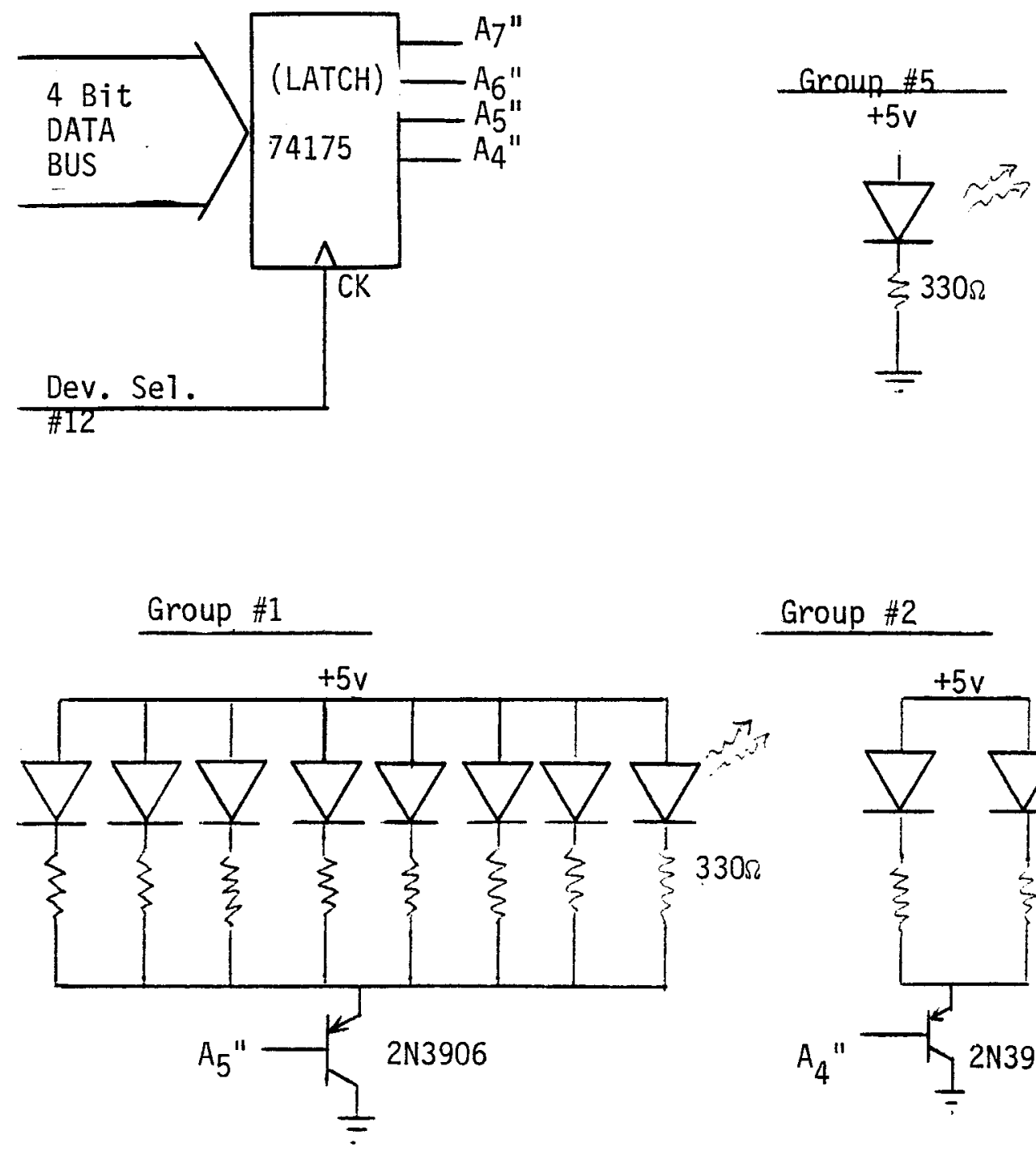

Group \#2

Group \#3

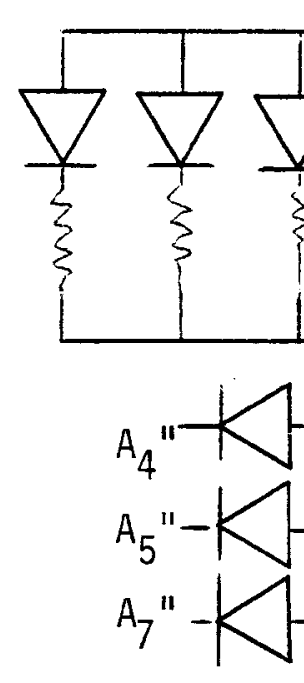

$+5 \mathrm{v}$

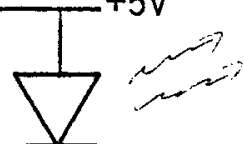

3308

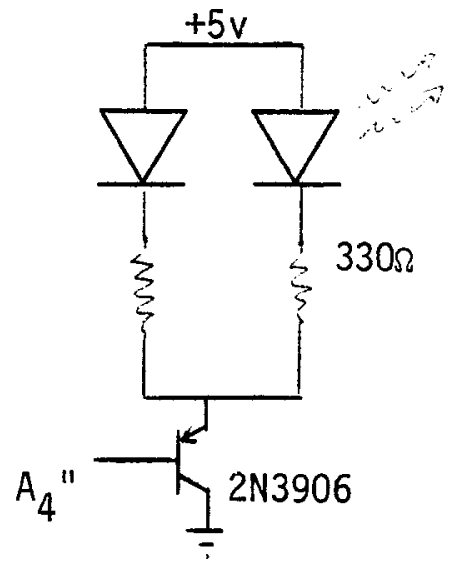

Group \#4

$+5 v$

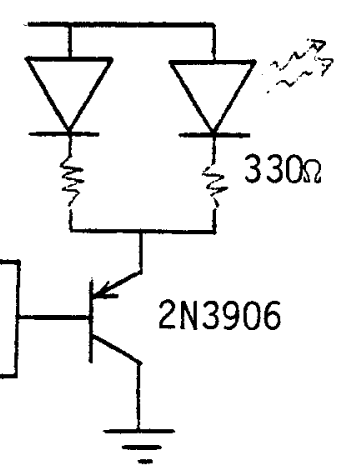

NOTE: (") denotes latched data.

FIGURE 14 - Operation Sign Circuitry 
up next to a label explaining what information is needed. If the information is to be input to keys other than the keypad keys, an LED lights up below the column of keys to be used. Thus, two sets of LEDs are used: one for the labels and one for the key columns. Within a set, the LEDs are mutually exclusive of one another. Like the operation sign, the prompts are latched and not multiplexed. The prompt latch is located at device address $14_{10}$. The prompt circuit is shown in Fig. 15 .

6. Interface Summary

The LED display is designed to present arithmetic problems to the user. To do this, it displays three numbers (each consisting of three digits and a minus sign), an operation sign, and an equals sign. The prompt latch, which drives the prompt LEDs to aid device programming by the teacher is also treated as part of the display. (Device address information for the displays appears in TABLE $V$ ). The Seven-Segment displays take a BCD code input. In addition, all of the displays (including prompts) interpret an all ones $\left({ }_{10}\right)$ input as a blanking code. The required driving codes of the other display devices appears in TABLE VI. 


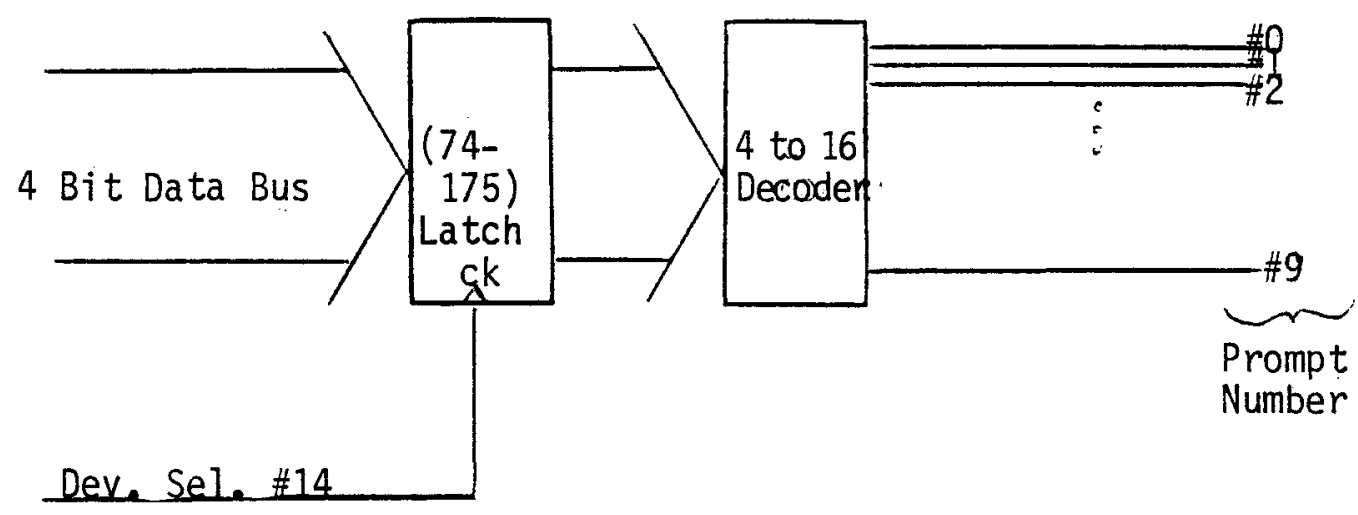

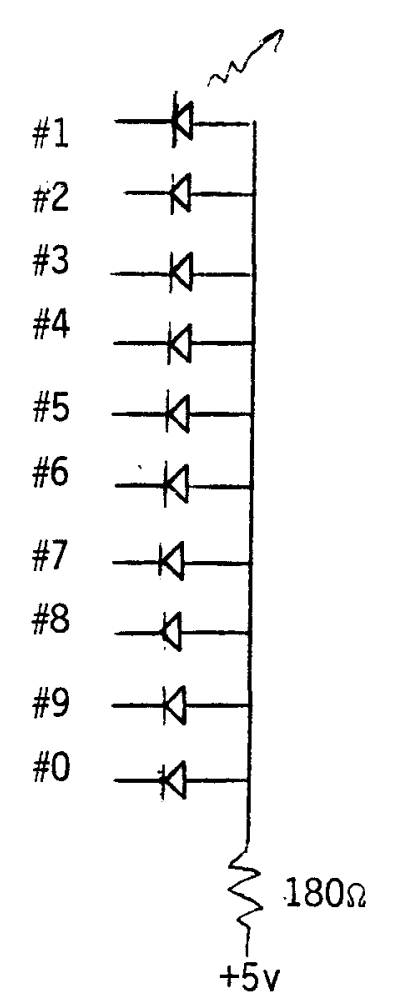

Label Prompts

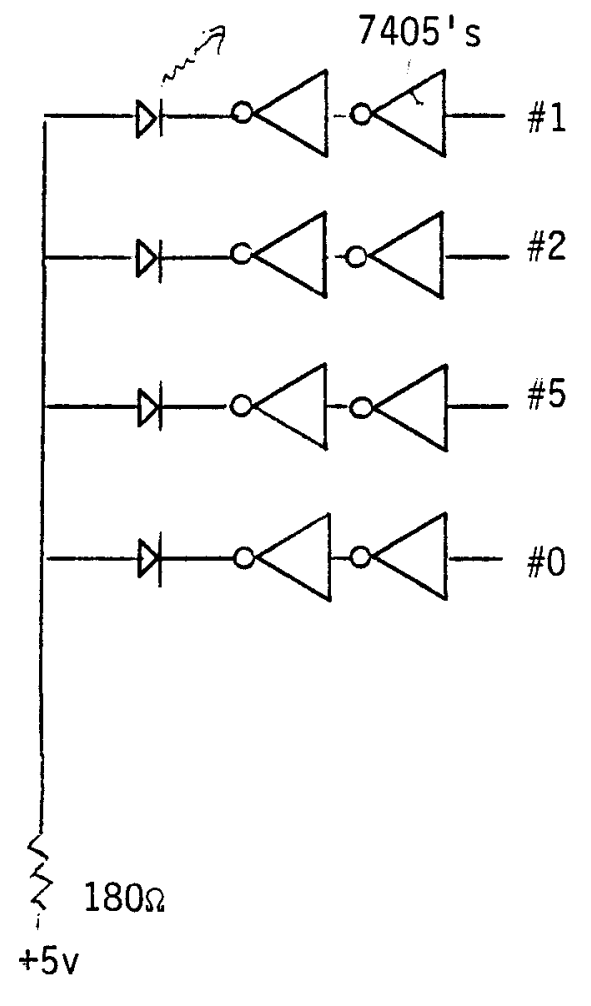

Column Prompts

FIGURE 15 - Prompt Circuit 
TABLE V

DEVICE ADDRESS INFORMATION

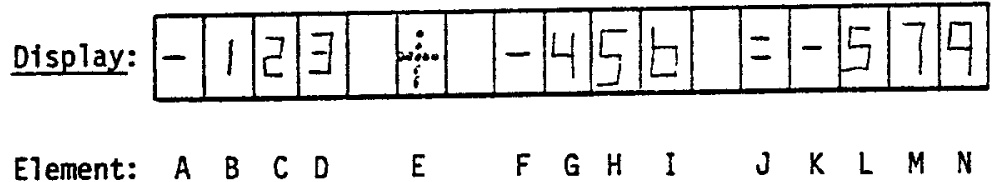

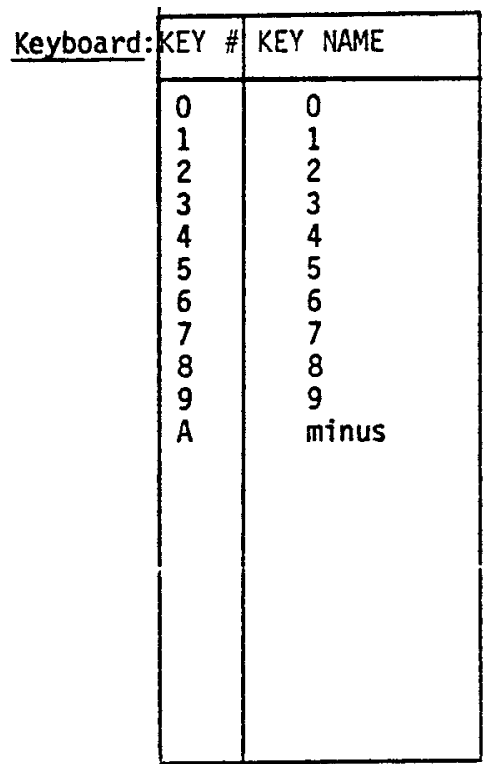

\begin{tabular}{|c|l|}
\hline KEY & KEY NAME \\
\hline B & Range Mode \\
$C$ & Level Mode \\
$D$ & Timed Option \\
$E$ & Speed Option \\
F & Power Option \\
10 & + \\
11 & $\bar{X}$ \\
12 & $X$ \\
13 & + \\
16 & ENTER \\
17 & REPEAT \\
& \\
& \\
& \\
\end{tabular}

\begin{tabular}{|c|c|c|c|c|}
\hline Device & \begin{tabular}{|l|} 
Device \\
Address
\end{tabular} & $\begin{array}{l}\text { Key } \\
\# \text { 's's }\end{array}$ & $\begin{array}{l}\text { Display } \\
\text { Element }\end{array}$ & $\begin{array}{l}\text { Dis. } \\
\text { Buf.Ad }\end{array}$ \\
\hline $\begin{array}{l}\text { Address } \\
\text { Assign- } \\
\text { ment }\end{array}$ & $\begin{array}{l}0 \\
1 \\
2 \\
3 \\
4 \\
5 \\
6 \\
7\end{array}$ & $\begin{array}{l}0,1 \\
2,3 \\
4,5 \\
6.7 \\
8.9 \\
A, B \\
C, D \\
E, F\end{array}$ & $\begin{array}{l}A \\
B \\
C \\
D \\
F \\
G \\
H \\
\star\end{array}$ & $\begin{array}{l}\$ 005 \\
\$ 007 \\
\$ 0008 \\
\$ 0009 \\
\$ 000 A \\
\$ 000 B \\
\$ 000 C \\
\$ 0000\end{array}$ \\
\hline
\end{tabular}

\begin{tabular}{|c|l|l|l|}
\hline Device & Key & Display Dis. \\
Addres & \#'s & Elemen & Buf. Ad \\
\hline 8 & 10,11 & $K$ & $\$ 000 E$ \\
9 & 12,13 & L & $\$ 000 F$ \\
$A$ & - & $M$ & $\$ 0010$ \\
$B$ & 16,17 & $N$ & $\$ 0011$ \\
$C$ & - & $E$ & $\$ 0012$ \\
$D$ & - & $J$ & $\$ 0013$ \\
E & - & Pro. & $\$ 0014$ \\
F & - & - & $\$ 0015$ \\
& & & \\
& & & \\
& & & \\
& & & \\
& & & \\
\end{tabular}


TABLE VI

DISPLAY DEVICE DRIVING CODES

\begin{tabular}{lcll}
\hline Device Name & Code & Resulting Display & \\
\hline Minus \& equals sign & 1000 & On & \\
& 1111 & Off & \\
Operations Display & 0111 & Plus & \\
& 1011 & Minus & \\
& 1101 & Times & \\
& 1110 & Divide & \\
Prompts & 1111 & Off & Prompt On \\
& 0000 & Keypad & Prompt On \\
& 0001 & Prob. Set & Prompt On \\
& 0010 & Pacing Option & Prompt On \\
& 0011 & Min:Sec. & Prompt On \\
& 0100 & No. of Prob. & Prompt On \\
& 0101 & Operation & Prompt On \\
& 0110 & Ans. Pos. & Prompt On \\
& 0111 & Level & Prompt On \\
& 1000 & Hi. Lim. & Prompt On \\
& 1001 & Lo. Lim. &
\end{tabular}




\section{SOFTWARE}

Currently, the popularity of modular programming is on the rise. Dividing a large program into smaller sections does have advantages. A small section of a program with a single function is easier for a programmer to work with because it is possible to simultaneously grasp a11 of the interrelationships present. A1so, as each module is completed, it can be tested before it becomes part of the larger program.

This modular approach was employed in developing the software for the mathematics trainer. The control program is arranged in an hierarchical structure. At the top of that structure is a program called MAIN. MAIN is a module (or subroutine) that calls upon other modules which perform various functions. These subroutines may also call other subroutines. Generally speaking, anytime a large function was required in a program, the program for that function was broken down into smaller subroutines.

\section{A. Software Development}

The only software development tool available was the J-BUG monitor program on the 02 microcomputer. 28 The lack of an assembler within JBUG, meant that al1 programs had to be assembled by hand. Consequently, it was desirable that program changes be performed without having to hand reassemble the code. As a result of this, program corrections were made by using patches. A patch is branch from the normal path, to the program correction, followed by a branch 
back to the original path. As programs develop, their sizes change. With limited memory, these size changes require that subroutine locations be shifted to efficiently utilize the limited memory space. Any shifting of subroutine locations would normally require that the program be reassembled; however, the use of relative branching and Link (a programming technique) prevents this.

Any discussion of the device's software must be prefaced by a description of the internal architecture of the 6800 microprocessor. The 6800 has three internal data storage register; a 16-bit index register (x-reg.), and two eight-bit accumulators (the $A$ and $B$ registers). The index register is often used as a pointer to address locations in memory. In addition there are three registers whose presence is somewhat invisible to the programmer: the condition code register (contains the carry bit, overflow bit, etc.), the stack pointer (keeps track of the information in the stack, a LIFO buffer), and the program counter (points to the location of the next instruction).

\section{B. The Software}

The software can be divided into four major functional divisions: control routines, input/output routines, arithmetic routines, and special function routines.

Control subroutines act as high level administrators of the device's operations. As various functions need to be performed, the control routines call the needed subroutines. For example, in the teaching mode, TEACH is the control program; it would call GENERATE (to set up the next problem), GETANS (To solve for the answer), and SAYDISP (to say the problem). For a glossary of the control routines 
and the other routines see TABLE VII.

The next major functional subdivision involves the transferring of information to and from the various input/output devices. Because the trainer requires simultaneous display output and keyboard input, a single routine had to be able to perform both input and output functions; that routine is SCAN. The information to be output by SCAN is stored in two buffers, the speech buffer (SPKBUF) and the display buffer (DISBUF). The other I/0 routines either load information into the buffers (e.g., DISPLAY and SPKWD) or call SCAN repeatedly to bring in a series of keystrokes (e.g., GETDIG).

The third major division of the software is the arithmetic routine division. The 6800 microprocessor is 1 imited in the types of arithmetic functions it can perform. To overcome these limitations and to eliminate repetition of instruction sequences, various arithmetic subroutines were created. To supplement the 6800 's instruction set, double-byte binary addition and subtraction subroutines (DADD and BISUB) were added to the programming repetoire.

It was decided that $B C D$ arithmetic should be used in generating the problems. The motivation to use $B C D$ representation stemmed from a need to do manipulations upon various digits of the number (when checking for regrouping, for example) that would be difficult to perform if the numbers were in a binary format. The BCD format employed is a 2-byte representation, with the sign bit occupying the most significant bit of the high order byte. The hundreds digit is contained in the low nibble of the high order byte. The low order byte contains the ten's and one's digits in the high and low nibbles, respectively. 
Various subroutines were written in order to perform $B C D$ arithmetic. BCDADD does simple unsigned additions, and ADDEM uses $B C D A D D$ to do signed $B C D$ addition. Signed $B C D$ multiplications are performed using BCDMULT. In solving for the answers to the problems created by GENERATE, GETANS calls various BCD subroutines. Magnitude comparisons of BCD numbers can be done by using HI-LO and COMPARE. To generate random numbers, a subroutine (RANDOM) was developed using an 11 stage linear-feedback shift register, realized in software.

The last major software division covers the subroutines that are labeled as special function subroutines. Those routines result from modularizing the control routines. The subroutines RIGHT and ERROR are called by TEACH to signal correct and incorrect student answers. They could have been built into TEACH, but having them separate allowed TEACH to be a simpler module. In a similar way, RESTART is the initializing module for MAIN. Anytime a reset occurs, RESTART is called and, in turn, calls MAIN.

A glossary of subroutines is shown in TABLEVII, and the calling hierarchy of those routines is shown in TABLE I of Appendix III A functional description of the subroutines follows, with first level subroutine calls identified. The commented disassembled listing of the entire program is shown in Appendix III 1. Control Subroutines

These subroutines form the control structure of the math trainer's software.

a. MAIN Program. MAIN orchestrates the sequencing of the device's functions (see Fig. 16). The order of the functions 


\section{TABLE VII}

GI OSSARY OF SUBROUTINES, ARRANGED BY FUNCTIONAL DIVISION

\section{Control Subroutines}

DRILL - trains the student to use the keyboard.

MAIN - sequences the calling of the other control routines.

PROGRAM - allows the teacher to define the problem set via the keyboard.

REPORT - gives information on the student's performance on the current problem session.

TEACH - presents problems to the student and keeps track of the student's performance. 
Input/Output Subroutines

BLANK - erases the contents of the LED display buffer.

BLANKIT - erases the missing number from the LED display buffer.

DISPLAY - puts the present problem, including the answer, into the LED display.

GETDIG - retrieves up to 6 digits from the keyboard while outputting the contents of the speech and display buffers.

GETEM - prompts for input and calls GETDIG to retrieve digits.

LDPAUS - loads a variable length pause (up to five seconds) into the speech buffer.

PACK - takes three digits and the sum entered via the keyboard and compresses them into a two-byte signed BCD number.

SAYDISP - takes a two-byte number and loads the words needed to say it into the speech buffer.

SCAN - outputs the contents of the display and speech buffers until a single key is pressed or a pre-specified amount of time has passed. This is the routine that actually performs all of the I/O operations.

SPKEY - loads the name of the pressed key into the speech buffer (used for echoing entries).

SPKWD - loads the word in the A-register into the speech buffer.

UNPACK - takes a signed two-byte BCD number and expands it and stores it in the display buffer.

WAIT - holds up program execution while outputting display and speech buffer contents. Execution is delayed until WAIT empties the speech buffer. 
Arithmetic Subroutines

ADDEM - performs two-byte signed BCD addition.

$B C D A D D$ - performs two-byte unsigned BCD addition.

$B C D I N C$ - $(B C D)$ increments the contents of two memory locations.

BCDMULT - performs signed BCD multiplication.

BISUB - performs two-byte binary subtraction.

COMPARE - performs two-byte signed BCD comparison.

DADD - performs two-byte binary addition.

GETANS- solves for answer to problem.

HI-LO - determines if random number is between two limits.

RANDOM - generates a signed three digit random decimal number.

Special Function Subroutines

ERROR - causes the display to blink and an error tone sequence to be sounded.

GENERATE - randomly picks the numbers for a problem within limits provided by the teacher.

INTERRUPT - is called by an interrupt when the speech synthesizer has finished saying a word.

LINK - allows easy program relocation.

LOADX - allows parameter passing.

MINTOBI - converts data entered as minutes and seconds to binary seconds.

OPGEN - randomly picks a single number (when in the level of difficulty mode) using the definition supplied by TBLOOK (see below).

RIGHT - causes a tone scquence indicating correct to be sounded.

RESTART - initializes the math trainer on power up or when the reset button is pressed.

SAYNUM - loads the correct pronunciation of a three digit number into the speech buffer.

TBLOOK - looks up the problem set definition from the level of difficulty supplied by the teacher.

2BEEP - loads the words "GO PLEASE" into the speech buffer. 


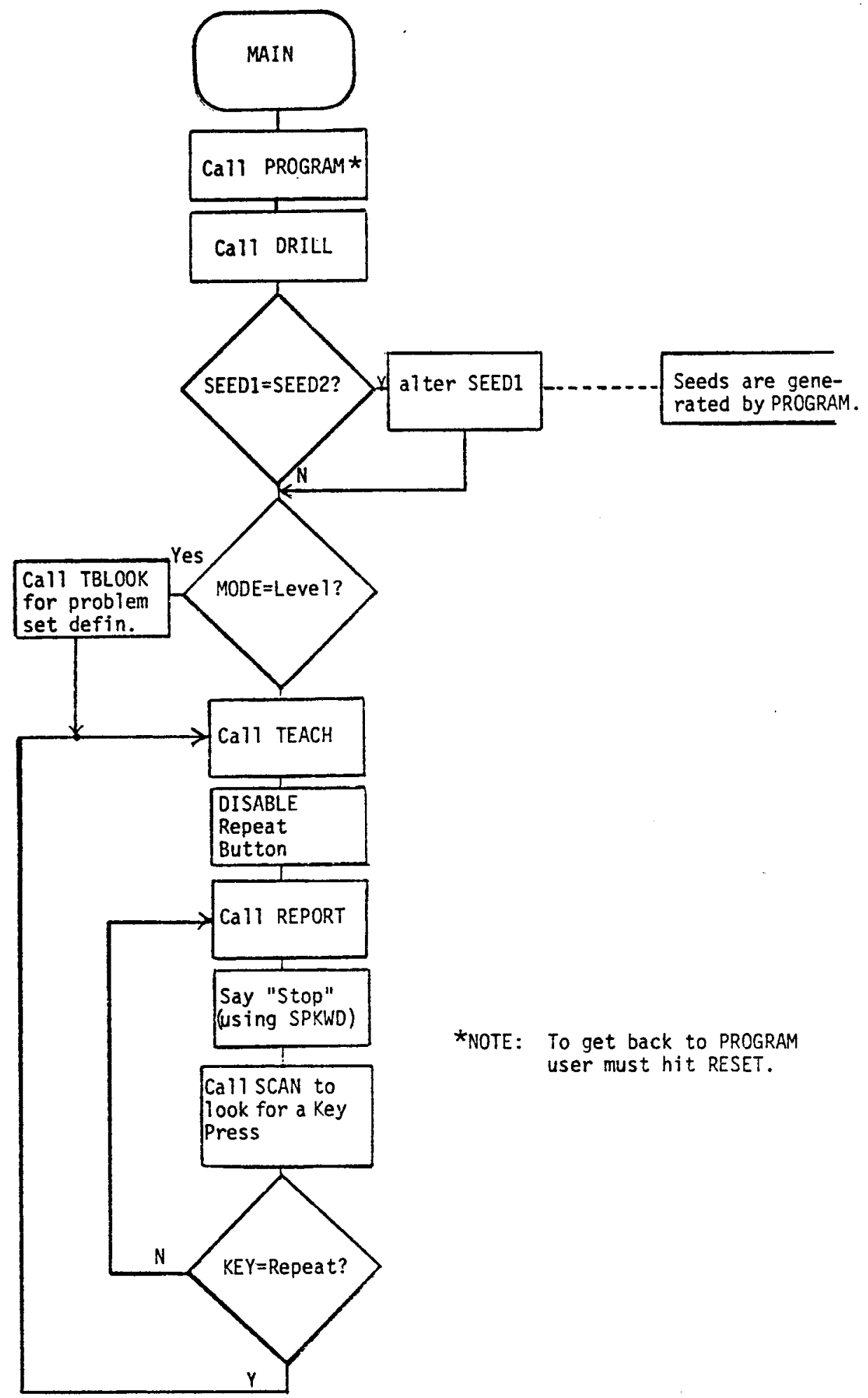

FIGURE 16 - MAIN Subroutine 
called by MAIN are: PROGRAM (allows the teacher to define the problem set), DRILL(the user's keyboard training dri11), TEACH (the subroutine that presents the problems), and REPORT (the subroutine that reports on the student's performance). In addition, MAIN insures that the seeds used for the random number generator (used to randomly generate problems) are not equal. The problem set definitions are looked up by TBLOOK when the machine is in the Level of Difficulty mode. An entire problem set can be repeated by pushing the repeat button after the report has been given.

b. DRILL Subroutine. DRILL is a keyboard familiarization drill for the student. The device says N-"please" via SPKEY, where $N$ is the name of a key (see Fig. 17). The student then attempts to push the named key. If the student doesn't push the named key, the pushed key's name is echoed and, after a pause, the key is again requested. If the student does press the correct key, the key name is echoed and a tone is sounded. DRILL then proceeds to the next key, and sequentially steps through the keys, zero to nine, and then the minus key.

c. PROGRAM SUBROUTINE. The FROGRAM subroutine shown in Fig. 18 prompts the teacher to enter the information that determines which problems are to be presented and how those problems are to be presented. In addition, PROGRAM a7so generates the random number seeds which are used for generating random problems by counting the number of scans that take place before the teacher responds. Information entered under control of PROGRAM, is then used by the TEACH subroutine, which presents the selected problems to the student. 


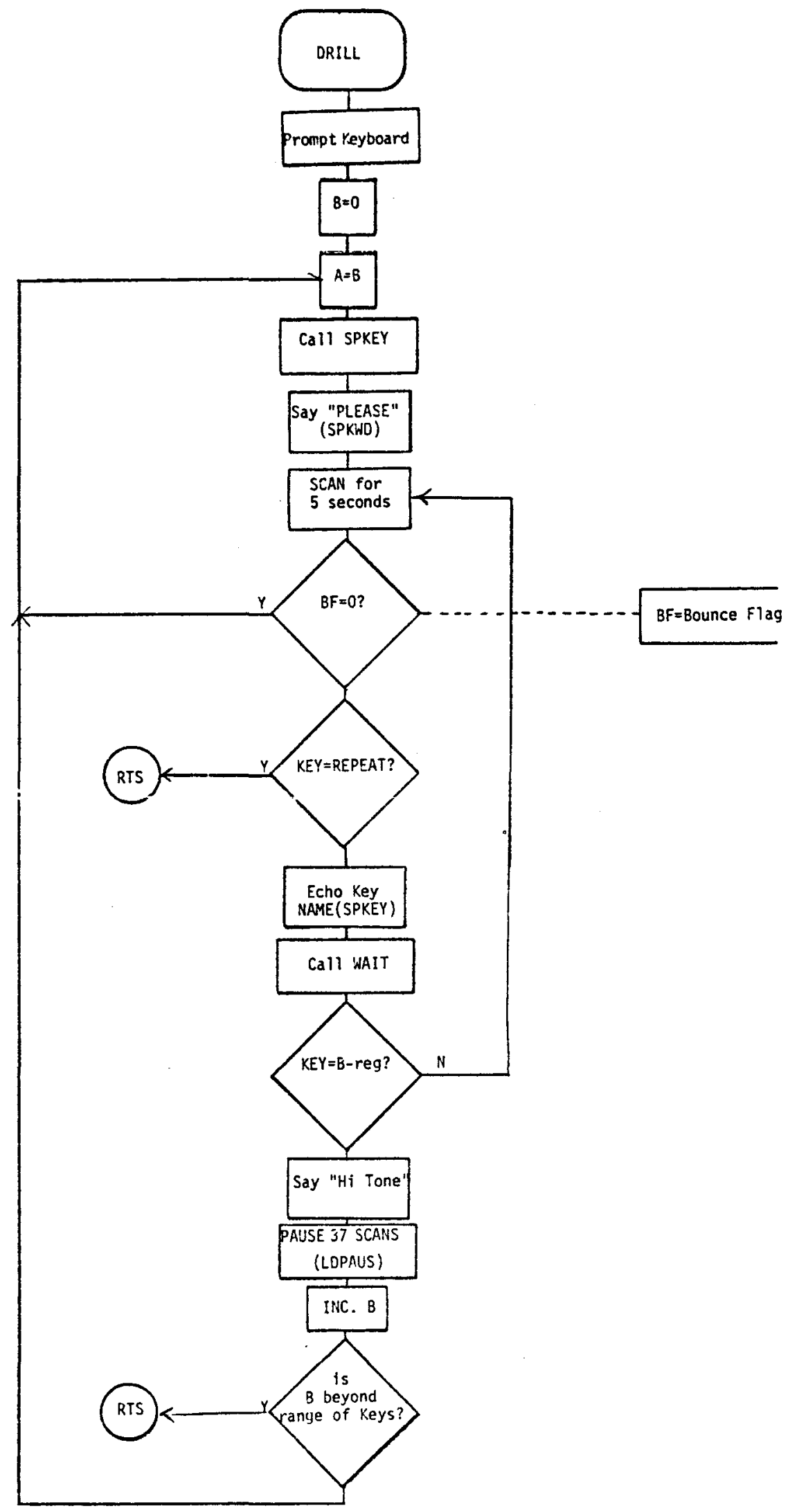

FIGURE 17 -DRILL Subroutine 


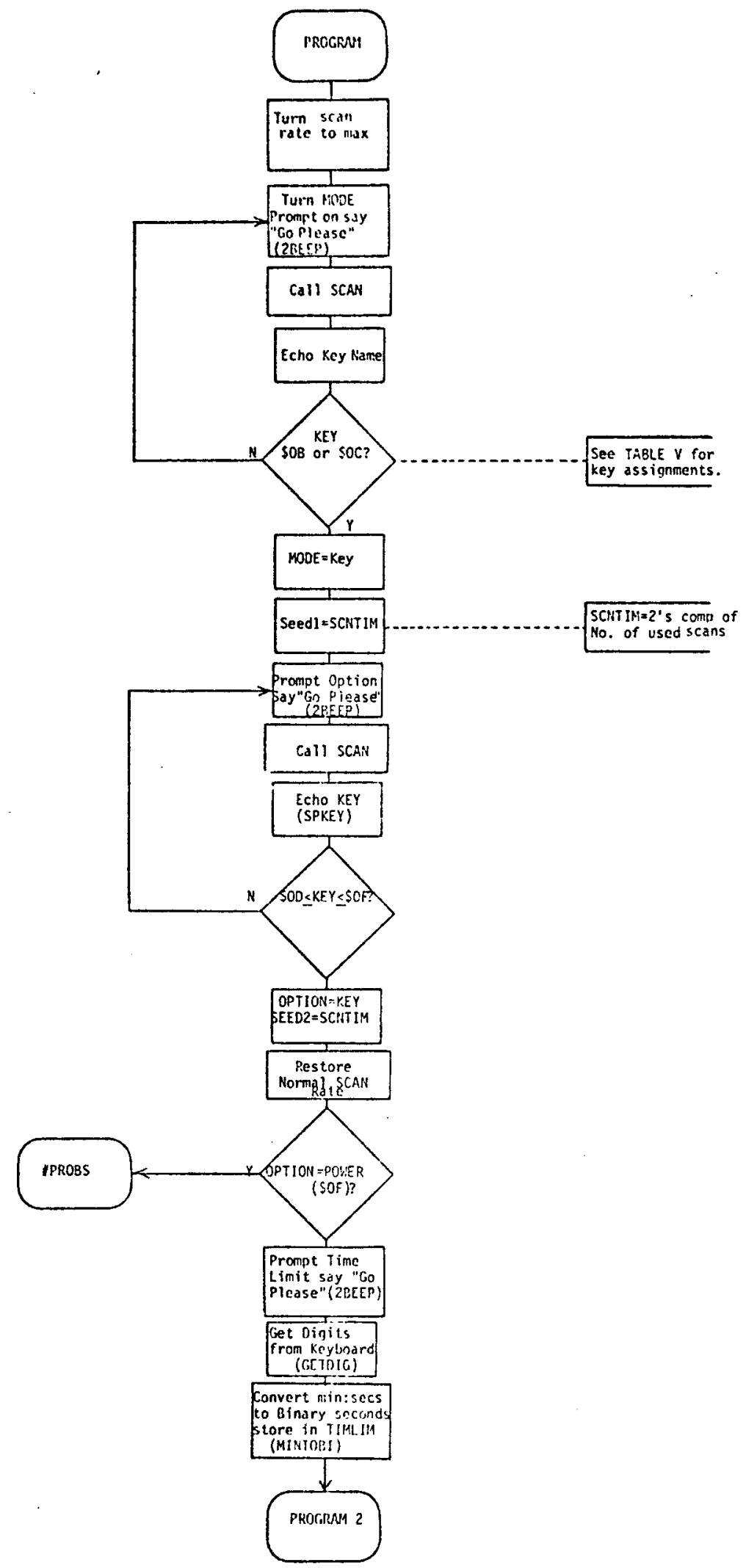

FIGURE 18 - Program Subroutine 


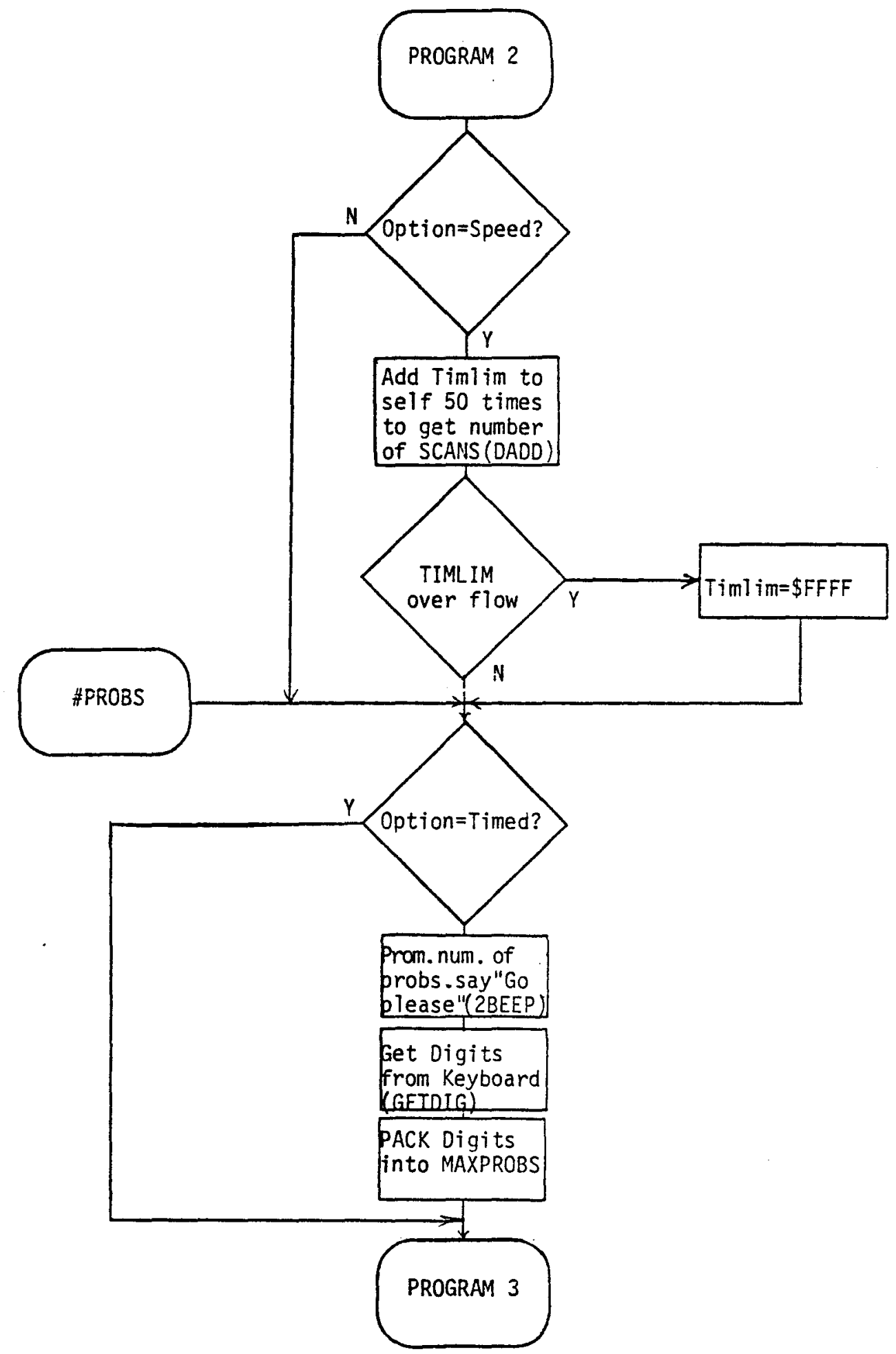

FIGURE 18 - Continued 


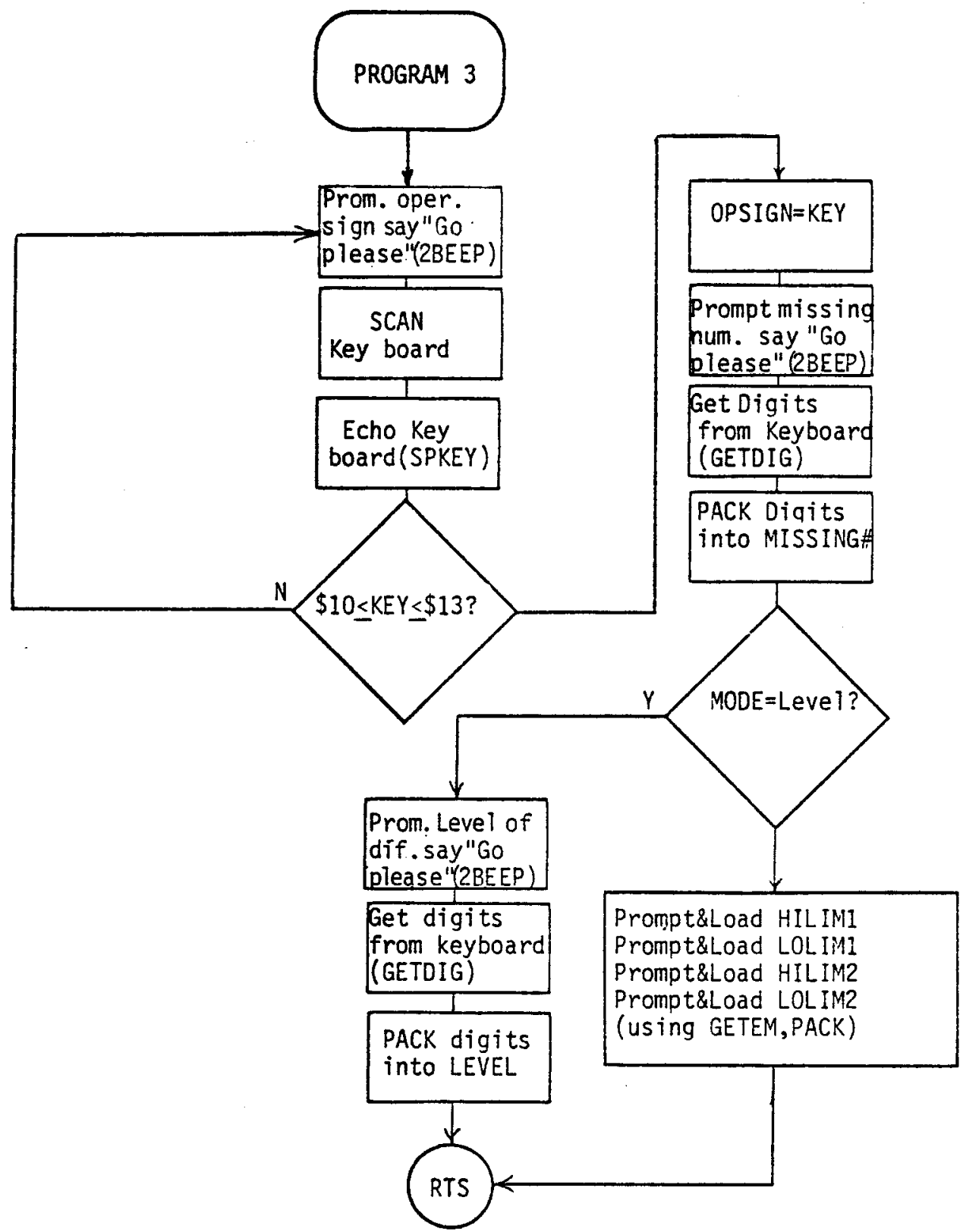

FIGURE 18 - Continued 
d. REPORT Subroutine. The REPORT subroutine reports how well the student performed on the last problem set. The total number of correct problems, the number of problems attempted, and the total amount of time spent by the student are reported both visualiy (in the LED display) and vocally (via the synthesizer). The flowchart of REPORT appears in Fig. 19.

e. TEACH subroutine. The TEACH subroutine quizzes the student on arithmetic problems. TEACH presents the problem using the LED display and the voice synthesizer. The student's answer is entered via the keyboard. Two attempts to correctly answer the problem are permitted. If the answer is incorrect, two high tones are sounded and the display blinks. If the student's answer is correct, three low tones are produced by the synthesizer. Also, if the answer was correct or if two incorrect attempts have been made, TEACH will present both the problem and the correct answer to the student, in the form of a complete mathematical sentence.

TEACH keeps track of the number of questions that the student has been asked, the number of problems missed, and the total amount of time the student has used to solve the problems.

Depending on the option that is selected by the teacher, TEACH presents the problems in different ways (see Fig.20). If the timed option is selected, the student has a fixed amount of time in which to work as many problems as possible. There is no fixed limit on the amount of time that can be spent on one given problem. If the speed option has been chosen, the student has a fixed amount of time for each attempt and a prescribed number of problems to do. The power option 


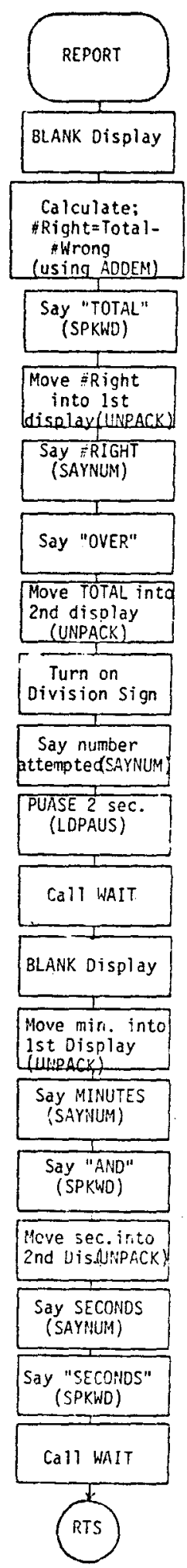

FIGURE 19 - REPORT Subroutine 


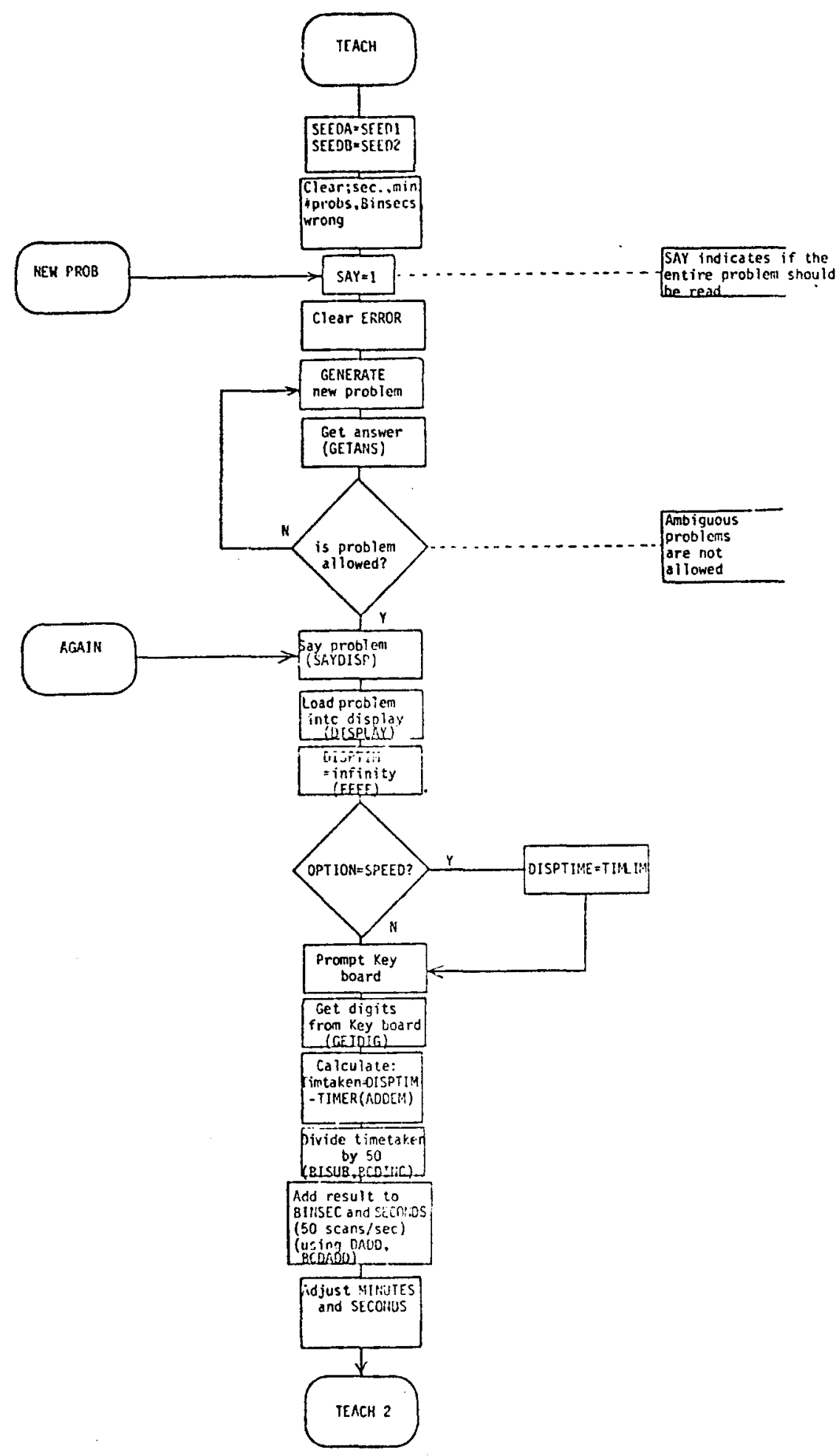

FIGURE 20 - TEACH Subroutine 


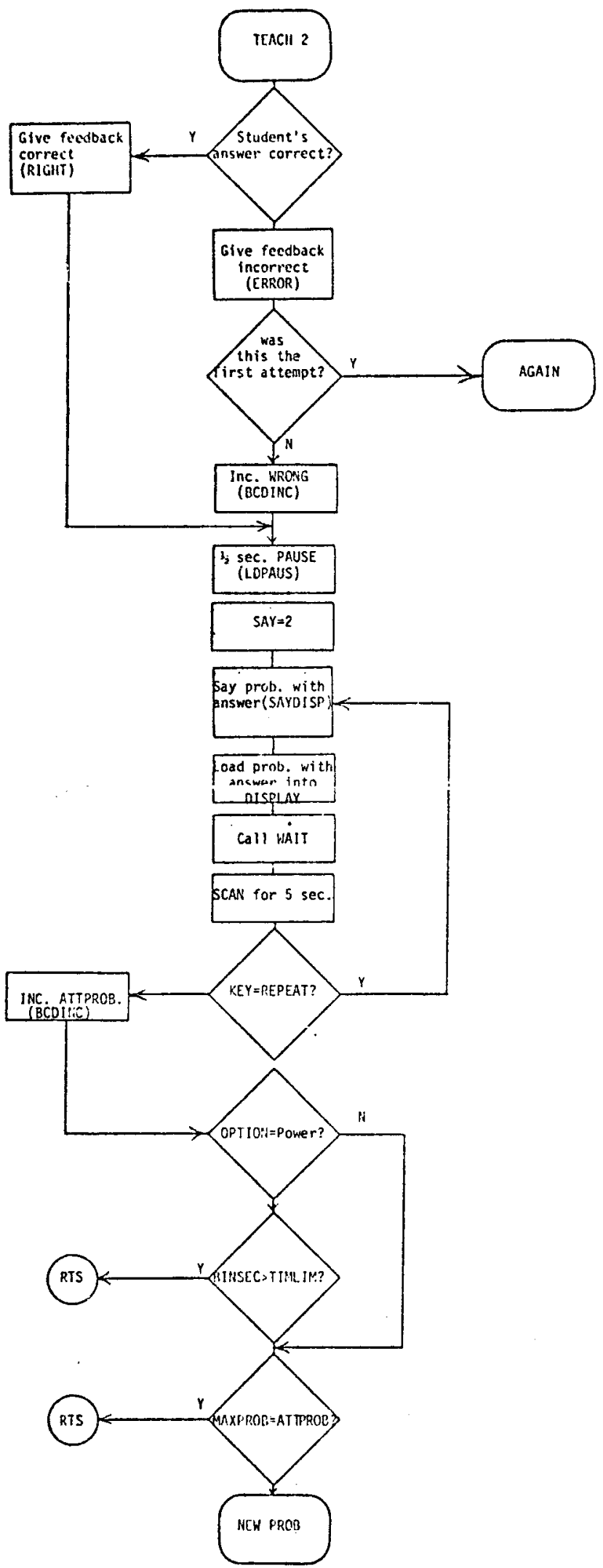

FIGURE 20 - Continued 
specifies that the student has a fixed number of problems to solve and an unlimited amount of time in which to do them.

2. Input/Output Subroutines

These routines control the information flow between the display, keyboard, and speech synthesizer via the microprocessor-controller.

a. BLANK Subroutine. BLANK (shown in Fig.21) stores a blank $\left(F F_{16}\right)$ in 211 of the locations of the display buffer. The effect of BLANK is to turn off the display while SCAN is executed.

b. BLANKIT Subroutine. BLANKIT, which is shown in Fig. 22, blanks the missing number in the display buffer. If a problem is to be displayed without the answer appearing on the LED's, the routine DISPLAY would be called to put the entire display into the buffer and BLANKIT would be called to blank the answer.

c. DISPLAY Subroutine. DISPLAY calls UNPACK to Toad the contents of NUM1, NUM2, and NUM3 into the corresponding display buffers (see Fig. 23). The buffers for the equal sign and the operation sign are also loaded with their proper values. Leading zeros in the display are blanked by storing a blanking code (FF) in place of the zeros. d. GETDIG Subroutine. GETDIG, shown in Fig. 24, is used whenever a multidigit number is needed from the keyboard. GETDIG is entered with the time limit (in scans) stored in the $X$ register (1ike SCAN). GETDIG returns when the time limit is exhausted, or if six digits have been entered. Pushing the enter key also causes a return from GETDIG. The entered digits are stored in a push down stack consisting of DIG1 through DIG6. The last digit entered is always stored at DIG1, and previous entries are pushed down toward DIG6. The total 


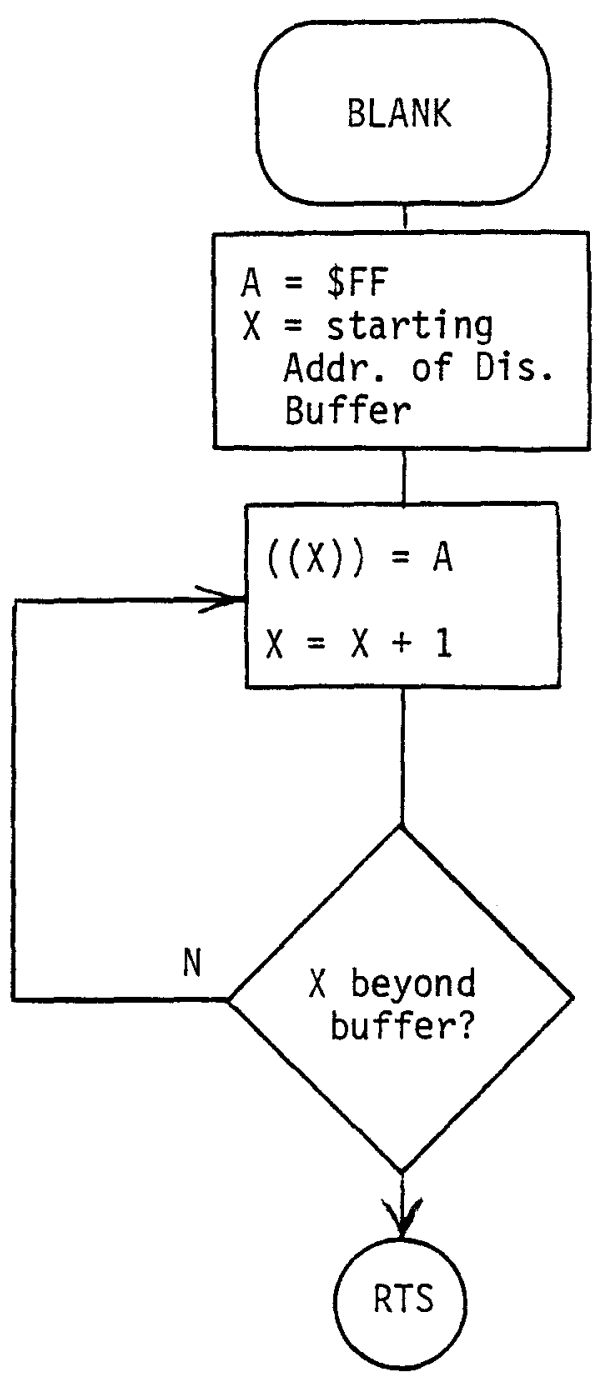

FIGURE 21 - BLANK Subroutine 


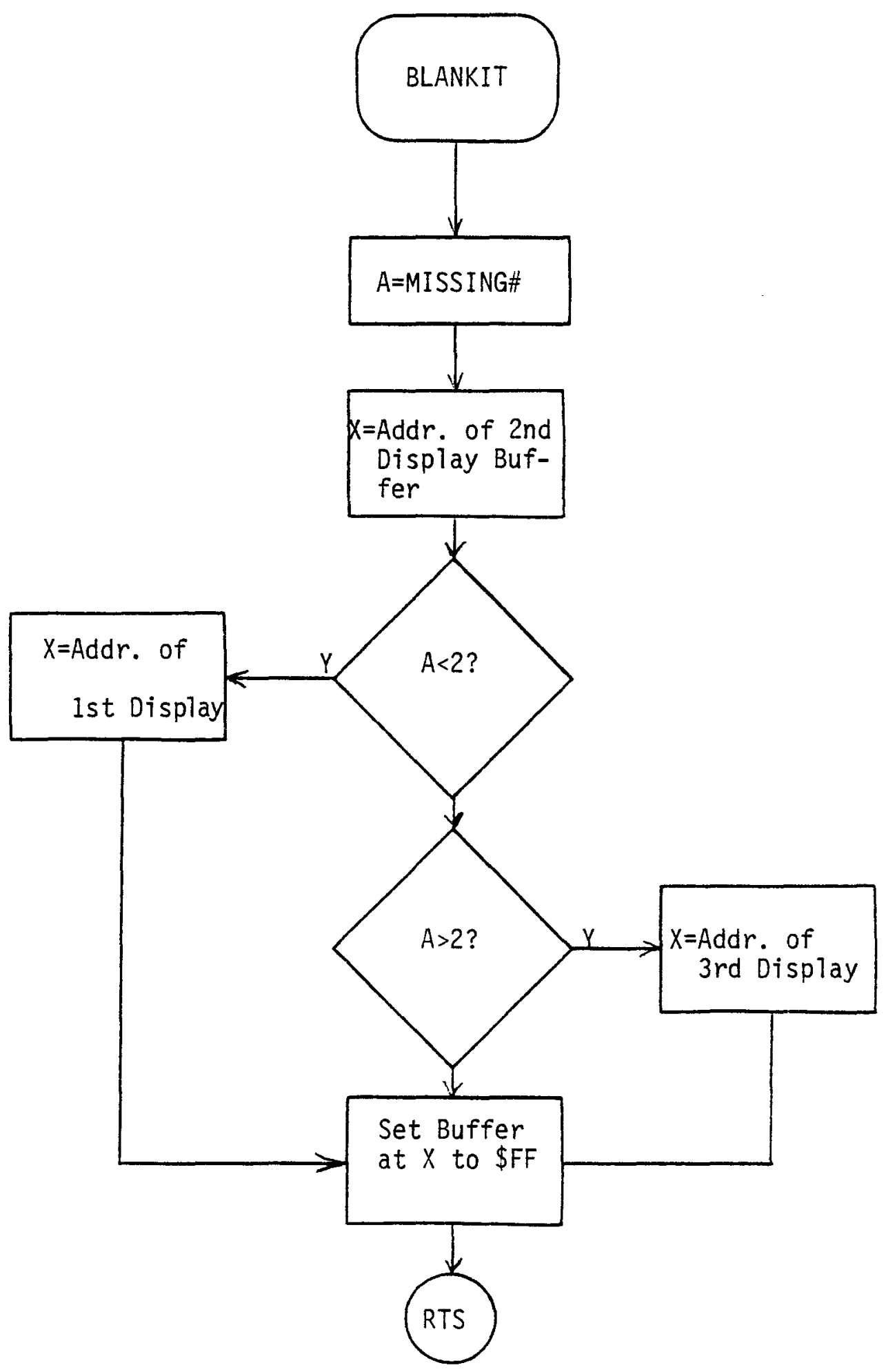

FIGURE 22-BLANKIT Subroutine 


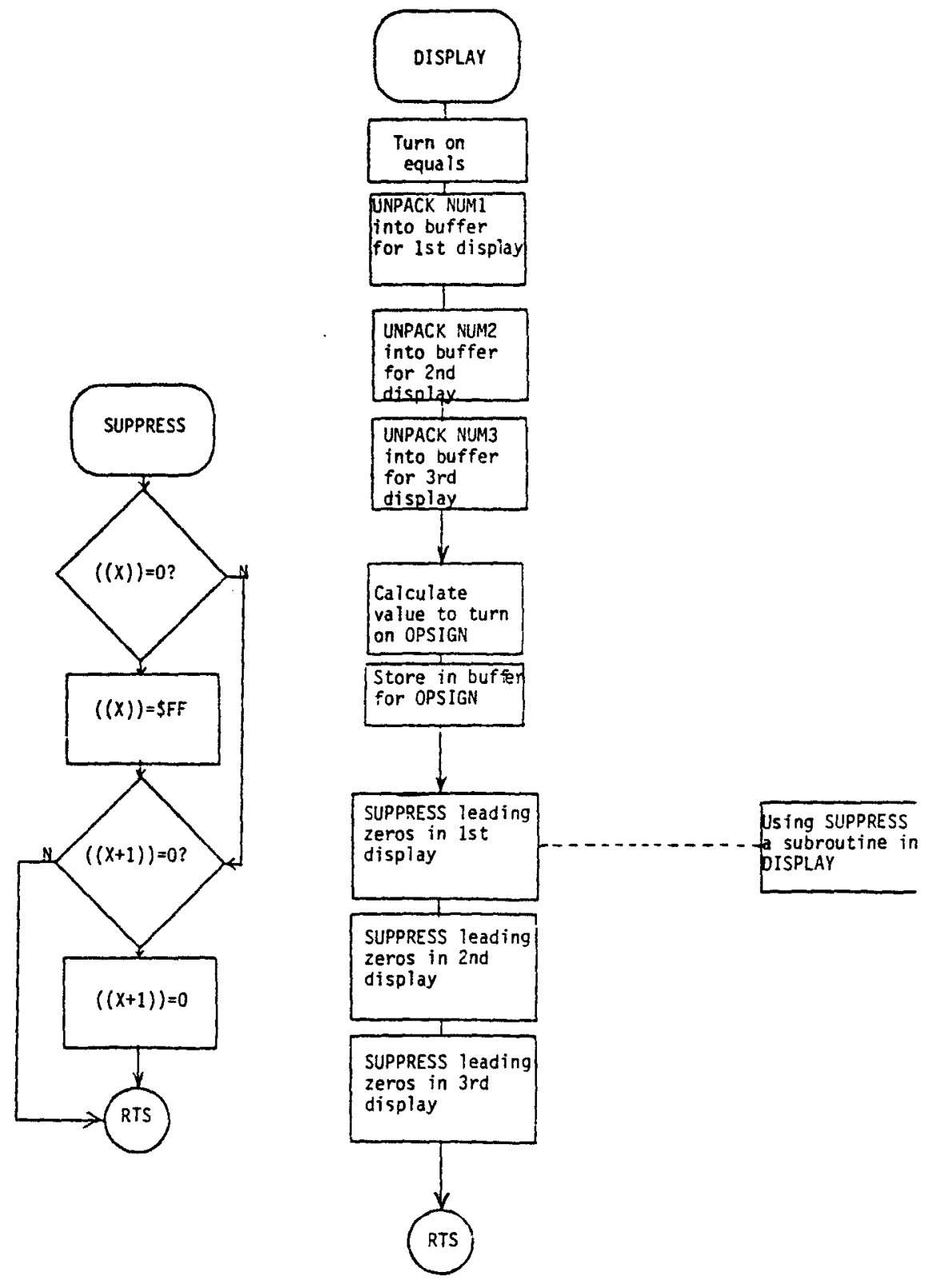

FIGURE 23 - DISPLAY Subroutine 


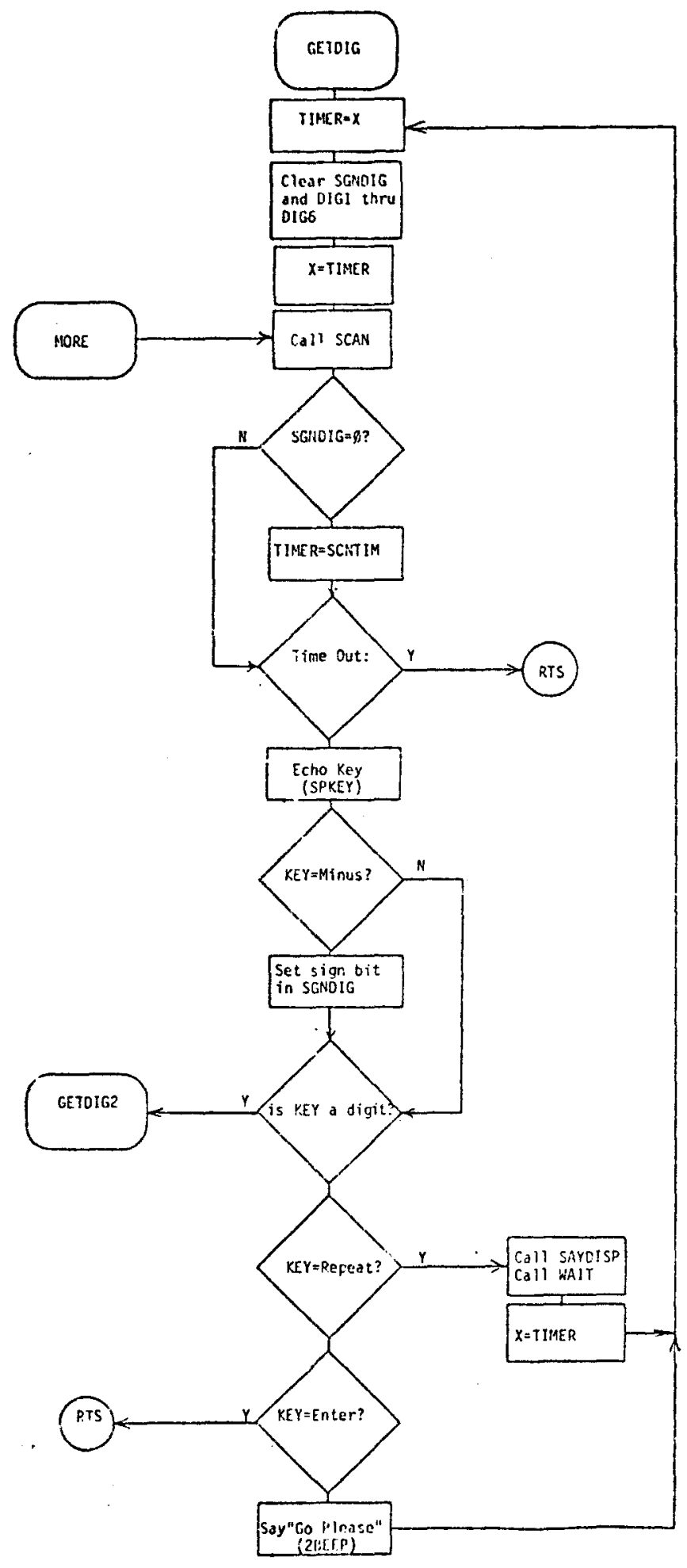

FIGURE 24 - GETDIG Subroutine 


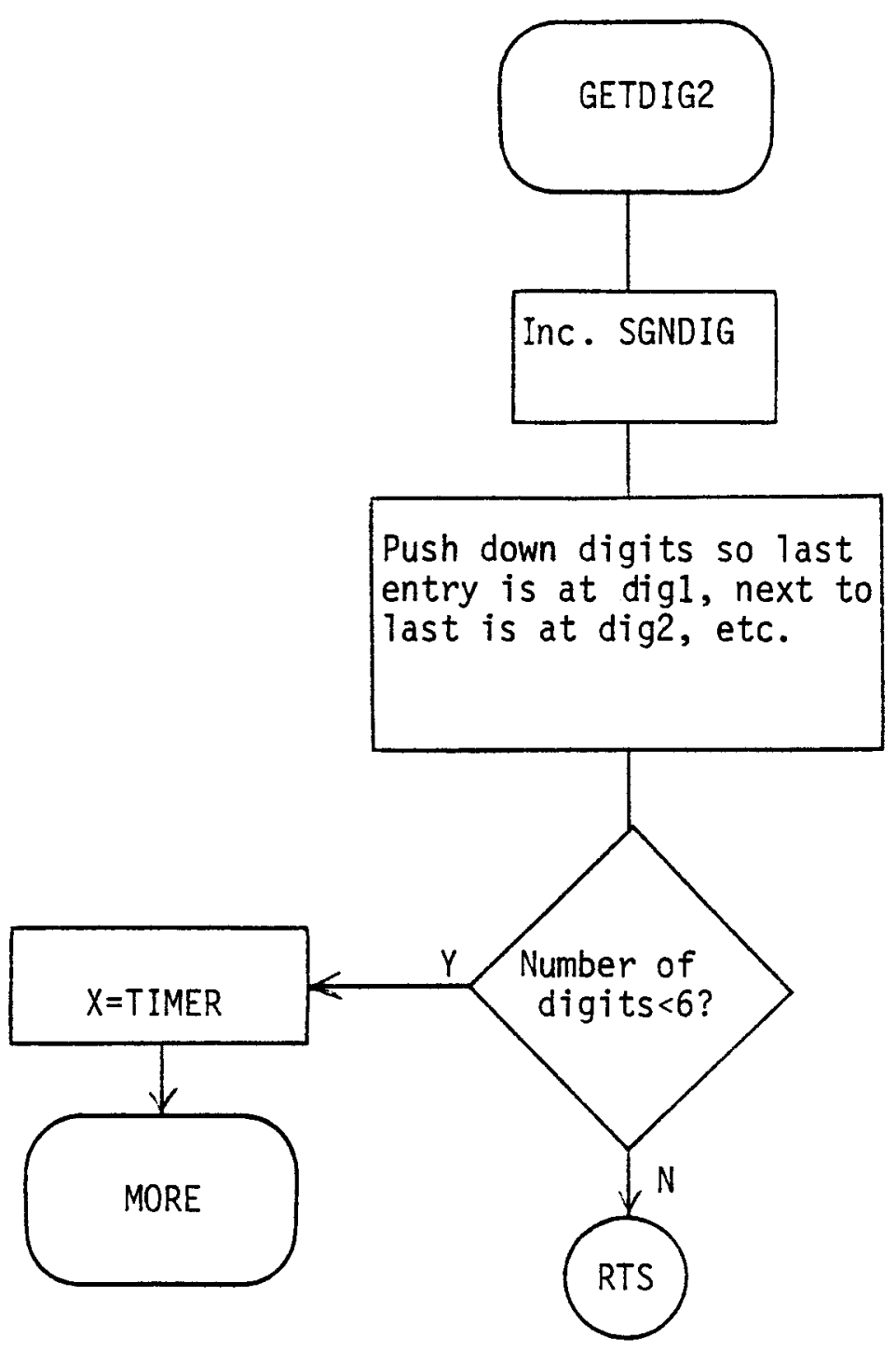

FIGURE 24 -Continued 
number of digits entered is stored in SGNDIG. Pushing the minus key causes the sign bit (bit 7) of SGNDIG to be set. Pushing the repeat button causes a call to SAYDISP, and GETDIG is restarted (clearing any entered digits).

e. GETEM Subroutine. GETEM (see Fig.25) is a general purpose prompt and keyboard entry subroutine. The contents of the A-register are stored in the prompt buffer. GETEM then causes the words "GO PLEASE" to be loaded into the speech buffer. A call to GETDIG brings in up to 6 digits from the keyboard (see Fig. 24).

f. PACK Subroutine. PACK takes the information received from the keyboard by GETDIG and compacts it into a two-byte packed BCD number at the memory location addressed by $X$ and $X+1$ (see Fig.25).

g. SAYDISP Subroutine. SAYDISP is the routine that loads the present problem into the speech buffer. Depending on the value of the variable SAY, one of three things will happen: 1) if SAY is equal to zero then SAYDISP will return with no action having been taken, 2) if SAY is equal to one, SAYDISP will load the problem into the buffer with a low tone in place of the missing number and 3) if SAY is equal to two, the entire problem including the missing number, is loaded into the speech buffer. The flowchart for SAYDISP is shown in Fig. 26.

h. SCAN Subroutine. SCAN is the routine that controls all of the input and output functions for the device; it performs the keyboard scanning for input data, and multiplexes the data to the LED display. The desired number of SCANS (at 50 scans/sec) is stored in the X-register before calling SCAN. When SCAN is called, the 


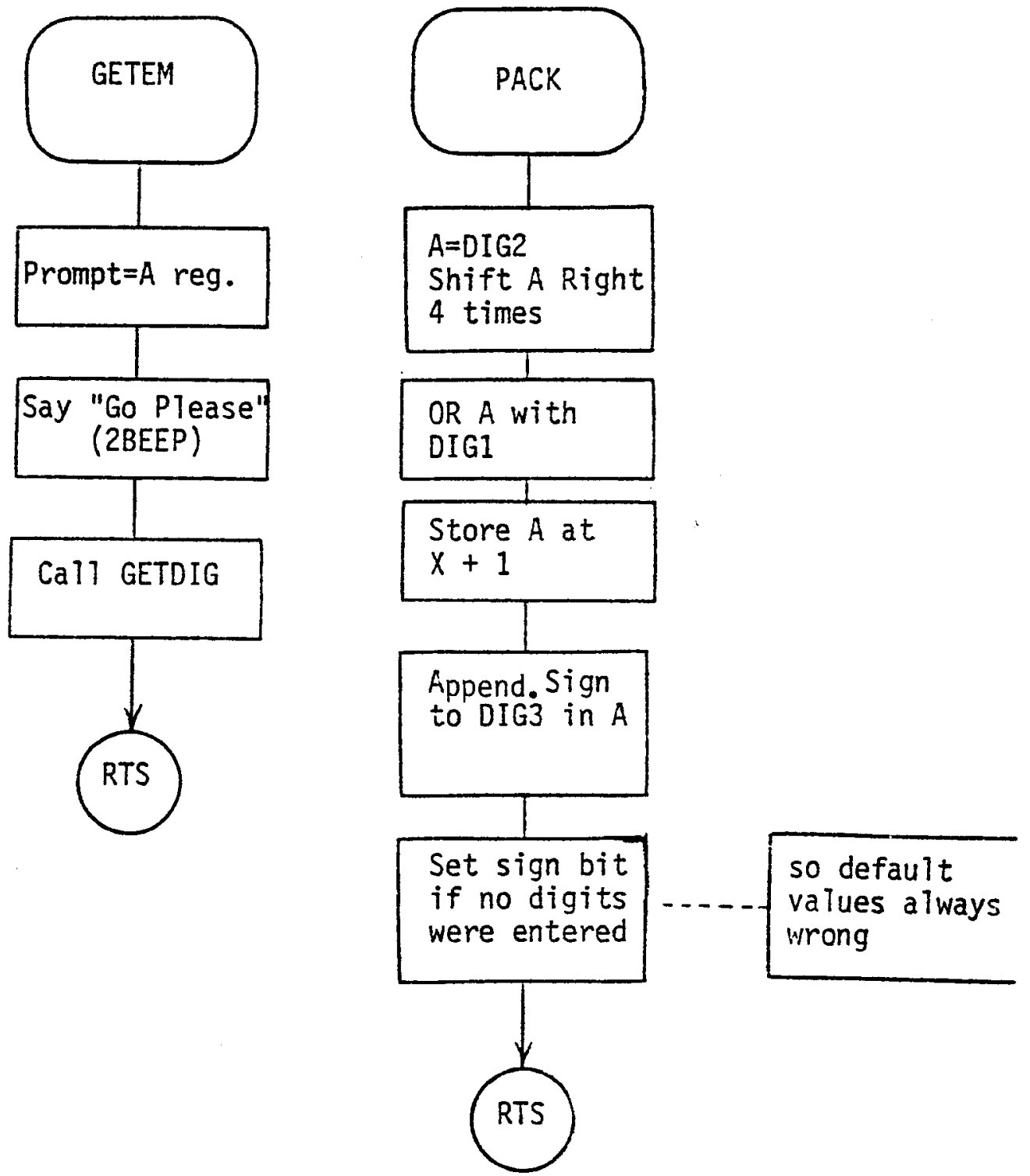

FIGURE 25 - GETEM and PACK Subroutines 

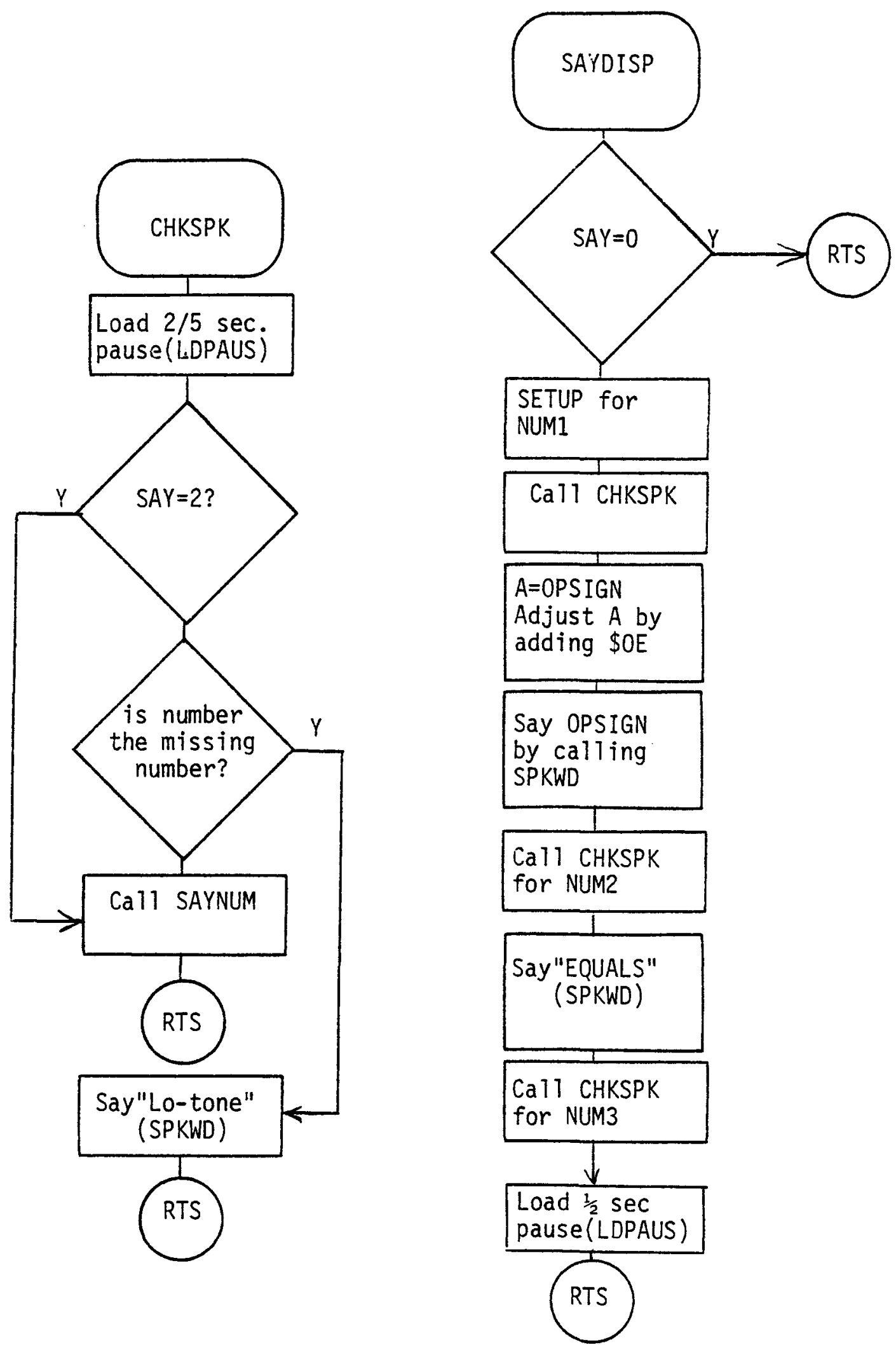

FIGURE 26 -SAYDISP Subroutine 
information stored in the display buffer (DISBUF) is routed to the display. SCAN also controls the speech synthesizer. Data stored in the speech buffer (SPKBUF) is sent to the synthesizer, one word at a time, until the speech buffer is empty. SCAN continues execution until one of two things happen: 1) if the desired number of scans has been completed, SCAN wil1 return; and 2) depressing and releasing a key on the keyboard will cause a return from SCAN.

SCAN is divided into four major segments: SCAN DISPLAY, CHECK SPEECH, CHECK TIME, and KEY DEBOUNCE, that are executed sequentially.

SCAN DISPLAY controls the LED display and the keyboard. The display, shown in Fig. 10, plus the prompts are divided into 15 parts, each with its own four-bit device address. Corresponding to each device address is an output buffer location (in DISBUF). A7so, each device address selects two keys as inputs. SCAN DISPLAY outputs the device addresses along with the data stored in DISBUF, and brings in the key information. A total is kept in SUM of the number of keys down simultaneously, if any. Also, the key number is stored in KEY (see Fig.27). After SCAN DISPLAY has output to all 15 device addresses, control is passed on to CHECK SPEECH.

CHECK SPEECH, shown in Fig.28, drives the TSI speech synthesizer. The synthesizer has 8 signal lines: six input data lines, one start line, and one busy status output line. When the start line is brought to the low state, the synthesizer begins saying the word selected by the six data lines. While the synthesizer is saying aword, its busy line is held in the low state. When the word is finished the busy 


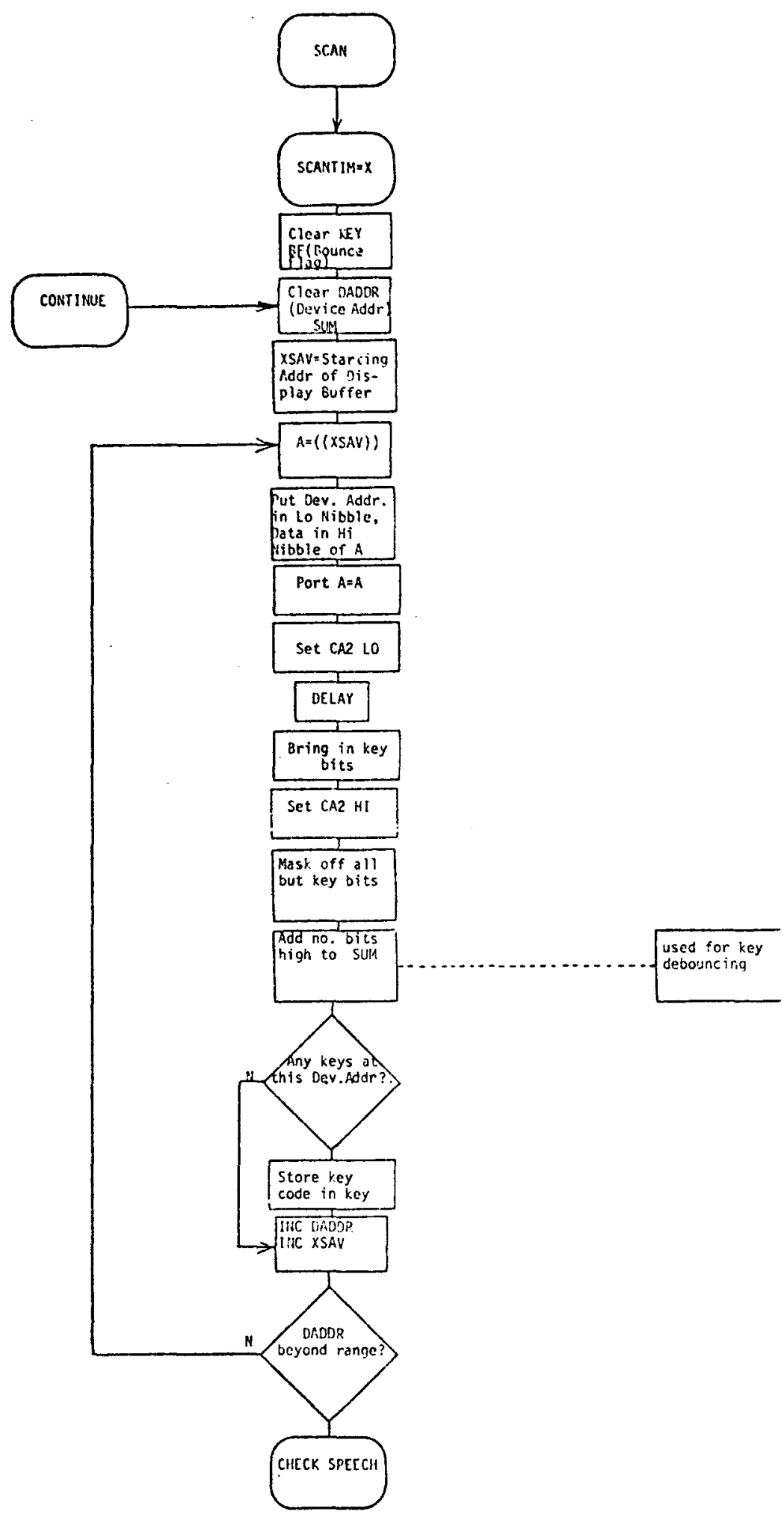

FIGURE 27 - SCAN DISPLAY SUbroutine 


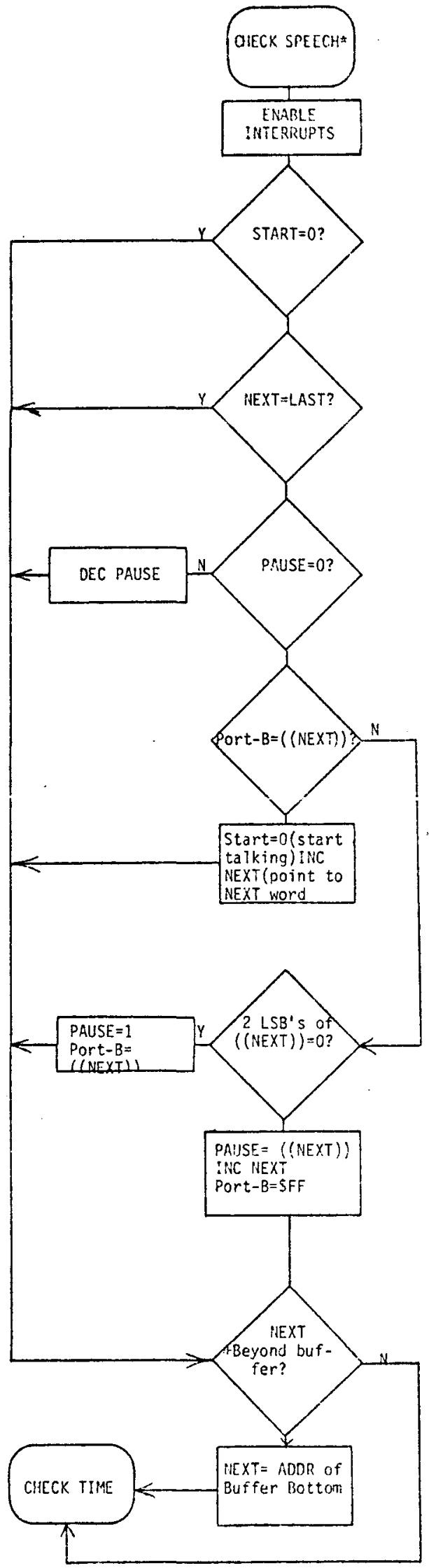

*NOTE: When busy goes high an interrupt brings START high.

FIGURE 28 - CHECK SPEECH Subroutine 
line returns to the high state and causes an interrupt reentry to CHECK SPEECH. CHECK SPEECH stores the data that is to be output to the synthesizer in a software FIFO (first-in, first-out buffer). The FIFO is organized as a circular buffer. Fig. 29 illustrates that buffer in two states, before and after data wrap around. Two pointers are used in this buffer; NEXT and LAST. NEXT always points to the next word in the buffer that is to be output. LAST Points to the location beyond the newest data word. When a new word is loaded into the buffer it is stored where LAST points and then LAST is incremented. In a similar way, when the word pointed to by NEXT has been spoken, NEXT is incremented by CHECK SPEECH to point to the next word in the buffer. If NEXT is incremented beyond the top of the buffer, it is set equal to the address at the bottom of the buffer. When NEXT equals LAST the buffer is empty.

The data in the buffer is of two types; words and pauses. A word is data that is destined to be routed to synthesizer. The six most significant bits of the word are sent to the synthesizer over the six data lines. The two least significant bits of a word must be zeros. If the two least significant bits of the buffer data are not zero, then the data is assumed to be a pause. A pause is an eight bit number representing the number of scans that should lapse before the next word is spoken. The maximum pause length is $2^{8}-1$ or 255 scans. At 50 scans per second the maximum PAUSE is 5.1 seconds. When the device is initialized, the start line is set to its high state and NEXT and LAST are set equal. If SCAN is called at this point, the fact that NEXT equals LAST tells CHECK SPEECH that the 


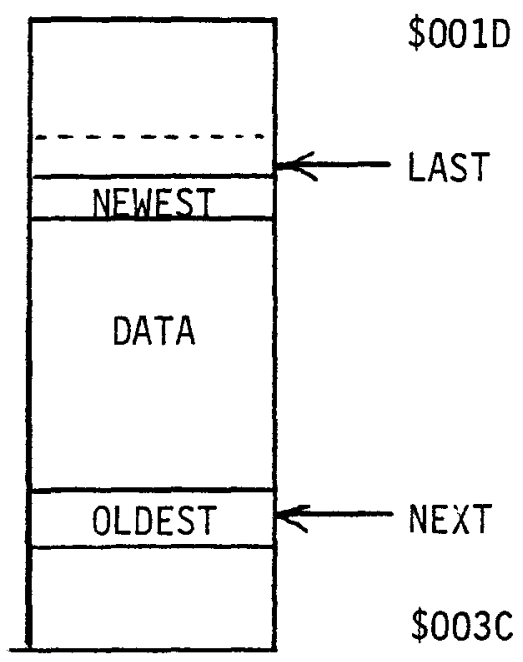

Circular F1F0 Buffer before Data wrap around

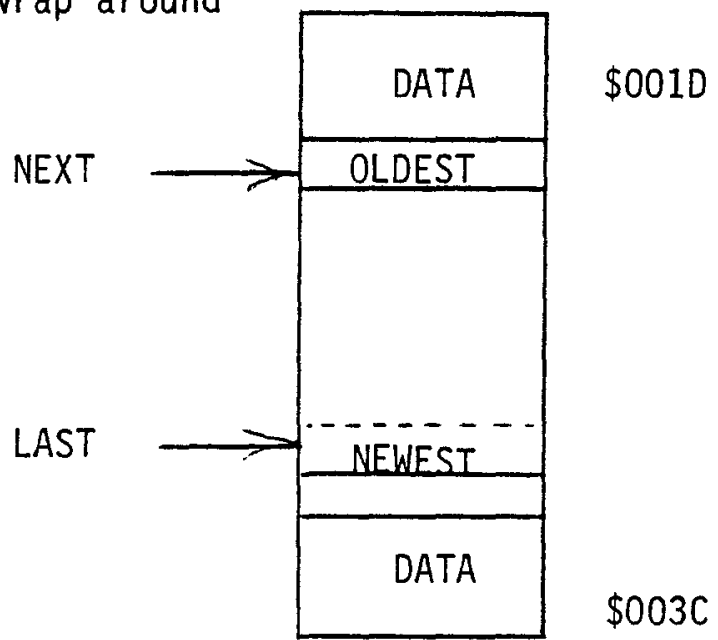

Circular F1F0 Buffer after Data wrap around

FIGURE 29 -Circular FIFO (Speech Buffer) 
buffer is empty, and the rest of CHECK SPEECH is bypassed (see Fig. 28). When data has been stored in the buffer and SCAN is called, CHECK SPEECH is not bypassed. On the first pass through CHECK SPEECH, the data pointed to by NEXT is stored in the variable PAUSE if it is a pause and NEXT is INCREMENTED. If the data is a word to be spoken, it is put on the six data lines to the synthesizer and the PAUSE register is set to one. Further passes through CHECK SPEECH only decrements the PAUSE register. When the PAUSE register has been decremented to zero, and the data pointed to by NEXT is present on the data lines, CHECK SPEECH brings the start line from high to low. This triggers the synthesizer to begin saying the word. CHECK SPEECH also increments the value of NEXT, pointing it at the next data item. While the start line is low, CHECK SPEECH is bypassed. After the synthesizer has finished saying the word, it brings the busy line high, which causes an interrupt. The INTERRUPT routine brings the start line high, enabling CHECK SPEECH.

The buffer is 32 bytes long. It was felt that this length was large enough that the author would not have to be concerned about the program overflowing it. Also, having the audio output stored in a queue allows the device to simultaneously output speech, output to the LED display, and bring in key information.

The third major segment of SCAN is CHECK TIME. When SCAN is called, the number in the X-register is stored in SCNTIM. Normally, on each pass through CHECK TIME, SCNTIM is decremented. This occurs only if SCNTIM is not equal to its maximum value $65,535_{10}$ (or FFFF in hexidecima1). When SCNTIM has been decremented to zero, a return is 
performed and the computer exits SCAN. The maximum amount of time in SCAN is 21.84 minutes $(65,535$ scans). However, if SCAN is called with the $X$-register containing $\$$ FFFF $_{16}$, SCAN will not automatically time out (see Figs. 30 and 31 ).

The KEY DEBOUNCE portion of SCAN takes the information provided by SCAN DISPLAY and uses it to determine when a key has been pushed and released. For a key to be valid, it must be held down for two scans of the keyboard and then released. If more than one key is depressed, then the keys are ignored. This technique of debouncing is often used in calculators. ${ }^{29}$ KEY DEBOUNCE is a software emulation of a finite state machine (see Figs.30 and 31 ). When a key is released KEY DEBOUNCE causes a RTS to be executed.

i. SPKEY Subroutine. The SPKEY subroutine interprets the data in the A-register as a key number. If the key has a corresponding word in the synthesizer's vocabulary, that word is loaded into the speech buffer; otherwise, a high tone is loaded into the speech buffer (see Fig. 32). The keys that have corresponding words are zero through nine and the minus key.

j. SPKWD and LDPAUS Subroutines. SPKWD and LDPAUS are the subroutines that load data into the speech buffer. SPKWD is the routine that is used to load a word, stored in the A-register, into the buffer. LDPAUS takes the number in the A-register and stores it in the buffer. The routine calling LDPAUS must insure that one of the two least significant bits is a one, if SCAN is to interpret the number as a pause. After the data is inserted into the buffer, at the location pointed to by LAST, LAST is incremented so that it points to the 


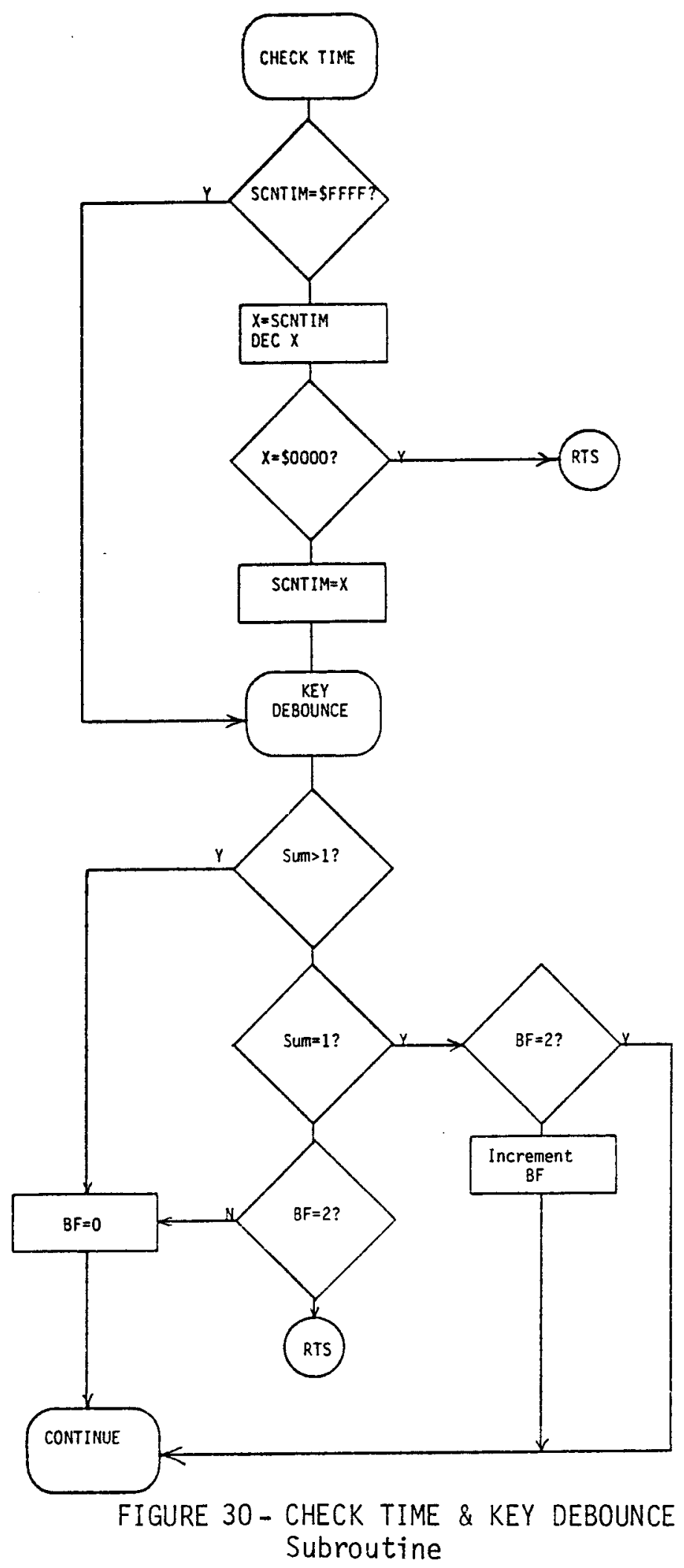




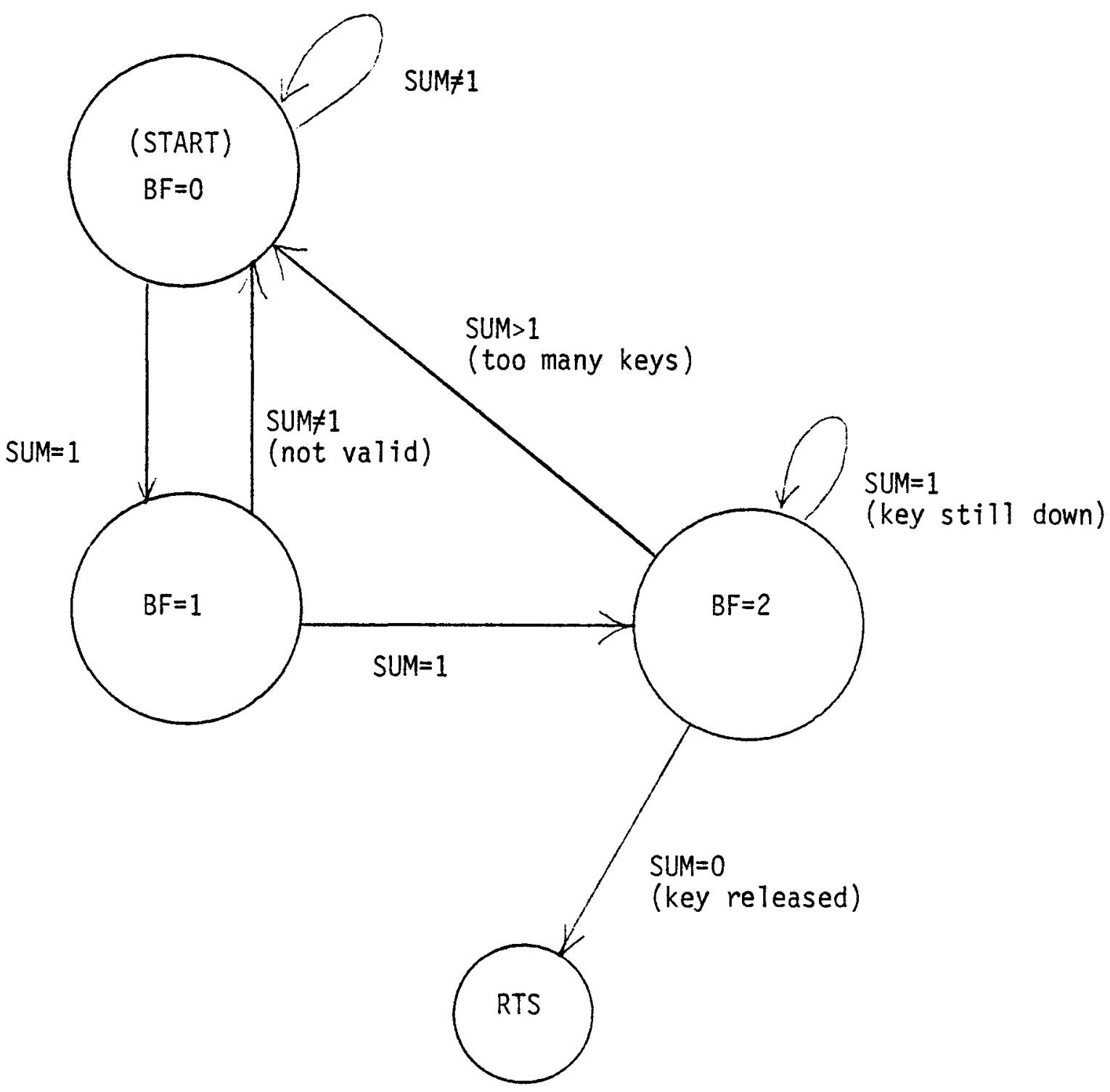

FIGURE 31 -Finite State and Key Debounce 


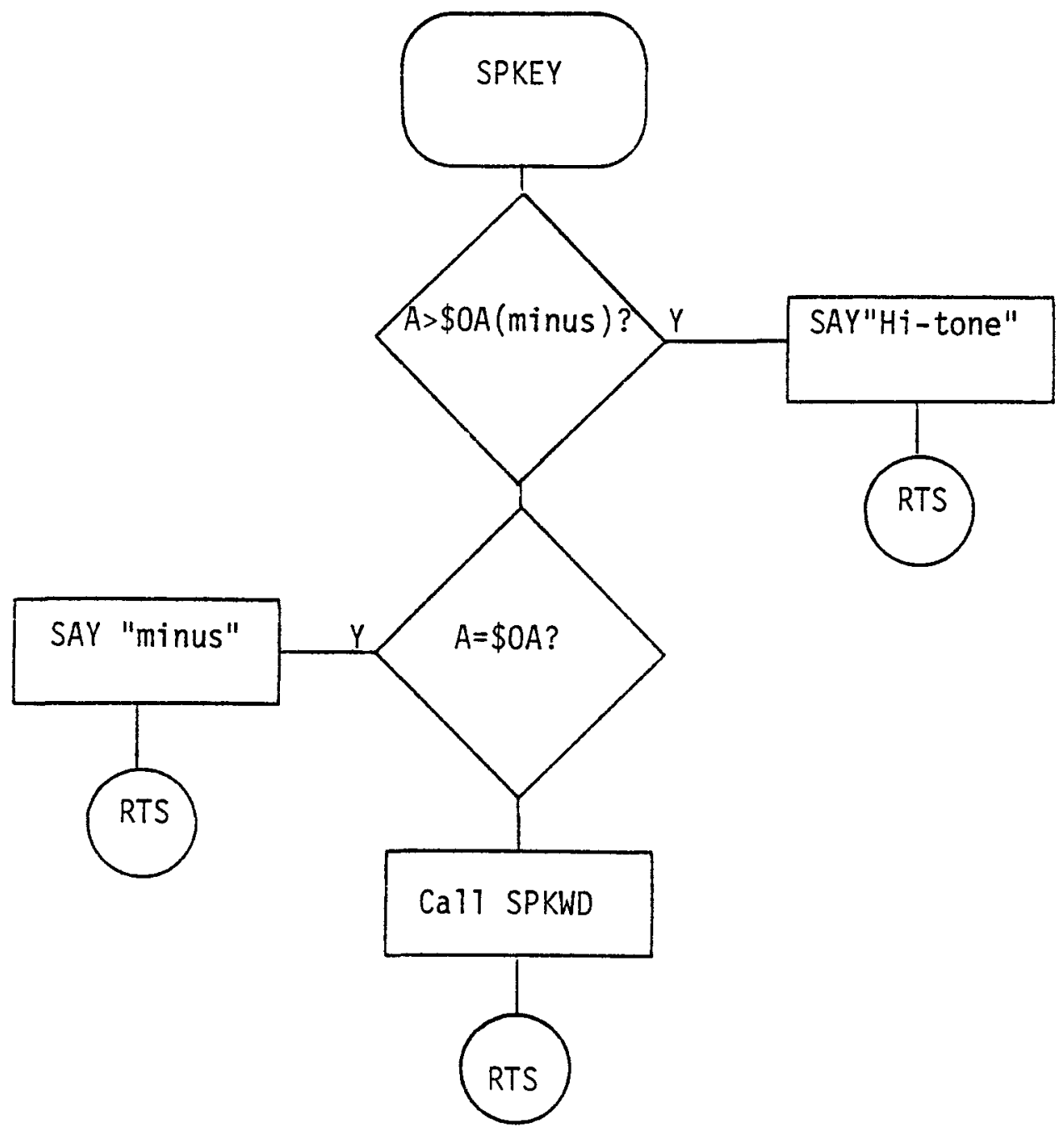

FIGURE 32 - SPKEY Subroutine 
next empty buffer location (see Fig.33).

k. UNPACK Subroutine. Decimal numbers, internal to the device, are stored in packed BCD format of the form:

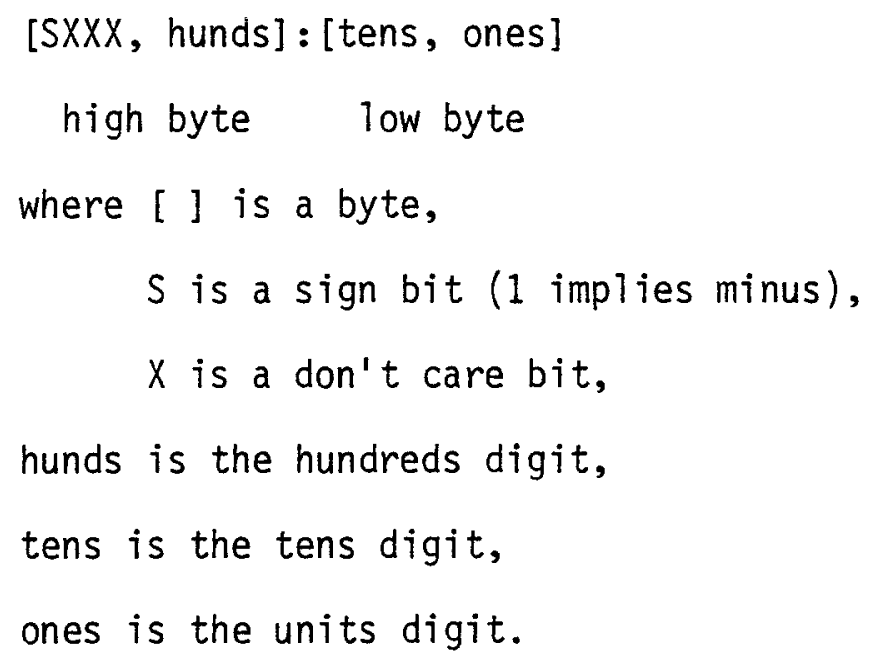

UNPACK takes the number stored in $A: B$ and puts this data, one digit per byte, into four bytes starting at the memory location addressed by the $X$-register. Because the routine is used to load the display buffer, the digits are stored in the high nibbles of the unpacked data bytes (see Fig.34).

1. WAIT Subroutine. WAIT performs a function very similar to its name. WAIT continues to SCAN the display and output words to synthesizer until the speech buffer is empty. WAIT holds up program execution while the speech buffer is being emptied; it prevents the speech from getting too far behind the programs that generate the speech (see Fig.35). 3. Arithmetic Subroutines

These routines perform the necessary background computations to generate problems for the student. 


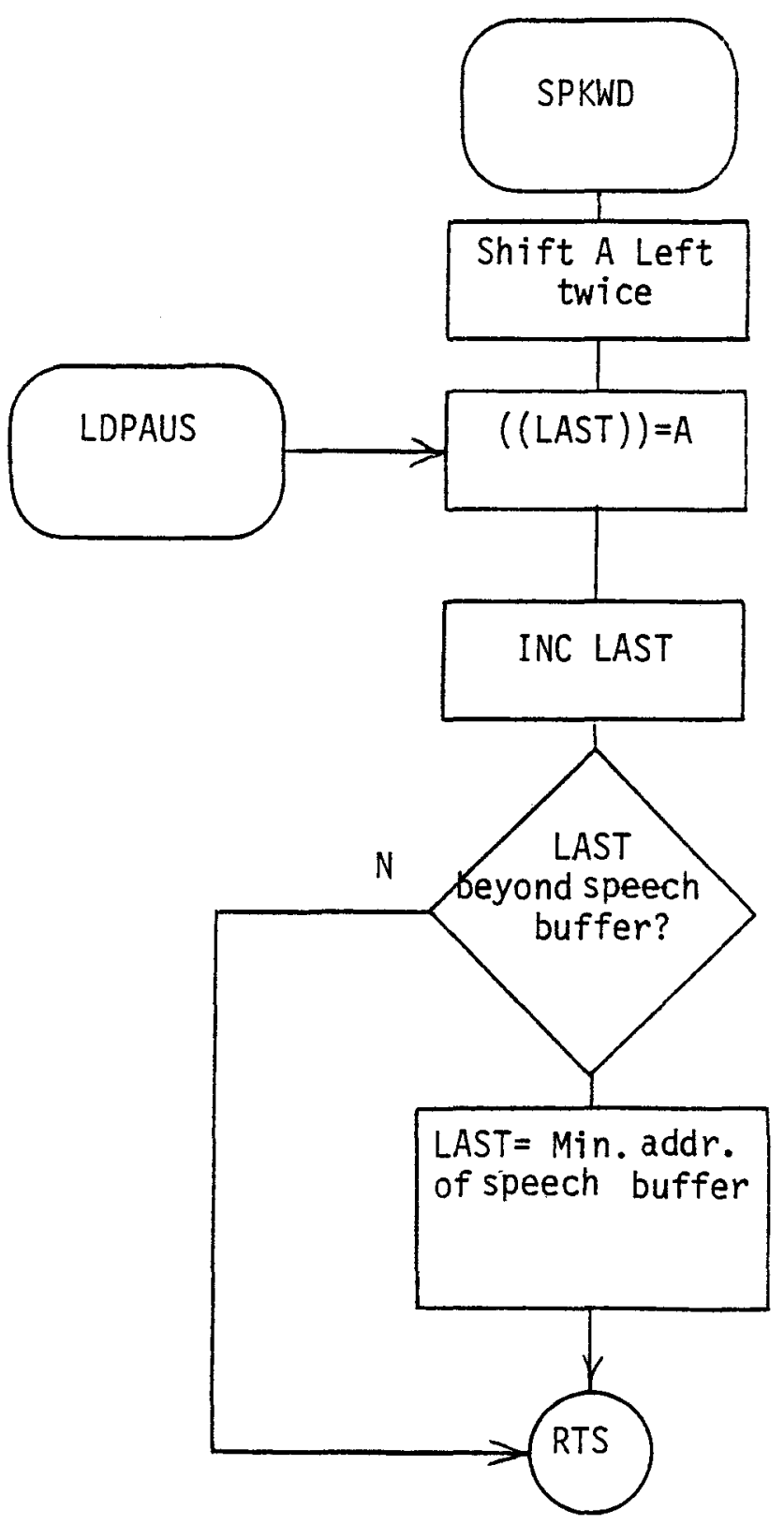

FIGURE 33 - SPKWD and LDPAUS Subroutines 


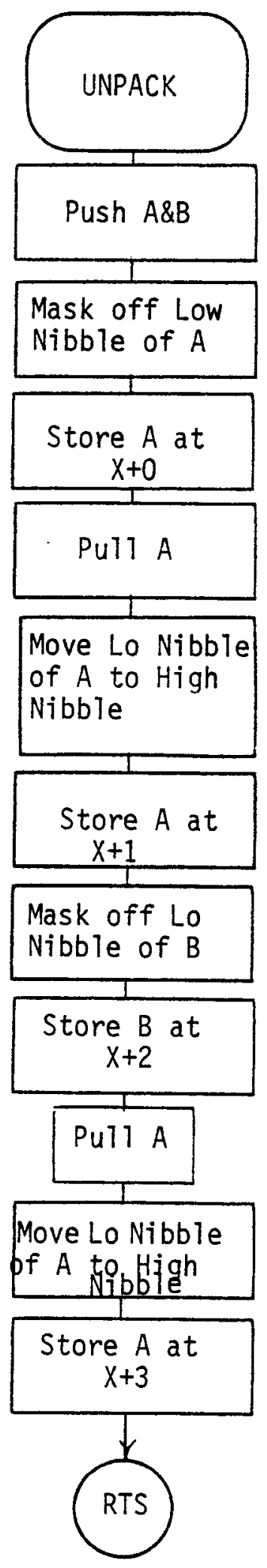

FIGURE 34 -UNPACK Subroutine 


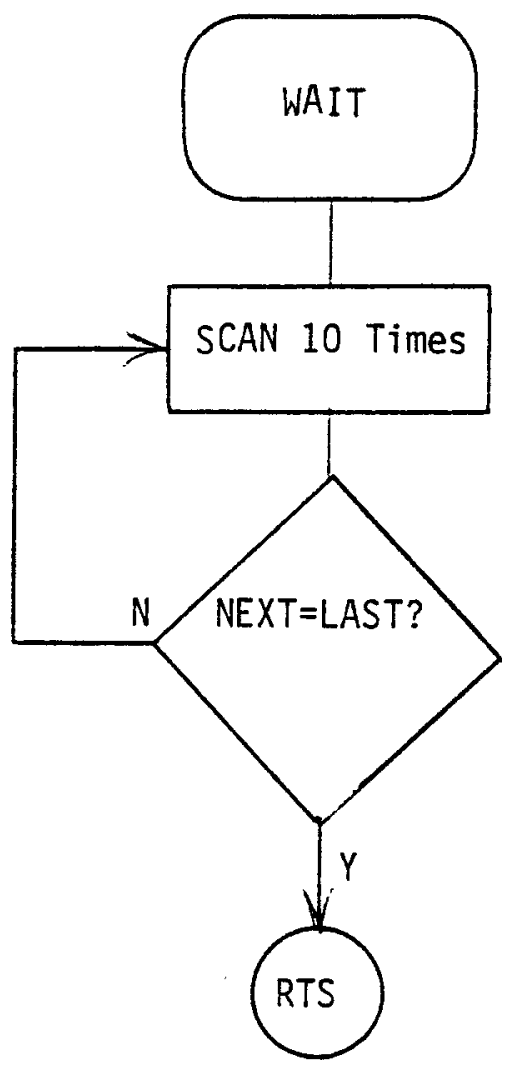

FIGURE 35 - WAIT Subroutine 
a. ADDEM Subroutine. ADDEM is a signed BCD addition routine. It adds the signed BCD numbers in UNE and DEUX and places the result in TROIX.

ADDEM uses $10^{\prime}$ 's complement arithmetic to add negative numbers (see Fig. 36). If one of the numbers is negative, the $10^{\prime}$ 's complement of that number is formed. The numbers are then added. If the result is negative, the ten's complement of the answer is taken and the sign bit is set.

b. BCDADD Subroutine. The BCDADD subroutine takes the twobyte $B C D$ data word stored in $A: B$ and decimal adds it to the contents of the location addressed by the X-register (see Fig.37).

c. BCDINC Subroutine. The BCDINC subroutine loads A:B with one and jumps to BCDADD. The net effect is to increment (BCD) the contents of the locations addressed by the X-register (see Fig.38).

d. BCDMULT Subroutine. BCDMULT is a signed BCD multiplication routine. The two numbers to be multiplied are in stored in packed BCD notation. The numbers are located in the double byte variables NUM1 and NUM2 and the result is stored in NUM3. NUM1 and NUM2 are not destroyed in the multiplication process. BCOMULT requires that NUM1 and NUM2 be between -99 and +99 , and the resulting product must 7 ie in the range of -999 to +999 . A flow chart of BCDMULT appears in Fig. 39

e. BISUB Subroutine. The BISUB subroutine is a general purpose double byte binary subtraction routine. When called, it subtracts the number in $A: B$ from the number addressed by $X$ and $X+1$ (see Fig. 40 ). 


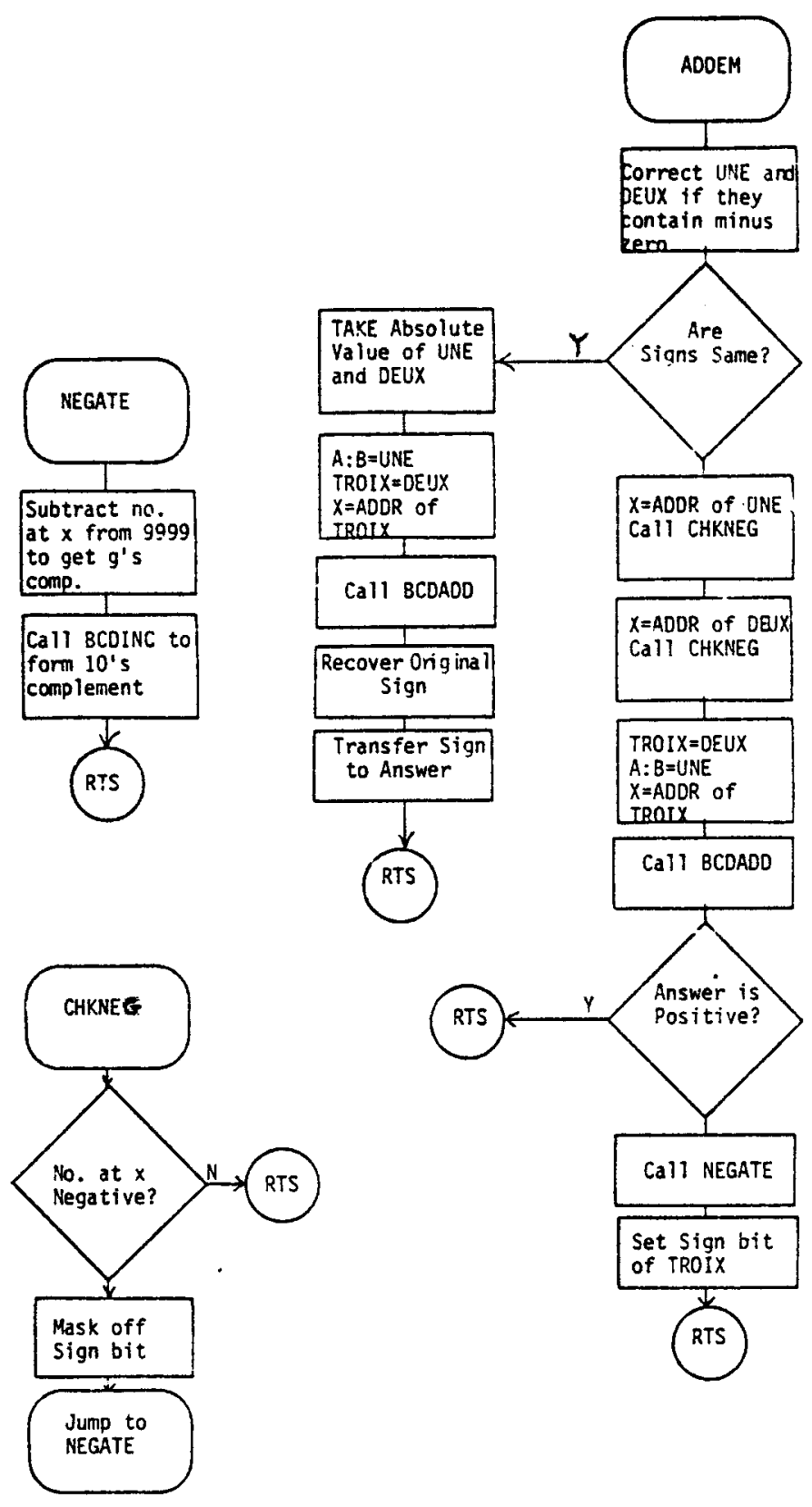

FIGURE 36 - ADDEM Subroutine 

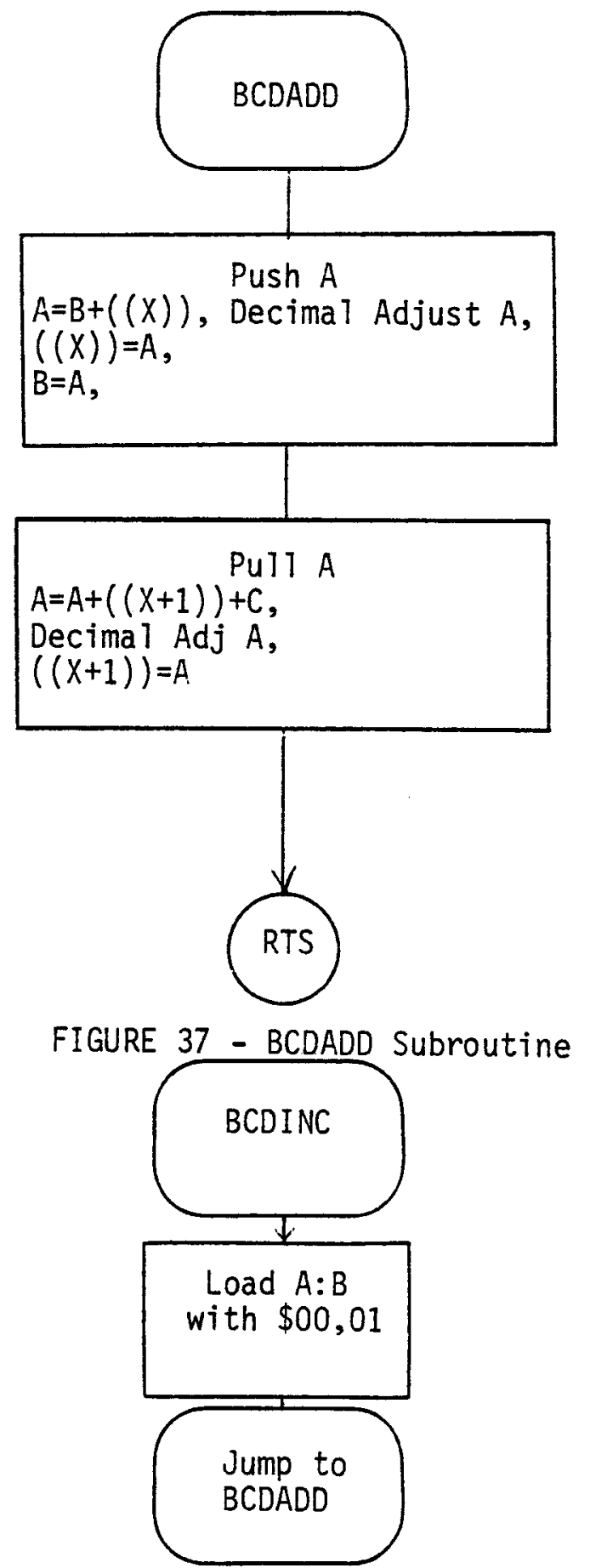

FIGURE 38 - BCDINC Subroutine 

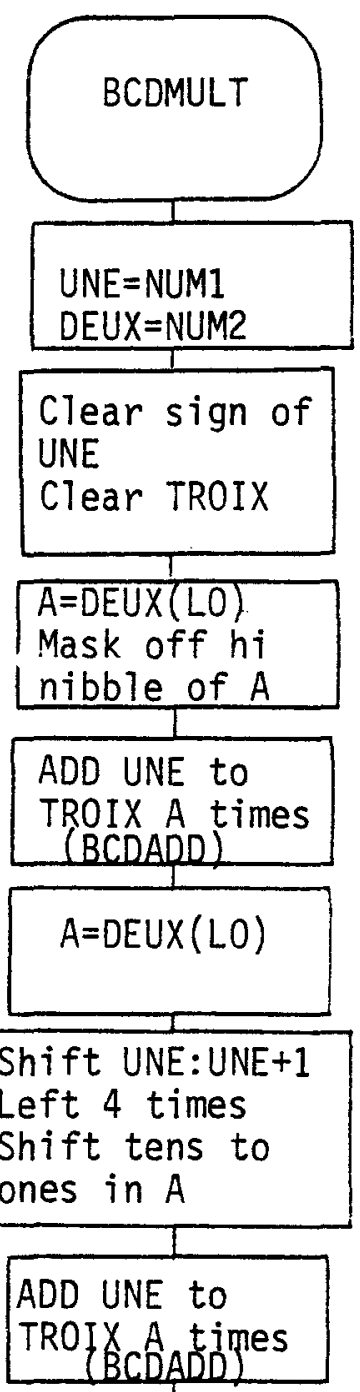

Sign of TROIX $=$

Sign of NUM1 $\theta$

Sign of NUM2

NUM3 $=$ TROIX

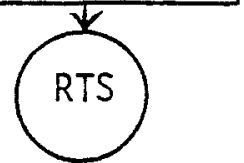

FIGURE 39 - BCMULT Subroutine 
f. COMPARE Subroutine. The need to be able to compare signed $B C D$ numbers prompted the writing of COMPARE. COMPARE subtracts the number in the X-register from the variable VALUE using signed BCD arithmetic. The result is returned in the X-register (see Fig.41). Branching can be reliably done using the $\mathrm{Z}$ and $\mathrm{N}$ bits in the condition code register.

g. DADD Subroutine. DADD is a double byte binary addition routine. $D A D D$ adds the contents of $A: B$ to the contents of the memory locations addressed by $X$ and $X+1$. (See Fig. 42).

h. GETANS Subroutine. GETANS is the routine that finds the answer to the problem defined by NUM1, NUM2, and OPSIGN. If, for example, OPSIGN was multiplication, then GETANS would call BCDMULT to find the product of NUM1 and NUM2 (see Fig.43). The result of the multiplication would be stored in NUM3.

GETANS doesn't always perform the operation suggested by OPSIGN. If OPSIGN corresponds to division, GETANS will multiply the contents of NUM1 and NUM2. The resulting product is moved to NUM1 and the original NUM1 and NUM2 are moved to NUM2 and NUM3 respectively. These moves correspond to forming the complementary devision problem of the multiplication of NUM1 times NUM2.

Normally, subtraction is accomplished in GETANS by reversing the sign of the second number, and adding the two operands. However, if MODE corresponds to Level of Difficulty and bit 14 of PROBTYPE (called the T-bit) is set, then subtraction is done by adding NUM1 and NUM2. The sum is stored at NUM1 and the original NUM1 and NUM2 are moved to NUM2 and NUM3, respectively. This 


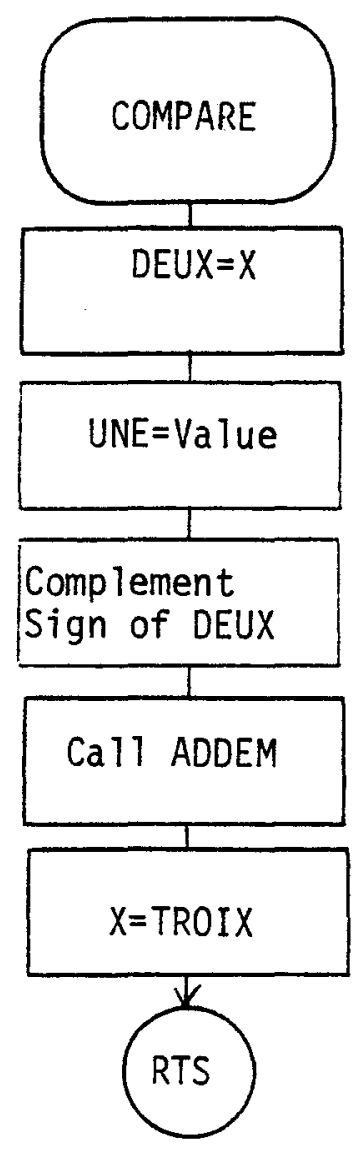

FIGURE 40 - COMPARE Subroutine

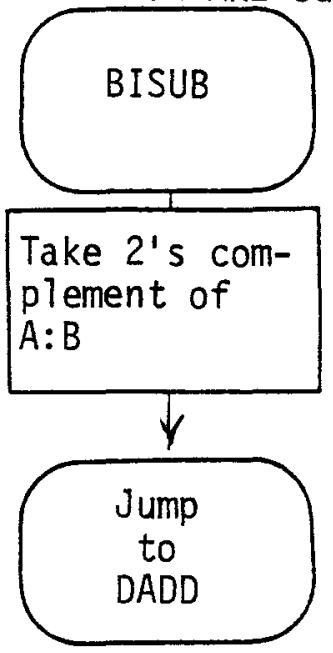

FIGURE 41 - BISUB Subroutine 


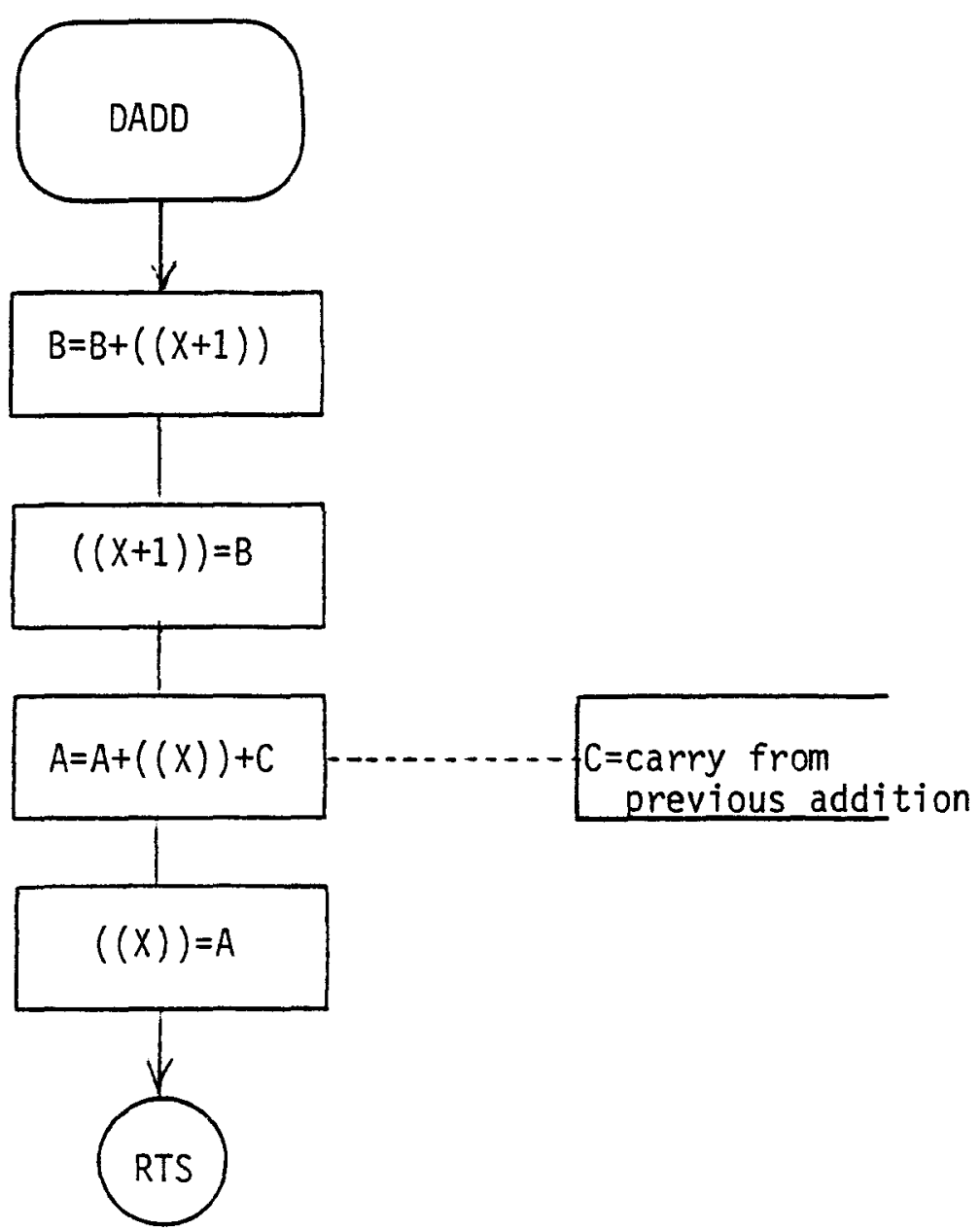

FIGURE 42 - DADD Subroutine 


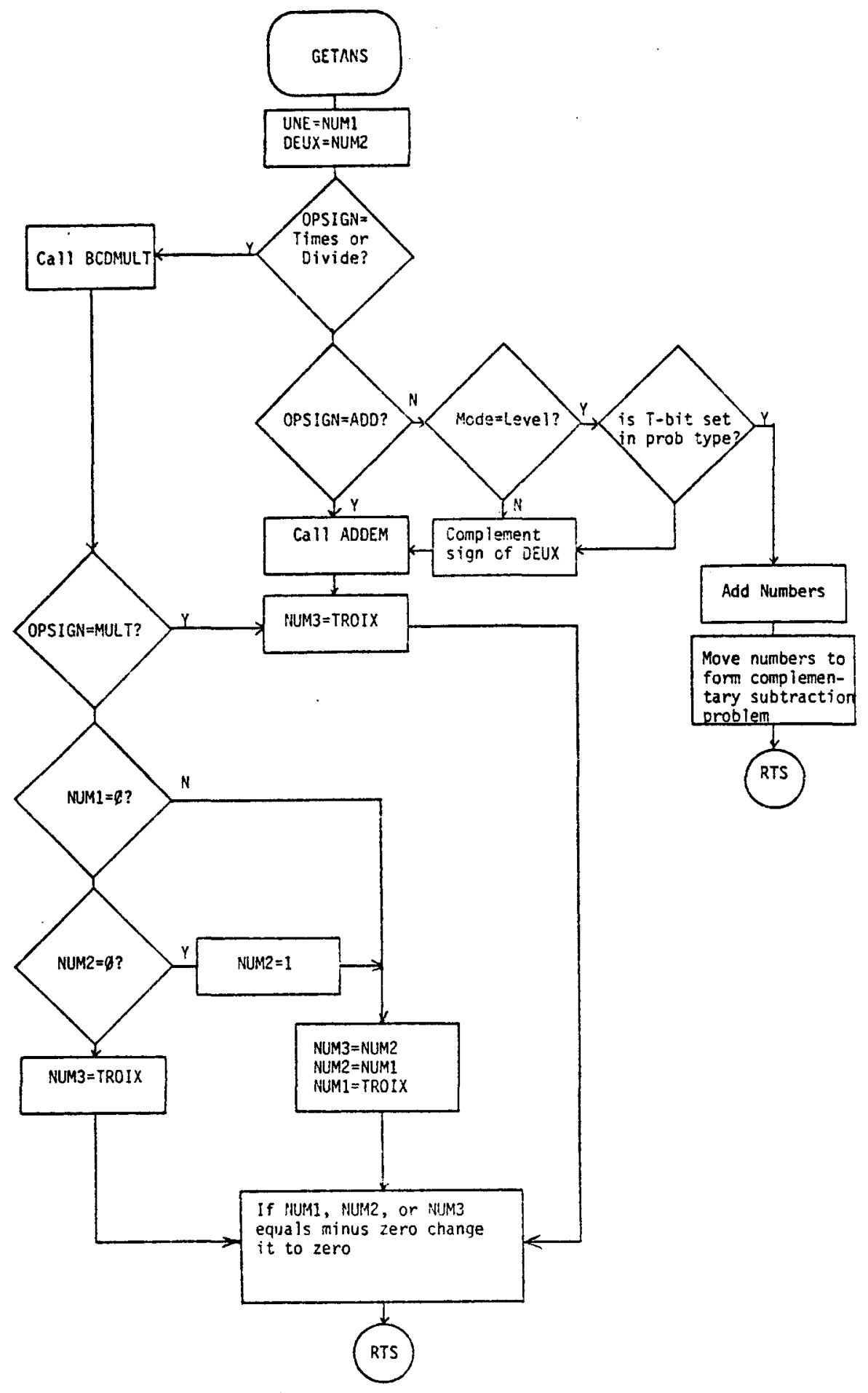

FIGURE 43 - GETANS Subroutine 
produces the complementary subtraction problem to the problem, NUMI plus NUM2.

i. HI-LO Subroutine. HI-LO compares the contents of VALUE and the upper and lower bounds imbedded in the code of the calling routine (see Figs. 44 and 45 ); if VALUE is between the 1 imits then the carry bit is set, otherwise it is cleared.

HI-LO calls LOADX to retrieve the inline data and to increase the return address stored on the stack so that when the RTS instruction is executed, the program counter points to the next instruction in the calling routine, and not to the data. HI-LO calls COMPARE to determine if VALUE is between the limits.

j. RANDOM Subroutine. The RANDOM subroutine generates a random number using the two byte seed addressed by the $X$-register. The new seed is stored at the two memory locations addressed by $X$. The resulting random number is stored in the two byte variable VALUE.

The seed is treated as a linear feedback shift register. The seed is shifted left and the new bit zero is formed by Exclusive OR'ing the previous bit zero and bit ten together (see Fig.46). This feedback register has a period of $2^{11}-1(=2045) .30$ The seed is Exclusive OR'ed with a mask to further randomize the number. The random number is then converted from binary to decimal and stored in VALUE.

4. Special Function Subroutines

This section contains the descriptions of subroutines that perform special functions for the control subroutines. 


\section{Calling routine}

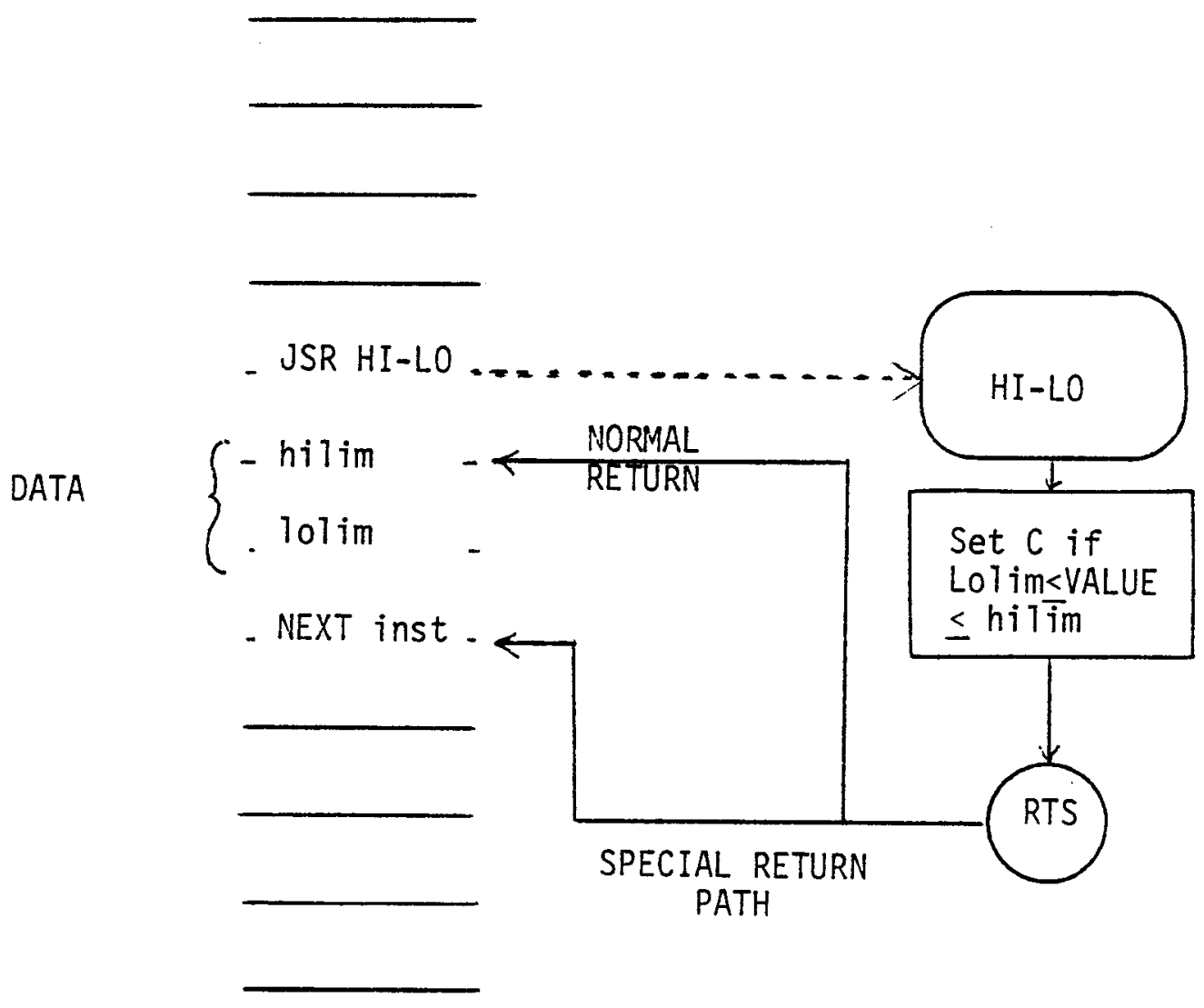

FIGURE 44 - How HI-LO Works 


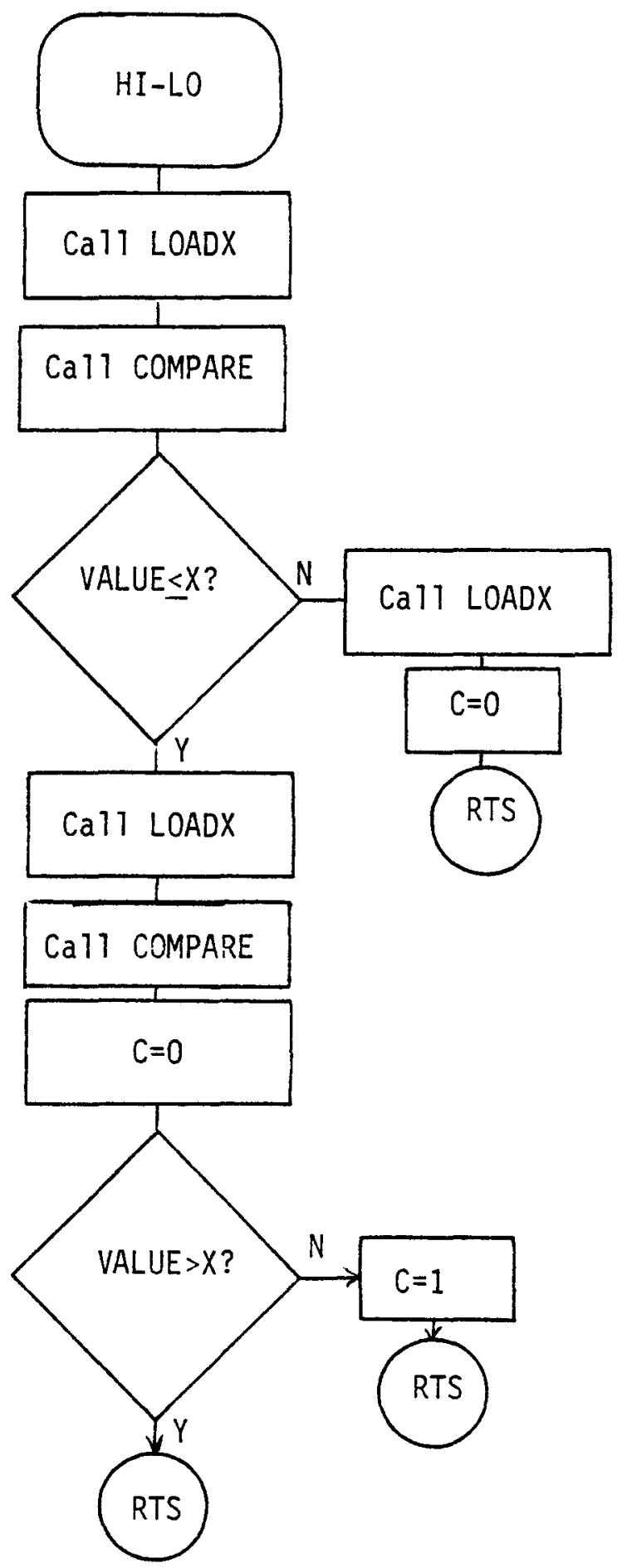

FIGURE 45 - HI-LO Subroutine 

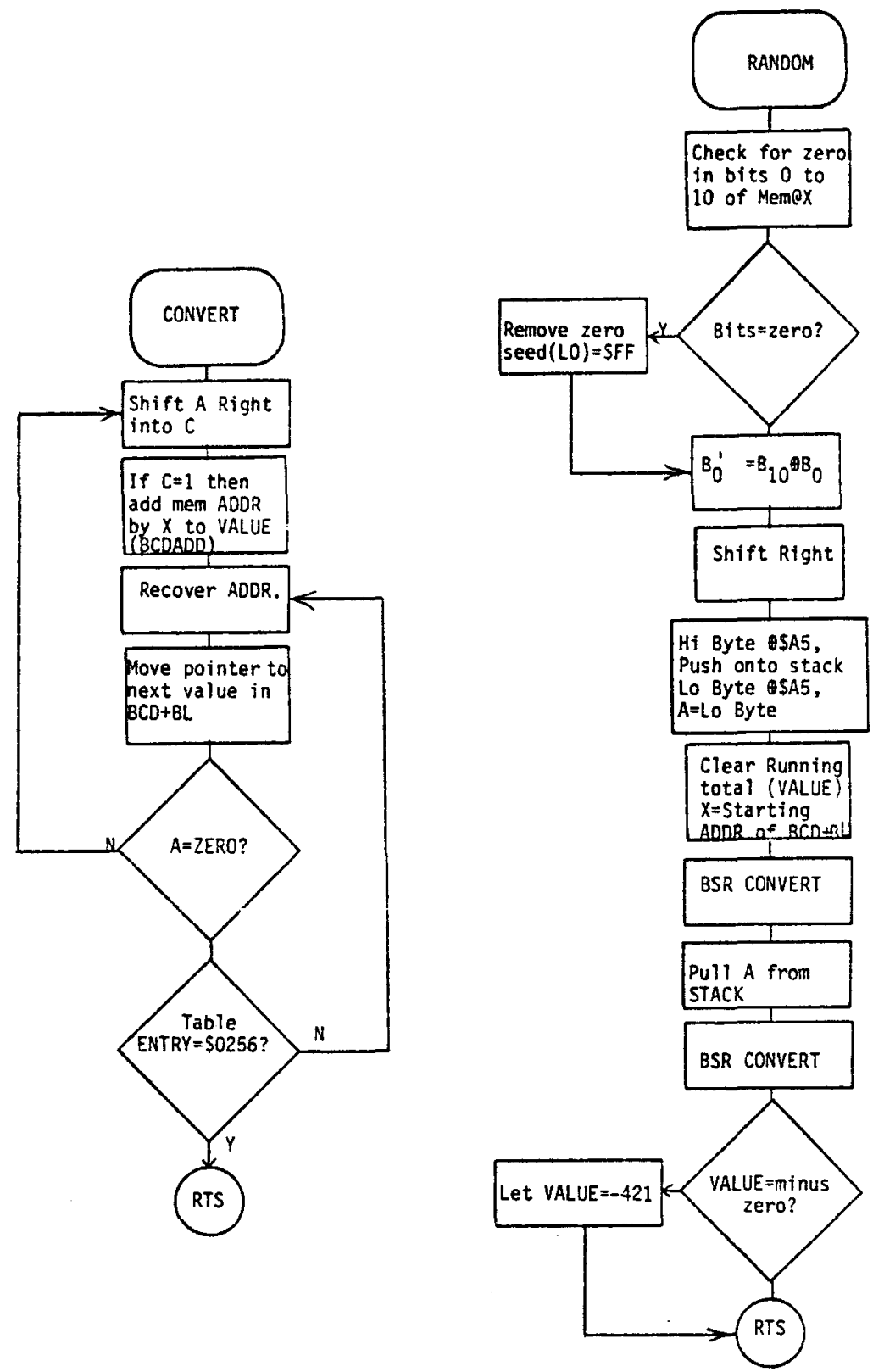

FIGURE 46 - RANDOM Subroutine 
a. ERROR Subroutine. The ERROR subroutine causes the display to blink several times and the speech synthesizer to output two high tones (see Fig. 47). ERROR is used as negative feedback by TEACH when the student enters an incorrect answer.

b. GENERATE Subroutine. The GENERATE subroutine, using the information provided by the teacher, randomly chooses the values of the two operands, NUM1 and NUM2. In the level of difficulty mode, GENERATE calls OPGEN to obtain the values for NUM1 and NUM2. Also, if regrouping is not allowed, GENERATE insures that is is not present in the problem (see Fig. 48). If the Range mode is selected, GENERATE insures that NUM1 is between HILIM1 and LOLIMI, and that NUM2 is between HILIM2 and LOLIM2.

c. INTERRUPT Program. When the speech synthesizer is through talking, its Busy lines goes low, and imitates an interrupt. When an interrupt is received, the interrupt program sets the synthesizer's start line to its high state (see Fig.49) and thereby informs SCAN that the synthesizer has completed talking. After the interrupt has been serviced, the computer resumes what it was doing previously.

d. LINK. LINK is neither a program nor a subroutine. LINK provides a way of tying together all of the subroutines used in the device. All subroutine calls are passed by jump statements in LINK to the called subroutines. This allows a subroutine to be moved in memory with very little trouble. Normaliy, when a subroutine is moved, all of the calls to that subroutine must be changed. With LINK all of the calls to a particular subroutine actually call a jump statement in LINK; the jump statement then transfers control to the called 


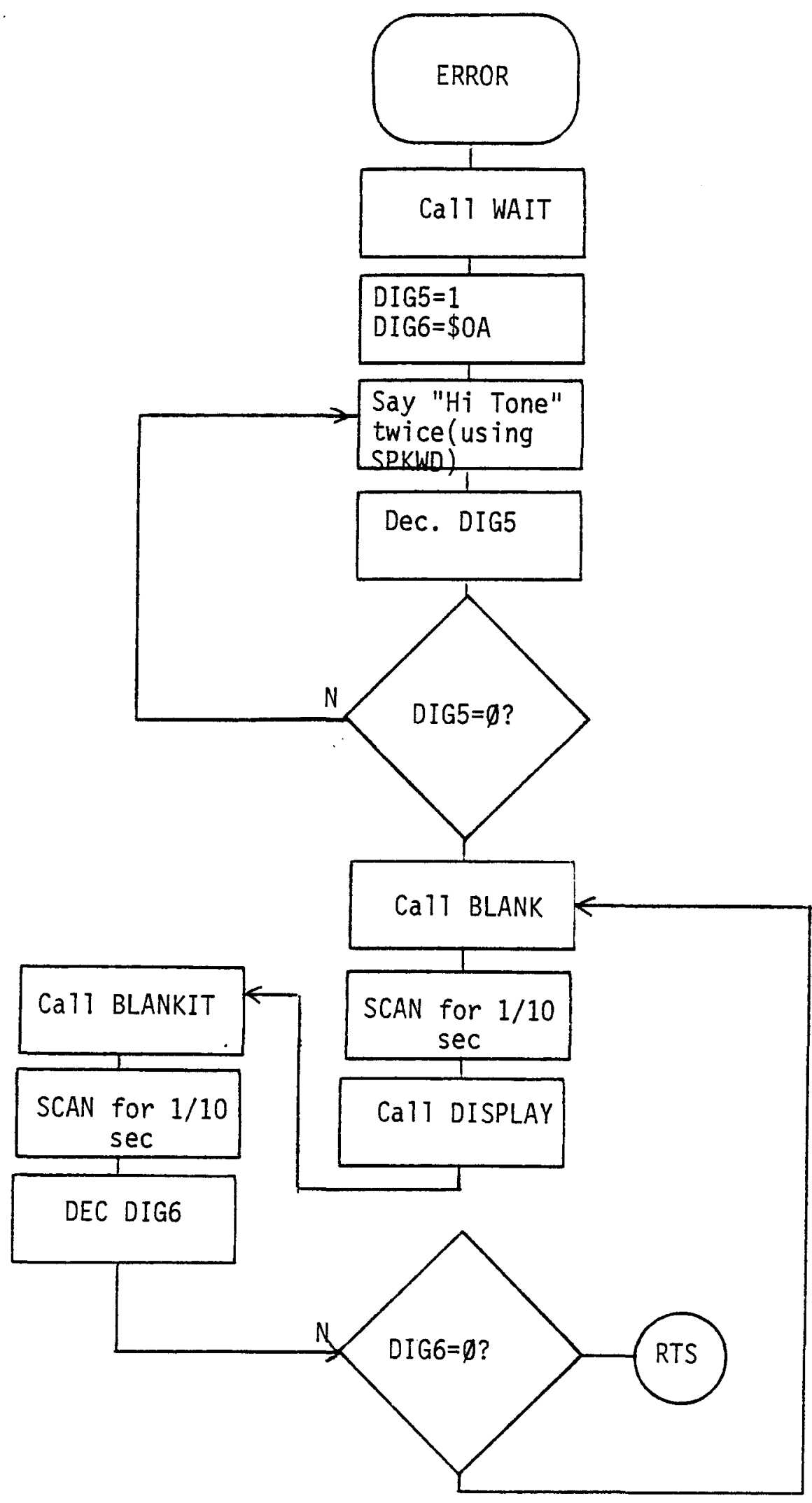

FIGURE 47 - ERROR Subroutine 


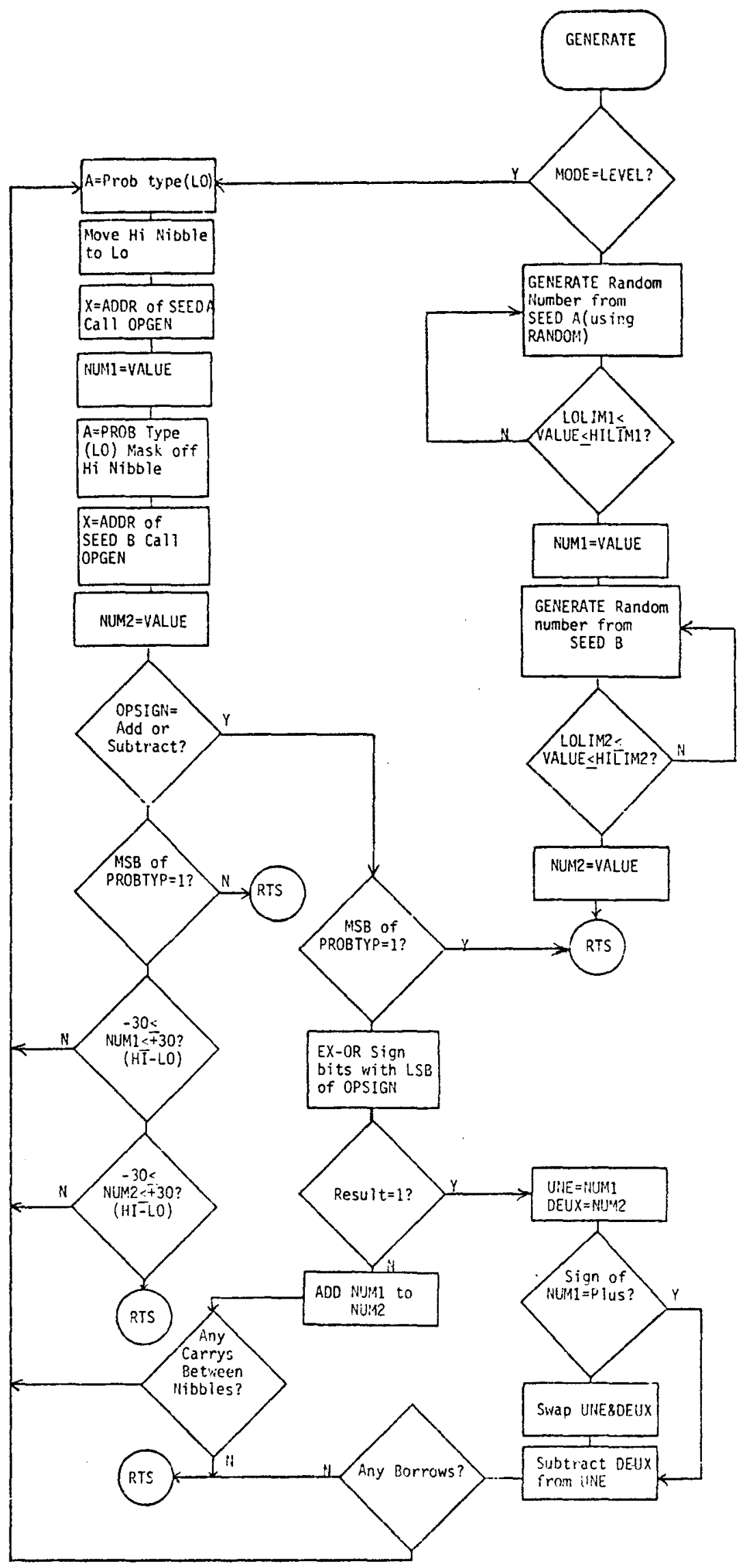

FIGURE 48 - GENERATE Subroutine 


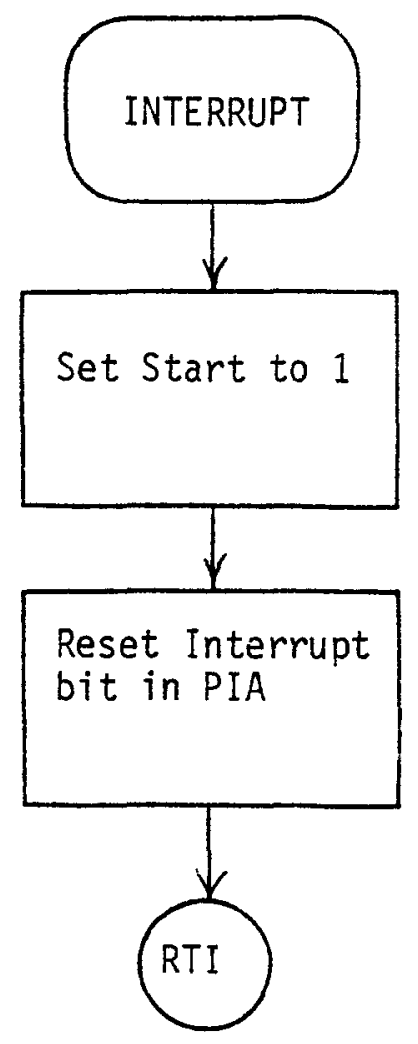

FIGURE 49 - INTERRUPT Subroutine 
subroutine. Thus, when the called routine is moved, onty the jump address in LINK must be changed.

e. LOADX Subroutine. LOADX passes parameters from a primary routine to a secondary routine. The two byte parameter is embedded in the primary routine immediately after the call to the secondary routine (Figs. 50 and 51 ). . The secondary routine calls LOADX, which loads the parameter into the X-register. LOADX also adjust the primary routine's return address located on the stack, so that a RTS in the secondary routine causes a return to the primary routine beyond the parameter. LOADX preserves the values of registers $A$ and $B$ by storing them on the stack.

f. MINTOBI Subroutine. The MINTOBI subroutine derives its name from MINutes TO BInary. This subroutine assumes that GETDIG has been called previously and that a number of the form, [tens of minutes, unit minutes, tens of seconds, unit seconds], has been entered. MINTOBI converts this data to binary seconds and stores it at the two memory locations addressed by the X-register (see Fig.52). MINTOBI does this by multiplying the digits 1 through 4 by weighting factors.

g. OPGEN Subroutine. The OPGEN subroutine generates a random number within a certain range. This range varies with the contents of the A-register when OPGEN is called (see TABLE VII.). The Seed used for the random number is stored at the memory locations addressed by the $X$-register when OPGEN is called.

OPGEN calls RANDOM to generate the random number (see Fig.53). The number is then adjusted to fit the limits defined by $A$ (i.e. if the 


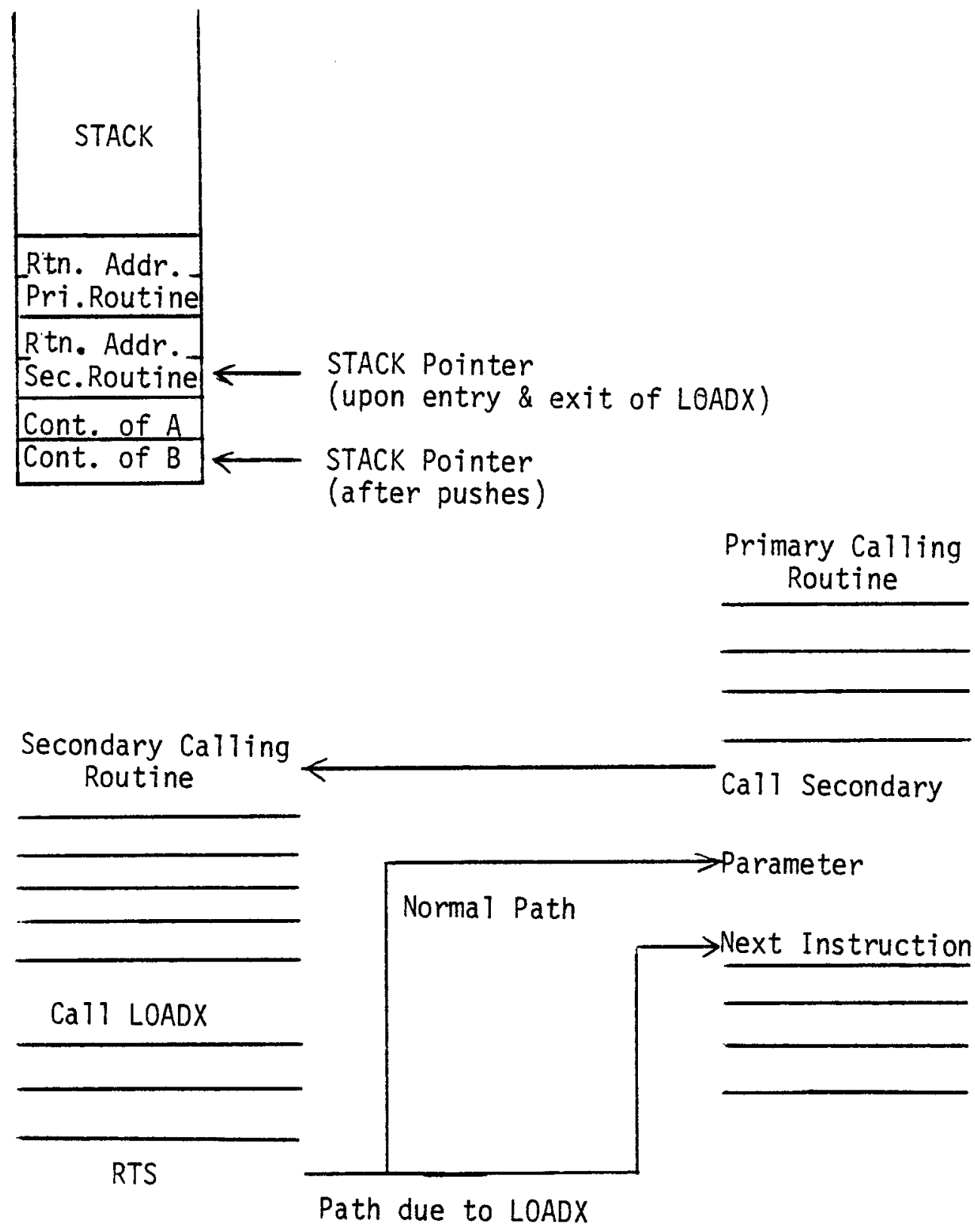

FIGURE 50 - How LOADX Works 


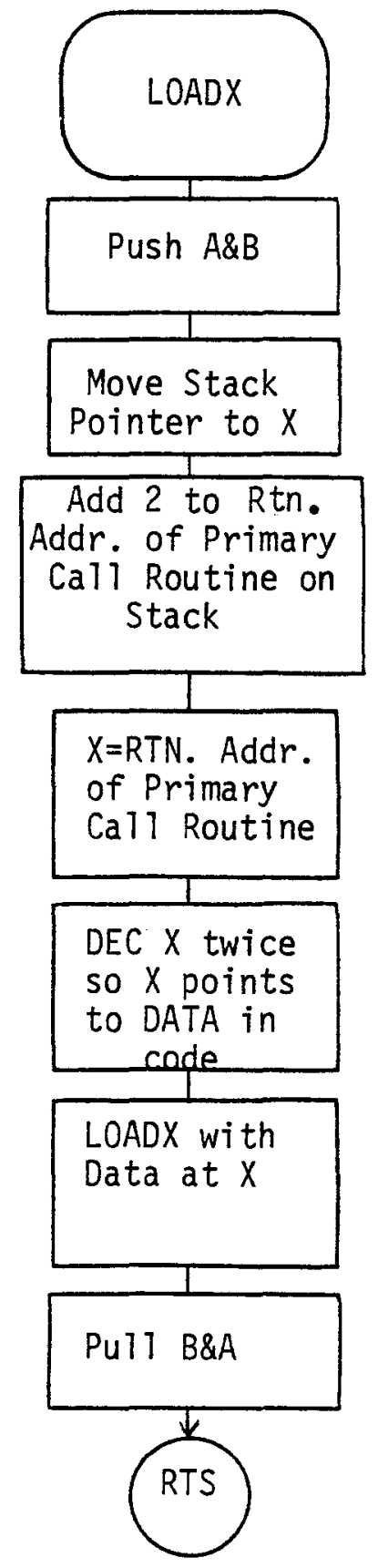

FIGURE 51 - LOADX Subroutine 


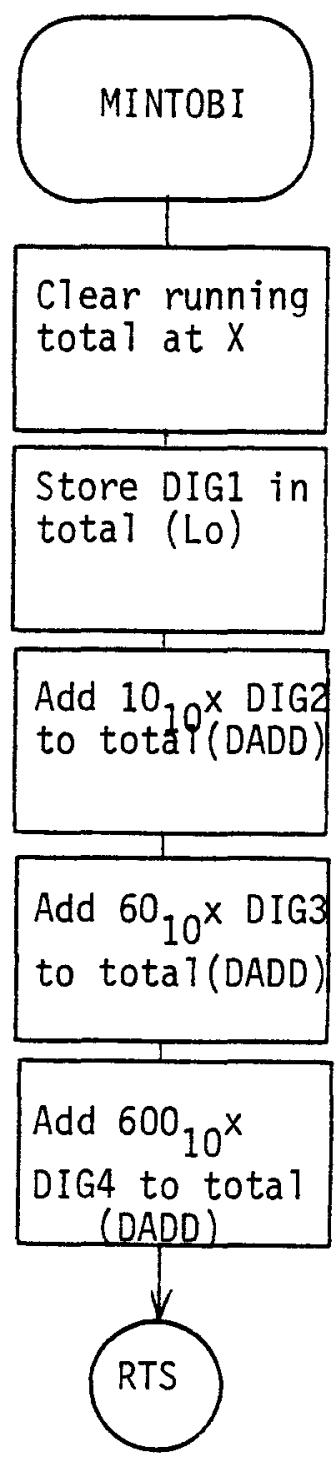

FIGURE 52 - MINTOBI Subroutine 


\section{TABLE VI II \\ OPERAND RANGE AS DEFINED BY A-REGISTER}

\begin{tabular}{|c|c|}
\hline Contents of $A$ (hex) & Range of Operand \\
\hline 0 & 0 to +4 \\
\hline 1 & -4 to +4 \\
\hline 2 & +5 to +9 \\
\hline 3 & -9 to -5 and +5 to +9 \\
\hline 4 & 0 to +9 \\
\hline 5 & -9 to +9 \\
\hline 6 & $0,10,20, \ldots, 90$ \\
\hline 7 & $-90,-80,-70, \ldots, 70,80,90$ \\
\hline 8 & +10 to +99 \\
\hline 9 & -99 to -10 and +10 to +99 \\
\hline A & -99 to +99 \\
\hline B & +100 to +499 \\
\hline C & -499 to -100 and +100 to +499 \\
\hline D & -499 to +499 \\
\hline$E$ & Same as D \\
\hline $\mathrm{F}$ & Same as $D$ \\
\hline
\end{tabular}




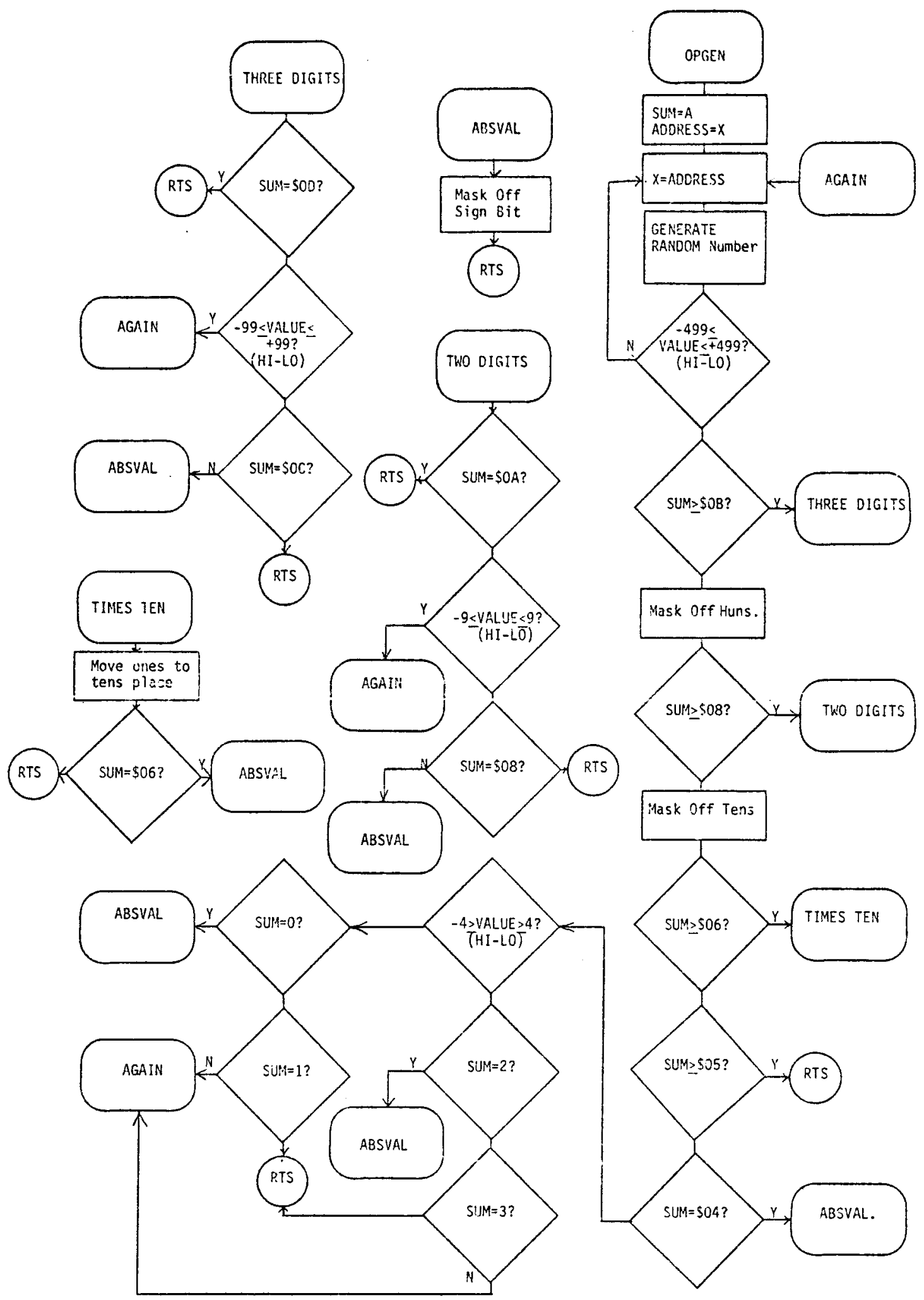

FIGURE 53 - OPGEN Subroutine 
number is defined as two digits, then the third digit is blanked). If the number is still outside the defined limits, another random number is generated and the limits are checked again.

h. RIGHT Subroutine. The RIGHT subroutine is used by TEACH as positive feedback for the student. When called, RIGHT turns off the prompt and sounds a low tone three times. A flowchart of RIGHT appears in Fig. 54 .

i. RESTART Program. The RESTART program is called on device power-up or when the reset button is pushed. RESTART initializes the PIA's and it initializes the variable that controls scan speed (RATE), the display buffer (DISBUF), the pointers for the speech buffer (NEXT and LAST) (see Fig.55). The processor's stack pointer is also initialized to its starting position at \$OOFF. After RESTART is executed, control is passed to MAIN.

j. SAYNUM Subroutine. The SAYNUM subroutine takes the number addressed by the $X$-register and says it. The number is assumed to have the following two byte format:

\author{
$[S \times X X$, hundreds]: [tens, ones]$$
\text { at }(X) \uparrow \quad \text { at }(X+1) \uparrow
$$$$
\text { where; } S \text { is the sign bit (set implies minus) }
$$$$
Z \text { is a "don't care" bit }
$$$$
\text { hundreds, tens, and ones are stored in }
$$$$
B C D \text { notation }
$$ 


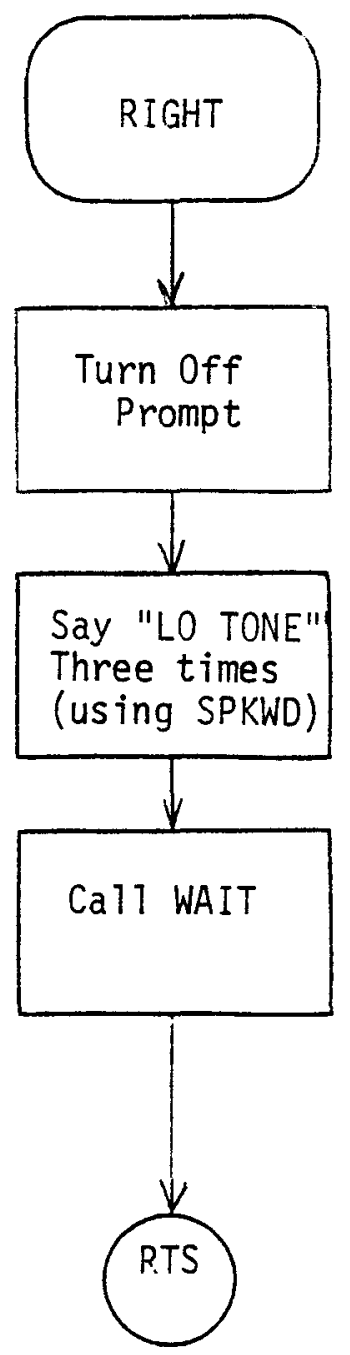

FIGURE 54 - RIGHT Subroutine 


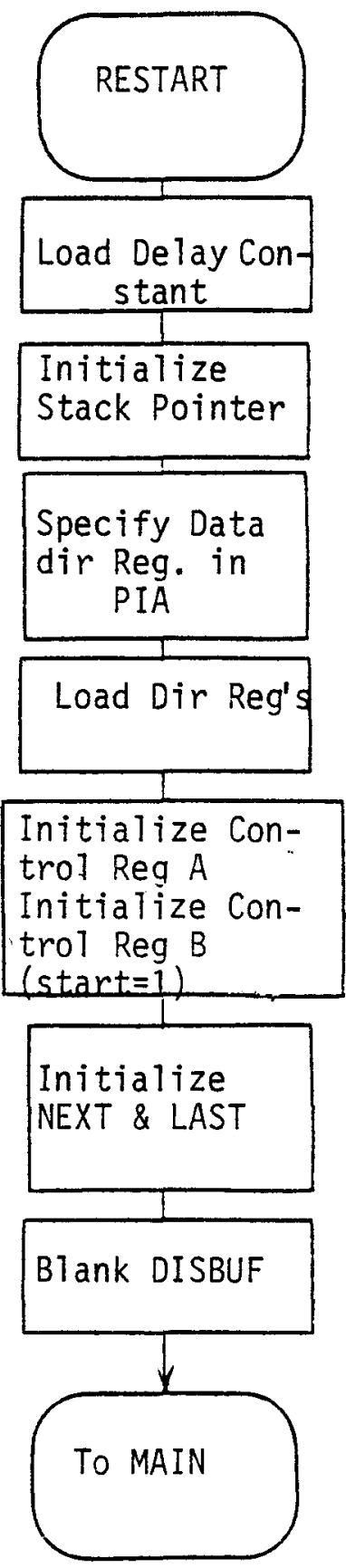

FIGURE 55 - RESTART Subroutine 
(See Figure 56 for the exact algorithm used to say the number). SAYNUM says the numbers as the students are taught to say them. For example, -327 is pronounced as "minus three hundred twenty-seven", not as"minus three two seven."

k. TBLOOK Subroutine. TBLOOK is the subroutine that looks up the problem set information when the device is in the Level of Difficulty mode. The problem set information is contained in three different tables. If the operation is addition, then the probiem set information is in ADDTBL. If the operation is subtraction then SUBTBL contains the information. Multiplication and division information is stored in M-DTBL. All of the tables end with the flag \$FFFF. If the level of difficulty exceeds the number of problem sets(and the flag is found), TBLOOK will cause the device to restart (see fig. $57)$.

1. 2BEEP Subroutine. The 2BEEP subroutine is an audio prompting subroutine. Originally call 2BEEP would cause two "hi tones" to be sounded, hence its name. 2BEEP was changed so that calling it causes the words "Go Please" to be loaded into the speech buffer (see Fig.58). 


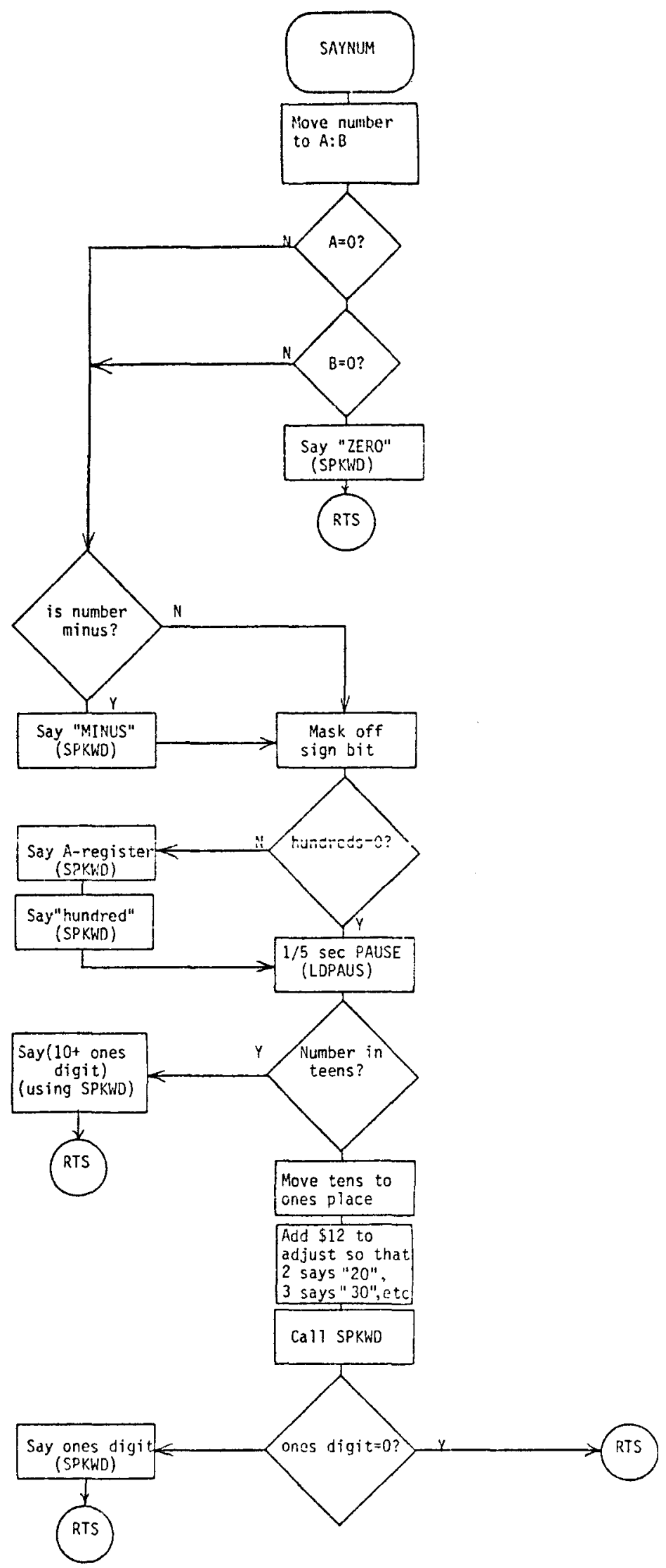

FIGURE 56 - SAYNIM Subroutine 


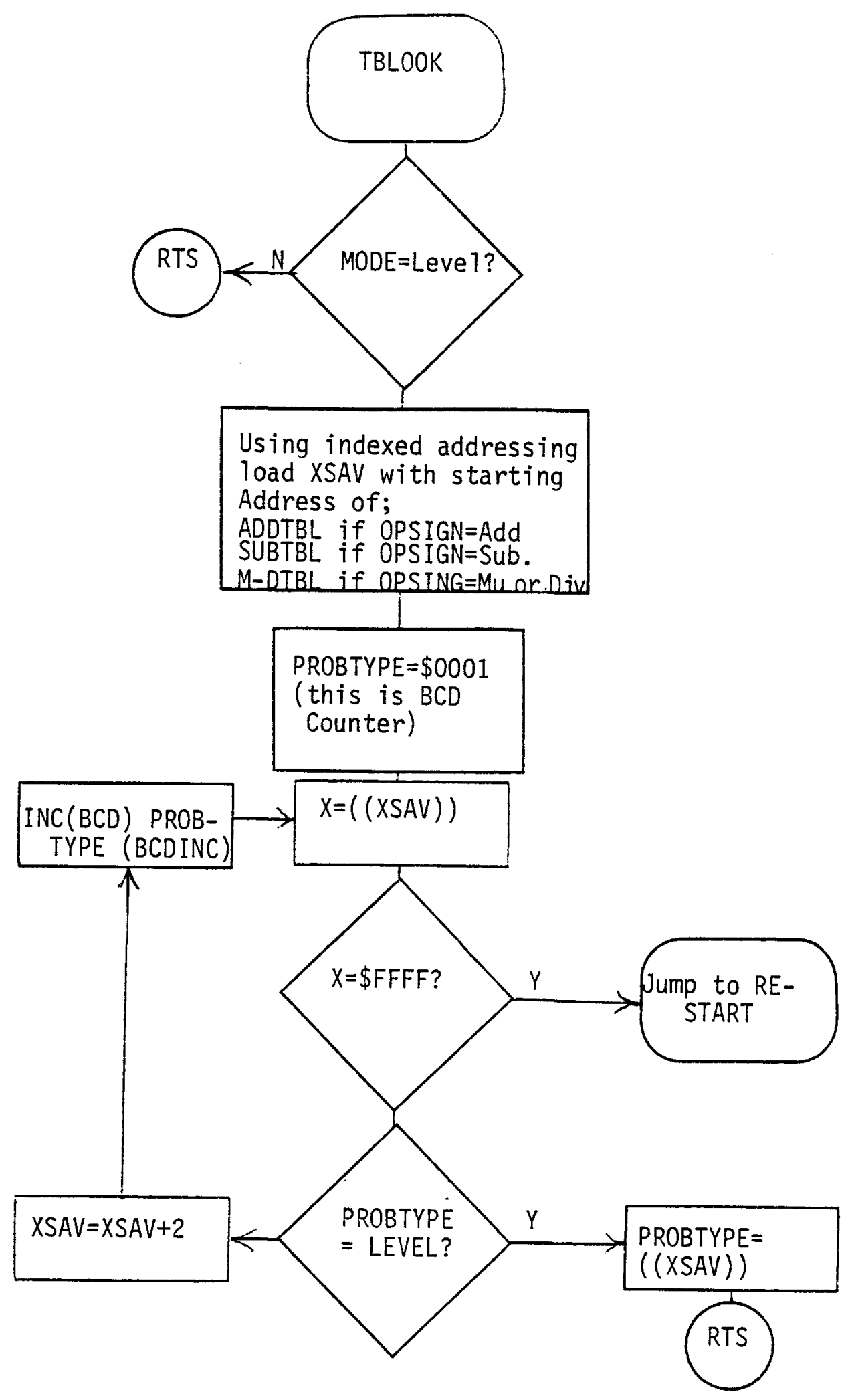

FIGURE 57 - TBLOOK Subroutine 


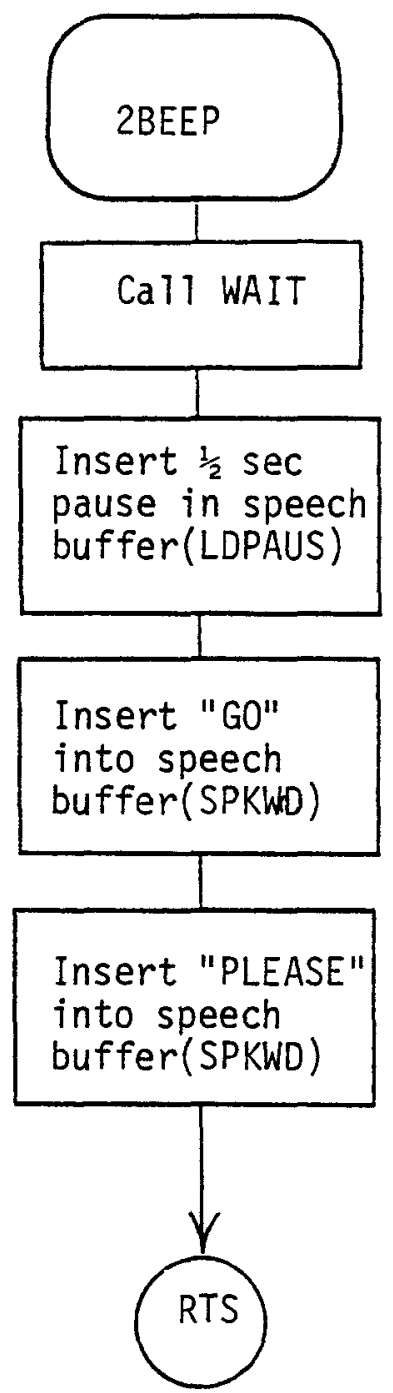

FIGURE 58 - 2BEEP Subroutine 


\section{CONCLUSIONS AND RECOMMENDATIONS}

\section{A. Cost Analysis}

The Math Trainer was designed to be a proof-of-concept prototype. As such, it was not designed to be mass produced in its present form. This version is too expensive to be marketable in reasonable quantity. After evaluating the device's usefulness and implementing any necessary changes, use of production oriented technology could render it more marketable. A breakdown of costs for the components of the device is shown in TABLE.IX. Not shown in TABLE XI are the development costs and the cost of the labor required to assemble the device.

\section{B. Device Improvement Recommendations}

The Math Trainer works as it was designed to. The lack of funds to install solenoids as prompts has left the device somewhat difficult, but not impossible, for a blind teacher to program. If such funds become available in the future, the installation of solenoids is highly recommended.

It was noted that some users find the order of programming questions unnatural. Rearranging the question order would be a simple matter and, as such, may be desirable. If PROGRAM were to be rewritten, a useful addition would be to implement error checking of the numeric inputs (preventing negative numbers entered as a position, for example). The trainer could be made more compact by using a CMOS microprocessr and a single voltage 4K EPROM. Doing that 
TABLE IX

DEVICE COSTS

Speech Synthesizer........................\$189.00

Support Circuits for Synthesizer.................. 70.00

D1 Microcomputer.................................. 75.00

(4) 2708 EPROMS........................... 48.00

Cabinet for Device......................... 100.00

Power Supply............................ 50.00

(13) DL747 LED Displays....................... 13.00

Keyboard Components........................ 15.00

Miscellaneous Electronic Components.............. 75.00

Miscel laneous Hardware......................... 40.00

TOTAL COST $\$ 675.00$ 
would allow the bulky multi-voltage supply to be replaced by a much smaller power supply.

Currently, the device is slated to be evaluated by using it at the Kentucky School for the Blind in the Fall of 1979. Some changes may be suggested by that evaluation.

\section{Notes on Doing Similar Projects}

Several things became apparent while working on the Math Trainer. The creation of the device at the assembly language level made the device difficult to change. Any feedback from users was difficult to take advantage of due to the difficulty of changing existing programs. Anyone working on a similar project would be prudent to insure that the man-machine interface design was finalized before writing the control software. For some projects, a high level language program (e.g. in BASIC) could be written to simulate the device. Changes could be easily made to the simulation program in response to user feedback. These changes could then be incorporated into the machine language control program from the beginning. The use of a "Tiny Basic" may even allow the final control program to be written in a high level language.

An assembler would also be a great aid in producing control programs. Although an assembler was made available to the author it was not used because most of the software was written by the time the assembler was obtainer. A great deal of time was spent by the author debugging incorrectly hand-assembled programs. 
One resource that was not taken full advantage of was the extensive amount of arithmetic software already written for the 6800 . The author's experience indicates that it would be worthwhile to use some of this available software even if some data conversion were required. 
REFERENCES CITED

1. Nolan, C. Y. and Ashcroft, S. C., "The Stanford Arithmetic Computation Tests; a Study of an Experimental Adaptation for Brailler Administration". International Journal for the Education of the Blind, Vol. 8, (1959), pp. 89-92.

2. Brothers, Roy J., Arithmetic Computation: Achievement of Visually Handicapped Students in Public Schools, American Printing House for the BTind (September, 1972), Louisville, KY.

3. Nolan and Ashcroft.

4. Brothers.

5. Brothers, Roy J., "Arithmetic Computation by the BI ind, A Look at Current Achievement", Education of the Visually Handicapped, (March, 1974).

6. Telesensory Systems, Inc., 1889 Page Mill Road, Palo Alto, Cal ifornia 94304.

7. Sinclair, F. L. and Sanderson J., "Talking Calculator Survey", Visual Impairment and Blindness, (Apri1, 1978), P. 151.

8. Obtained from Quota Registrations (as of Jan. 5, 1976), provided by J. E. Morris of American Printing House for the BTind, Louisvil le, KY.

9. "Speak and Spe11" pamphret, Texas Instruments, P0 225012, Da11as, TX 75295.

10. Telesensory Systems, Inc.

11. Votrax Audio Response System Operators Manual Voiced Interface Division, Federal Screw Works

12. Personal communication with Dr. Charles S. Thompson, Elementary Education, University of Louisville.

13. Ibid.

14. Ibid.

15. Texas Instruments, P0 5474, Dal1as, TX 75222.

16. Holding, D. H., "The Acquisition of Ski1l" from Principles of Training, Pergamon, (1965). 
17. Ibid.

18. Ibid.

19. Haviland, R. P., The Compulator Book, TAB Books, (1970), p. 41.

20. Litronix, Inc., 19000 Homestead Road, Vallco Park, Cupertino, California 95014.

21. Telesensory Systems, Inc.

22. Ibid.

23. Motorola Semiconductor Group, 5005 E. McDowell Road, Phoenix, Arizona 85008.

24. Ibid.

25. M6800 Microprocessor Applications Manual, Motorola, Inc., (1975) pp. 4-42.

26. Pro-Log Corporation, 2411 Garden Road, Monterey, Cal ifornia 93940.

27. Litronix, Inc.

28. Motorola Semiconductor Group.

29. Haviland, R. P.

30. Gschwind, H. W. and McCluskey, E. J., Design of Digital Computers, 2nd Edition, Springer-Verlag, (1975), p. 191. 


\section{BIBLIOGRAPHY}

1. Brothers, Roy J., "Arithmetic Computation by the B1 ind, A Look at Current Achievement", Education of the Visually Handicapped, March, 1974.

2. Brothers, Roy J., Arithmetic Computation: Achievement of Visually Handicapped Students in Public Schools, American Printing House for the Blind, Louisville, KY, September, 1972.

3. Gschwind, H. W. and McCluskey, E。 J., Design of Digital Computers, 2nd Edition, Springer-Verlag, 1975.

4. Haviland, R. P., The Compulator Book, TAB Books, 1970.

5. Holding, D. H., "The Acquisition of Skill" from Principles of Training, Pergamon, 1965.

6. Motorola M6800 Microprocessor Applications Manual, Motorola, Inc., 1975.

7. Motorola M6800 Programming Reference Manual, 1976, Motorola, Inc.

8. Motorola "M6800 Microprocessor Instruction Set Summary", Motorola, Inc., 1976.

9. Nolan, C. Y and Ashcroft, S. C., "The Stanford Arithmetic Computation Tests; A Study of An Experimental Adaptattion for Braille Administration", International Journal for the Education of the Blind, Vol. 8,1959 .

10. Sinclair, F. L. and Sanderson J., "Talking Calculator Survey" Visual Impairment and Blindness, April, 1978.

11. Texas Instruments, "Speak and Spe11" pamphlet, Texas Instruments, PO 225012, Dallas, TX 75295.

12. Texas Instruments, TTL Databook, Texas Instruments, Inc., 1973

13. Texas Instruments, MOS Memory Data Book, Texas Instruments, Inc., 1978.

14. Personal Communication with Dr. Charles S. Thompson, Elementary Education, University of Louisville. 


\section{APPENDIX I}

DEVELOPMENT CIRCUITRY 


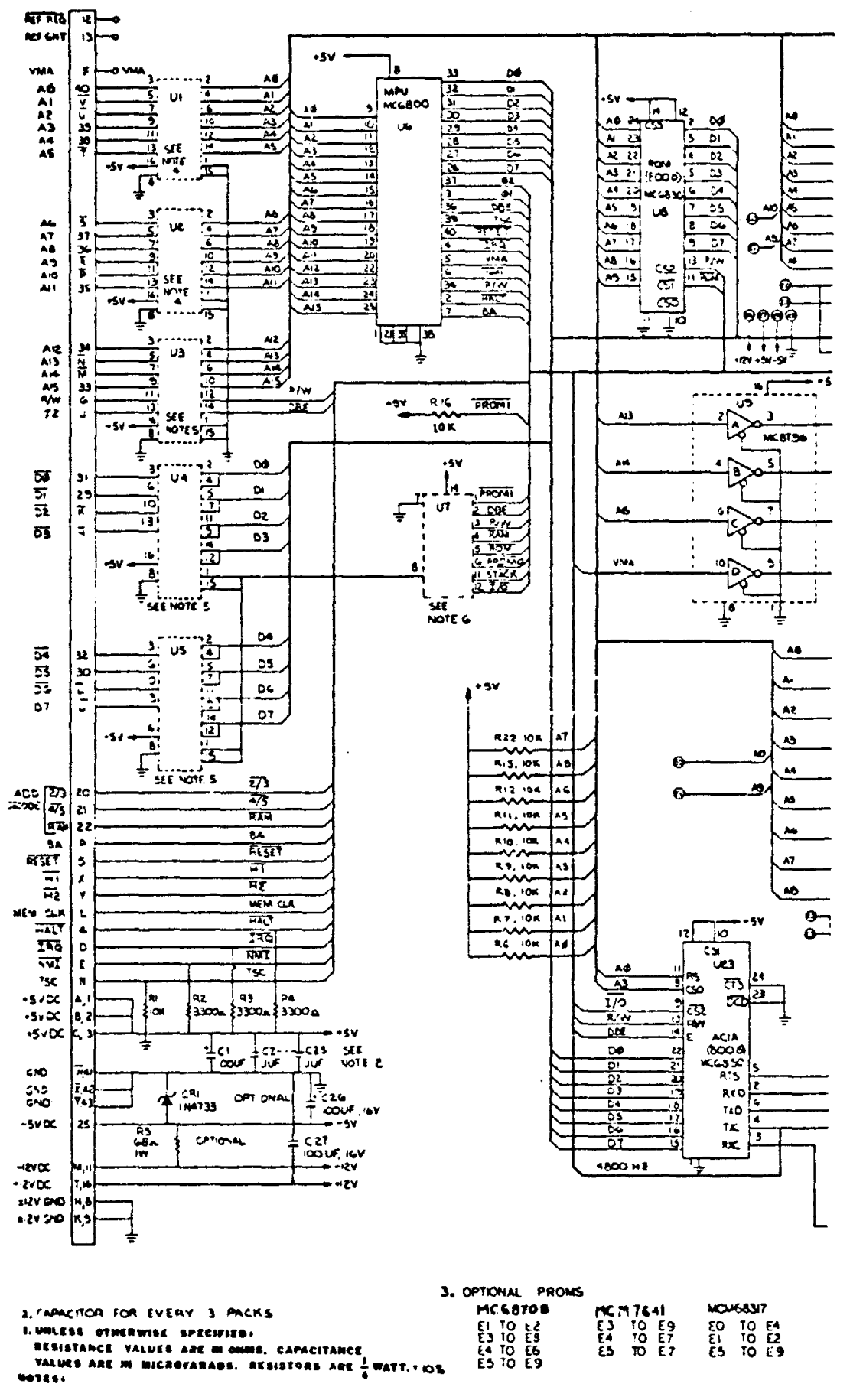

FIGURE 1 - D2 Board Microcomputer Module 


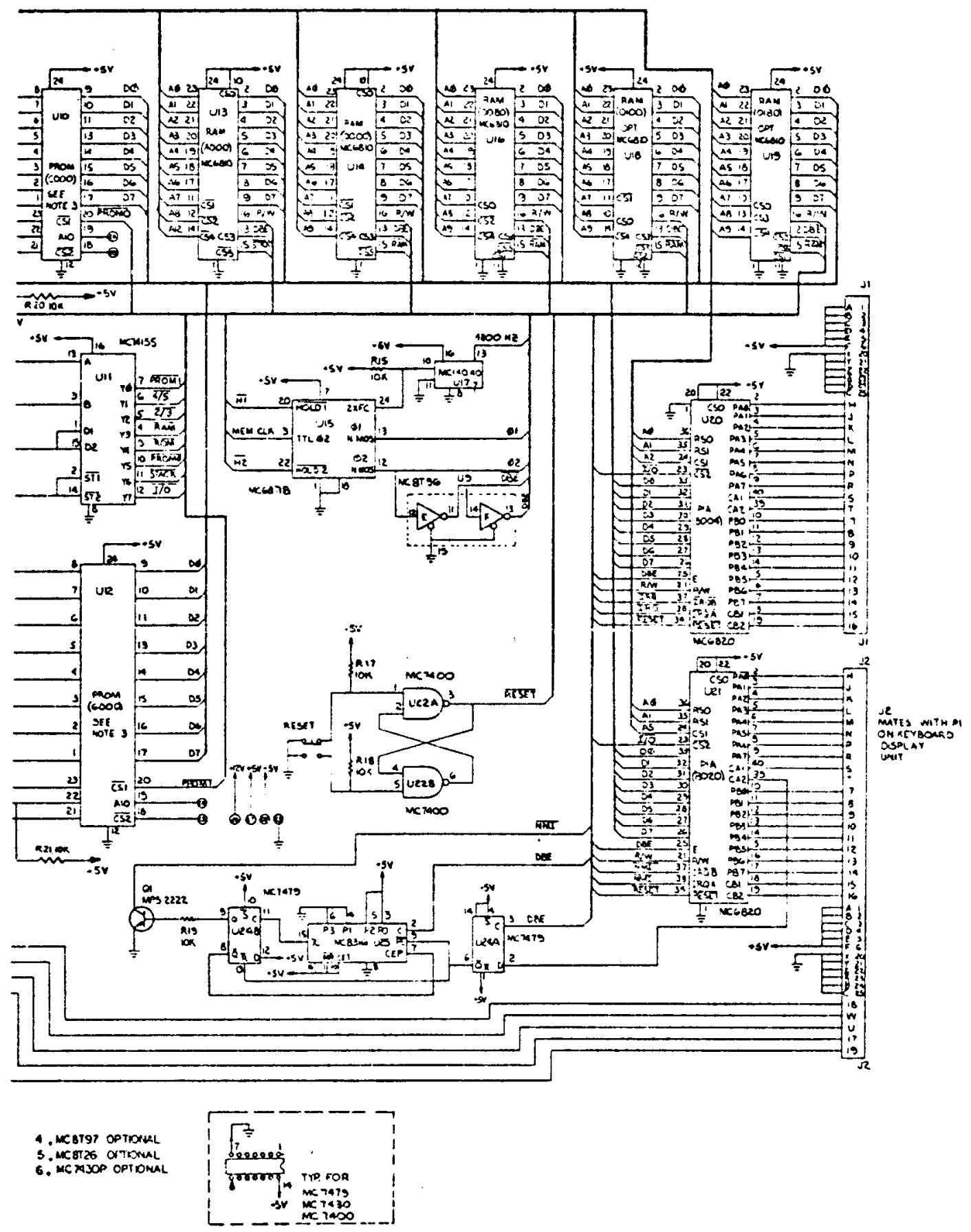

FIGURE 1 - D2 Board Microcomputer Module (continued) 


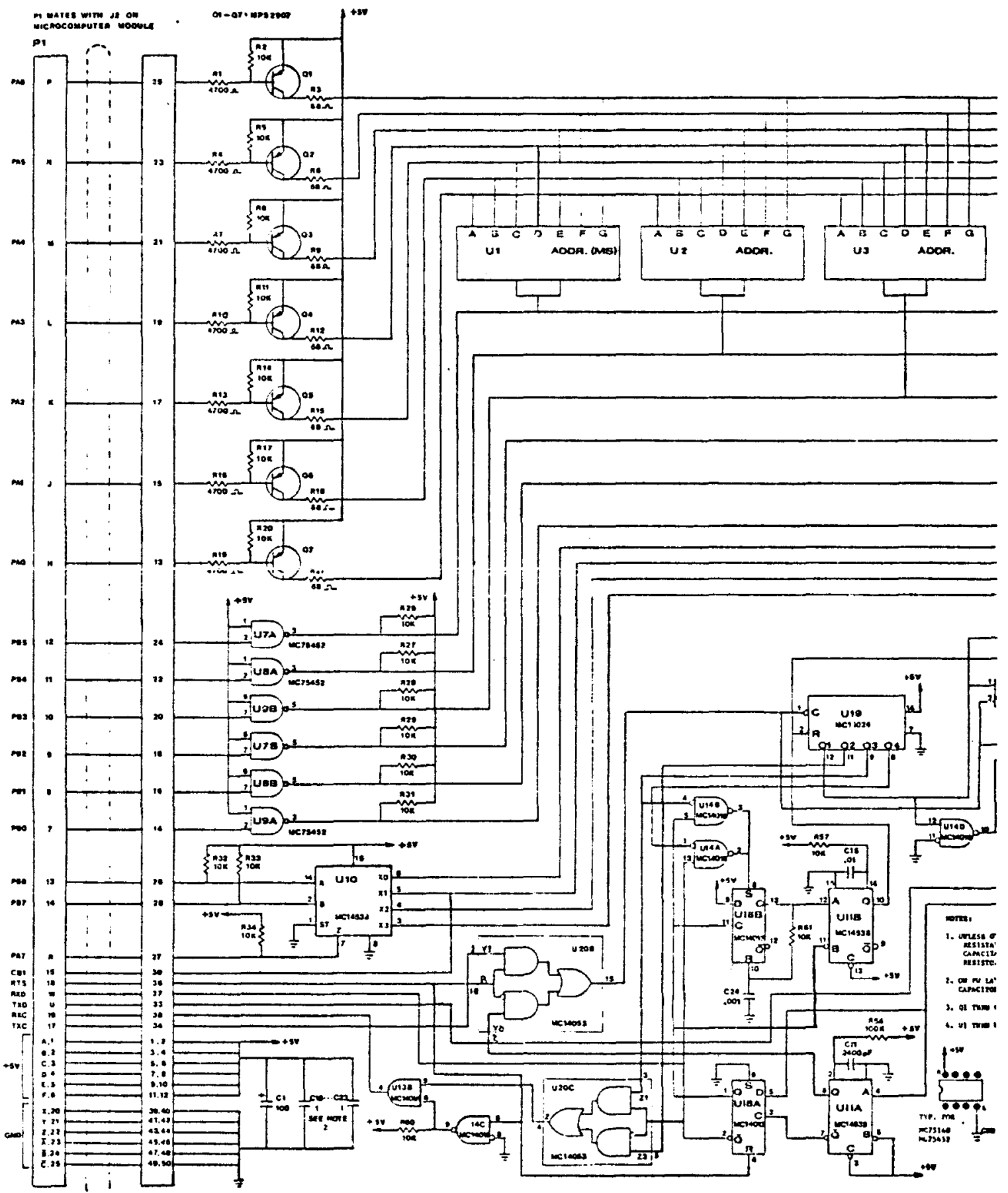

FIGURE 1 - D2 Display Module 


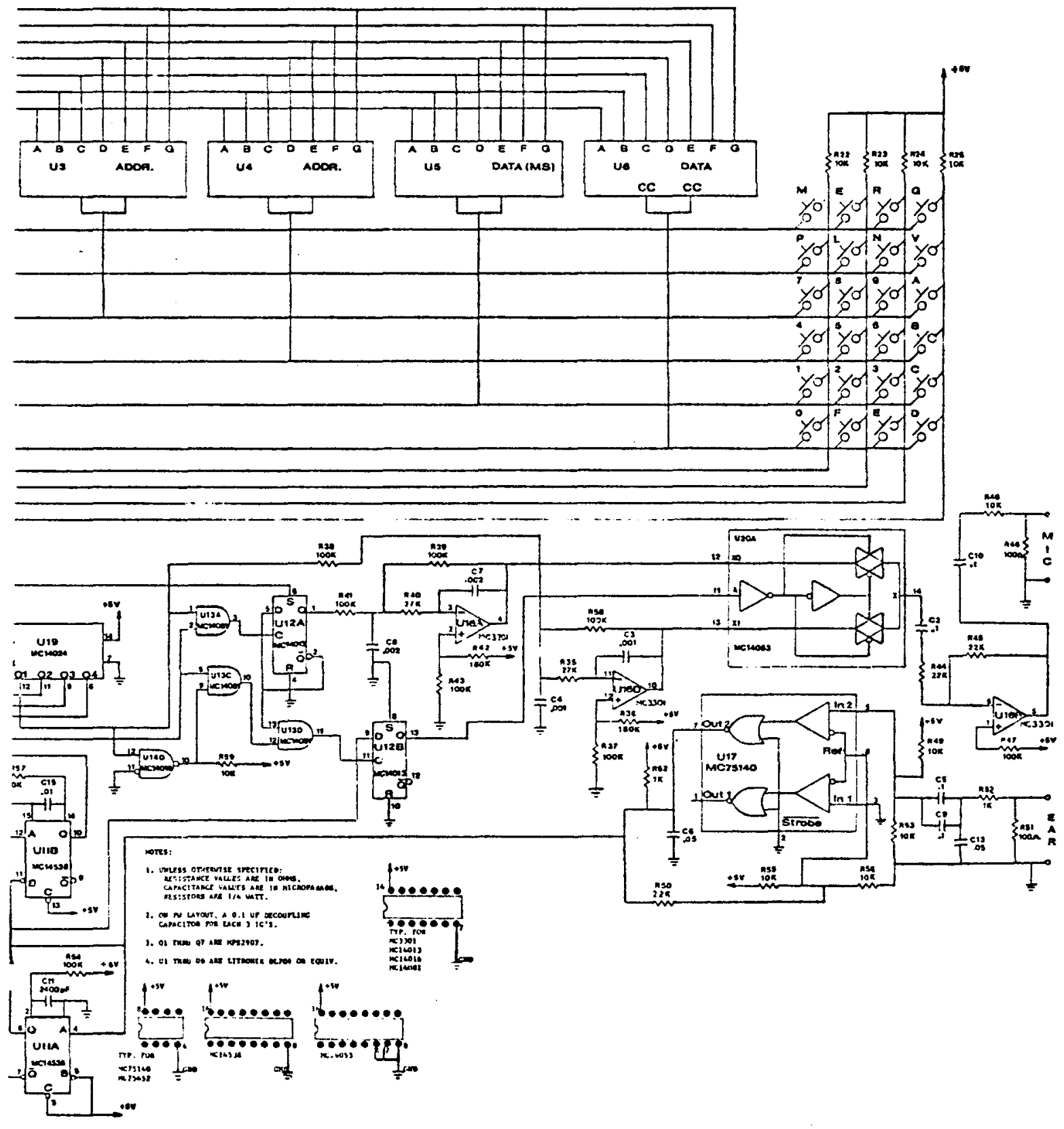

FIGURE 1 - D2 Display Module (continued) 

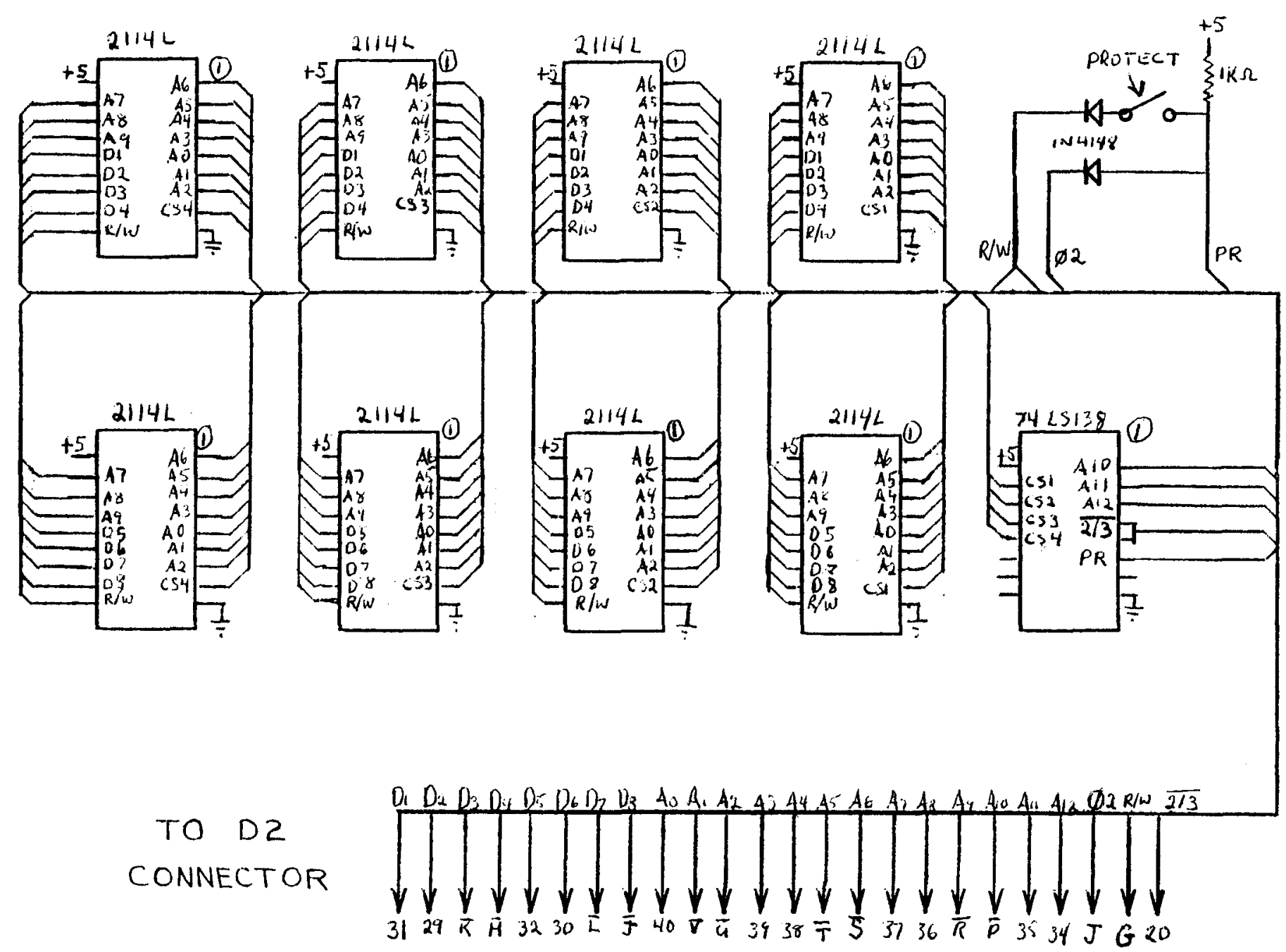

FIGURE 2 - 4K RAM Board 


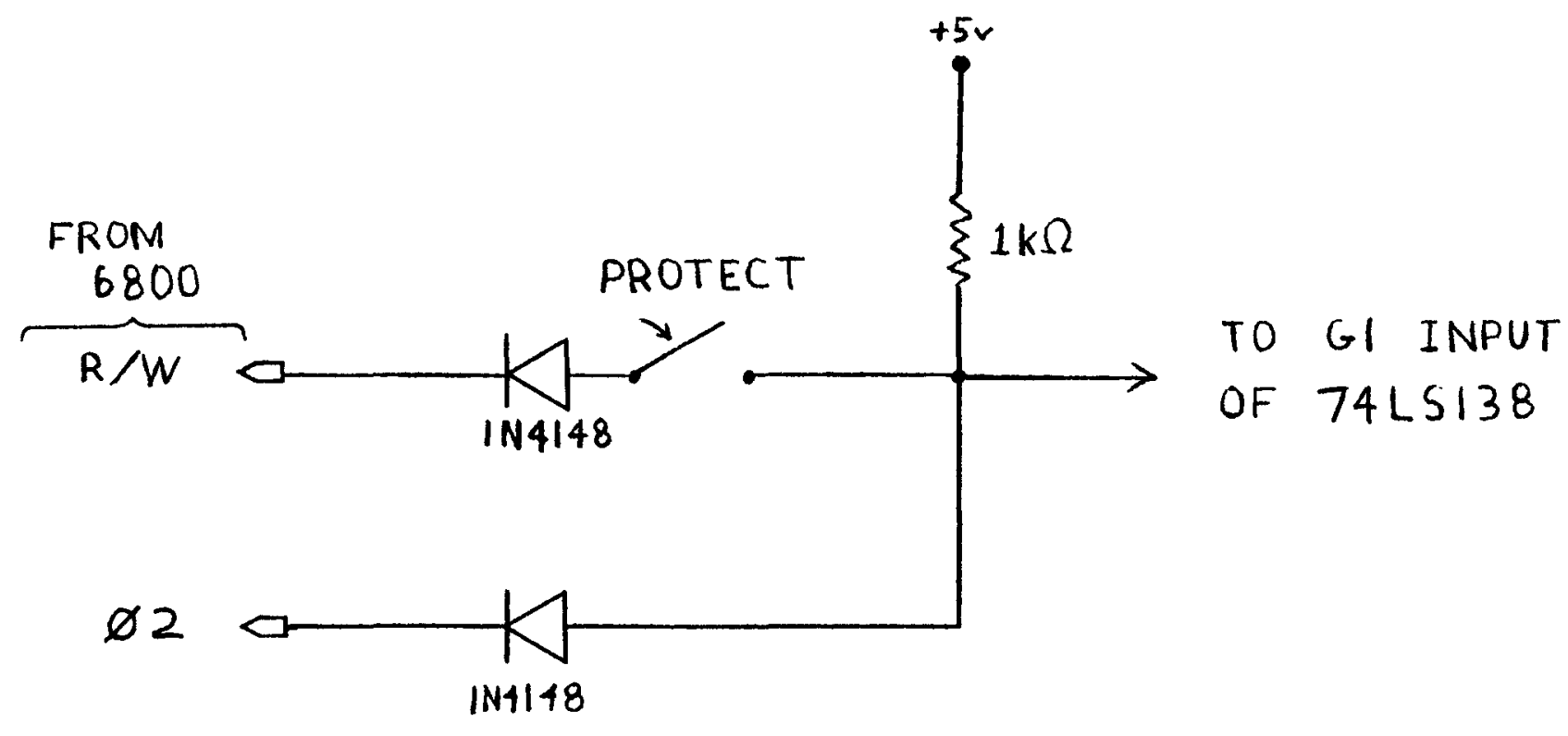

FIGURE 3 - Memory Protect Circuit 


\section{APPENDIX II}

DEVICE HARDWARE DOCUMENTATION 


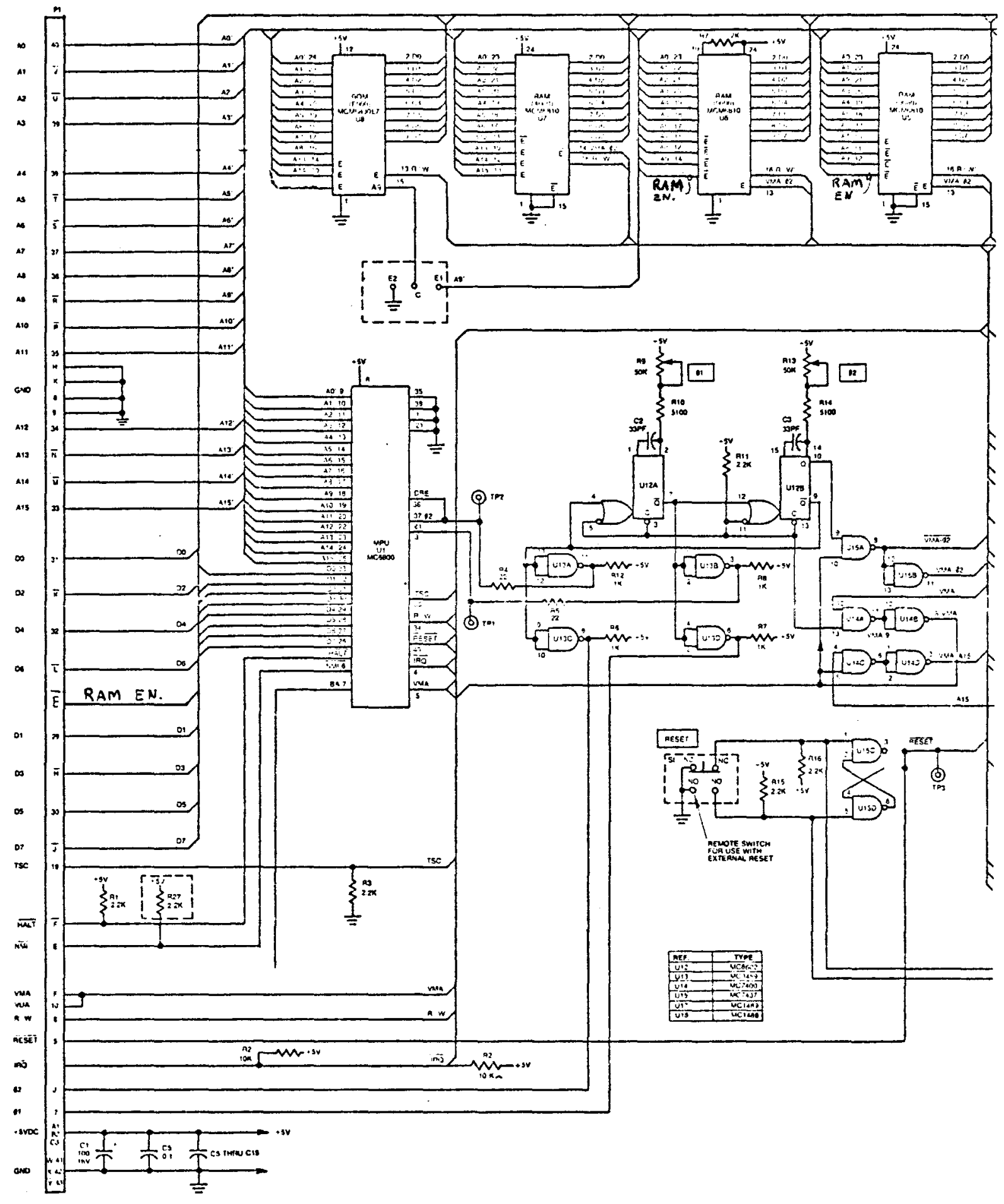

FIGURE I - D1 Board with Changes 


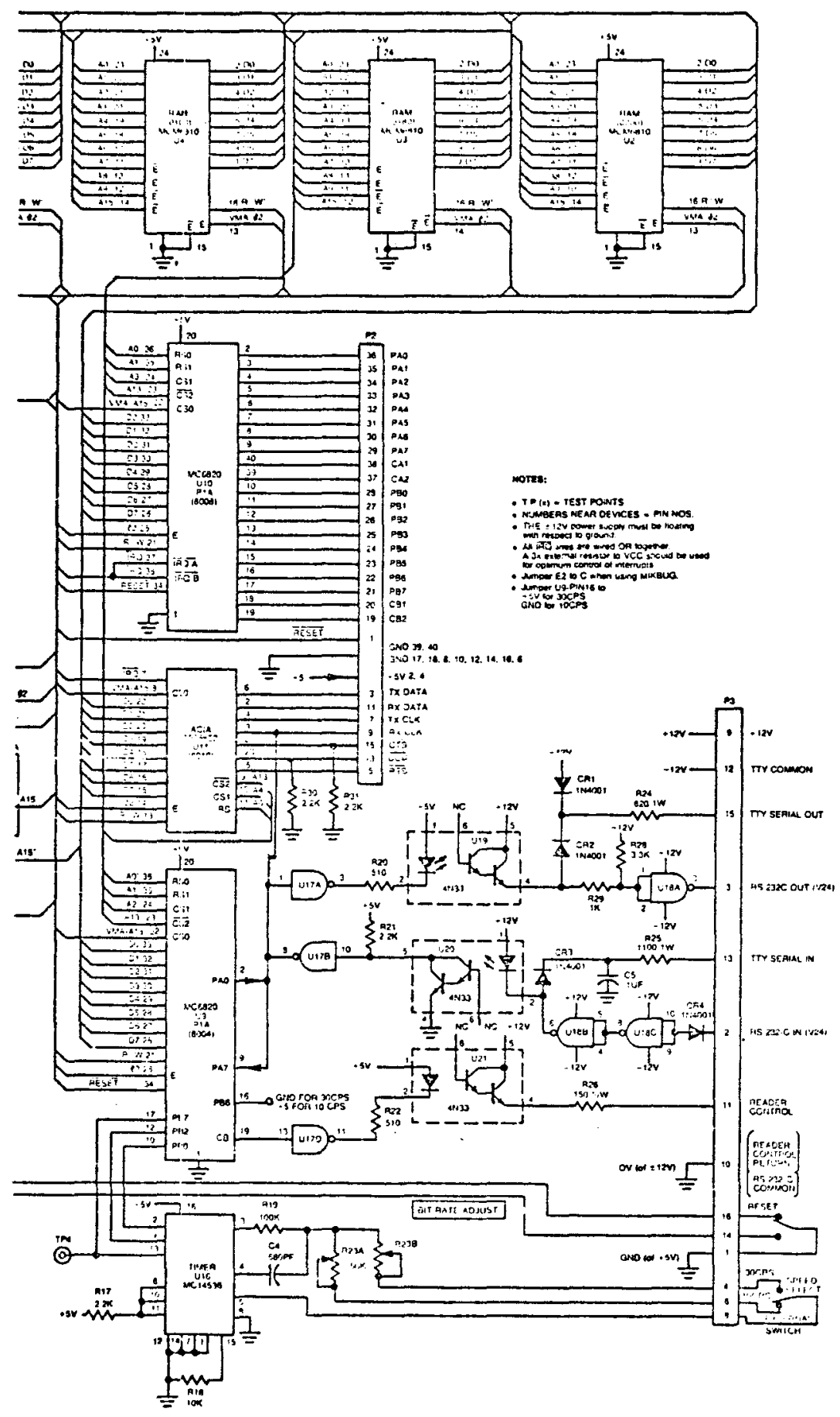

FIGURE 1 - Continued 
To Sec. 2

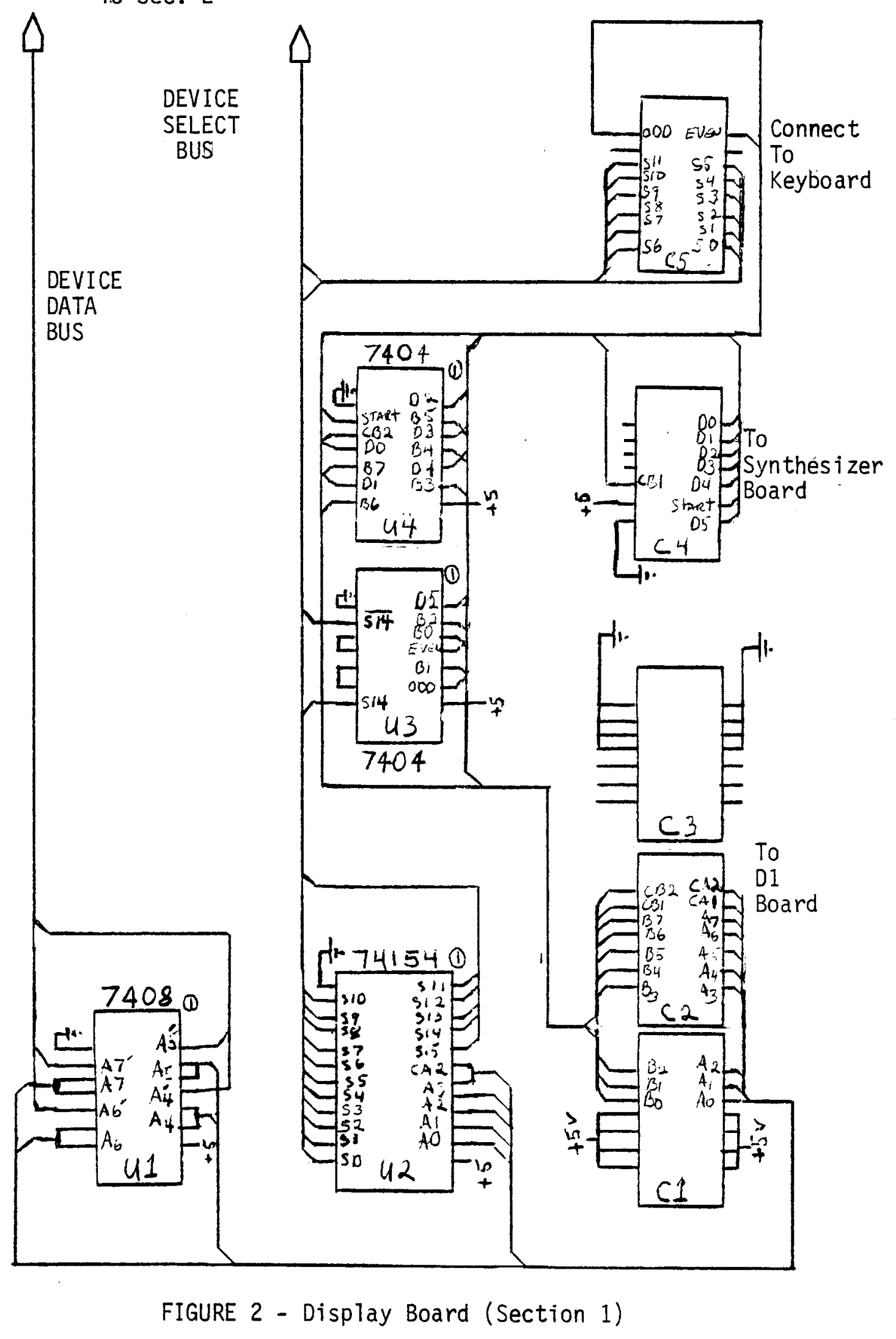




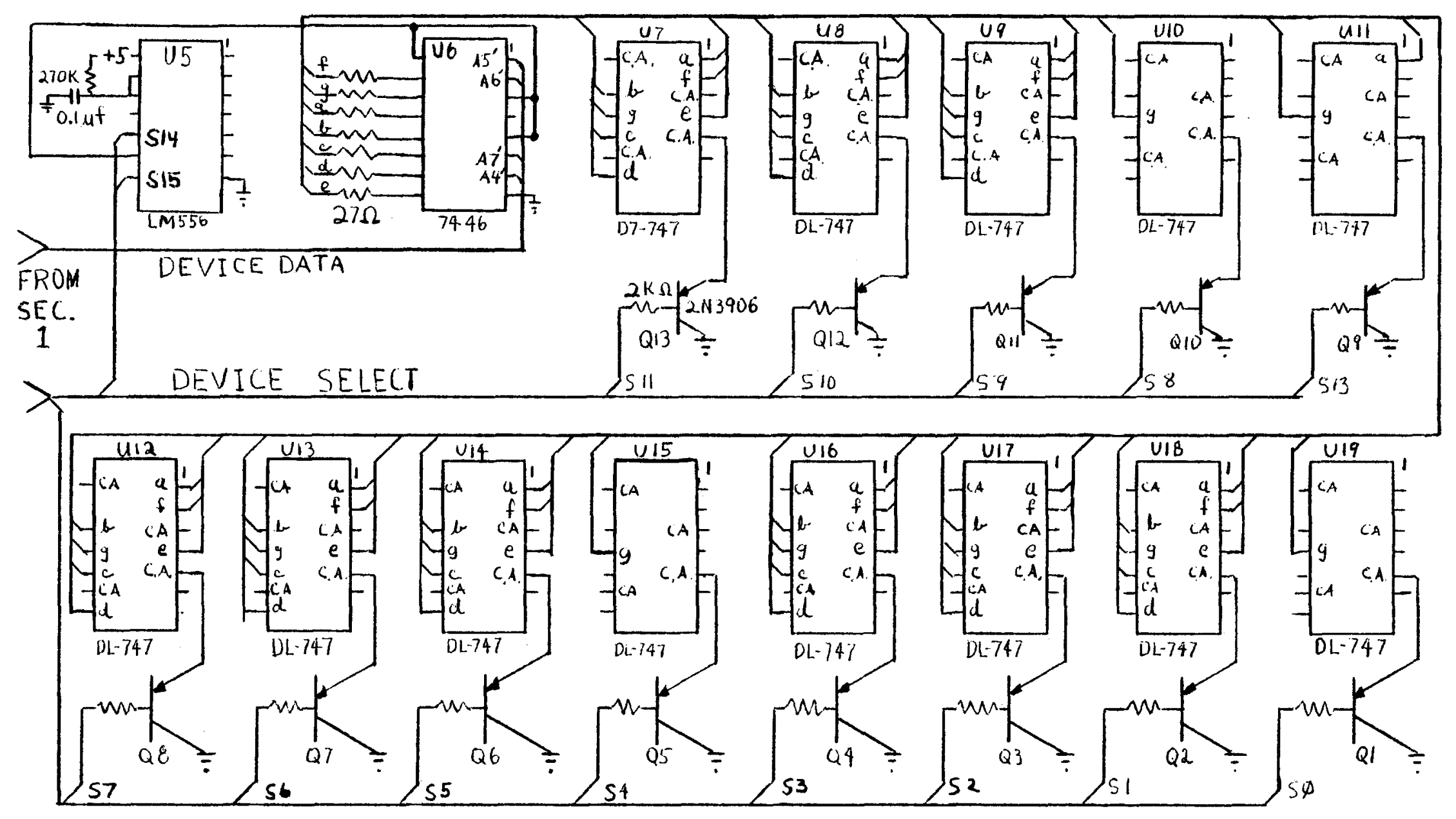

FIGURE 2 - Display Board Section 2 (LED Display) 


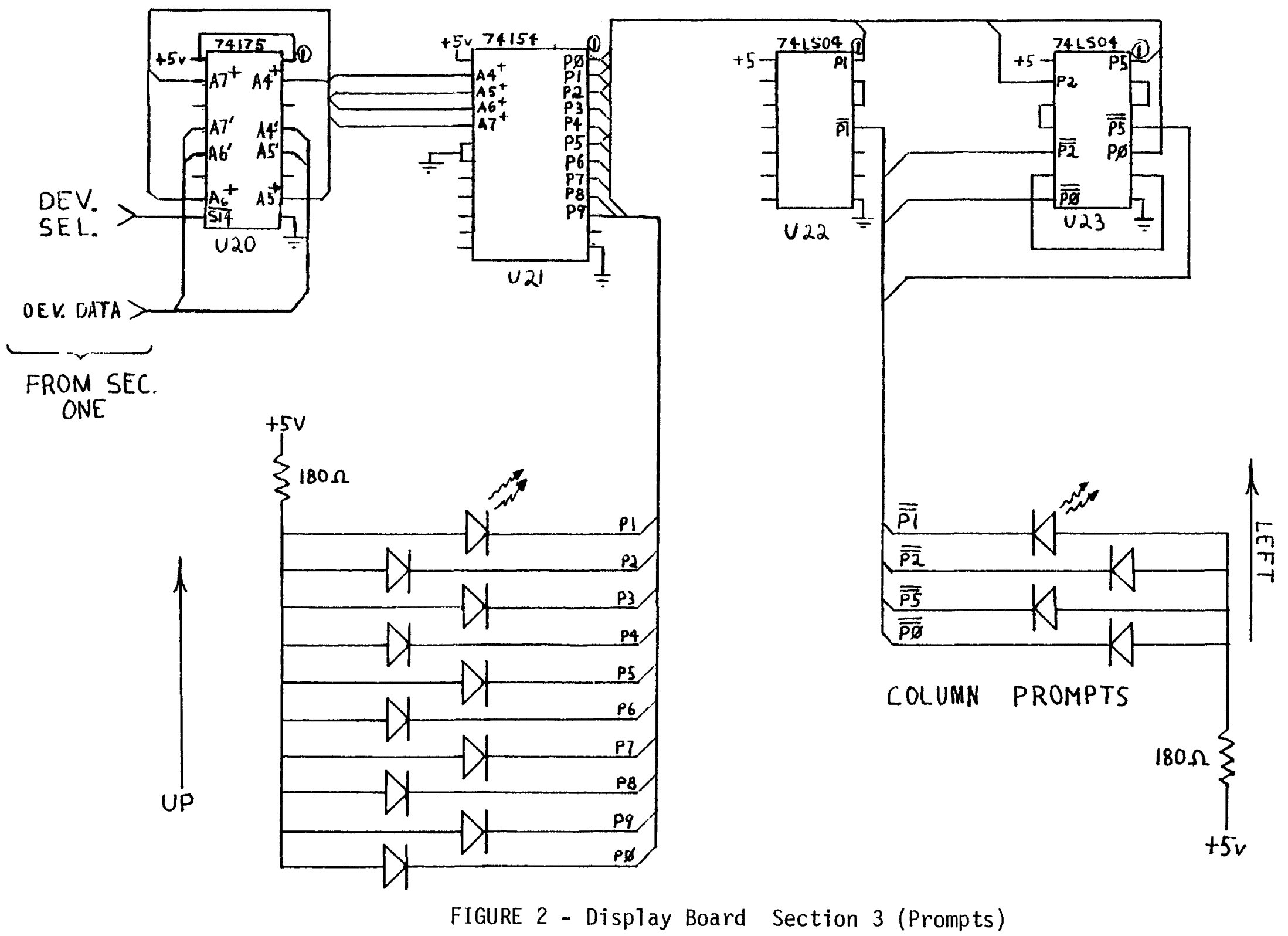




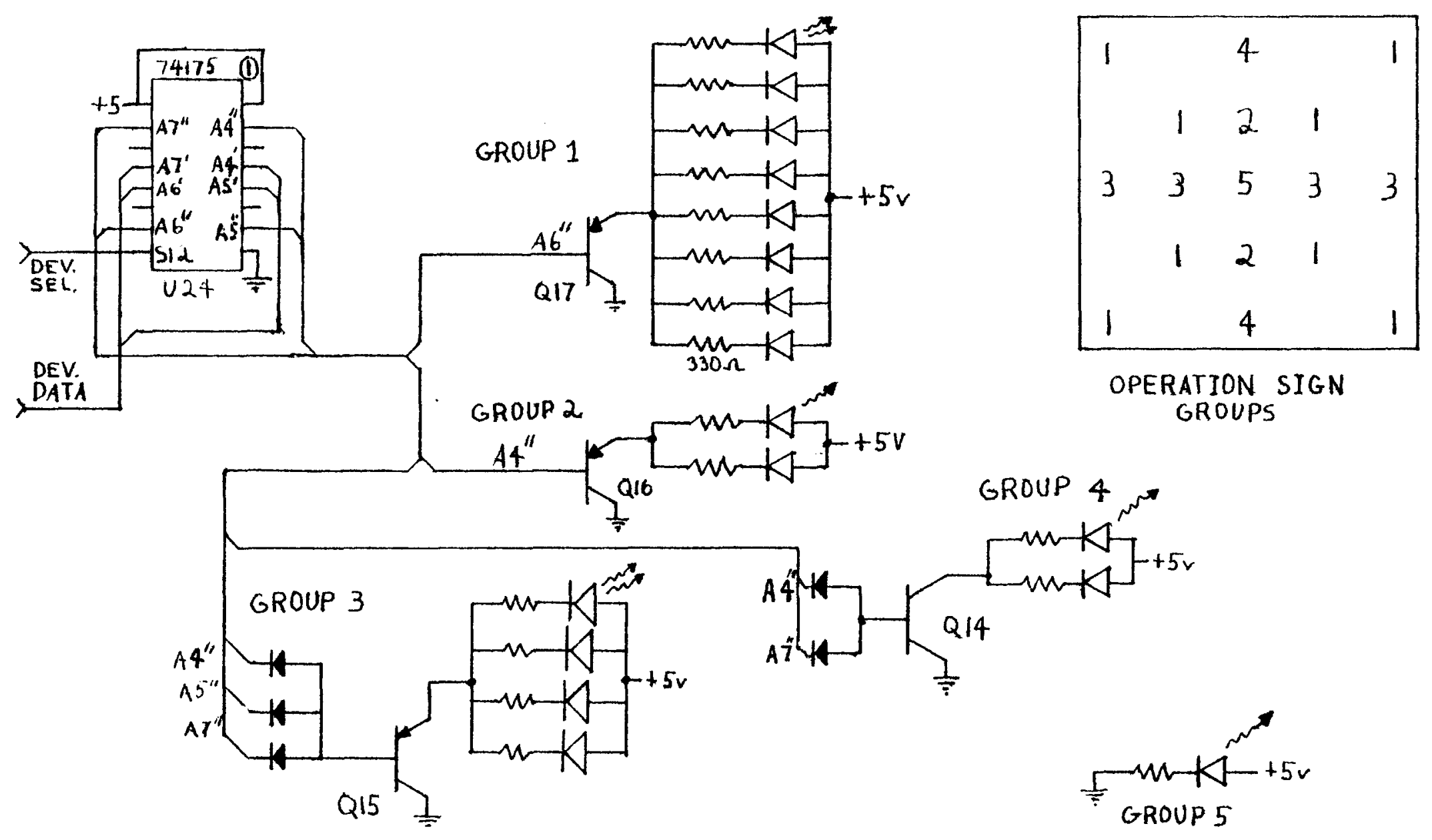

NOTE: Q14-Q17

$2 N 3906$

FIGURE 2 - Display Board Section 4 (Operation Sign) 


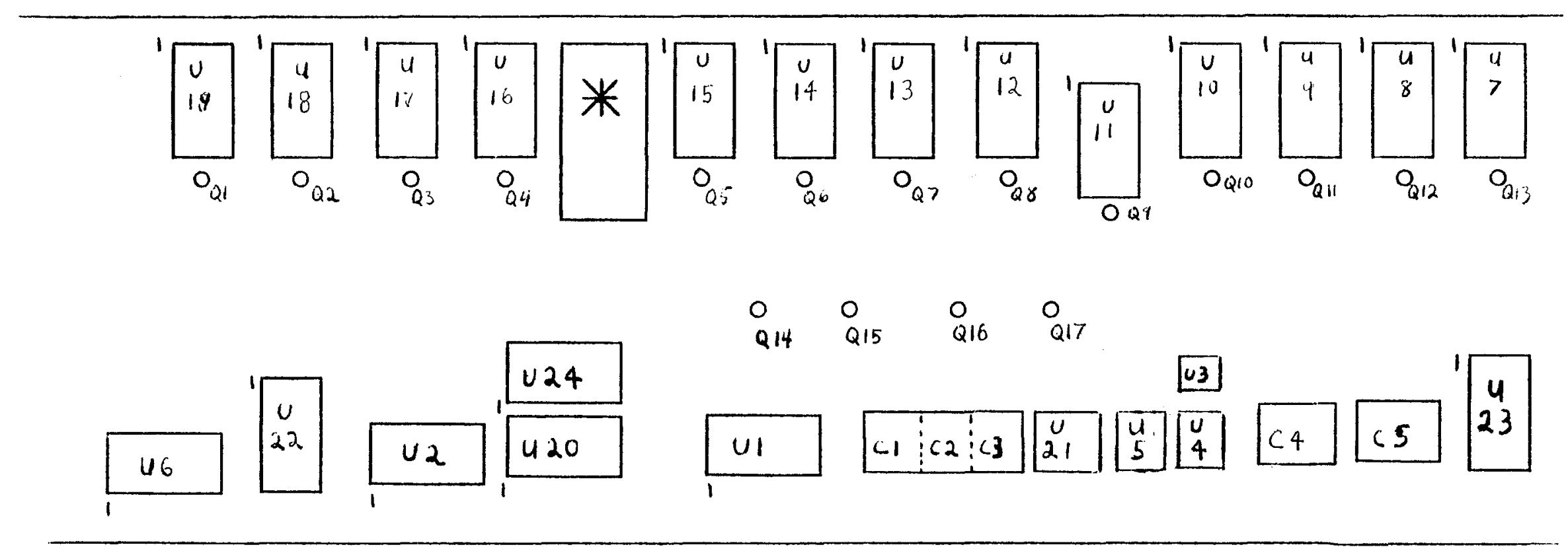

FIGURE 2 - Display Board Section 5 (Front View) 


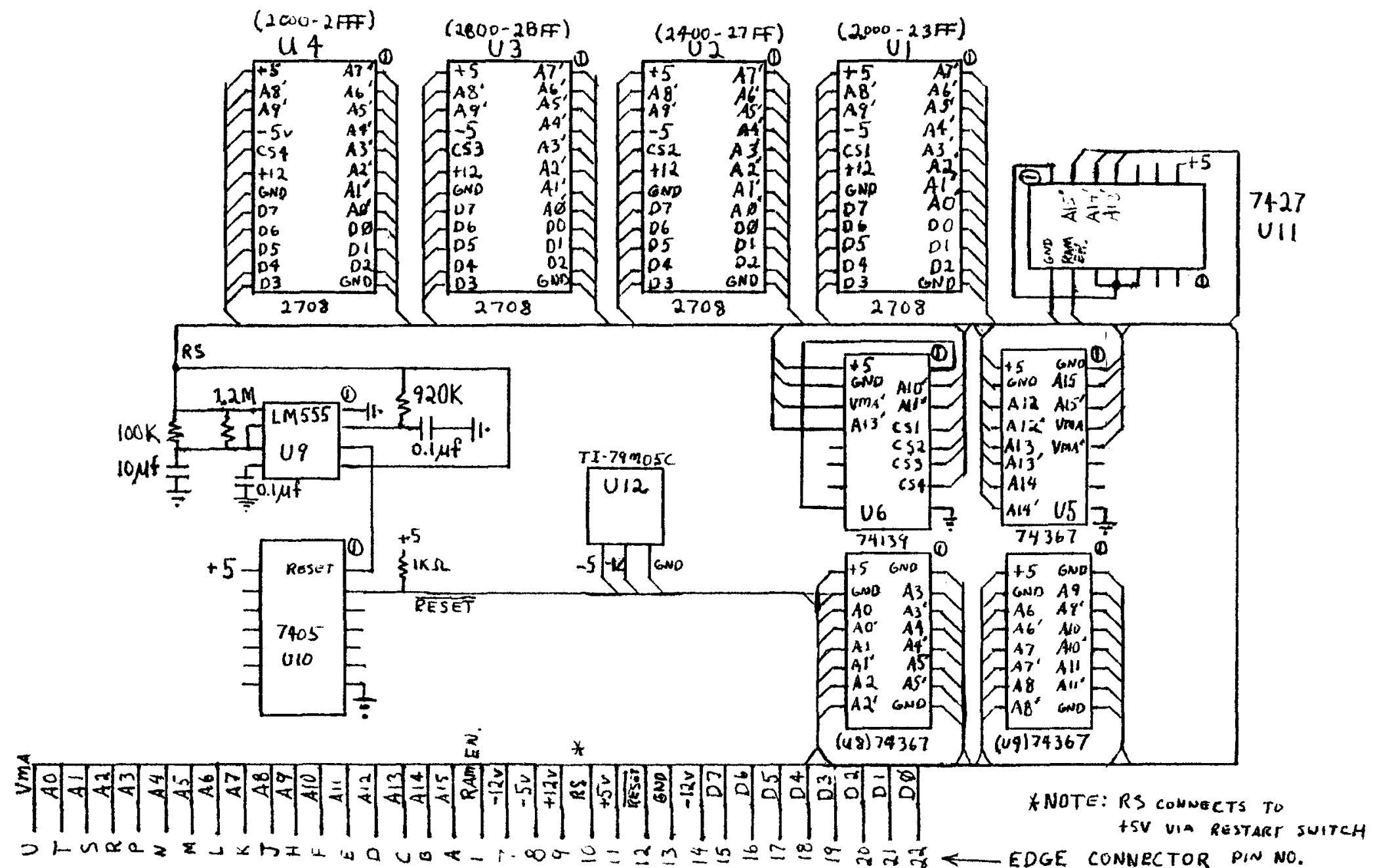

FIGURE 3 - EPROM Board (Back View) 


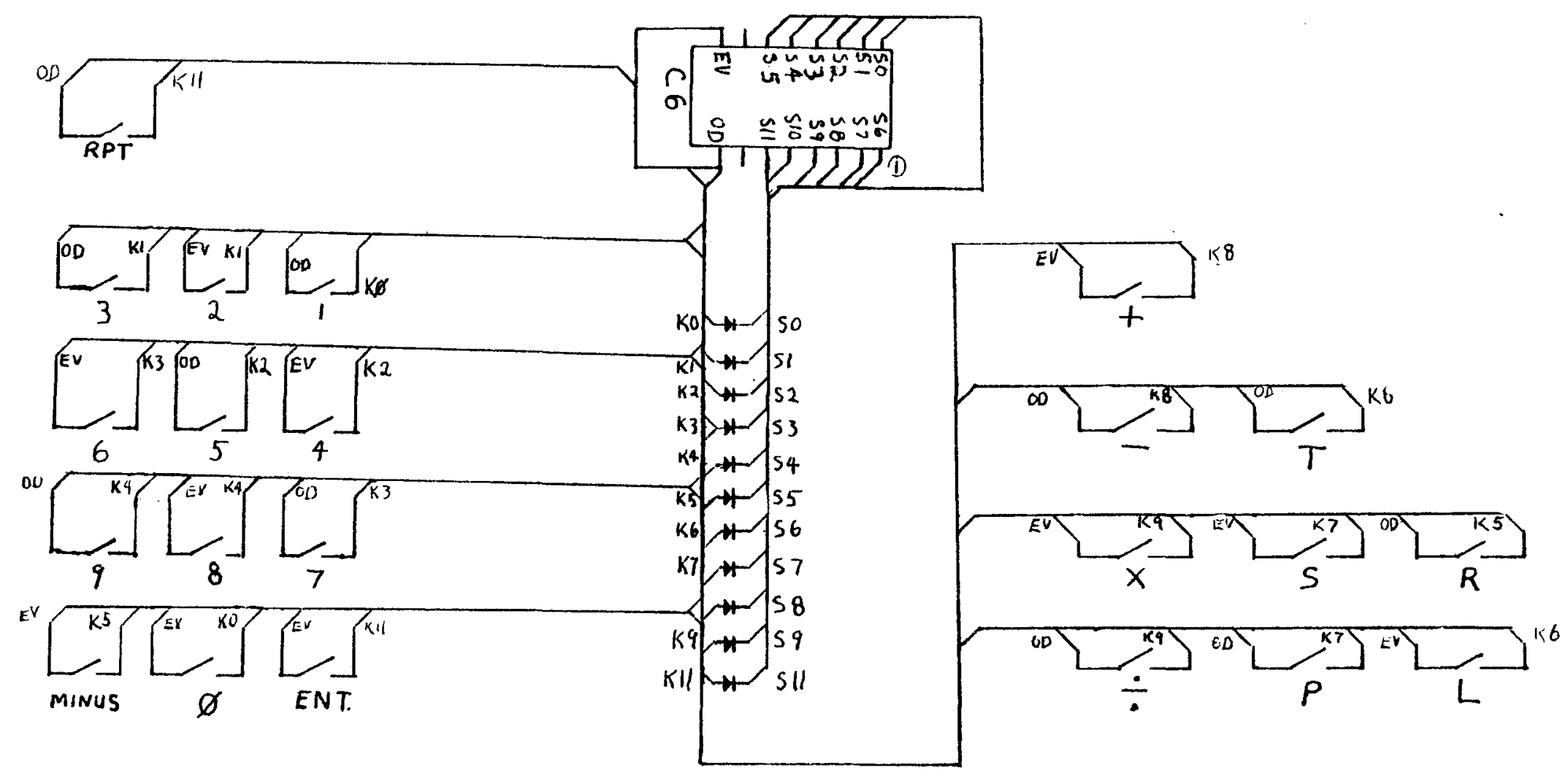

FIGURE 4 - Keyboard (Back View) 


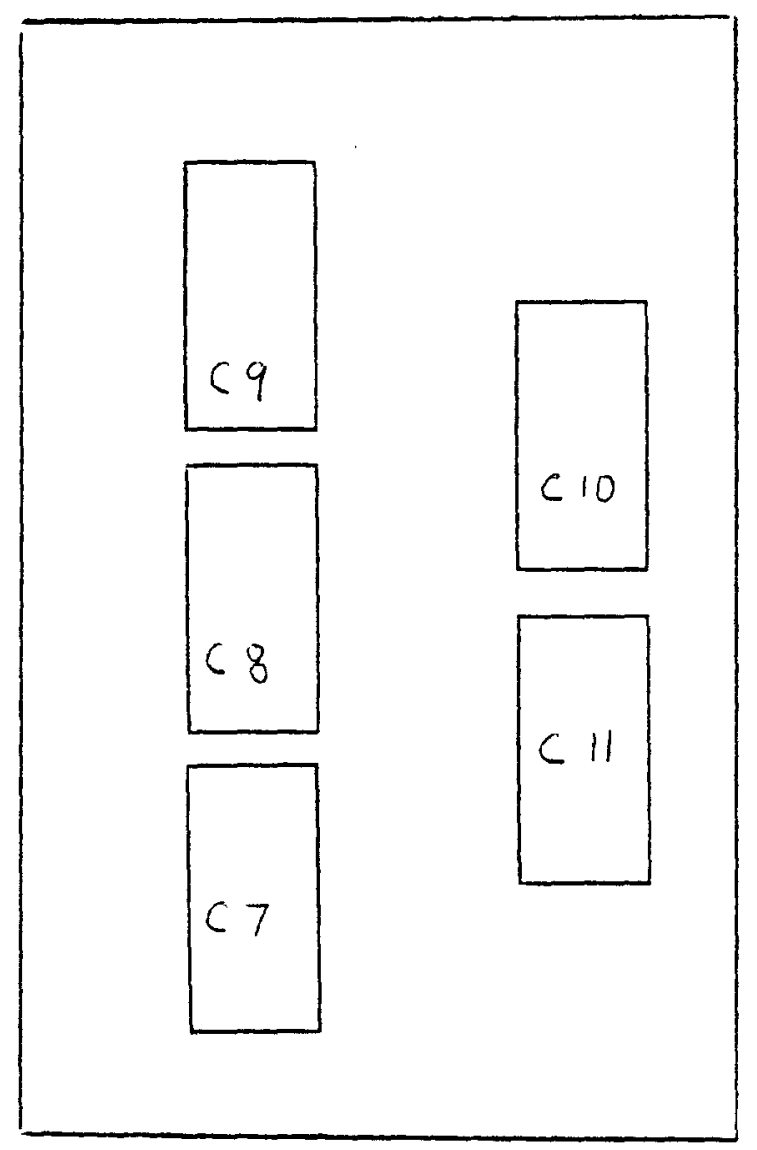

FIGURE 5 - Jumper Board (Back View) 


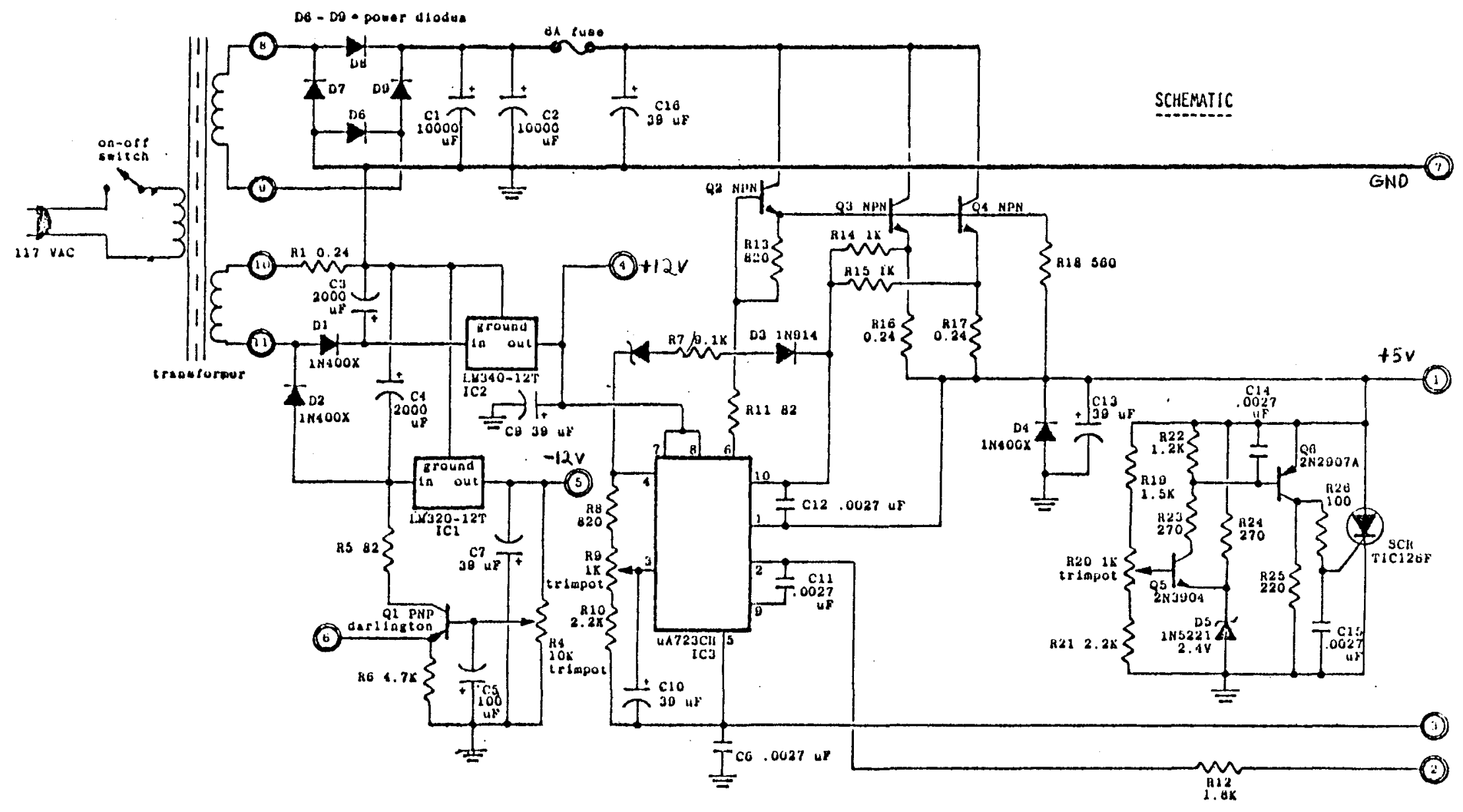

FIGURE 6 - Power Supply 
TABLE I

CONNECTOR INFORMATION

Connector Cl maps directly to pins on $\mathrm{C7}$.

Connector C2 maps directly to pins on C8.

Connector C3 maps directly to pins on C9.

Connector $\mathrm{C5}$ maps directly to pins on $\mathrm{C6}$.

CONNECTOR C7

Pins 4 through 11 are GND。 Other pins not connected.

CONNECTOR C8

$$
\begin{aligned}
\text { Pin } 1 & =C 11,1 \\
2 & =C 11,13 \\
3 & =C 11,2 \\
4 & =C 11,12 \\
5 & =C 11,3 \\
6 & =C 11,11 \\
7 & =C 11,4
\end{aligned}
$$

$$
\begin{aligned}
\text { Pin } 8 & =C 10,2 \\
9 & =C 10,13 \\
10 & =C 10,6 \\
11 & =C 10,9 \\
12 & =C 10,5 \\
13 & =C 10,10 \\
14 & =C 10,4
\end{aligned}
$$

CONNECTOR C9

$$
\text { Pin } \begin{aligned}
1 & =+5 v \\
2 & =+5 v \\
3 & =+5 v \\
4 & =+5 v \\
5 & =C 10,8 \\
6 & =C 10,7 \\
7 & =C 11,14
\end{aligned}
$$

$$
\begin{aligned}
\text { Pin } 8 & =C 10,11 \\
9 & =C 10,3 \\
10 & =C 10,12 \\
11 & =+5 \mathrm{v} \\
12 & =+5 \mathrm{v} \\
13 & =+5 \mathrm{v} \\
14 & =\text { Not Connected }
\end{aligned}
$$

CONNECTOR C4

Pin $1=$ Pin 9 on SPEECH BOX

$2=$ Pin 10 on SPEECH BOX

$3=$ Pin 11 on SPEECH BOX

$4=$ Pin 12 on SPEECH BOX

$5=$ Pin 13 on SPEECH BOX

$6=\operatorname{Pin} 14$ on SPEECH BOX

$7=$ Pin 15 on SPEECH BOX

14 Not Connected
Pin $8=$ Pin 1 on SPEECH BOX

$9=$ Pin 2 on SPEECH BOX

$10=$ Pin 3 on SPEECH BOX

11 Not Connected

12 Not Connected

13 Not Connected 
EPROM CONNECTOR

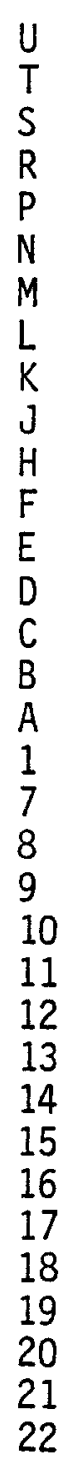

PIA CONNECTOR

Pin $\begin{array}{r}38 \\ 37 \\ 36 \\ 35 \\ 34 \\ 33 \\ 32 \\ 31 \\ 30 \\ 29 \\ 28 \\ 27 \\ 26 \\ 25\end{array}$

DI CONNECTOR

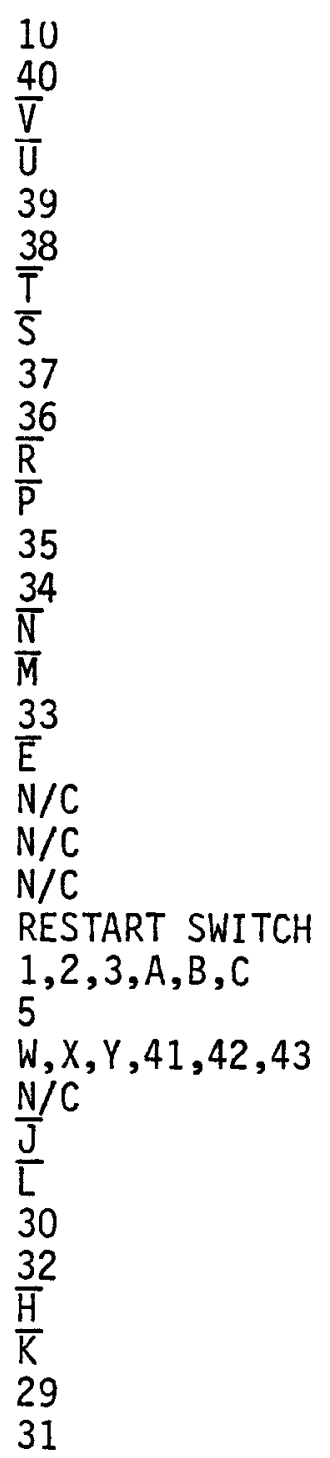

CONNECTED TO

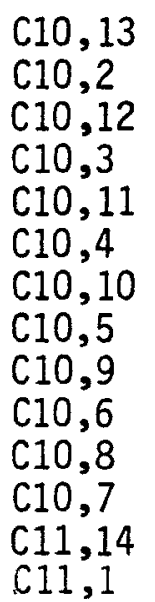

$\mathrm{C} 10,13$

$\mathrm{C} 10,2$

C 10,12

C10,3

C 10,11

$\mathrm{C} 10,4$

C10,10

C10,5

C10,9

$\mathrm{C} 10,6$

C10,8

C10,7

C11,1 
PIA CONNECTOR

Pin 24

23

22

21

20

19
CONNECTED TO

C11, 13

C11, 2

$\mathrm{C} 11,12$

C11,3

C11,11

C11,4 


\section{APPENDIX III}

SOFTWARE DOCUMENTATION

These listings were produced by using a disassembler program on a D2 microcomputer. The disassembled listings, output by the D2, were transferred to the University of Louisville's DEC-10 computer via a digital cassette recorder. Using the DEC-10's text editors (SOS and TECO), comments and symbolic addresses were added. The listings were printed on a DEC-WRITER. The SOS editor was also used to generate the subroutine hierarchy listings. 
TABLE I

SYMBOL TABLE

Stack starts at \$0OFF

PIA Addresses

$\$ 8008=$ PORT $-A$
$\$ 8009=$ CONT $-A$
$\$ 800 A=$ PORT $B$
$\$ 880 B=$ CONT $-B$

RAM Addresses

$\$ 0000=K E Y$

$\$ 0001=B F$

$\$ 0002=D A D D R$

$\$ 0003=$ SUM

$\$ 0004-04=X S A V$

$\$ 0006-15=$ DISBUF

$\$ 0016-17=$ NEXT

$\$ 0018-19=$ LAST

$\$ 001 A-1 B=$ SCNTIM

$\$ 001 C=$ PAUSE

$\$ 001 D-3 C$ (32 bytes) $=$ SPKBUF

$\$ 003 D=$ SGNDIG

$\$ 003 E-43=$ DIG1-DIG6

$\$ 0044-45=$ TIMER

$\$ 0047-47=$ RATE

$\$ 0048=$ MODE

$\$ 0049=$ OPTION

$\$ 004 A-4 B=$ SEED 1

$\$ 004 C-4 D=$ TIML IM

$\$ 004 \mathrm{E}-4 \mathrm{~F}=$ MAX PROBS

$\$ 0050=$ OPSIGN

$\$ 0051-52=$ MISSING \#

\$0053-54 = HILIM1/LEVEL

\$0055-56 = PROBTYPE/LOLIM1

$\$ 0057-58=$ HILIM2

$\$ 0059-5 A=$ LOL IM1

$\$ 005 \mathrm{~B}-5 \mathrm{C}=\mathrm{NUM} 1$

$\$ 005 \mathrm{D}-5 \mathrm{E}=\mathrm{NUM} 2$

$\$ 005 \mathrm{~F}-60=\mathrm{NUM} 3$

$\$ 0061=S A Y$

$\$ 0062-63=$ SEED 2

$\$ 0064-65=$ ATTPROBS

$\$ 0066-67=$ WRONG

$\$ 0068-69=$ SECONDS 


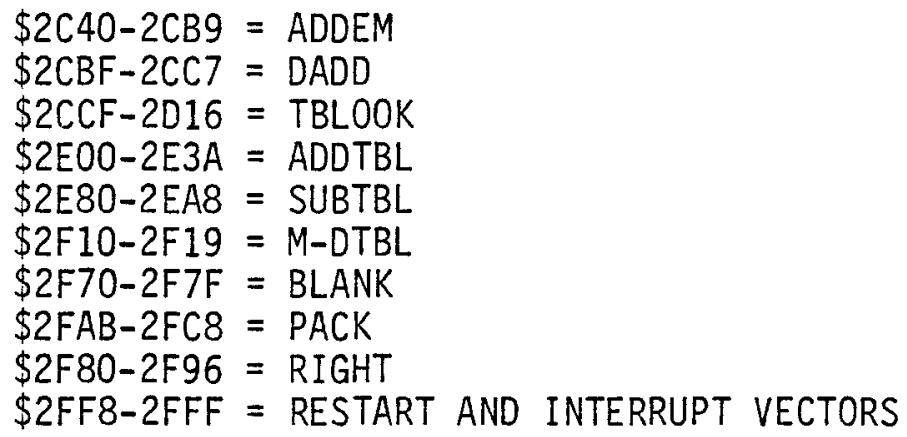


TABLE II

SUBROUTINE HIERARCHY

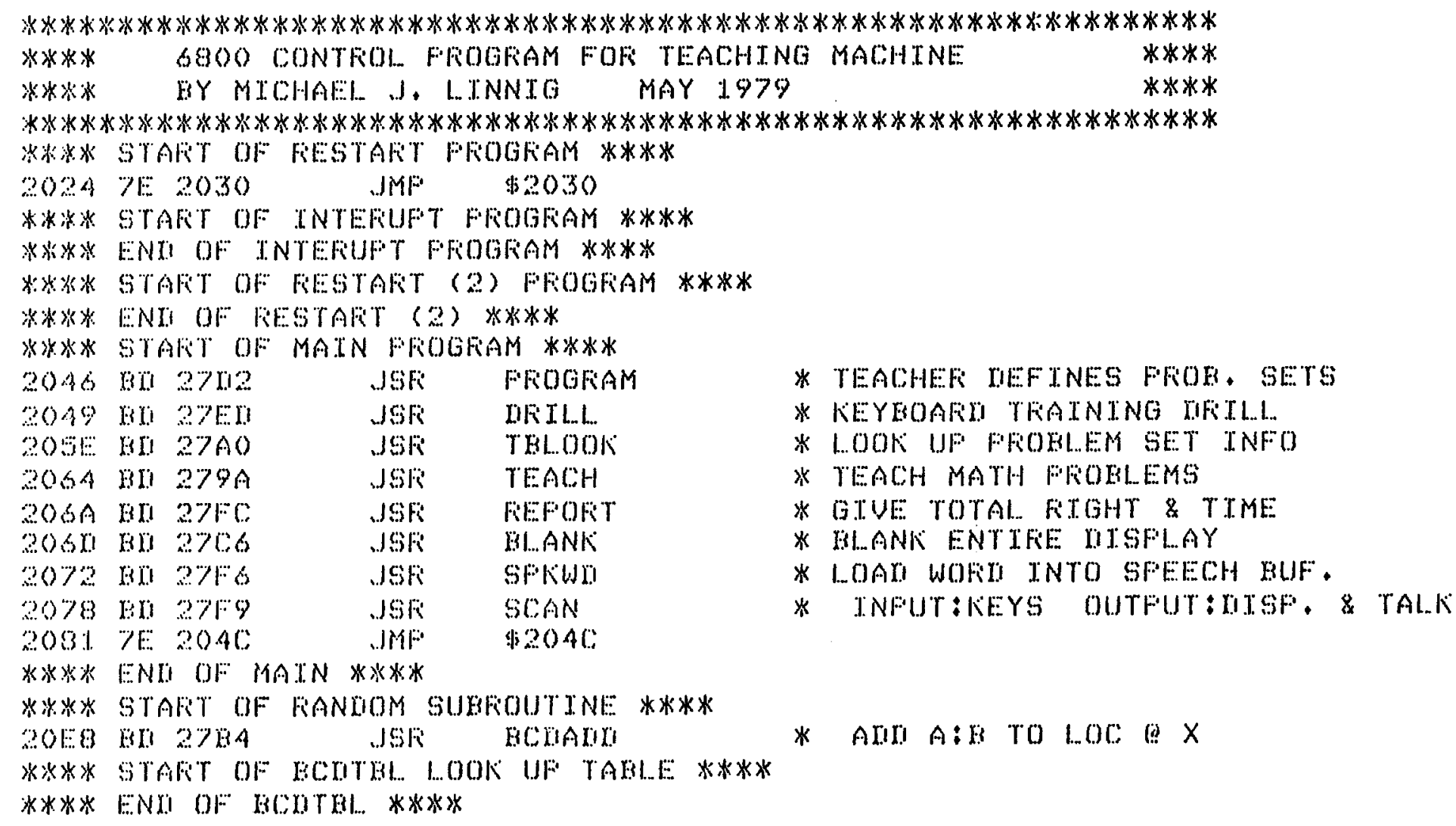

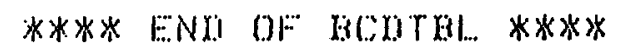

* TEACHEF TEEFTES FFOB. GETS

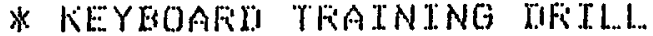

* LOOK UF PFOBLEM SET TNFO

* TEACH MATH FROBLEMS

* gTUE TOTAL fitght \& TrME

* HLANIK ENTIFEE IITSFI..AY

* logar wofig into sfeech buF.

* TNFUT:LEYS OUTFUT:MTSF。 \& TALK 


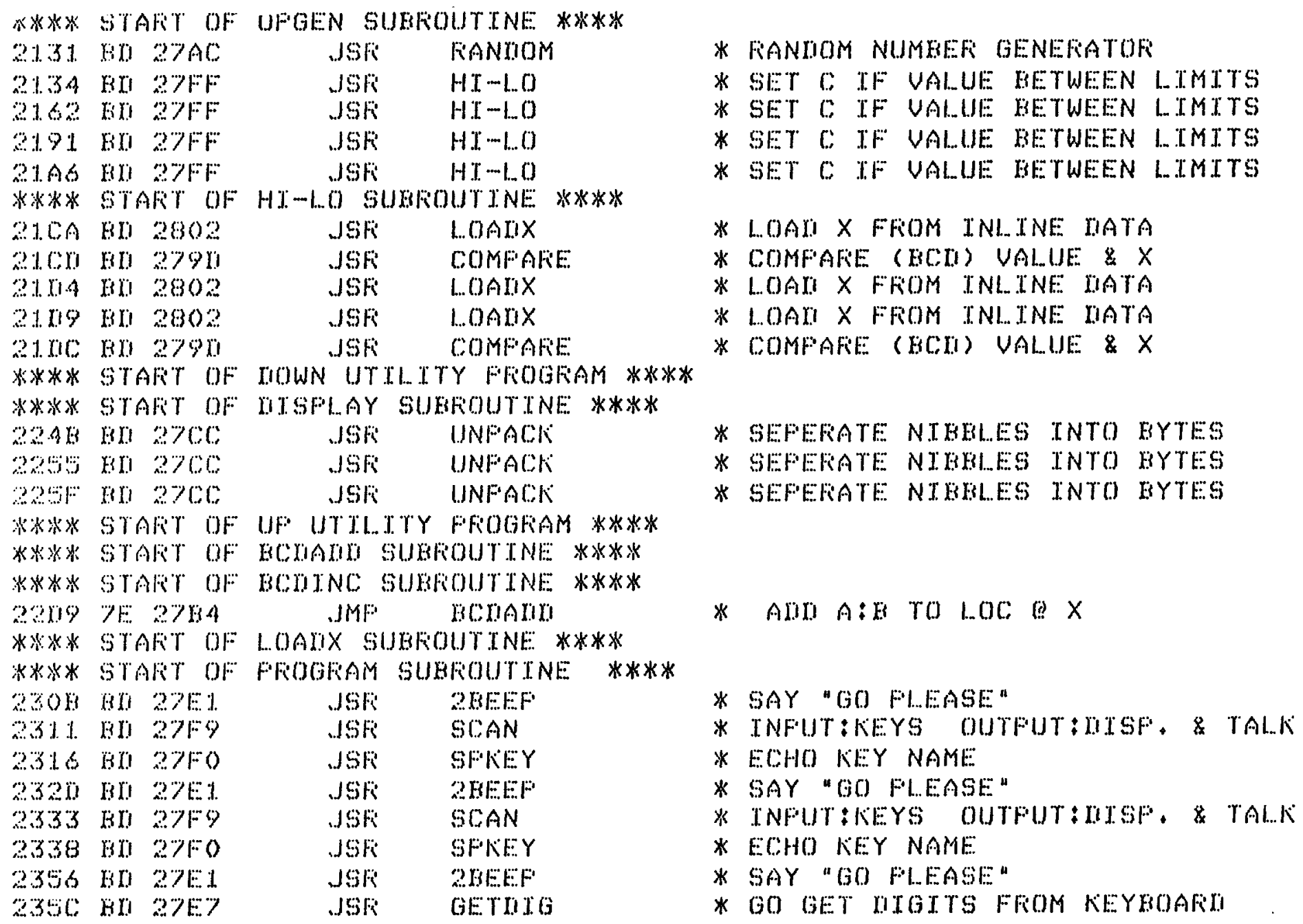




\begin{tabular}{|c|c|c|c|c|c|}
\hline 2362 & $B I$ & $2710:$. & JSFi & MINTOEI & \\
\hline 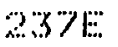 & BII & 27118 &.$J 5 R$ & IIAI!I! & \\
\hline $237 \%$ & {$[: ! 1$} & 271. & JSEF & 2XFE:F & \\
\hline 23019 & ISII & $2 \% 1: 7$ & $15 F$ & GETIIO & \\
\hline $23 A B$ & Sin & $2 \% 11 \mathrm{H}$ & $.15 F$ & FACK & \\
\hline 23A & mII & 2751 &.$S B$ & 2DEEF & \\
\hline 2360 & 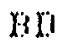 & $\because 7 F 9$ & JSK & SCAN & \\
\hline $23 x$ & $\mathrm{BOH}$ & 27100 & JSF & SFKKY & \\
\hline 2308 & BII & $27 E 1$ & JSF & 2DEEF & \\
\hline $23 \mathrm{CO}$ & 131 & $27: 07$ & ISF & GETIIIG & \\
\hline $23 \times 14$ & $\mathrm{BII}$ & 27116 & $.1 S F$ & FACK & \\
\hline 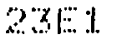 & HiI & $27 \mid \div 1$ & JSiri & 2BEEF & \\
\hline $231=7$ & 130 & 278 &.$S \mathrm{SF}$ & GETIIB & \\
\hline $2 \times 3 \mid: 11$ & 51.1 & $2711 \mathrm{H}$ & JSF & FACK & \\
\hline $2 x+3 x$ & Bn & 27110 & 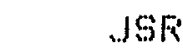 & GETEM & \\
\hline$\therefore 3 F 9$ & BII & $\therefore 701 \mathrm{~K}$ & .518 & $\because A C K$ & \\
\hline $23 F$ & $9 n$ & 27115 & $.15 \%$ & GETEM & \\
\hline 2904 & HII & $2 \%$ lit & JSFi & $\because A C N$ & \\
\hline$\therefore 409$ & 80 & 271013 & . & GETEM & \\
\hline$\because 201=$ & $B I$ & 27 III & JSF & サACK & \\
\hline 2419 & EII & 270 & $.15 F$ & (B):El:M & \\
\hline$\therefore 41 \mathrm{~A}$ & In! & 271013 & $.3 \mathrm{sin}$ & ツACK゙ & \\
\hline **** & STA & Ant $0 \%$ & 2सLE: & SUBFOUYNE * & *2*** $* *$ \\
\hline تئ3: & $\mathrm{Bn}$ & $2 \% \hat{m}$ &.$J S F$ & WAIT & \\
\hline $24: 3 A$ & $\mathrm{BL}$ & $2.7 F .3$ & JSF & LIPFAIJS & \\
\hline 24010 & $\mathrm{BII}$ & $27 F 6$ & JSF & SFK゙WD & \\
\hline$\because 464$ & BII & 27106 & .JSF & 8*kいn & \\
\hline 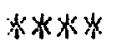 & GTA & AFIT OF & MINYOEI & - SUBFOUT INE & E $*$ 必必 \\
\hline 2468 & 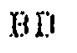 & $2 \% \square 18$ & .JSE & IIARII & \\
\hline
\end{tabular}

* CONUERT MMM:Ss TO BIN. SECS

* TWO BYTE HINAFY ALII

* SAY "BO FLEASE"

* GO GET MTGTS FROM KEY MOARI

* FACK MUL.TIIITIT TNFO

* SAY "GO FLEASE"

* TNFUT:KEYS OUTFUT: MTSF \& TALK

* ECHO KEYY NAME:

* SAY "GO FLEASE"

* GO GET IIGTYS FROM KEEYBOAFI

* FACKR MUL.TTITGTT INFO

* SAY "QO FIEASE"

* GO GEr IIGTTS FFOM KEYEOAFI

* FACK MUI.TTIIUTT INFO

* FROMFT \& SCAN FOF RESFONSE.

* FACK MIJLTTITGTT TNFO

* promer \& scan for riesfonst:

* FACK MUI..TTIITET INFO

* FROMFT \& SCAN FOF RESFONSE

* FACK MUL.TTITGTT TNFO

* FlOMFT \& SCAN FOF REGFONSE

* FACK MULTTHGTT JNFO

* WATT TILL SFEECH-HLF EMFYY

* LOAII FAIISE INTO SFEFCH WUF

* LOAT WOFII TNTO GFEECH RUF.

* LOAI WOFI TNTO SFEECH BUF

* TWO BYTE HTNAFiY Alir! 


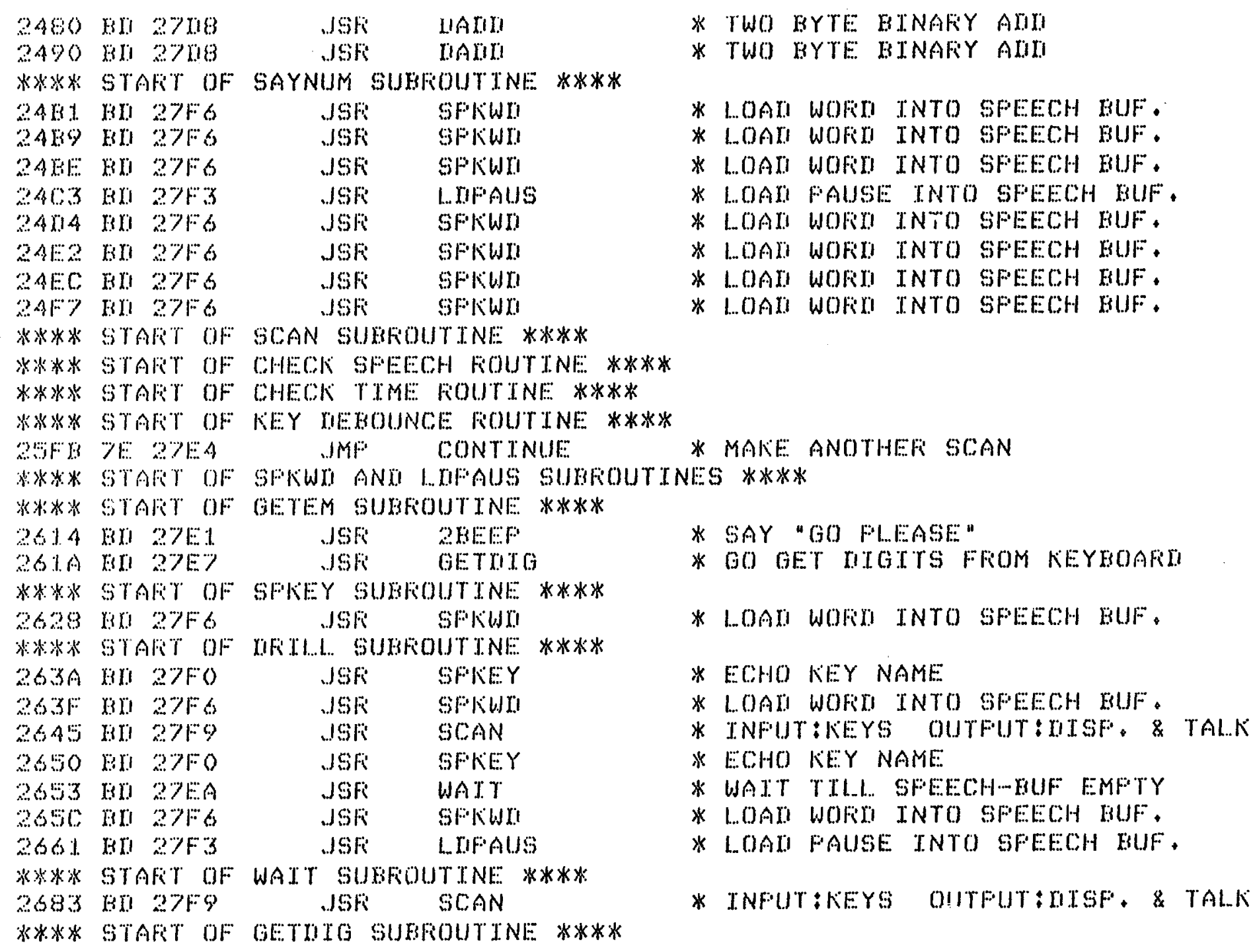




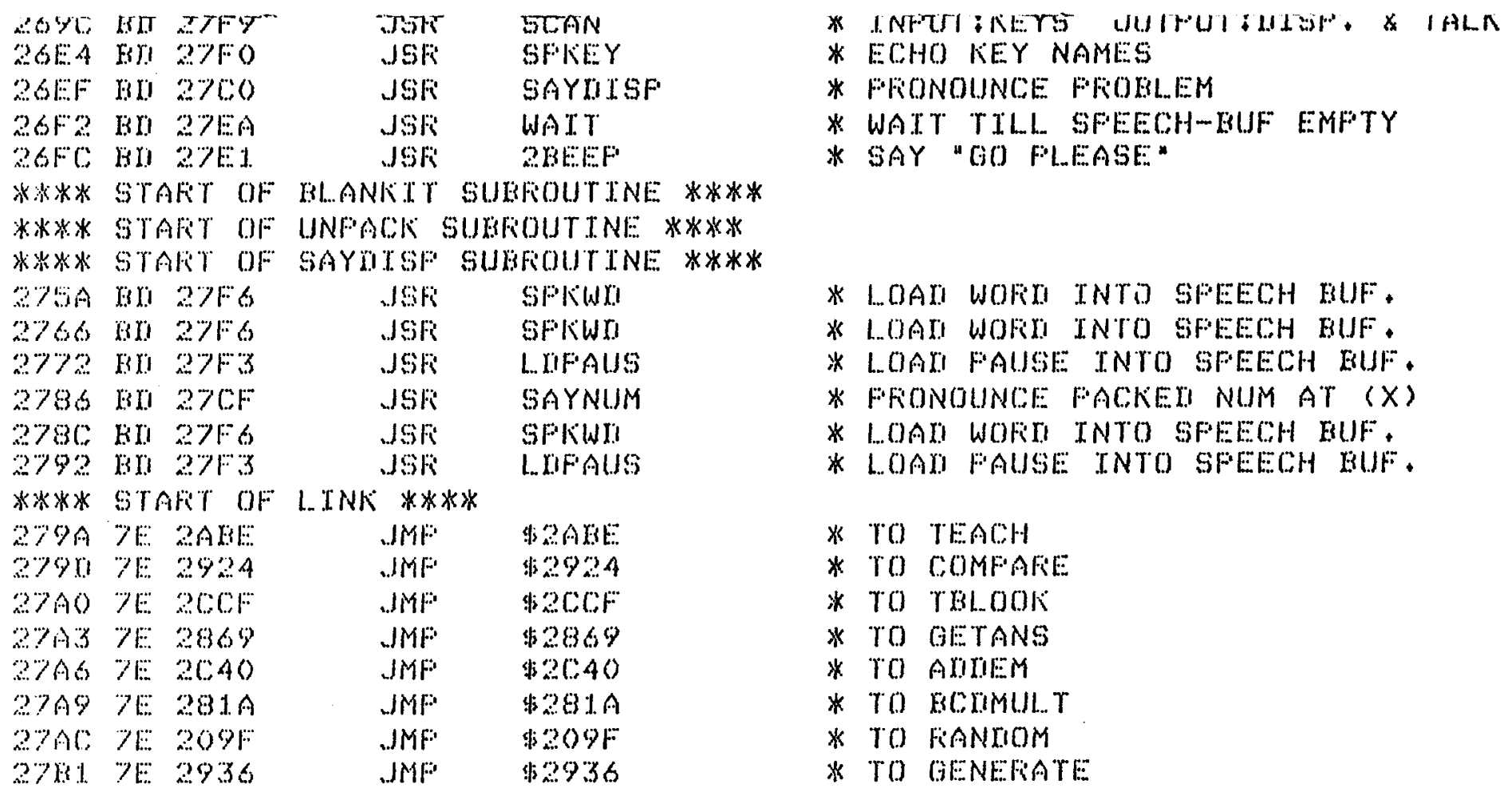




\begin{tabular}{|c|c|c|c|c|}
\hline 2784 & $7[:$ & 2007 & $J M F$ & $4220 \%$ \\
\hline$\therefore 787$ & $\neg E$ & $22 \times 16$ &.$|M| * *$ & $\$ 22210$ \\
\hline$\therefore \mathrm{BA}$ & $7 E$ & $\therefore(0)$ & JMF & $\$ 2000$ \\
\hline $2 \%$ KI & $7 E$ & $291 \mathrm{C}$ &.$J M F$ & $\$ 2910$ \\
\hline 2700 & 76 & $274 A$ &.$J M F$ & $w_{274}$ \\
\hline $2 \% 03$ & $\because E:$ & 2710 & JMF & $\$ 2710$ \\
\hline $2 \% 0 ; 6$ & $\Rightarrow E$ & 2670 & JMF: & 42570 \\
\hline 2709 & $7:$ & 2240 & $J M F$ & 42240 \\
\hline $2 \% 0$ & $7 E$ & 2730 &.$J M F$ & $\$ 27.30$ \\
\hline $270 \%$ & $7 E$ & $24 A 7$ & JMF & $\$ 24 A 7$ \\
\hline $271 \%$ & $7 E$ & 2254 &.$J M F$ & 求?2FA \\
\hline 27116 & $7:=$ & $2611 ?$ &.$J M F$ & 42612 \\
\hline 27118 & $7 E$ & 2.CHF & JMF & $\$ 2 C: B 1=$ \\
\hline 27018 & 78 & 28118 &.$J M F$ & $\$ 2 F A A$ \\
\hline 2711:: & $7 E$ & 2469 &.$J M F$ & $\$ 246 \%$ \\
\hline 2751 & $7 E$ & $24: 36$ &.$M M F$ & $\$ 2455$ \\
\hline $27 \because: 4$ & $7:$ & 2009 &.$I M F \cdot$ & $\$ 2509$ \\
\hline $27: 7$ & $7 F$ & $\therefore 680$ & JMF & $\$ 2681$ \\
\hline 27EA & $\neg E$ & 2680 & JMF & 432680 \\
\hline $27 E 0$ & $7 F$ & 2634 & $J M F$ & $\$ 2634$ \\
\hline 27100 & $7 E$ & 2620 &.$J M F$ & $\$ 2620$ \\
\hline 275 & 7 & $\therefore 602$ & JN保 & 432602 \\
\hline
\end{tabular}

* To Henario

* To aciline:

* TO Fififor

* to risub

* to saymisf

* ro BL.ANKTT

* TO RI...ANK

* TO UIISFI..Ay

* TO UNFACK

* rO SAYNIJM

* to progham

* TO GETEM

* TO Tialit!

* TO FACKE

* TO MINTOLI

* TO DREEF

* TO CONTTNUE (LOCATELI TN SCAN)

* TO GETIL

* To WATt

* To rifíli...

* TO SFKEY

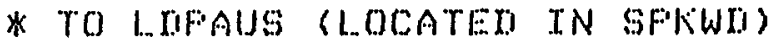




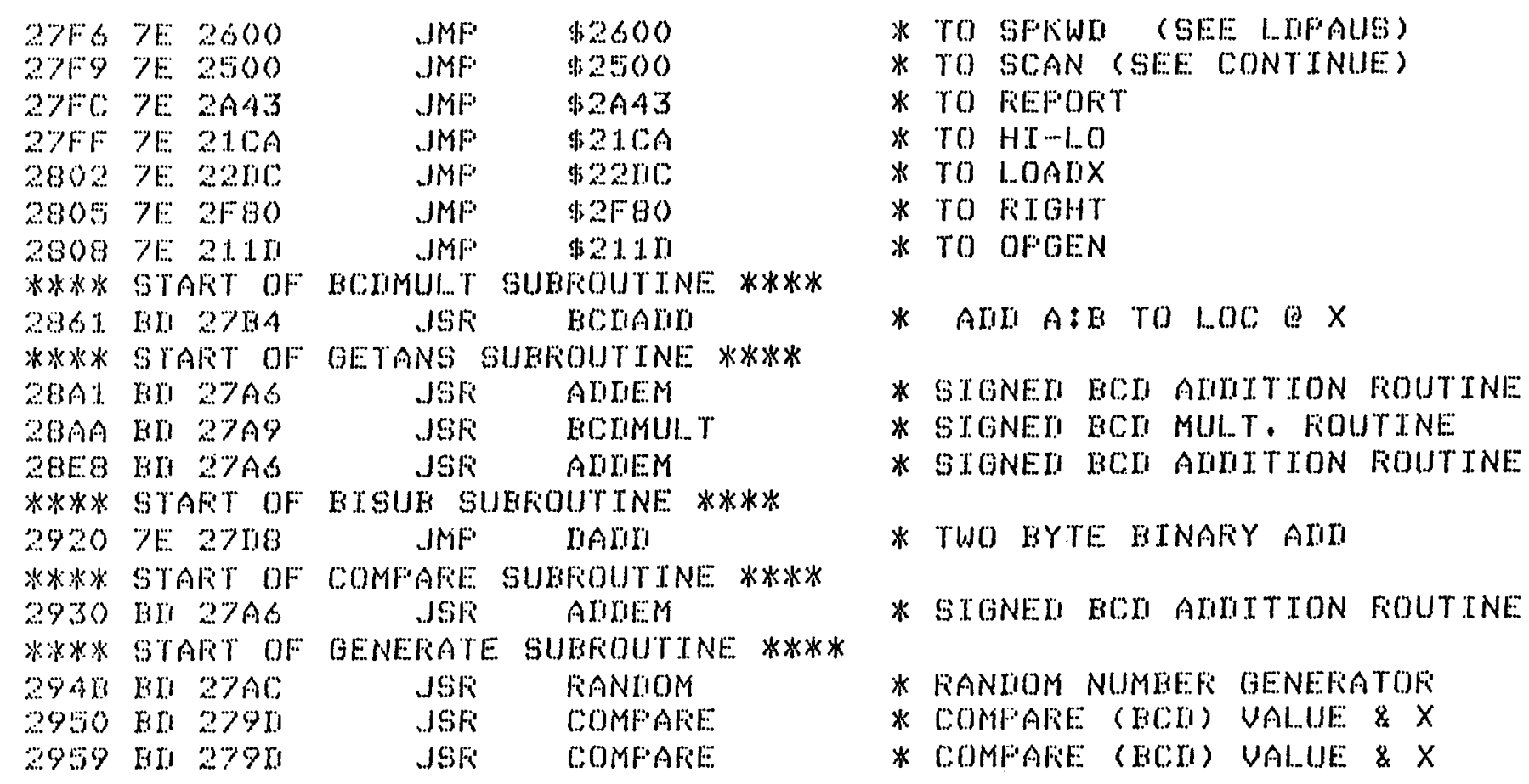




\begin{tabular}{|c|c|c|c|c|c|c|c|}
\hline $\begin{array}{l}\because 9675 \\
\therefore 96 A\end{array}$ & lini & $\begin{array}{l}270 \mathrm{AC} \\
2 \% 9 \mathrm{li}\end{array}$ & $\begin{array}{l}.15 F \\
.1 S F\end{array}$ & $\begin{array}{l}\text { FANRICIM } \\
\text { COMFAFIE }\end{array}$ & & $\begin{array}{l}* \\
*\end{array}$ & $\begin{array}{l}\text { FANTIOM NUMEEF GENEFATOR } \\
\text { COMFAME (BCII) VALIIE \& X }\end{array}$ \\
\hline 297.3 & an & 2790 & $J S F$ & COMFAFE & & * & COMFAFE (BCH) UALUEE \& X \\
\hline 2980 & lin & 2808 & JSFi & OFGEN & & * & GENEFATE ONE OFEFANI \\
\hline 2999 & 131 & 2808 & . JSF & OFGEN & & * & GENEFATE ONE OFEFANI \\
\hline$\therefore 9 A A$ & Eili & $27 F+\cdots$ & $J S R$ & $H .1 .0$ & & * & SET C IF UALUE BETWEEN LIMITS \\
\hline $29 \mathrm{HO}$ & $\mathrm{Br}$ & $27 F$ & JSF & $H T-L_{0} O$ & . & * & SET C IF UALUUE BETWEEN LIMITS \\
\hline 必必必冰 & $\$ \gamma$ & AF OF & FEFOF' & SUBFOUTINE: & $* * * * *$ & & \\
\hline $2 A 43$ & $\mathrm{~B} \times$ & 2706 & JSF & IILANII & & * & HLANK ENTIFE DISFILAY \\
\hline $2 \mathrm{~A}=3$ & BII & $27 A B$ & . 5 SEF & AIIIEM & & * & GTGNEM BOI AIIITION FOUTINE \\
\hline $2 A \because 9$ & lin & 2976 &. $\mathrm{SEF}$ & 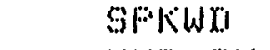 & & * & LOAR WOFII TNTO SFEECH EUF. \\
\hline $2 A B x$ & $B[!$ & 270 &. $\mathrm{SER}$ & UNFACKK & & * & SEFEFATE NIHBLES TNTO BYTES \\
\hline$\because 469$ & Mn & $27 \mathrm{CH}$ &.$J S F$ & SAYNUM & & 幽 & FHONOUNCE FACKEII NUM AT $(X)$ \\
\hline $2 A 61$ & lili & $2.7 \% 6$ & JSF & SWkiWl! & & * & LOAD WOFI TNTO SFEEOH BUF. \\
\hline$\therefore A 78$ & IiII & 270 & $.9 F$ & UNFACK & & \# & SEWEFATE NTBRLES TNTO BYTES \\
\hline $2 A B 2$ & BIII & 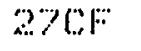 & JSFi & SAYNIJM & & * & FFONOUNCE FACKEII NUM AT $(X)$ \\
\hline $2 A 87$ & 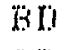 & $27 F 3$ & JSF & I...IFALAS & & * & LOAL FAUSE TNTO SFE:ECH EIUF . \\
\hline$\because A 8 A$ & BDi & 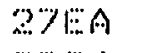 & .96 & WATT & & * & WAIT TILL SFEECH-BUF EMFTY \\
\hline$\therefore A B I$ & BI! & 2766 & .156 & BHL...ANKK & & * & BI..ANK ENTIFE IIISF'AAY \\
\hline$\therefore A 9 \%$ & BII & $2 \% 0$ & $.19 \%$ & UNFACK & & * & SEFEATE NTEBLES TNTO EYTES \\
\hline$\therefore A 9 I$ & Xil & $270 \%$ & JSir: & SAYNUM & & 水 & FFONOUNC:E FACKEEI NUM AY $(X)$ \\
\hline$\therefore A A ?$ & lin & $27 \% 6$ & 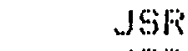 & SFバWD & & 水 & LOAM WOFI TNTO SFEECH BUF. \\
\hline$\therefore A \cap$ & EII & 270 & $.5 \%$ & UNFACK & & * & SFFERATE NIEBLES TNTO EYTES \\
\hline ?AA $A$ & $B \Pi$ & $2 \% \mathrm{CF}$ &.$J S F$ & SAYNIIM & & * & FFONOUNCE FACKEEI NUM AT $\langle X\rangle$ \\
\hline $2 A B \%$ & BII & $27 \% 6$ & $.15 \%$ & SFkWI & & * & LOAI WOFIS TNTO SFEECH BUF \\
\hline $2 A B A$ & Bin & $27 \mathrm{~A} A$ & JSF & WAIT & & * & WAIT TLLL SHEECHWHU EMFTY \\
\hline$* * * *$ & $8 \mathrm{rt}$ & AT OF & TEACHS & WHLOUT TNE & **** & & \\
\hline$\because A C O$ & EII & 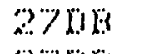 & WEFi & FACK & & * & FACK MUL TIITET INFO \\
\hline$\therefore A C A$ & $\mathrm{BO}$ & $27 \mathrm{x}[\mathrm{n}$ & Jisti & B. S SUH & & * & WNGIGNEI DTNAFYY SUETFACTION \\
\hline$? A 11 \%$ & RII! & $? \% \mathrm{kin}$ & $.15 \%$ & ET Sol.tis & & * & UNGIGNER HTNAFY GUBTFACTION \\
\hline$\therefore A E I$ & Mil & $27 \mathrm{B \%}$ &.$J S F$ & ECIITNC: & & * & INCHEMENT (BCOI) AT $X \& X+1$. \\
\hline $2 A 1 \cdots 3$ & BII & $\therefore 8 \%$ & JSF & BCIINC: & & 米 & INCFEMENT (BCH) AT $X \& X+1$ \\
\hline $2 \mathrm{R} 1 \mathrm{H}$ & $\mathrm{BCI}$ & 2700 & $.5 F$ & SAYUISH & & * & FRONOUNC:E FHOLLE:E \\
\hline
\end{tabular}




\begin{tabular}{|c|c|c|c|c|c|c|}
\hline $21: 23$ & Bil.t & $271.2 \%$ & .55 & IIISPI..AY & $*$ & IOAR FFOH, INTO IISFLAY \\
\hline 2628 & Bli. & 270.3 & JSF & BILANRIIT & * & BIIAK MISSING NO. IN IISF. \\
\hline 2E:3 & $\mathrm{Br}$ & $27 E 7$ & WSF & GETCTO & * & GO GET IITITS FFOM NEYBOAFII \\
\hline 2139 & $\notin 0$ & $2 \% \mathrm{BA}$ & $.1 S F$ & E:FEOR & * & AFFLY NEG . FEEMBACK \\
\hline 2877.3 & Eiri & $27 F 3$ & .195 & L.IFFAUS & * & I.OAD FAUSE INTO GFEECH KUF. \\
\hline $28 \% 6$ & $B !$ & 2700 & $.1 S F$ & SAYIISF & * & FHNOUNCE PROBIEM \\
\hline 2182 & Hil. & $271 \% 9$ & .58 & SGAN & * & DUTFUT:DISF \& TALK \\
\hline 2BBE: & dix! & 27197 & $.5 \mathrm{sin}$ & BCITNC & * & TNCFEMENT (BCII) AT $X \& X+1$ \\
\hline 2899 & lin & 2805 & $.1 S F$ & FICHYr & * & AFFI..Y FOSITTUE FEELEACK \\
\hline $289 F$ & Bin & $2 \div 81$ & $.5 F$ & GENE:FATE & * & GENEFATE: FFOHLEM \\
\hline$\therefore B A 2$ & Hin & $27 A 3$ & $.8 F$ & GEYANS & * & FINI COFFIECT ANSWEF \\
\hline 2021 & Hiil & $27 \times 6$ & J6F & SFliWL & * & LOAL WOFI INTO SFEECH BUF. \\
\hline$\therefore 0 ? 3$ & $\mathrm{BII}$ & 270 & $.15 F$ & BL.ANK & * & BLANK ENTIFE IISFLAY \\
\hline $20 \mathrm{cos}$ & 13i! & $27 F 9$ & JSF & SC:AN & * & OUTFUT:IISF + \& TALK \\
\hline 2025 & ily & 2709 & .161 & IITSFLAY & $*$ & LOAII FFOH, TNTO IIISFLAY \\
\hline 20.31 & $\$ !$ & 270.3 & .65 & BLLANIITY & * & BLANK MISSINO NO. IN IITSF \\
\hline $20.3 \%$ & $\mathrm{HII}$ & 2719 & $.15 \%$ & SCAN & * & OUTFUT:MISF \& TALK \\
\hline$x * x *$ & sta & Mr OF & AlIIEM 6 & GUBFOUTINE ***** & & \\
\hline$\therefore 0 \% 3$ & $B l i$ & 27134 & $.9 F$ & BI:DIALIII & * & Alln $A: B$ TO \\
\hline $20: 94$ & din & 2784 & $.15 F$ & EC:YAMIN & * & AlIII A:E TO LOCO \& $X$ \\
\hline$\therefore C A A$ & Bï & $27 B \%$ & $J S F$ & RCIINC & * & INCFEMENT (ECII) AT $X \& X+1$ \\
\hline
\end{tabular}




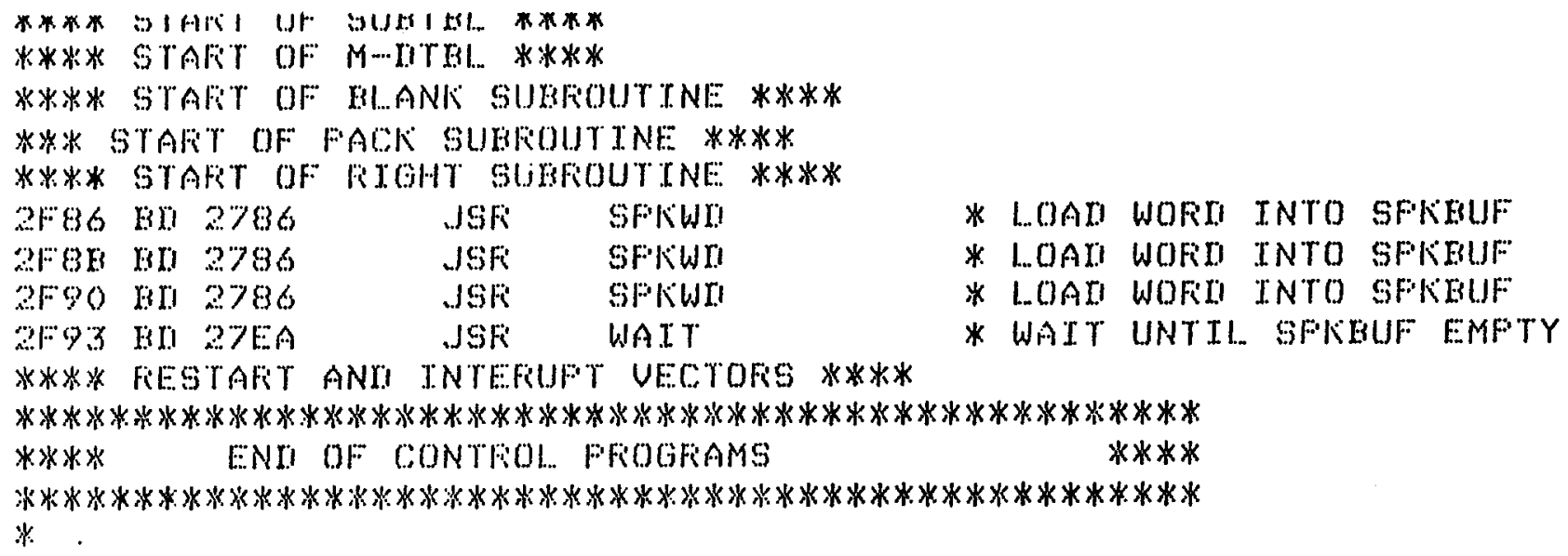




\section{TABLE III}

\section{PROGRAM LISTING}

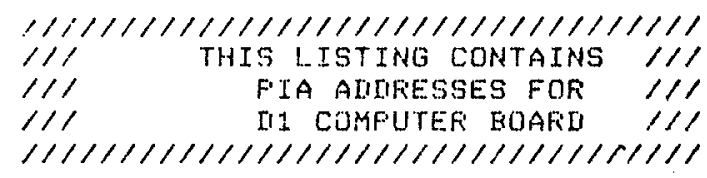


**** END OF INTERUPT FROGFAM ****

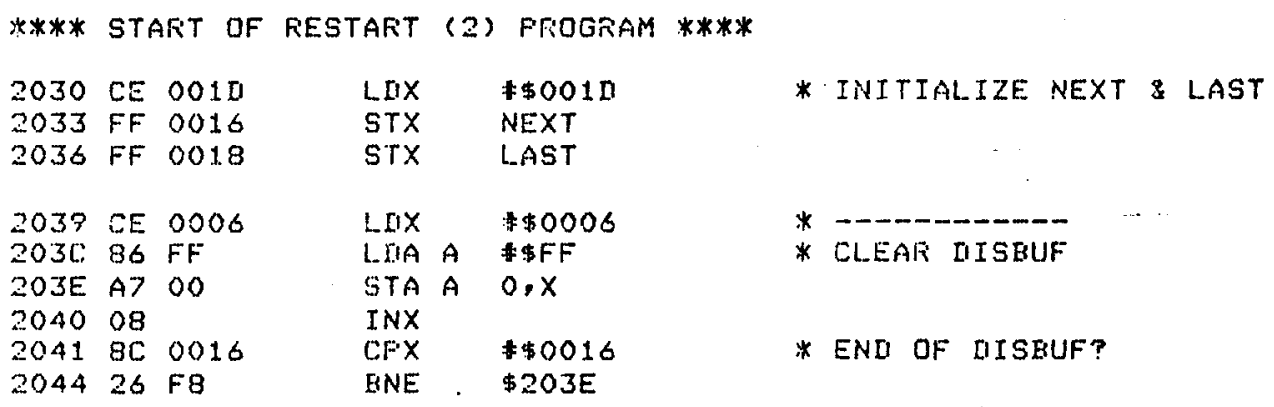

***** ENII OF RESTAFT (2) *****

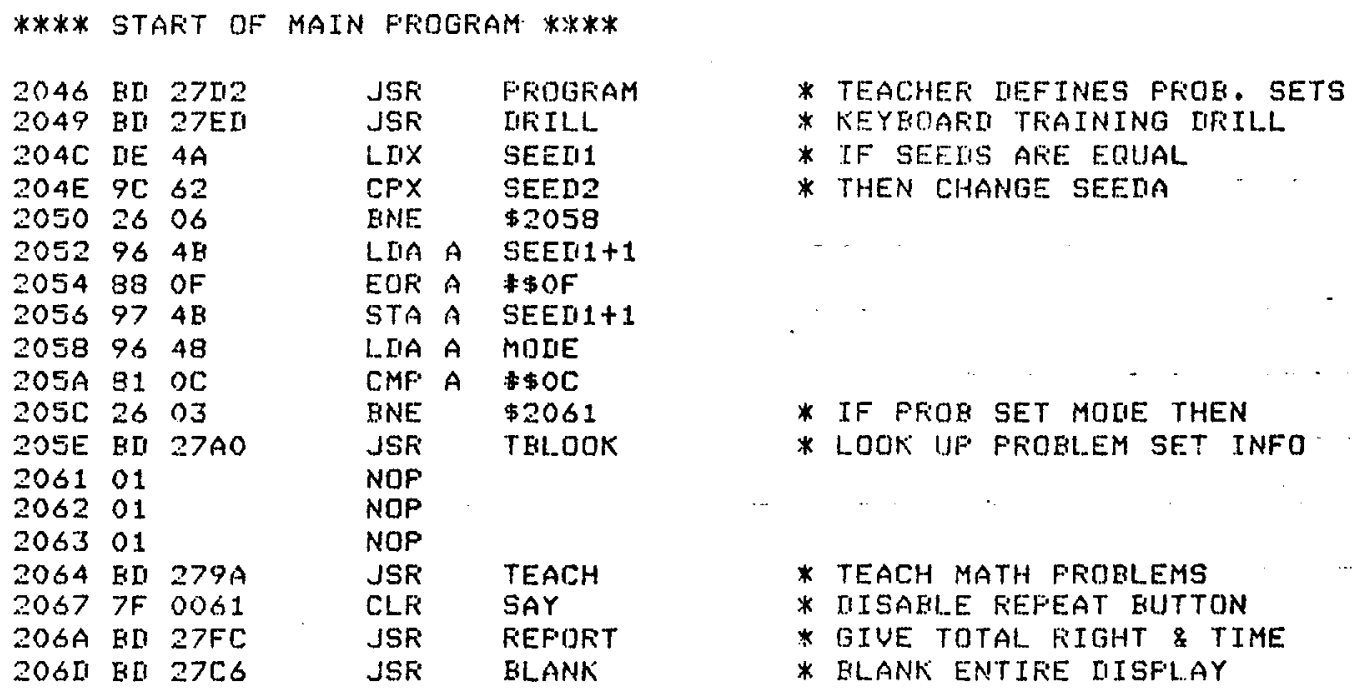




\begin{tabular}{|c|c|c|c|c|c|}
\hline $\begin{array}{l}2070 \\
2072 \\
2075\end{array}$ & $\begin{array}{l}86 \\
\text { BI } \\
\text { CE }\end{array}$ & $\begin{array}{l}3 C \\
27 F S \\
F F F F\end{array}$ & $\begin{array}{l}\text { LDA } \\
\text { JSR } \\
\text { LDX }\end{array}$ & $A$ & $\begin{array}{l}\$ \$ 3 C \\
\text { SFKWI } \\
: \$ F F F F\end{array}$ \\
\hline 2078 & $\mathrm{BD}$ & $27 \mathrm{~F} 9$ & JSR & & SCAN \\
\hline $207 \mathrm{~B}$ & 96 & 00 & LIA & A & KEY \\
\hline $207[1$ & 81 & 17 & CMF & A & $\$ \$ 17$ \\
\hline $207 \mathrm{~F}$ & 26 & E9 & BNE & & $\$ 206 A$ \\
\hline 081 & $7 E$ & $204 C$ & JMF & & $\$ 204 C$ \\
\hline
\end{tabular}

* say "stuf.

* Loali wofir tMto sfeech buf.

* Cal... scan unt tl key fieleased

* INFUT:KEYS OUTFUT:IIISP. \& TALK

* KEY FEFEAT THEN REFEAT fRORS

* ELSE FEFORT

**** END OF MAIN ****

\begin{tabular}{|c|c|c|c|c|c|c|c|c|c|}
\hline $209 \mathrm{~F}$ & $A G$ & 00 & I.IA & $A$ & $0, x$ & & * & CHECK FOF ZERO & \\
\hline $20 A 1$ & 84 & 07 & AND & A & $\$ \$ 07$ & & * & IN BO-E10 & \\
\hline $20 A 3$ & $A A$ & 01 & OFA & A & $1, x$ & & & & \\
\hline $20 \mathrm{AS}$ & 26 & 02 & BNE & & $\$ 2019$ & & & & \\
\hline $20 A 7$ & 63 & 01 & COM & & $1 \cdot x$ & & * & FE:MOUE ZERO & \\
\hline $20 A 9$ & A6 & 00 & LLA & $A$ & $0, x$ & & & & \\
\hline $20 \mathrm{AB}$ & 44 & & L.SR & A & & & & & \\
\hline $2 O A C$ & 44 & & L.SF & A & & & & & \\
\hline $20 A D$ & $A B$ & 00 & EOR & A & $0, x$ & & & & \\
\hline 2OAF & 44 & & LSR & $A$ & & & * & BO:=EO EOF E10 & \\
\hline $2 O B O$ & 69 & 01 & ROL & & $1, x$ & & & & \\
\hline 2082 & 69 & 00 & FOL & & $0, x$ & & & & \\
\hline $20 B 4$ & AG & 00 & LLIA & $A$ & $0, x$ & & $*$ & DESTROY FREIICTAEL ITY & \\
\hline $\begin{array}{l}2086 \\
2088\end{array}$ & $\begin{array}{l}88 \\
84\end{array}$ & $\begin{array}{l}\text { AS } \\
03\end{array}$ & $\begin{array}{l}\text { EOR } \\
\text { ANII }\end{array}$ & $\begin{array}{l}A \\
A\end{array}$ & $\begin{array}{l}\$ \$ A 5 \\
\$ \$ 03\end{array}$ & & & - & \\
\hline 2OEA & 36 & & $\mathrm{FSH}$ & A & & & & & \\
\hline $\begin{array}{l}20 \mathrm{BB} \\
20 \mathrm{BI}\end{array}$ & $\begin{array}{l}A 6 \\
88\end{array}$ & $\begin{array}{l}0.1 \\
45\end{array}$ & $\begin{array}{l}\text { LOA } \\
\text { EOFi }\end{array}$ & $\begin{array}{l}A \\
A\end{array}$ & $\begin{array}{l}1, x \\
1 \$ A 5\end{array}$ & & & & \\
\hline $\begin{array}{l}20 \mathrm{BF} \\
20 \mathrm{C2}\end{array}$ & $\begin{array}{l}\mathrm{CE} \\
\mathrm{IF}\end{array}$ & $\begin{array}{l}0000 \\
75\end{array}$ & $\begin{array}{l}\operatorname{LIXX} \\
\text { STX }\end{array}$ & & $\begin{array}{l}\$ \$ 0000 \\
\text { UALUE }\end{array}$ & & * & CLF RUNNING TOTAL. & \\
\hline 2004 & $F E$ & 27AF & L.LIX & & $\$ 27 A F$ & & * & STAFTING AIIIR OF BCD & TABLE \\
\hline 2007 & IfF & 04 & STX & & XSAV & & & & \\
\hline 2009 & $8 \mathrm{II}$ & 10 & ESR & & $\$ 20118$ & & & & \\
\hline $20 \mathrm{CB}$ & 32 & & FUL & A & & & & & \\
\hline $20 \mathrm{cc}$ & $8 \pi$ & On & BSR & & $\$ 200 \mathrm{~B}$ & & & - & \\
\hline $20 C E$ & $C E$ & 8000 & LIIX & & $\$ \$ 8000$ & & * & UALUE =MINUS ZERO? & \\
\hline 2001 & $9 \mathrm{C}$ & 75 & $C F X$ & & UALUE & & & & - \\
\hline $20[13$ & 26 & 05 & BNE & & $\$ 20[1 A$ & & & & \\
\hline 2005 & $C E$ & 8421 & LIIX & & $\$ \$ 8421$ & & * & VALUE $=-421$ & \\
\hline 2008 & LIF & 75 & STX & & UALUE & & & & \\
\hline
\end{tabular}




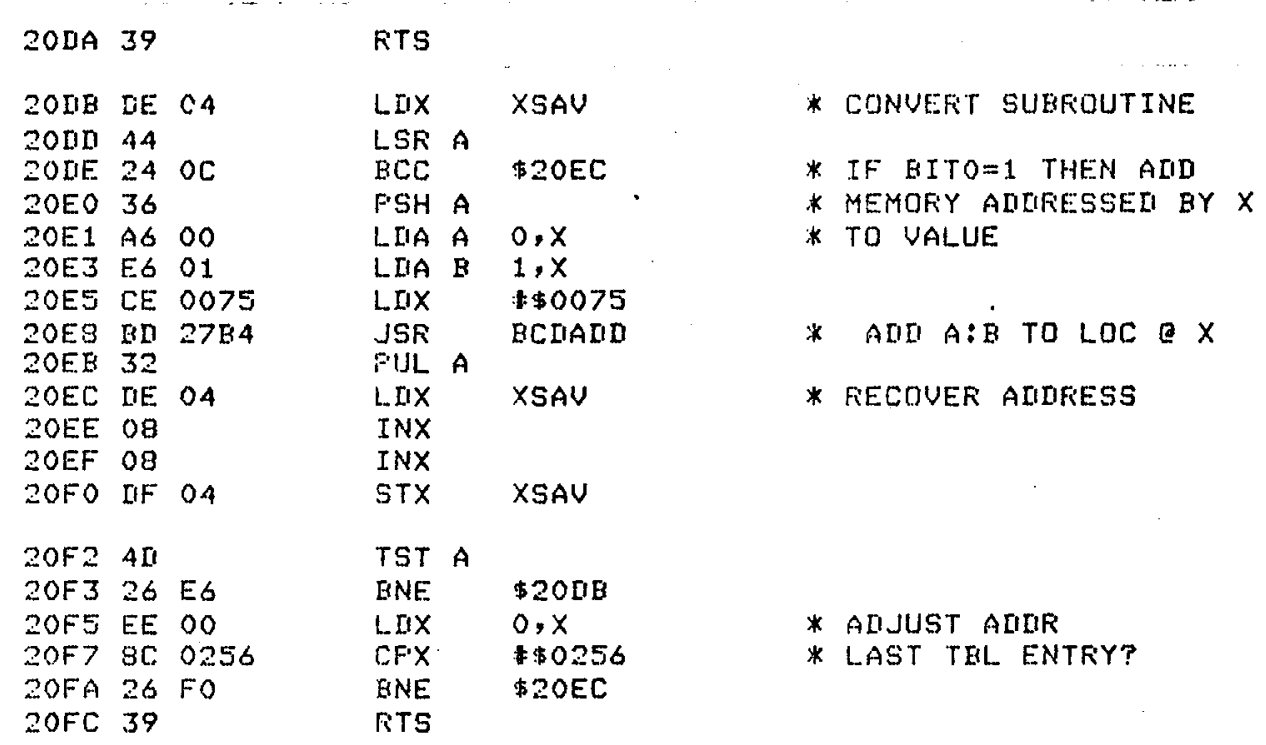

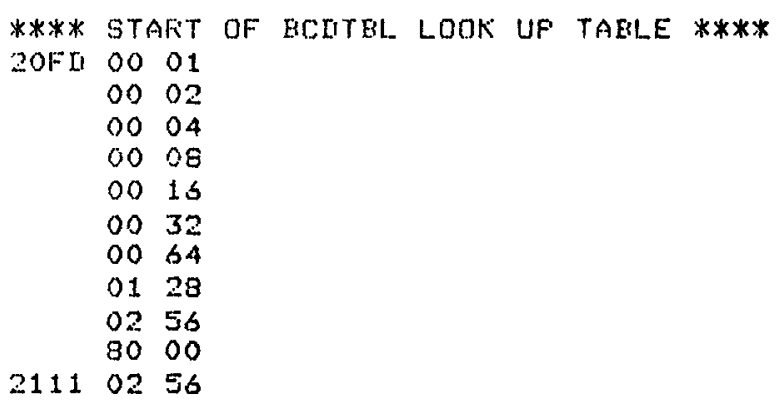

**** ENI OF BCOTBL ****

**** STAFT OF OFGEN SUEROUTINE ****

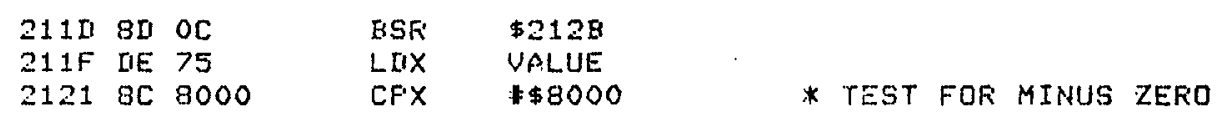




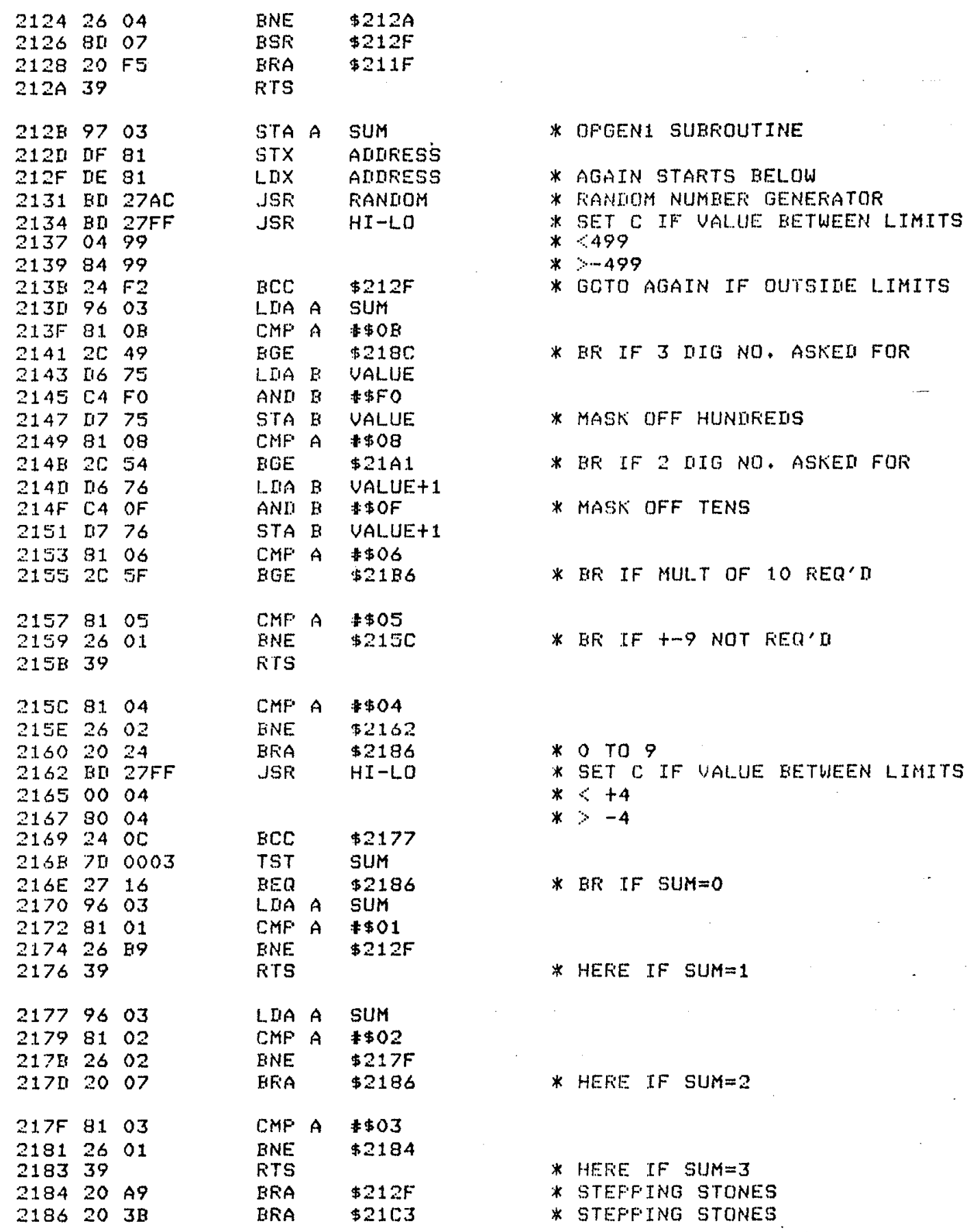




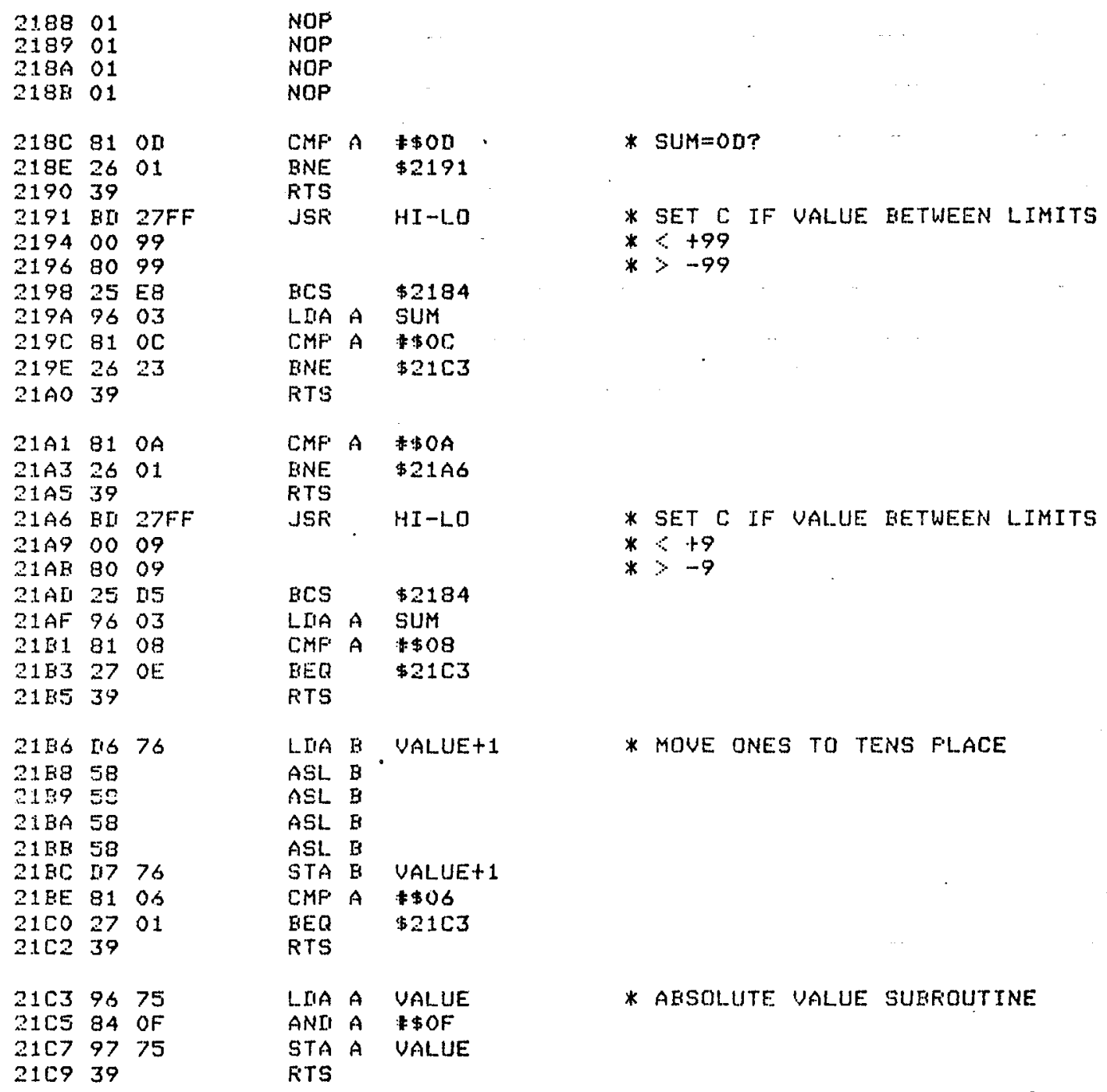

**** START OF HI-LO SUEROUTINE ****

21CA BII 2802 JSF LOALX LOAI X FROM INLINE DATA

21 CI $\mathrm{BI}$ 279D JSF COMPARE * COMFARE (BCD) VALUE \& $X$

$211102 \mathrm{~B} \quad \mathrm{O} \quad \mathrm{BMI} \quad \$ 21 \mathrm{II}$

2111227 O5 $\quad$ BEQ $\$ 21119$ 


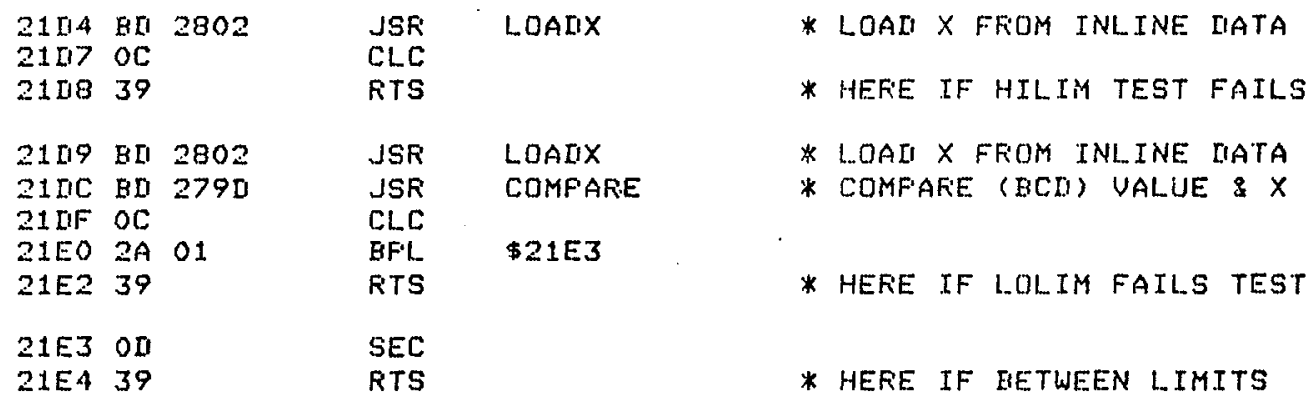

**** START OF IIOWN UTILITY FFOGFAM ****

\begin{tabular}{|c|c|c|c|c|c|}
\hline $220 \mathrm{~F}$ & $F E$ & 2202 & $\operatorname{LI} x$ & & $\$ 2202$ \\
\hline 2212 & 08 & & INX & & \\
\hline 2213 & 08 & & INX & & \\
\hline 2214 & $F F$ & 2202 & STX & & $\$ 2202$ \\
\hline 2217 & $F E$ & 2200 & L_LXX & & $\$ 2200$ \\
\hline $221 \mathrm{~A}$ & AG & 00 & LIIA & $A$ & $0, x$ \\
\hline 2210 & 08 & & $I N X$ & & \\
\hline 2211 & $\mathrm{BC}$ & 2202 & CFX & & $\$ 2202$ \\
\hline 2220 & 27 & $O E$ & $B E Q$ & & $\$ 2230$ \\
\hline 2222 & FF & 2200 & STX & & $\$ 2200$ \\
\hline 2225 & $F E$ & 2204 & LIIX & & $\$ 2204$ \\
\hline 2228 & A7 & 00 & STA & A & $0, x$ \\
\hline $222 \mathrm{~A}$ & 08 & & INX & & \\
\hline $222 \mathrm{H}$ & FF & 2204 & STX & & $\$ 2204$ \\
\hline $222 E$ & 20 & E) & EFA & & $\$ 221$ \\
\hline
\end{tabular}

**** STAFT OF DTSFLAY SUBROUTINE ****

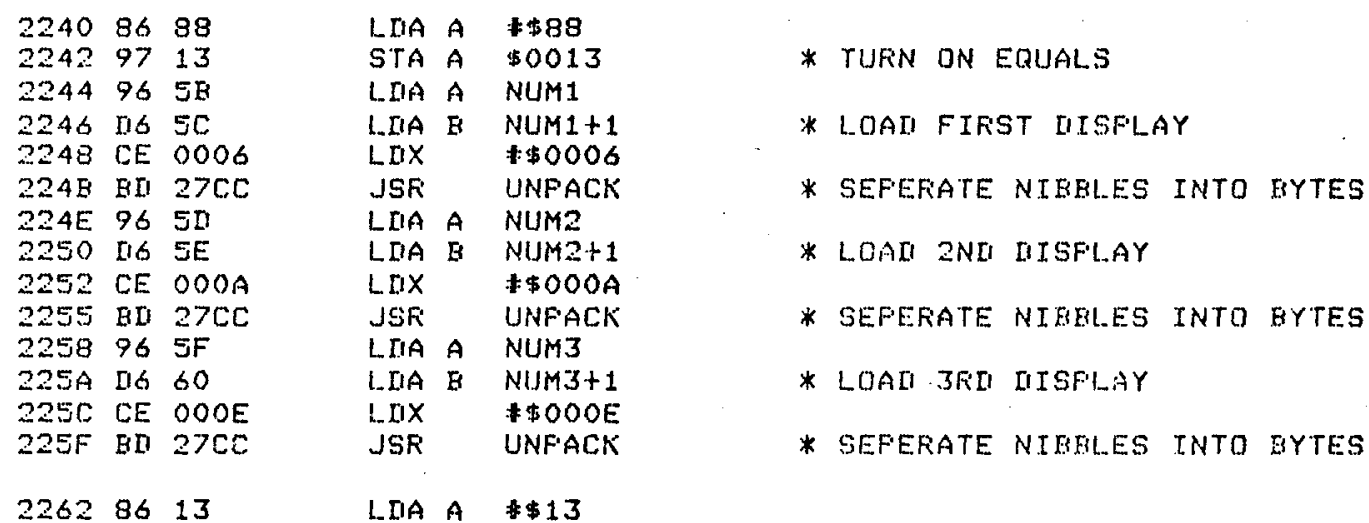




\begin{tabular}{|c|c|c|c|c|c|}
\hline $\begin{array}{l}2264 \\
2266 \\
2268\end{array}$ & $\begin{array}{l}\text { C6 } \\
91 \\
27\end{array}$ & $\begin{array}{l}E F \\
50 \\
04\end{array}$ & $\begin{array}{l}\text { LIA } \\
\text { CMF } \\
\text { BEQ }\end{array}$ & $\begin{array}{l}B \\
A\end{array}$ & $\begin{array}{l}\text { \$WEF } \\
\text { OPSIGN } \\
\text { \$226E }\end{array}$ \\
\hline $\begin{array}{l}228 A \\
226 B\end{array}$ & $\begin{array}{l}4 A \\
58\end{array}$ & & $\begin{array}{l}\text { IEC } \\
\text { ASL }\end{array}$ & $\begin{array}{l}A \\
B\end{array}$ & \\
\hline 2280 & 20 & 58 & BFAA & & $\$ 2266$ \\
\hline $\begin{array}{l}226 E \\
2270\end{array}$ & $\begin{array}{l}07 \\
01\end{array}$ & 12 & $\begin{array}{l}\text { STA } \\
\text { NOP }\end{array}$ & $B$ & $\$ 0012$ \\
\hline 2271 & 01 & & NOF & & \\
\hline 2272 & 01 & & NOP & & \\
\hline 2273 & $C E$ & 0007 & LIIX & & $\$ 0007$ \\
\hline 2276 & 80 & $\mathrm{OB}$ & BSF & & $\$ 2283$ \\
\hline 2278 & CE & $000 E$ & $\operatorname{LIIX}$ & & $\$ \$ 000 \mathrm{~B}$ \\
\hline $22>\mathrm{B}$ & $8 \mathrm{I}$ & 06 & $B S R$ & & $\$ 2283$ \\
\hline 2271 & $C E$ & $000 \mathrm{~F}$ & L. DIX & & $\$ \$ 000 \mathrm{~F}$ \\
\hline $\begin{array}{l}2280 \\
2292\end{array}$ & $\begin{array}{l}80 \\
39\end{array}$ & 01 & $\begin{array}{l}\text { BSR } \\
\text { FIS }\end{array}$ & & $\$ 2283$ \\
\hline 2283 & 61 & 00 & TST & & $0 . x$ \\
\hline 2285 & 26 & 08 & ENE & & $\$ 228 \mathrm{~F}$ \\
\hline 2287 & 63 & 00 & COM & & $0, x$ \\
\hline 2289 & 60 & 01 & TST & . & $1, x$ \\
\hline $228 \mathrm{~B}$ & 26 & 02 & ENE & & $\$ 228 F$ \\
\hline 2280 & 63 & 01 & COM & & $1, x$ \\
\hline $228 \mathrm{~F}$ & 39 & & FTS & & \\
\hline
\end{tabular}

* loal ofefiation sign

* Lending zero sufFress

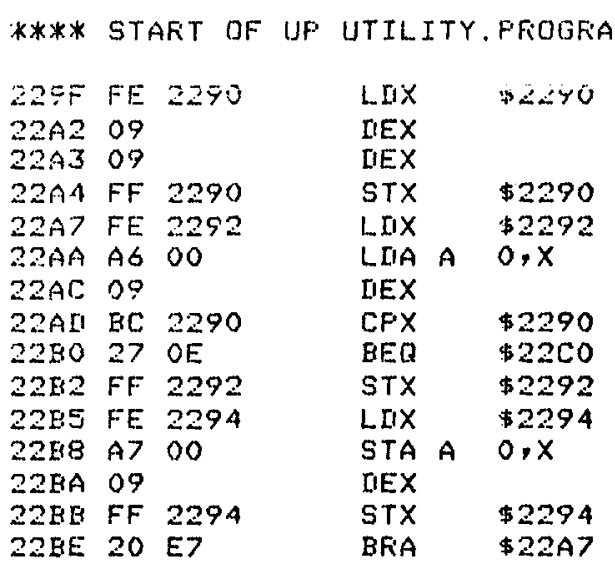

**** START OF BCDANI SUEFIOUTINE ****

220736

$22 \mathrm{C8} 17$
PSH A

TEA 


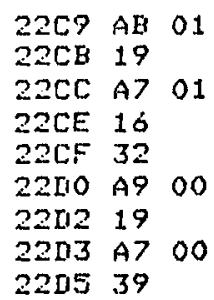

$$
\begin{array}{ll}
\text { AIII A } & 1, x \\
\text { IIAA } & \\
\text { STA A } & 1, x \\
\text { TAB } & \\
\text { FUL A } & \\
\text { AIIC A } & 0, X \\
\text { IIAA } & \\
\text { STA A } & 0, X \\
\text { RTS } &
\end{array}
$$

* ALII LOW DIYTES

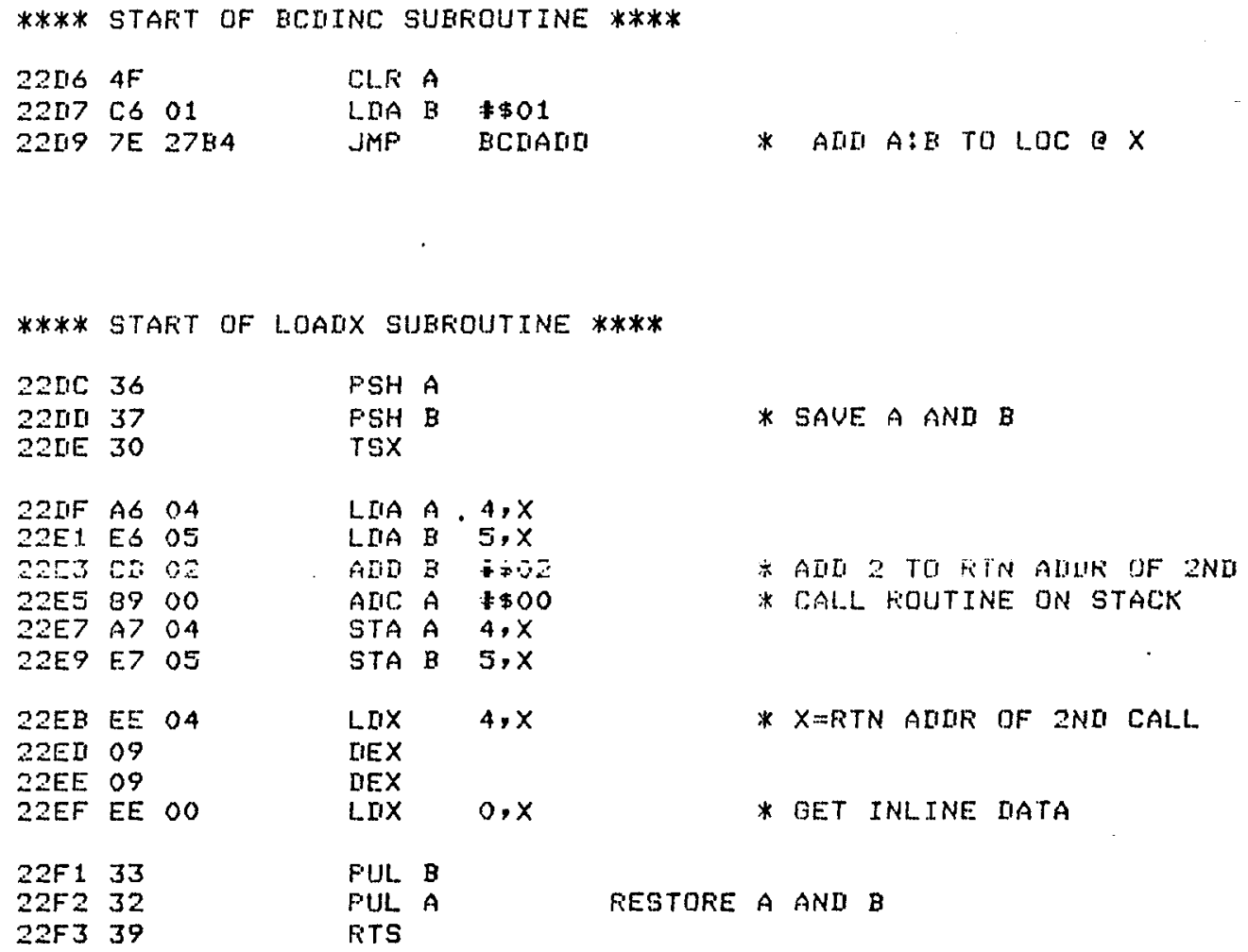

FUL. B

FUL A REgTORE A AND B

FTS

**** START OF FROGFAM SUBROUTINE ****

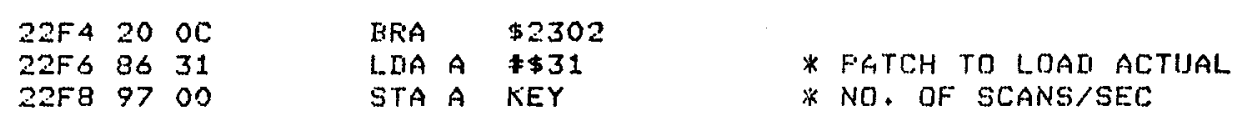




\begin{tabular}{|c|c|c|c|c|c|c|c|}
\hline $22 F A$ & 39 & & Fits & & & & \\
\hline $22 F E$ & 97 & 49 & STA & $A$ & OFTION & $*$ & FATCH TO LOAL OPTION \\
\hline $22 \mathrm{FII}$ & LE & $1 \mathrm{~A}$ & LIIX & & SCNTIM & * & ANDI SEEI2 \\
\hline $22 F F$ & [IF & 62 & sTx & & SEEL2 & & \\
\hline 2301 & 39 & & RTS & & - & & - \\
\hline 2302 & CE & 0001 & L.IXX & & $\$ \$ 0001$ & & \\
\hline 2305 & LIF & 46 & STX & & RATE & $*$ & TUFIN SCAN RATE TO MAX \\
\hline 2307 & $\begin{array}{l}86 \\
97\end{array}$ & $\begin{array}{l}10 \\
14\end{array}$ & $\operatorname{LrIA}$ & $A$ & $\$ \$ 10$ & & TUEN MOTIF FEOMET IN \\
\hline $\begin{array}{l}2309 \\
230 \mathrm{E}\end{array}$ & 80 & $\begin{array}{l}14 \\
27 E_{1}\end{array}$ & $\begin{array}{l}\text { SIA } \\
\text { JSF }\end{array}$ & & $\begin{array}{l}\$ 0014 \\
2 B E E F\end{array}$ & $*$ & $\begin{array}{l}\text { TURN MOIE FFOMFT ON } \\
\text { SAY : } 30 \text { FLEASE. }\end{array}$ \\
\hline $\begin{array}{l}230 E \\
230 E\end{array}$ & $C E$ & FFFE & LIIX & & $\begin{array}{l}\text { FBEEF } \\
\text { \#FFFE }\end{array}$ & * & SAY "GO FLEASE \\
\hline 2311 & 80 & $27 F 9$ & JSR & & SCAN & * & INFUT:KEYS OUTFUT:[IISP. \& TALK \\
\hline 2314 & 96 & 00 & LIIA & $A$ & KEY & & \\
\hline $\begin{array}{l}2316 \\
2319\end{array}$ & {$[10$} & $\begin{array}{l}27 F 0 \\
00\end{array}$ & JSR & $A$ & $\begin{array}{l}\text { SFKEY } \\
\text { KEY }\end{array}$ & * & ECHO KKEY NAME \\
\hline 2318 & 81 & $O B$ & $\mathrm{CMF}$ & $A$ & $\$ \$ O B$ & * & OH=BOUNDEI MODE \\
\hline $231 \mathrm{II}$ & 27 & 04 & AEQ & & $\$ 2323$ & & \\
\hline $231 \mathrm{~F}$ & 81 & OC & CMF & A & $\$ \$ O C$ & * & $O C=$ LEVEL MOLE \\
\hline 2321 & 26 & E4 & ENE & & $\$ 2307$ & & \\
\hline 2323 & 97 & 48 & STA & A & MOIIE & & \\
\hline 2325 & $\mathrm{DE}$ & $1 \mathrm{~A}$ & $\operatorname{LIIX}$ & & SCNTIM & & \\
\hline $\begin{array}{l}2327 \\
2329\end{array}$ & $\begin{array}{l}\text { [IF } \\
86\end{array}$ & $\begin{array}{l}4 A \\
20\end{array}$ & $\begin{array}{l}\text { STX } \\
\text { LIIA }\end{array}$ & A & $\begin{array}{l}\text { SEEDI } \\
\$ \$ 20\end{array}$ & $*$ & LUAD FIANLIOM NO. SEED \\
\hline 2325 & 97 & 14 & STA & A & $\$ 0014$ & * & FROMFT OFTTON \\
\hline $232 \pi$ & EII & 27E1 & JSF & & 2EEEF & * & SAY "GO FLEASE" \\
\hline 2330 & $\mathrm{CE}$ & FFFE & LIIX & & I\$FFFE & & \\
\hline 2333 & BII & $27 F 9$ & JSFi & & SCAN & * & INFUT:KEYS OUTFUT:IISSF, \& TALK \\
\hline 2336 & 96 & $\infty 0$ & LIIA & A & KEY & & \\
\hline 2338 & $\mathrm{BL}$ & $27 F 0$ & JSF & & SFKKEY & $*$ & ECHO KEYY NAME \\
\hline 2338 & 96 & $\infty 0$ & LIIA & A & KEY & & \\
\hline 2335 & $\begin{array}{l}31 \\
2 n\end{array}$ & OI & $\begin{array}{l}\text { CMF } \\
\text { BLLT }\end{array}$ & A & $\begin{array}{l}\$ \$ 0 \text { II } \\
\$ 2329\end{array}$ & $*$ & OD=TIMEI OFTIOM KEY \\
\hline 2341 & 81 & OF & CMP & A & \# OF & $*$ & OF $=$ FOWEF OFTION KEY \\
\hline 2343 & $2 E$ & E4 & BGT & & $\$ 2329$ & & \\
\hline 2345 & 80 & B4 & BSF & & $\$ 22 \mathrm{FE}$ & $*$ & TO LOAI SEEII \& OFTION FATCH \\
\hline 2347 & CE & 0053 & $\operatorname{LIIX}$ & & $\$ \$ 0053$ & & \\
\hline $234 A$ & [IF & 46 & Stx & & RATE & * & FESTOFE: NORMAL SCAN RATE \\
\hline $234 \mathrm{C}$ & 96 & 49 & LDA & A & OFTION & & \\
\hline $\begin{array}{l}234 E \\
2350\end{array}$ & $\begin{array}{l}81 \\
27\end{array}$ & $\begin{array}{l}\text { OF } \\
3 E\end{array}$ & $\begin{array}{l}\text { CMF } \\
E E Q\end{array}$ & A & $\begin{array}{l}+\$ \text { OF } \\
\$ 238 \mathrm{D}\end{array}$ & * & OFTION = FOWER? \\
\hline 2352 & 86 & 30 & LIIA & A & $\$ \$ 30$ & & \\
\hline 2354 & 97 & 14 & STA & $A$ & $\$ 0014$ & $*$ & FROMPT TIME LIMIT \\
\hline 2356 & $\mathrm{BD}$ & 27E 1 & JSF & & 2BEEP & * & SAY " \\
\hline 2359 & $C E$ & FFFF & LIXX & & \$FFFF & & \\
\hline $235 \mathrm{C}$ & $\mathrm{BD}$ & $27 E 7$ & JSR & & GETDIG & $*$ & GO GET IIIGITS FRDM KEYBOARD \\
\hline $235 \mathrm{~F}$ & $C E$ & $004 C$ & LLIX & & $\$ \$ 004 C$ & & \\
\hline 2362 & E0 & $27 D E$ & JSR & & MINTOEI & $*$ & CONUERT MMM:SS TO EIN. SECS \\
\hline 2365 & 96 & 49 & L.IIA & A & OFTION & & \\
\hline 2367 & 81 & OE & CMP & A & $\$ O E$ & $*$ & OFTION=SFEED? \\
\hline 2369 & 26 & 22 & BNE & & $\$ 238 \pi$ & & \\
\hline
\end{tabular}




\begin{tabular}{|c|c|c|c|c|c|c|c|c|}
\hline $\begin{array}{l}236 \mathrm{~B} \\
236 \mathrm{E}\end{array}$ & $\begin{array}{l}\text { FE } \\
\text { UIF }\end{array}$ & $\begin{array}{l}004 C \\
04\end{array}$ & $\begin{array}{l}\text { LIXX } \\
\text { STX }\end{array}$ & & $\begin{array}{l}\text { TIMLIM } \\
X S A U\end{array}$ & & . & \\
\hline 2370 & $8 \Pi$ & 84 & BSR & & $\$ 22 F 6$ & & & \\
\hline 2372 & 70 & 0000 & TST & & KEY & * & AIII TIMLIM TO SELF 50 TIMES & \\
\hline 2375 & 27 & 16 & EEO & & $\$ 2381$ & * & TO GET NUMEEF OF SCANS/FROE & \\
\hline 2377 & $\overline{C E}$ & $004 C$ & LIIX & & $\$ \$ 004 C$ & & & \\
\hline $237 \mathrm{~A}$ & 96 & 04 & LIIIA & A & XSAU & & & \\
\hline 2370 & 116 & 05 & LIA & E & $X S A V+1$ & & & \\
\hline $23>E$ & $\mathrm{BO}$ & 27118 & JSF & & DIAIID & * & K TWO BYTE BINAFY ADD & \\
\hline 2381 & 25 & 05 & $\mathrm{BCS}$ & & $\$ 2388$ & & & \\
\hline 2383 & $7 A$ & 0000 & DEC & & KEY & & & \\
\hline 2386 & 20 & $E A$ & BFA & & $\$ 2372$ & & & \\
\hline 2388 & $C E$ & FFFF & LIIX & & *\$FFFF & * & SET TIME LIMIT TO INFINITY & \\
\hline $238 B$ & af & $4 \mathrm{C}$ & STX & & TIMLIM & & & \\
\hline 2380 & 96 & 49 & LIIA & $A$ & OPTION & & & \\
\hline $\begin{array}{l}238 F \\
2391\end{array}$ & $\begin{array}{l}81 \\
27\end{array}$ & $\begin{array}{l}\text { OII } \\
13\end{array}$ & $\begin{array}{l}\text { CMF } \\
\text { EEQ }\end{array}$ & A & $\begin{array}{l}\$ \$ O[1 \\
\$ 23 A 6\end{array}$ & * & TLMED? & \\
\hline 2393 & 86 & 40 & LIIA & A & $\# \$ 40$ & & & \\
\hline $\begin{array}{l}2395 \\
2397\end{array}$ & 97 & $\begin{array}{l}14 \\
27 E_{1}\end{array}$ & $\begin{array}{l}\text { STA } \\
\text { JSF: }\end{array}$ & $A$ & $\begin{array}{l}\$ 0014 \\
2 B E E F\end{array}$ & $\begin{array}{l}* \\
*\end{array}$ & $\begin{array}{l}\text { PFOMFT NO. OF FROELEMS } \\
\text { SAY "GO FLEASE" }\end{array}$ & \\
\hline $239 A$ & CE & FFFF & LIIX & & $*$ \$FFF & & & \\
\hline 2390 & $\mathrm{BO}$ & 2フE & $J S F$ & & GETIIIG & $*$ & GO GET IIIGITS FKOM KEYYBOARD & \\
\hline $23 A O$ & CE & $004 E$ & Lox & & $\$ \$ 004 E$ & & & \\
\hline $23 A 3$ & $\mathrm{BD}$ & $27 \mathrm{IIE}$ & $J S F$ & & FACK & * & FACK MULTIUCGIT INFO & \\
\hline $23 A 6$ & 86 & 50 & LIMA & $A$ & $\$ 50$ & & & \\
\hline $23 \mathrm{AB}$ & 97 & 14 & STA & $A$ & $\$ 0014$ & * & FROMFT OFERATION SIGN & \\
\hline $\begin{array}{l}23 A A \\
3 Z A R\end{array}$ & $B D$ & $\begin{array}{l}\text { ZTE. } \\
\text { FFFF }\end{array}$ & JSF & & $\begin{array}{l}\text { 2BEEF } \\
+ \text { AFFF }\end{array}$ & $*$ & "SAY "GO FLEASE" & \\
\hline 2380 & $\mathrm{BII}$ & $27 F 9$ & JSF & & SCAN & 莎 & OUTFLIT: IIISF \& & TALK \\
\hline $\begin{array}{l}2343 \\
2385\end{array}$ & $\begin{array}{l}96 \\
81\end{array}$ & $\begin{array}{l}00 \\
27 F 0\end{array}$ & $\begin{array}{l}\text { L.IIA } \\
\text { JSFR }\end{array}$ & $A$ & $\begin{array}{l}\text { KEY } \\
\text { SFKEY }\end{array}$ & $*$ & ECHO KEY NAME & \\
\hline $23 \mathrm{BB}$ & 96 & 00 & LIIA & $A$ & KEY & & & \\
\hline $\begin{array}{l}23 \mathrm{EA} \\
23 \mathrm{BC}\end{array}$ & $\begin{array}{l}81 \\
20\end{array}$ & $\begin{array}{l}10 \\
\text { E8 }\end{array}$ & $\begin{array}{l}\text { CMF } \\
\text { BLT }\end{array}$ & $A$ & $\begin{array}{l}\$ 110 \\
\$ 23 A 6\end{array}$ & $*$ & CHECK FOF LEGAL KEY & \\
\hline $238 E$ & 81 & 13 & Cirf & $A$ & $\$ 13$ & & & \\
\hline 2300 & $2 E$ & $E 4$ & $\mathrm{EGT}$ & & $\$ 23 A B$ & & & \\
\hline $23 \mathrm{C2}$ & 97 & 50 & STA & $A$ & OPSIGN & & & \\
\hline 2364 & 86 & 60 & L.DA & $A$ & $\$ \$ 60$ & & & \\
\hline 2316 & 97 & 14 & STA & A & $\$ 0014$ & $*$ & FrOMFT MISSTNG NO. & \\
\hline $23 \mathrm{C8}$ & $\mathrm{BII}$ & 27E 1 & JSR & & ZBEEF & * & SAY "OO PLEASE. & \\
\hline $23 C E$ & $C E$ & FFFF & LIIX & & FFFF & & & \\
\hline $23 C E$ & $\mathrm{BI}$ & $27 E 7$ & JSR & & GETIIG & * & GO GET IIGITS FFOH KEYBOARD & \\
\hline $23[11$ & $C E$ & 0051 & LIXX & & $\$ 0051$ & & & \\
\hline$2 3 \longdiv { 1 4 }$ & $B I I$ & $270 \mathrm{~B}$ & JSR & & FACK & * & FACK MULTIIIGIT INFO & \\
\hline 23117 & 96 & 48 & LIIIA & $A$ & MOIE & & & \\
\hline 23119 & 81 & $O B$ & CMF & $A$ & $1 \$ O B$ & & & \\
\hline $230 \mathrm{BB}$ & 27 & 14 & BEA & & $\$ 23 F 1$ & * & MODE = BOUNLED? & \\
\hline $23[10$ & 86 & 70 & LIA & A & $\$ \$ 70$ & & & \\
\hline 2306 & 97 & 14 & STA & $A$ & $\$ 0014$ & * & FFIOMFT LEUEL OF IIFFICULTY & \\
\hline
\end{tabular}




\begin{tabular}{|c|c|c|c|c|c|}
\hline $\begin{array}{l}23 E 1 \\
23 E 4\end{array}$ & $B I I$ & $\begin{array}{l}\text { 27E } 1 \\
\text { FFFF }\end{array}$ & JSR & & $\begin{array}{l}\text { 2EEEF } \\
\text { SFEFF }\end{array}$ \\
\hline $23 E 7$ & $\mathrm{BI}$ & 2ᄀE7 & JSF & & GETTIG \\
\hline $23 E A$ & $C E$ & 0053 & $\operatorname{Lnx}$ & & $\$ 0053$ \\
\hline $3 E n$ & BII & $27 \mathrm{IB}$ & JSF & & FACK \\
\hline $23 F O$ & 39 & & FITS & & \\
\hline $23 F_{1}$ & 86 & 80 & LDA & $A$ & $\$ \$ 80$ \\
\hline $23 F 3$ & $B I$ & 2705 & JSR & & GETEM \\
\hline $\begin{array}{l}23 F 6 \\
23 F 9\end{array}$ & $\begin{array}{l}C E \\
B I\end{array}$ & $\begin{array}{l}0053 \\
2711 E\end{array}$ & $\begin{array}{l}\text { LIIX } \\
\text { JSF }\end{array}$ & & $\begin{array}{l}\$ \$ 0053 \\
F A C K\end{array}$ \\
\hline $23 F C$ & 86 & 90 & LIIA & $A$ & $\$ \$ 90$ \\
\hline $23 F E$ & $\mathrm{BI}$ & 2705 & JSR & & GETEM \\
\hline 2401 & $C E$ & 0055 & $\operatorname{LIIX}$ & & $\$ \$ 0055$ \\
\hline 240.4 & BD & $27 \mathrm{nk}$ & JSF & & $F A C K$ \\
\hline $\begin{array}{l}2407 \\
2409\end{array}$ & $\begin{array}{l}86 \\
\text { BII }\end{array}$ & $\begin{array}{l}80 \\
27115\end{array}$ & $\begin{array}{l}\text { LIIA } \\
\text { JSR }\end{array}$ & A & $\begin{array}{l}\$ \$ 80 \\
\text { GETEM }\end{array}$ \\
\hline $.240 \mathrm{C}$ & $C E$ & 0057 & LIIX & & $\$ \$ 0057$ \\
\hline $240 F$ & EII & $2711 \mathrm{~B}$ & JSR & & FACK \\
\hline 2412 & 36 & 90 & LEA & A & $\$ \$ 90$ \\
\hline 2414 & $\mathrm{ED}$ & 27115 & JSR & & GETEM \\
\hline 2417 & CE & 0059 & $\operatorname{LLIX}$ & & $\$ \$ 0059$ \\
\hline $241 A$ & $\mathrm{ELI}$ & $270 \mathrm{BA}$ & JSR & & FACK \\
\hline 24111 & 39 & & RTS & & \\
\hline
\end{tabular}

**** STAFT OF 2BEEF SURFOUTINE *****

\begin{tabular}{|c|c|c|c|c|c|}
\hline 2455 & $\mathrm{BI}$ & $27 E A$ & $J S R$ & & WHIT \\
\hline $2+50$ & 86 & 19 & LLIH & $\mathrm{H}$ & $\div: 19$ \\
\hline$\frac{245 \mathrm{~A}}{245 \mathrm{I}}$ & $\begin{array}{l}80 \\
86\end{array}$ & $\begin{array}{l}27 F 3 \\
3 E\end{array}$ & $\begin{array}{l}J S R \\
\text { I.IIA }\end{array}$ & $A$ & $\begin{array}{l}\text { LIFAUS } \\
* \$ 3 \mathrm{~B}\end{array}$ \\
\hline $245 F$ & $\mathrm{BI}$ & $27 F_{6}$ & JSR & & SFKKWD \\
\hline $\begin{array}{l}2462 \\
2464\end{array}$ & $\begin{array}{l}86 \\
\text { BI }\end{array}$ & $\begin{array}{l}2 F \\
27 F 6\end{array}$ & $\begin{array}{l}\text { LIJA } \\
\text { JSR }\end{array}$ & $A$ & $\begin{array}{l}\text { \$2F } \\
\text { SFKKWD }\end{array}$ \\
\hline 2467 & 39 & & RTS & & \\
\hline
\end{tabular}

**** STAFT OF MINTOEI SUEFOUTINE ****

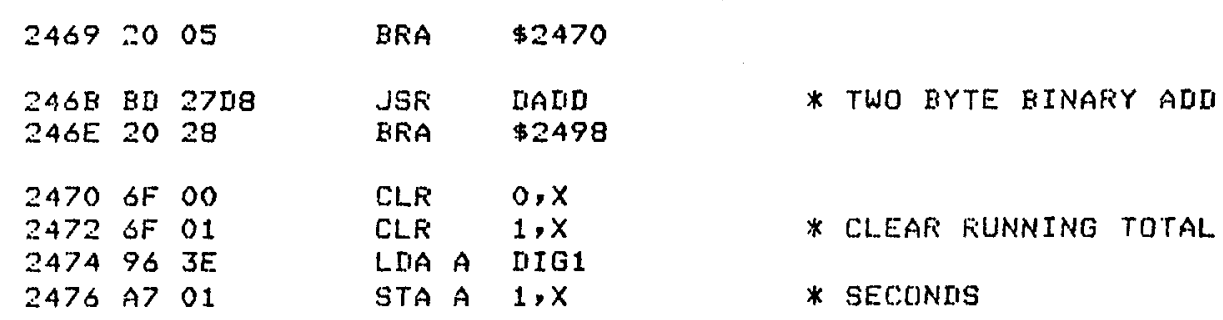

* say "go fleease.

* GO GET IIIGITS FFIOM KEYBOAFD

* packi multigigit info

* FROMFT FOF hILIMI

* prompt scan fofi fiesfonse

* pack multitigett info

* FFOMFT FOF LOLIMI

* promft \& scan fofi fiesponse

* pack multidigit info

* Fromprt far hil tma

* Fromft \& SCAN fOF response

* Fack multidigit info

* PFiOAFT FOF lol IM2

* Frompt \& scan fof fiEsFonge

* fack multegigit info

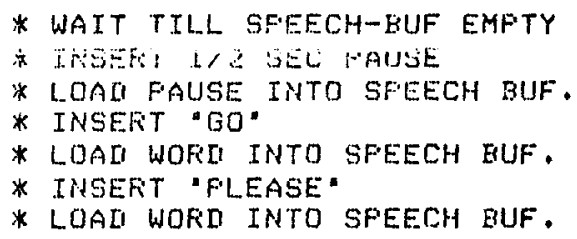




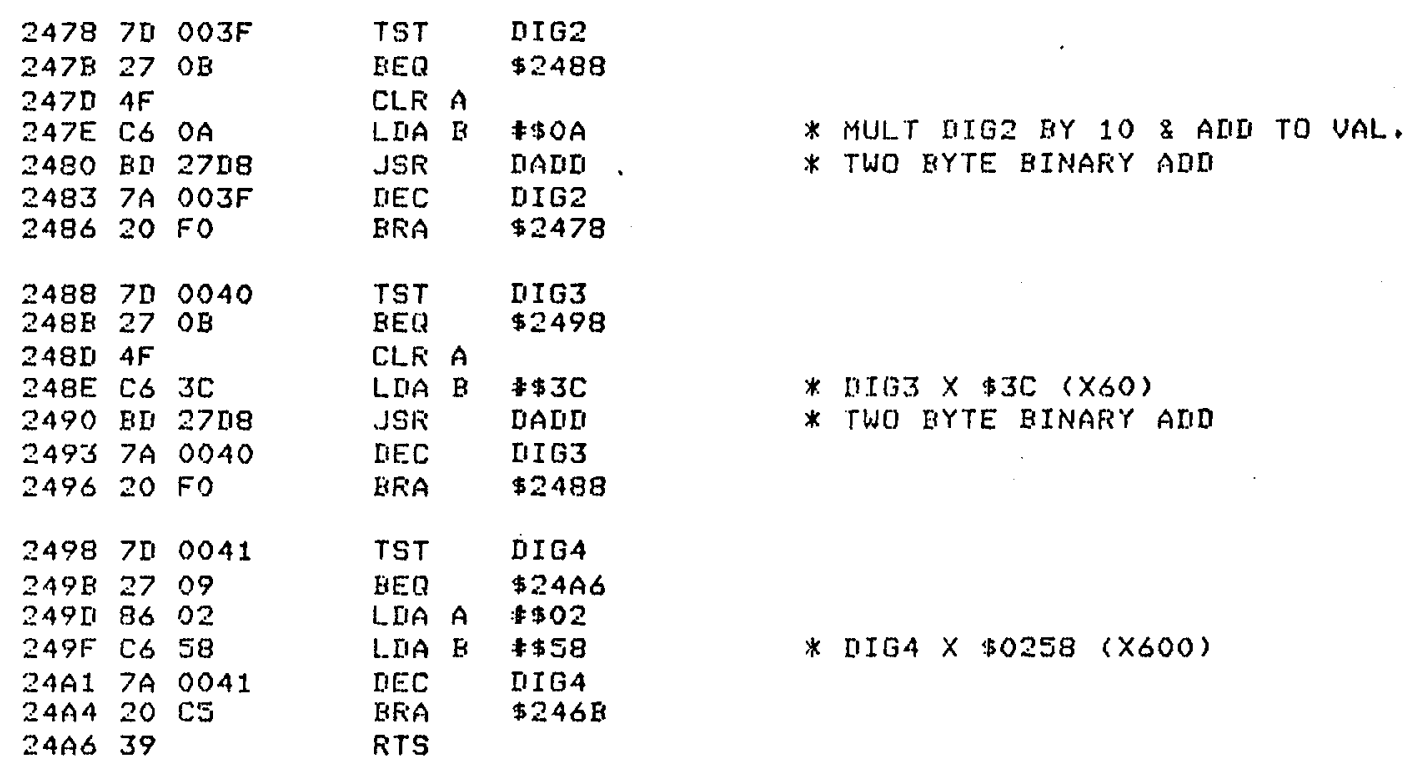

**** STAFT OF SAYNUM SUEROUTINE ****

$\begin{array}{lll}24 A 7 & A 6 & 00 \\ 24 A 9 & E 6 & 01 \\ 24 A B & 4 \Pi & \\ 24 A C & 20 & 42 \\ & & \\ 24 A E & 36 & \\ 24 A F & 86 & 1 F \\ 24 E 1 & B D & 27 F G \\ 24 B 4 & 32 & \\ 24 B 5 & 84 & O F \\ 24 B 7 & 27 & 08 \\ 24 B 9 & B D & 27 F 6 \\ 24 B C & 86 & 1 C \\ 24 B E & 8 D & 27 F 6 \\ & & \\ 24 C 1 & 86 & 0 A \\ 24 C 3 & B D & 27 F 3 \\ 24 C 6 & 37 & \\ 24 C 7 & 54 & \\ 24 C 8 & C 1 & 10 \\ 24 C A & 33 & \\ 24 C E & 20 & 0 C \\ 24 C D & 17 & \end{array}$

$\begin{array}{ll}\text { LIA A } & 0, X \\ \text { LIA B } & 1, X \\ \text { TST A } & \\ \text { GRA } & \$ 24 F O \\ \text { FSH A } & \\ \text { LUA A } & \$ 1 F \\ \text { JSR } & \text { SFKWI } \\ \text { FUL A } & \\ \text { AND A } & \$ \$ O F \\ \text { FEQ } & \$ 24 C 1 \\ \text { JSR } & \text { SFKWI } \\ \text { LIIA A } & \$ \$ 1 C \\ \text { JSF } & \text { SFKWD } \\ \text { LIA A } & \$ \$ O A \\ \text { JSR } & \text { LIFAUS } \\ \text { FSH B } & \\ \text { LSR B } & \\ \text { CMP B } & \$ \$ 10 \\ \text { FUL B } & \\ \text { BLT } & \$ 24 I 9 \\ \text { TEA } & \end{array}$

* move no. to a:B

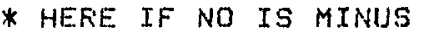

* say "minus.

* load wofí INTO SFEech guF.

* BF IF NO HUNAREIS

* Luafi wofid into sfeech buf. * "HUNDFEE"

* loar wofio into sfeech buf.

* i ls sec pelay

* loair faluse into sfeech buf.

* bRanch if teEns 


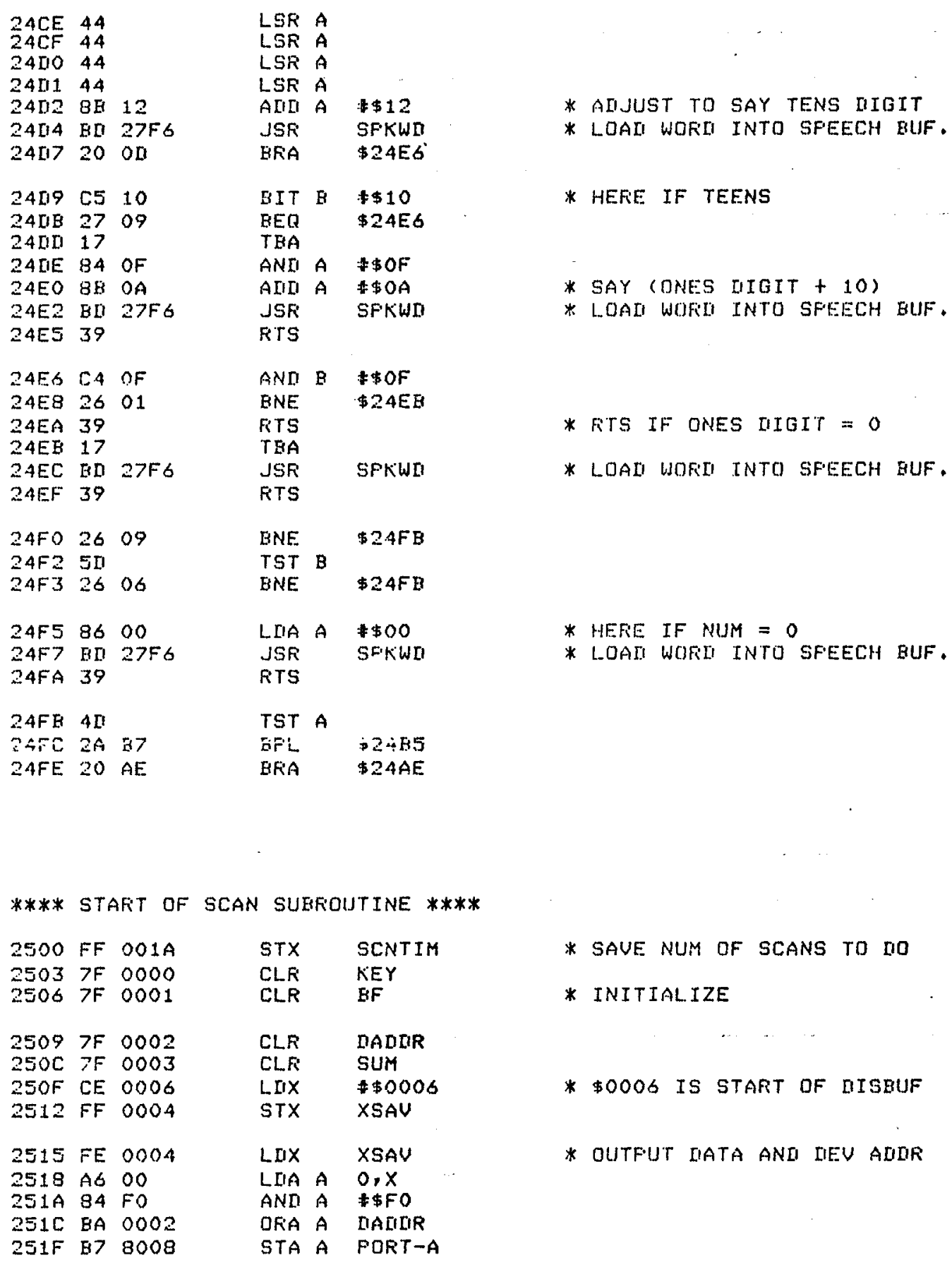




\begin{tabular}{|c|c|c|c|c|c|c|c|}
\hline $\begin{array}{l}2522 \\
2524\end{array}$ & $\begin{array}{l}80 \\
01\end{array}$ & 20 & $\begin{array}{l}\text { BSR } \\
\text { NOP }\end{array}$ & & $\$ 2551$ & * & STROEE IIECOLIER \& DELAY \\
\hline 2525 & 01 & & NOP & & & & . \\
\hline 2526 & 01 & & NOP & . & & & \\
\hline 2527 & 84 & 03 & AND & $A$ & $\$ 03$ & * & MASK OFF ALL BUT KEY BITS \\
\hline 2529 & 36 & & FSH & A & & & \\
\hline $252 \mathrm{~A}$ & 44 & & LSR & $A$ & 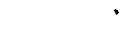 & & \\
\hline $52 \mathrm{~B}$ & 89 & 0003 & ALC & A & sum & $*$ & SUM CONTAINS \# OF KEYS IIOWN \\
\hline $252 E$ & E7 & 0003 & STA & $A$ & sum & & \\
\hline 2531 & 32 & & FUL & A & & & \\
\hline 2532 & $4 n$ & & TST & $A$ & & & \\
\hline 2533 & 27 & on & BEQ & & $\$ 2542$ & $*$ & ER IF NO KEY THIS AIIIR \\
\hline 2535 & 44 & & LSR & A & & & \\
\hline 2536 & 78 & 0002 & ASL & & DADIIR & & \\
\hline 2539 & EA & 0002 & OREA & A & DIADIIF: & * & GENEFATE COOE FOF KEY \\
\hline 2530 & 87 & 0000 & STA & $A$ & KEY & & \\
\hline $253 \mathrm{~F}$ & 77 & 0002 & ASR & & EIALIIIR & & \\
\hline 542 & $7 \mathrm{C}$ & 0002 & INC & & DIADIIIR & $*$ & NEXT DEU, ADOFESS \\
\hline 2545 & $7 C$ & 0005 & INC & & $X S A U+1$ & * & NEXT BIJFFER ADIIRESS \\
\hline $\begin{array}{l}2548 \\
254 \mathrm{~B}\end{array}$ & $\begin{array}{l}\text { B6 } \\
81\end{array}$ & $\begin{array}{l}0002 \\
10\end{array}$ & $\begin{array}{l}\text { LIA } \\
\text { CMF }\end{array}$ & $\begin{array}{l}A \\
A\end{array}$ & $\begin{array}{l}\text { DADIDR } \\
\$ \$ 10\end{array}$ & * & IIAULFI EEYOND RANGE? \\
\hline 2540 & 26 & C6 & BNE & & $\$ 2515$ & & \\
\hline $254 F$ & 20 & 16 & BRA & & $\$ 2567$ & & \\
\hline 551 & 86 & 34 & LIA & $A$ & $\$ \$ 34$ & & \\
\hline $\begin{array}{l}2553 \\
2556\end{array}$ & $\begin{array}{l}\text { B7 } \\
F E\end{array}$ & $\begin{array}{l}8009 \\
0046\end{array}$ & $\begin{array}{l}\text { STA } \\
\text { LDX }\end{array}$ & $A$ & $\begin{array}{l}\text { CONT-A } \\
\text { RATE }\end{array}$ & * & SET CAZ LOW TO STFOBE IIEC. \\
\hline 2559 & 09 & & nEX & & & $*$ & IIELAY LOOF TO SET SCAN RATE \\
\hline $255 A$ & 26 & FII & ENE & & $\$ 2559$ & $*$ & TO 50 SCANS/SEC \\
\hline 2550 & B6 & $800 \mathrm{~A}$ & LIIA & $A$ & FOFT - B & $*$ & BFING IN KEY BITS \\
\hline $205 F$ & 36 & & FSti & $\dot{H}$ & & & \\
\hline $\begin{array}{l}2560 \\
2562\end{array}$ & $\begin{array}{l}86 \\
\text { E7 }\end{array}$ & $\begin{array}{l}3 \mathrm{C} \\
8009\end{array}$ & $\begin{array}{l}\text { LIAA } \\
\text { STA }\end{array}$ & $\begin{array}{l}A \\
A\end{array}$ & $\begin{array}{l}\# 3 C \\
C O N T-A\end{array}$ & * & SET CAZ HIGH \\
\hline 2565 & 32 & & FUL & $A$ & & & \\
\hline 2566 & 39 & & FiTs & & & & \\
\hline
\end{tabular}

**** STAFT OF CHECK SFEECH FOUTINE *****

\begin{tabular}{|c|c|c|c|c|c|}
\hline 2567 & 01 & & NOP & & \\
\hline 2568 & $O E$ & & CLI & & \\
\hline 2569 & 86 & 08 & LIIA & $A$ & $\$ \$ 08$ \\
\hline $256 \mathrm{~B}$ & ES & $800 \mathrm{~B}$ & BIT & $A$ & CONT-B \\
\hline $256 \mathrm{E}$ & 27 & $4 A$ & EEQ & & $\$ 25 \mathrm{BA}$ \\
\hline $\begin{array}{l}2570 \\
2573\end{array}$ & $\begin{array}{l}F E \\
\mathrm{BC}\end{array}$ & $\begin{array}{l}0016 \\
0018\end{array}$ & $\begin{array}{l}\operatorname{LIIX} \\
\text { CFX }\end{array}$ & & $\begin{array}{l}\text { NEXT } \\
\text { LAST }\end{array}$ \\
\hline 2576 & 27 & 42 & BEQ & & $\$ 258 A$ \\
\hline 2578 & 70 & $001 \mathrm{C}$ & TST & & FAUSE \\
\hline $257 \mathrm{~B}$ & 26 & $2 B$ & ENE & & $\$ 25 A 8$ \\
\hline 7 & $\mathrm{~B}$ & $800 \mathrm{~A}$ & LIIA & $A$ & FOR \\
\hline
\end{tabular}

* branch if start $=0$ 


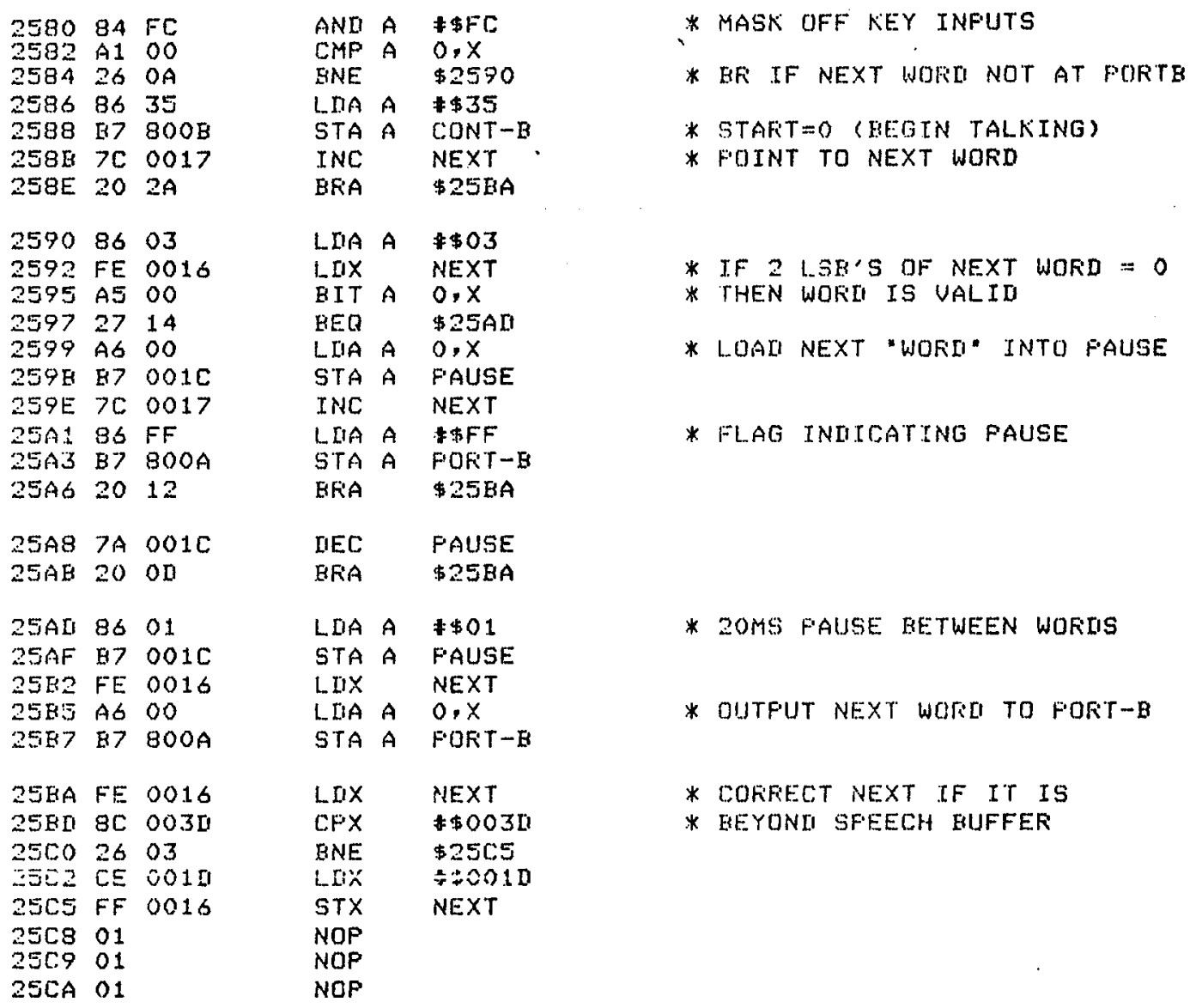

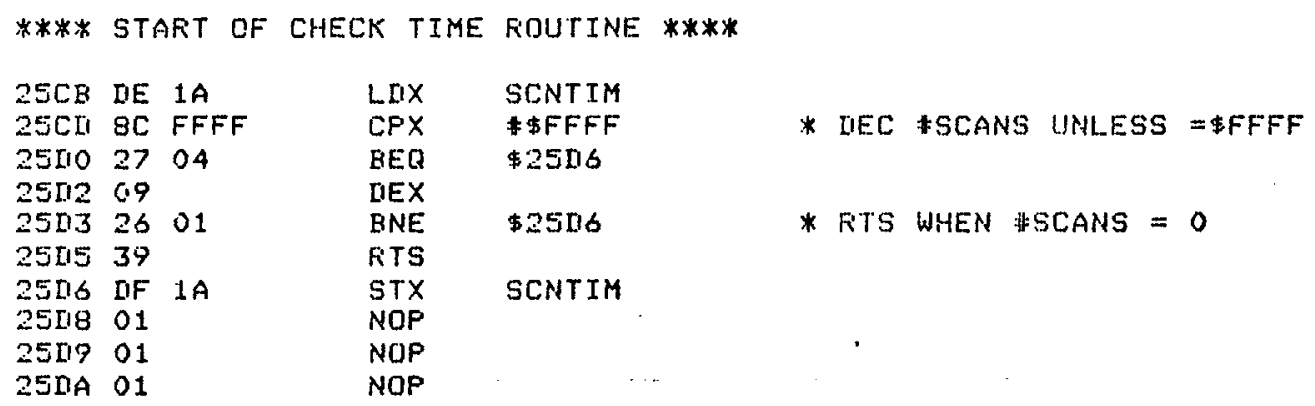




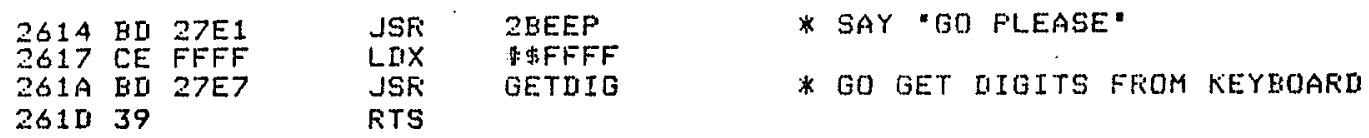

**** STAFIT OF SFKEY SUBROUTINE ****

\begin{tabular}{|c|c|c|c|c|}
\hline 2620 & $81 \mathrm{OA}$ & CMP & $A$ & $\triangle \$ O A$ \\
\hline 2622 & 2E 08 & EGT & & $\$ 262 \mathrm{C}$ \\
\hline 2624 & $\begin{array}{ll}26 & 02\end{array}$ & SNE & & $\$ 2628$ \\
\hline 2526 & $861 F$ & $L \Pi A$ & $A$ & $J \$ 1 F$ \\
\hline $\begin{array}{l}2628 \\
2628\end{array}$ & $\begin{array}{l}\mathrm{BD} \\
39\end{array}$ & $\begin{array}{l}\text { ISF } \\
\text { RTS }\end{array}$ & & SPKWI \\
\hline $52 C$ & $863 E$ & LIIA & A & $\$$ \$ $3 E$ \\
\hline $2 E$ & $20 \quad F 8$ & EKA & & $\$ 2628$ \\
\hline
\end{tabular}

* KEY $=$ MINUS

* KEy has no Name

* KEY NAME=KEY VALUE

* "MINUS"

* LoAI wofin into sfeech buF.

* 'HI-TONE'

**** STAFT OF IFILL SUBFDUTINE ****

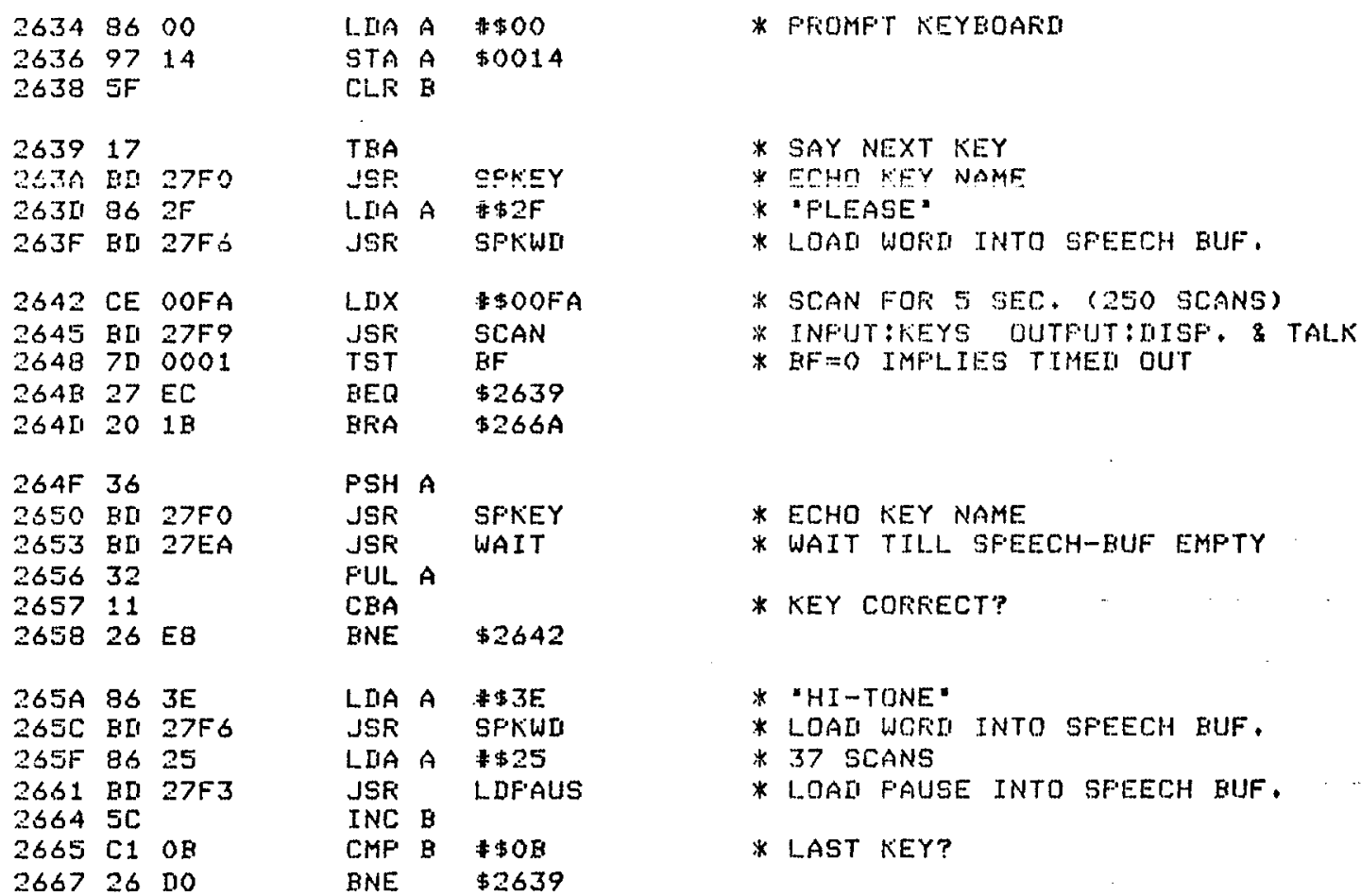




$\begin{array}{llll}266939 & \text { RTS } & \\ 266 A & 9600 & \text { LIA A } & \text { KEY } \\ 266 C & 11 & 17 & \text { CMF A } \$ \$ 17 \\ 266 E & 26 \text { DF } & \text { ENE } & \$ 264 F \\ 2670 & 39 & \text { RTS } & \end{array}$

**** STAFT OF WAIT SUBROUTINE ****

$\begin{array}{llllll}2680 & \text { CE } & \text { OOOA } & \text { LUX } & \$ \$ O O O A & * 10 \text { SCANS } \\ 2683 \text { GI } 27 F 9 & \text { JSF } & \text { SCAN } & * \text { TNFUT:KEYS OUTFUT:DITSP. \& TALK } \\ 2686 \text { DIE } 16 & \text { LIIX } & \text { NEXT } & & \\ 2688 \text { OC } 18 & \text { CFX } & \text { LAST } & * \text { IF SFEECH BUFFEF NOT EMFTY } \\ 268 A & 26 & \mathrm{~F} 4 & \text { BNE } & \$ 2680 & * \text { CONTINUE SCANNING UNTIL. IT IS } \\ 268 C 39 & \text { RTS } & & & \end{array}$

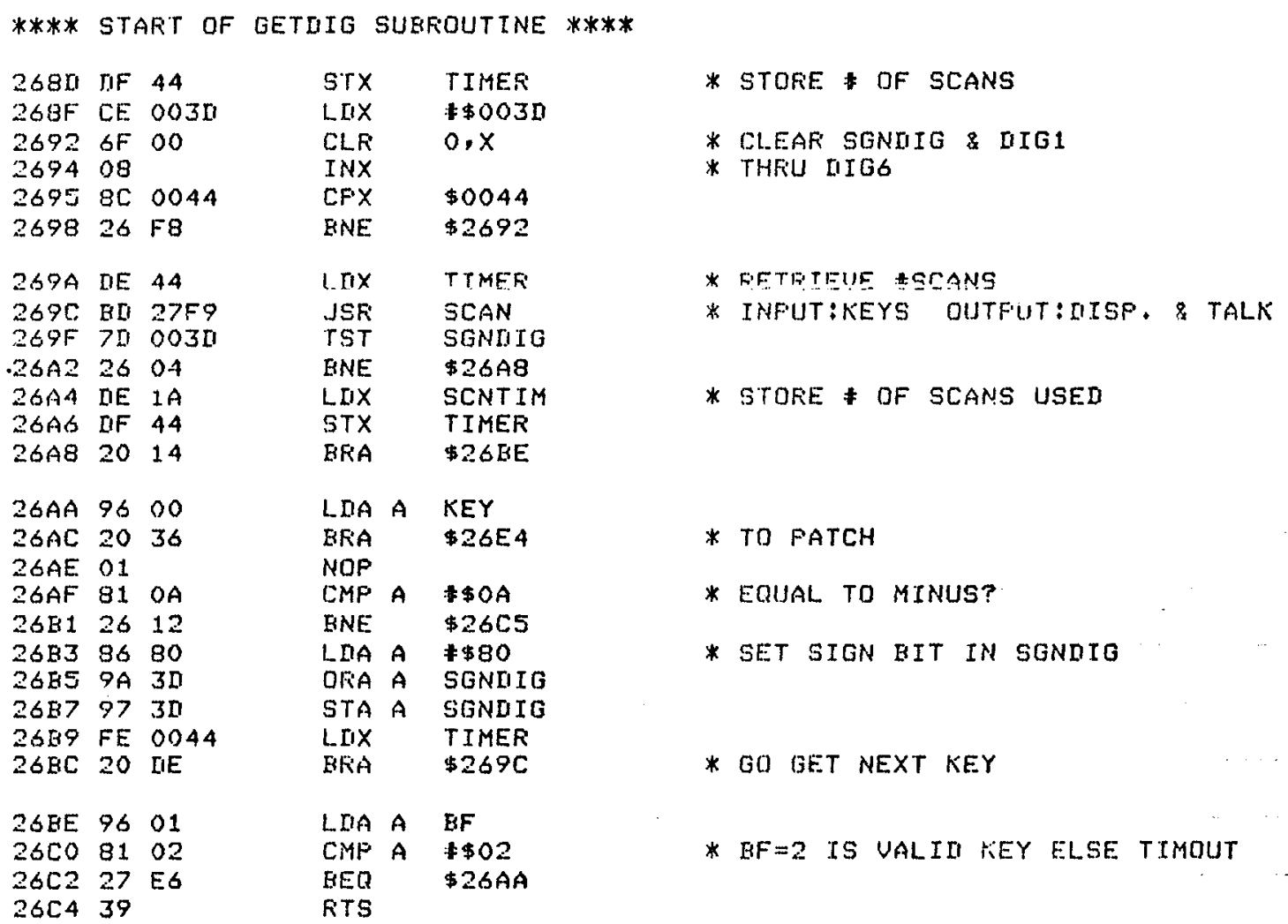




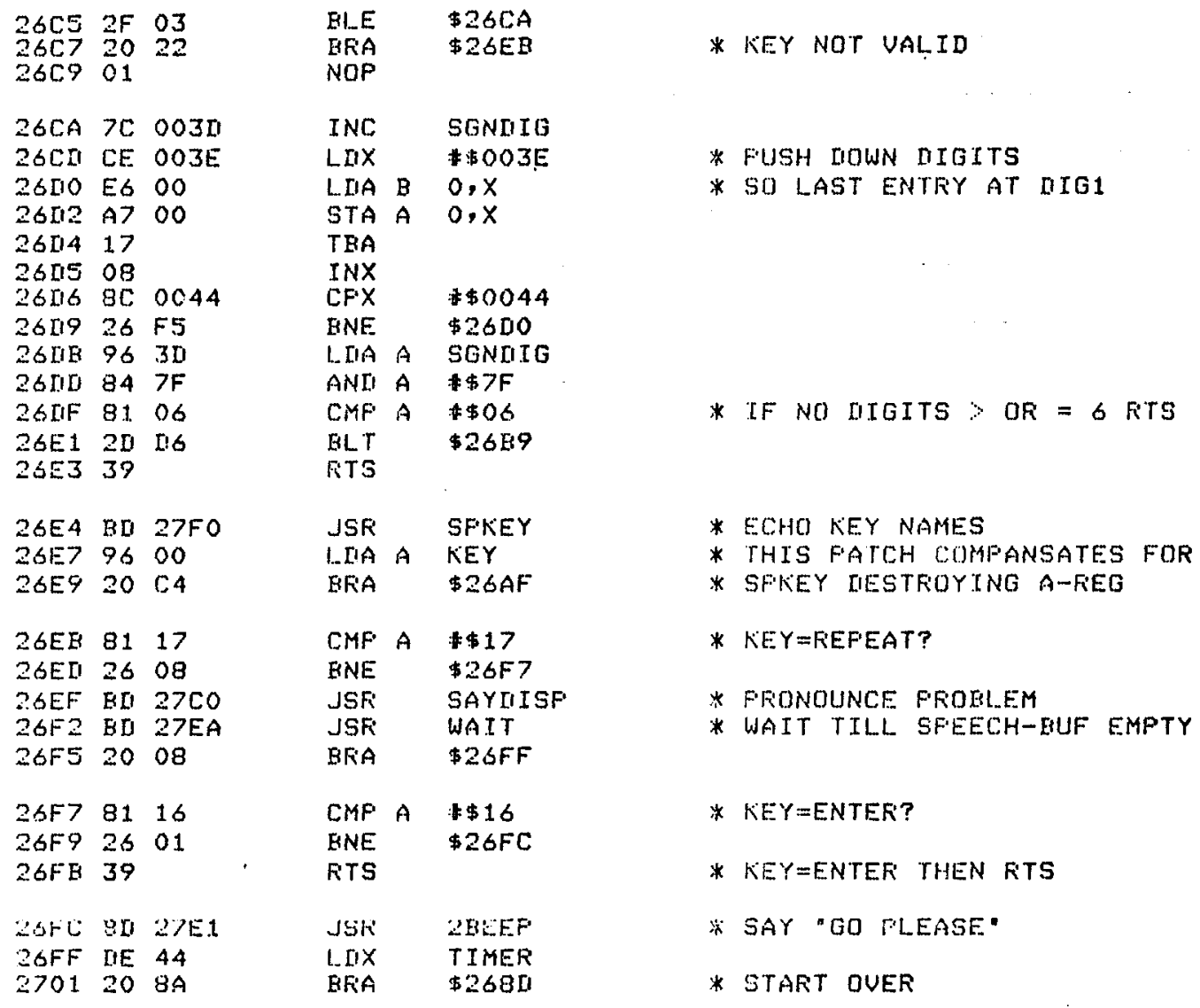

**** STAFT OF ELANKIT SUEROUTINE. ****

\begin{tabular}{|c|c|c|c|c|c|}
\hline 2710 & 96 & 52 & LIIA & $A$ & MISSING $\neq+1$ \\
\hline 2712 & $C E$ & OOOA & Lax & & $\$ \$ 000 \mathrm{~A}$ \\
\hline 2715 & 81 & 02 & CMF & A & $\$ \$ 02$ \\
\hline $\begin{array}{l}2717 \\
2719\end{array}$ & $\begin{array}{l}2 D \\
-3 E\end{array}$ & $\begin{array}{l}\text { on } \\
10\end{array}$ & $\begin{array}{l}\text { ELT } \\
\text { BGT }\end{array}$ & & $\begin{array}{l}\$ 2726 \\
\$ 2728\end{array}$ \\
\hline $271 \mathrm{E}$ & 86 & FF & LIA & $A$ & $\neq \$ F F$ \\
\hline 27111 & $A 7$ & 00 & STA & A & $0, x$ \\
\hline $271 \mathrm{~F}$ & A7 & 01 & STA & $A$ & $1, x$ \\
\hline $\begin{array}{l}2721 \\
2723 \\
2725\end{array}$ & $\begin{array}{l}A 7 \\
A 7 \\
39\end{array}$ & $\begin{array}{l}02 \\
03\end{array}$ & $\begin{array}{l}\text { STA } \\
\text { STA } \\
\text { RTS }\end{array}$ & $\begin{array}{l}A \\
A\end{array}$ & $\frac{2, x}{3, x}$ \\
\hline
\end{tabular}

* this foutine blanks

* THE MISSING NUMEER IN

* the lissflay by futting

* \$FF IN BUFFER 


\begin{tabular}{|c|c|c|c|c|}
\hline $\begin{array}{l}2726 \\
2729\end{array}$ & $\begin{array}{l}\mathrm{CE} \\
20\end{array}$ & $\begin{array}{l}0006 \\
\text { FO }\end{array}$ & $\begin{array}{l}\text { LIIX } \\
\text { BFiA }\end{array}$ & $\begin{array}{l}\$ \$ 0006 \\
\$ 2718\end{array}$ \\
\hline $\begin{array}{l}272 \mathrm{E} \\
272 \mathrm{E}\end{array}$ & $\begin{array}{l}C E \\
20\end{array}$ & $\begin{array}{l}\text { OOOE } \\
E E\end{array}$ & $\begin{array}{l}\text { LIIX } \\
\text { ERTA }\end{array}$ & $\begin{array}{l}\$ \$ 000 E \\
\$ 2718\end{array}$ \\
\hline
\end{tabular}

***** START OF UNFACK SUIEROUTINE ****

\begin{tabular}{|c|c|c|c|c|c|}
\hline 2730 & 37 & & FSH & $B$ & * routitine assumes iata to \\
\hline 2731 & 36 & & F'SH & A & * BE UNFACKEI IS IN A:B \\
\hline 2732 & 84 & FO & ANII & $\star \$ F O$ & * ANI FIRST CHESTINATION \\
\hline 2734 & $A 7$ & 00 & STA & $0, x$ & * AMUIRESS IS IN $x$ \\
\hline 2736 & 32 & & PUL & A & \\
\hline 2737 & 48 & & ASL & A & * ALsO: NIBELES akE FACKED \\
\hline 2738 & 48 & & ASL & A & * INTO LEFT HALF OF BYTES \\
\hline 2739 & 48 & & ASL & A & \\
\hline $273 A$ & 48 & & ASL & A & \\
\hline 2736 & $A 7$ & 01 & STA & $1, x$ & \\
\hline $273 \pi$ & CA & FO & ANII & $: \$ F O$ & \\
\hline $273 F$ & E7 & 02 & STA & $2, x$ & \\
\hline 2741 & 32 & & FULL. & A & \\
\hline 2742 & 48 & & ASL & A & \\
\hline 2743 & 48 & & ASL & A & \\
\hline $\begin{array}{l}2744 \\
2745\end{array}$ & $\begin{array}{l}48 \\
48\end{array}$ & & ASL & A & \\
\hline 2746 & A7 & 03 & تTA & $3, x$ & \\
\hline 2748 & 39 & & RTS & & \\
\hline
\end{tabular}

**** START OF SAYIISF SUEFOUTINE ****

$274 A \quad 700061$

$2740 \quad 27 \quad 40$

$274 F \quad C 6 \quad 01$

2751 CE $005 B$

2754 8I 20

$275696 \quad 50$

2758 8E OE

275A BD $27 F 6$

$275 \mathrm{D}$ CS 02

$275 F$ CE 0050

2762 8D 12

\begin{tabular}{|c|c|}
\hline $\begin{array}{l}\text { TST } \\
\text { BEQ }\end{array}$ & $\begin{array}{l}\text { SAY } \\
\$ 278 F\end{array}$ \\
\hline LIIA $B$ & $\neq \$ 01$ \\
\hline $\begin{array}{l}\text { LIIX } \\
\text { BSR }\end{array}$ & $\begin{array}{l}\$ \$ 005 \mathrm{~B} \\
\$ 2776\end{array}$ \\
\hline
\end{tabular}

LIIA A OFSIBN

$A[I I A \quad \# D E$

JSK SFKWI

LIA $B \quad \$ 02$

LIIX $\$ \$ 005 D$

BSF $\$ 2776$
* say mo say nothing

* say 1 say all eiut missing:

* say=z say all.

* FIRST DIGIT

* say ofeeration ( + - $x /$ )

* Loan wofin into sFeEch buf.

* 2NI NUmeER 


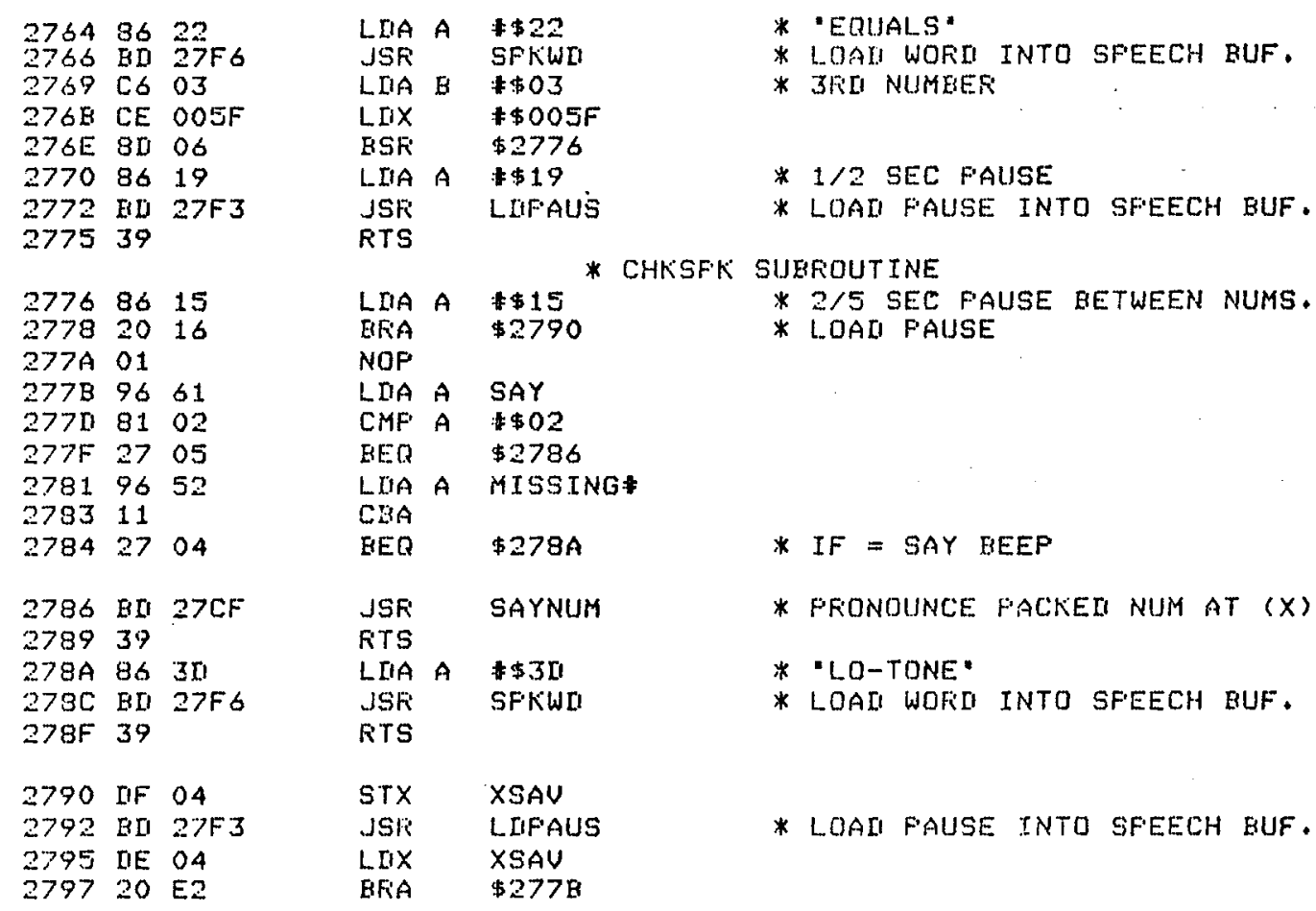

**** START OF LINK ****

\begin{tabular}{|c|c|c|c|c|}
\hline $279 A$ & TE & $2 A E E$ & JMF & \$2ABE. \\
\hline 2790 & ᄀE & 2924 & JMP & $\$ 2924$ \\
\hline $27 A 0$ & $7 E$ & ICCF & JMF & $\$ 2 C C F$ \\
\hline $\begin{array}{l}27 A 3 \\
27 A 6\end{array}$ & $\begin{array}{l}7 E \\
7 E\end{array}$ & $\begin{array}{l}2869 \\
2040\end{array}$ & $\begin{array}{l}J M F \\
J M F\end{array}$ & $\begin{array}{l}\$ 2869 \\
\$ 2040\end{array}$ \\
\hline $27 A 9$ & $7 E$ & $281 A$ & JMF & $\$ 281 \mathrm{~A}$ \\
\hline $\begin{array}{l}27 A C \\
27 A F\end{array}$ & $\begin{array}{l}7 E \\
20\end{array}$ & $\begin{array}{l}209 \mathrm{~F} \\
\mathrm{FD}\end{array}$ & JMF & $\$ 209 \mathrm{~F}$ \\
\hline $27 B 1$ & $7 E$ & 2936 & JMP & $\$ 2936$ \\
\hline $27 B 4$ & $7 E$ & $22 \mathrm{C7}$ & JMF & $\$ 2207$ \\
\hline $27 B 7$ & $7 E$ & 22116 & JMP & $\$ 22116$ \\
\hline $27 \mathrm{BA}$ & $7 E$ & 2000 & JMF & $\$ 2 C 00$ \\
\hline 27BI & $7 E$ & $291 \mathrm{C}$ & JMP & $\$ 291 \mathrm{C}$ \\
\hline $2>00$ & $7 E$ & $274 \mathrm{~A}$ & $J M P$ & $\$ 274 A$ \\
\hline $27 C 3$ & $7 E$ & 2710 & JMF & $\$ 2710$ \\
\hline 2706 & $7 E$ & 2670 & JMF & $\$ 2 F>0$ \\
\hline 2709 & $7 E$ & 2240 & JMF & $\$ 2240$ \\
\hline $270 \mathrm{C}$ & 7E & 2730 & JMP & $\$ 2730$ \\
\hline Ler & & A7 & IMP & $\$ 24 A 7$ \\
\hline
\end{tabular}

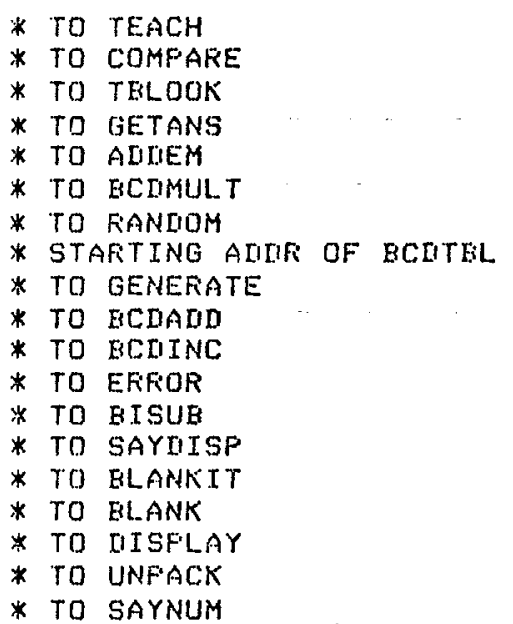




\begin{tabular}{|c|c|c|c|c|}
\hline 2712 & $7 E$ & $22 F 4$ & JMP & $\$ 22 F 4$ \\
\hline 2715 & $7 E$ & 2612 & JWF & $\$ 2612$ \\
\hline 2718 & $7 E$ & $2 \mathrm{CBF}$ & JMF & \$2CAF \\
\hline 2710 & $7 E$ & $28[1 \mathrm{E}$ & $J M P$ & $\$ 2 F A B$ \\
\hline 27IE & $7 E$ & 2469 & JMF & $\$ 2469$ \\
\hline 27E1 & $7 E$ & 2455 & JKF & $\$ 2455$ \\
\hline $27 E 4$ & $7 \bar{E}$ & 2509 & JMF & $\$ 2509$ \\
\hline 27E7 & 7E & 2680 & $J M F$ & $\$ 268 \mathrm{II}$ \\
\hline 27EA & $7 E$ & 2680 & $J M F$ & $\$ 2680$ \\
\hline $\begin{array}{l}\text { 27EII } \\
2 \text { PFO }\end{array}$ & $\begin{array}{l}7 E \\
7 E\end{array}$ & $\begin{array}{l}2634 \\
2620\end{array}$ & $\begin{array}{l}\text { JMF } \\
\text { JMF }\end{array}$ & $\begin{array}{l}\$ 2634 \\
\$ 2620\end{array}$ \\
\hline $27 F 3$ & $7 E$ & 2602 & $J M F$ & $\$ 2602$ \\
\hline $27 F 6$ & $7 E$ & 2600 & JMF & $\$ 2600$ \\
\hline $27 F 9$ & $7 E$ & 2500 & JMF & $\$ 2500$ \\
\hline $27 F C$ & $7 E$ & $2 A 43$ & JMF & $\$ 2 A 43$ \\
\hline 2DFF & TE & $21 \mathrm{CA}$ & $J M F$ & $\$ 21 C A$ \\
\hline 2802 & $7 E$ & 2200 & $J M F$ & $\$ 220 \mathrm{CC}$ \\
\hline 2805 & $7 E$ & $2 F 80$ & JMF & $\$ 2 F 80$ \\
\hline $\begin{array}{l}2808 \\
2808\end{array}$ & $\begin{array}{l}7 E \\
2 E\end{array}$ & $\begin{array}{l}21.10 \\
00\end{array}$ & $J M P$ & $\$ 2110$ \\
\hline $280 \mathrm{II}$ & $2 E$ & 80 & & \\
\hline $80 \mathrm{~F}$ & 2 & 00 & & \\
\hline
\end{tabular}

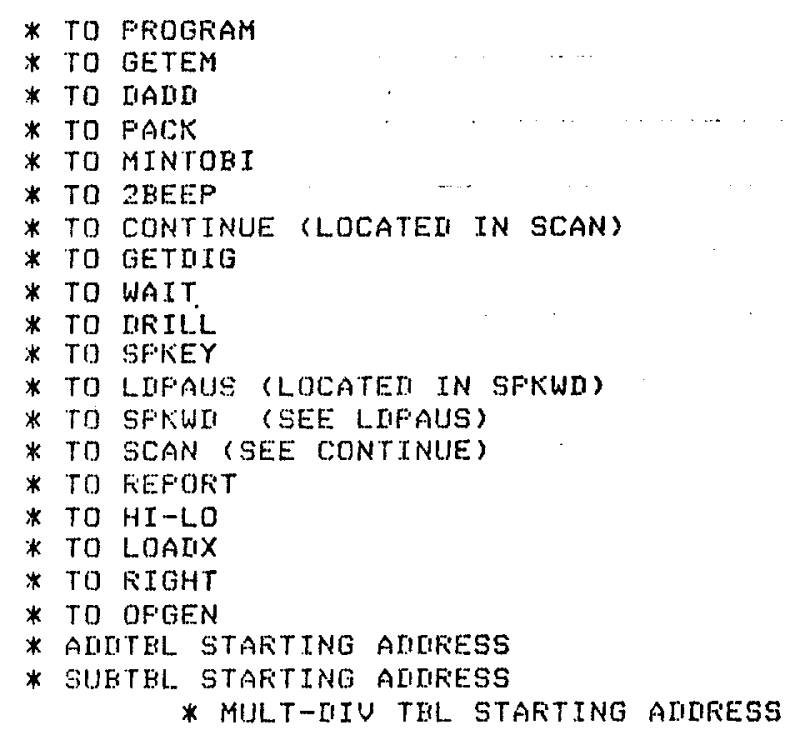

**** STAFit of ecImULt SUBFoutine ****

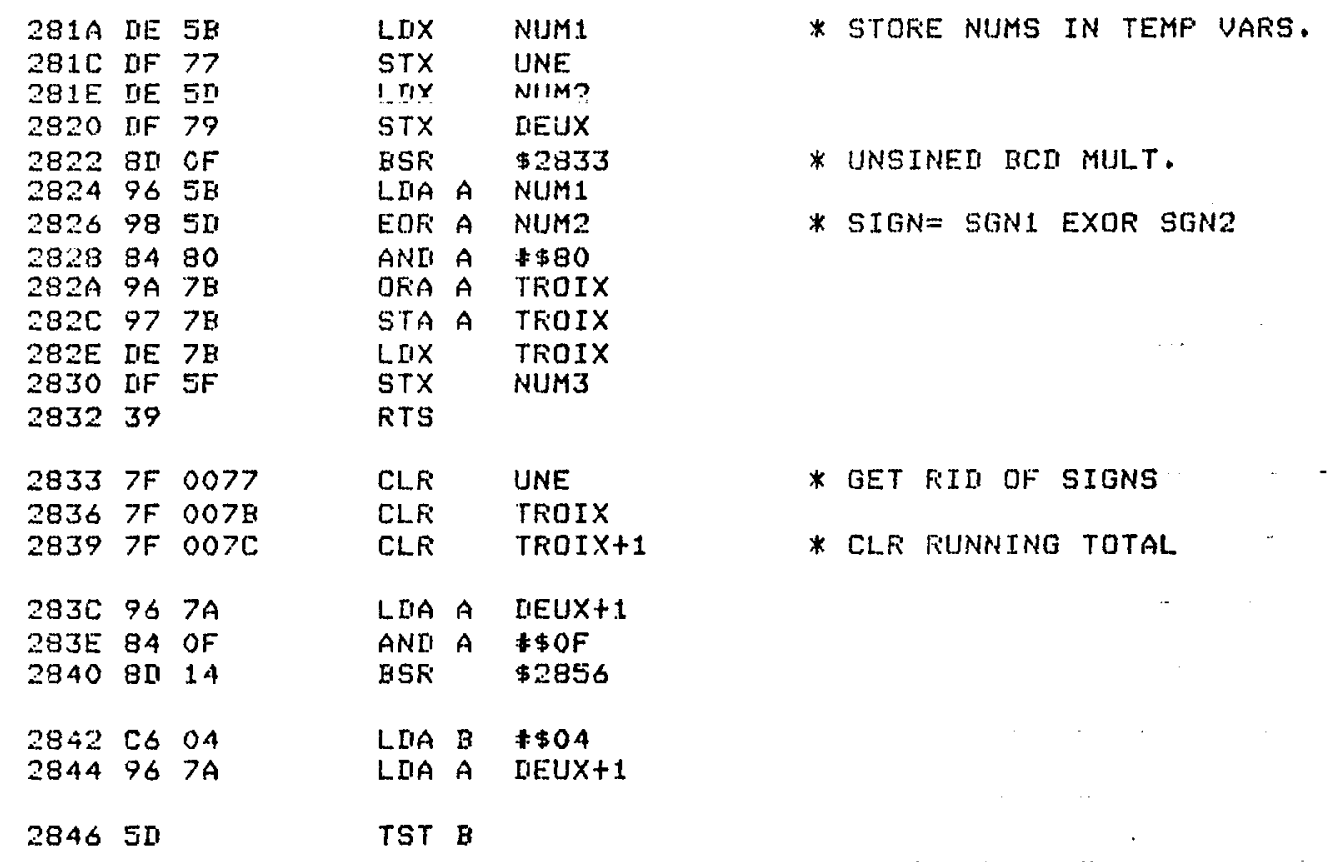




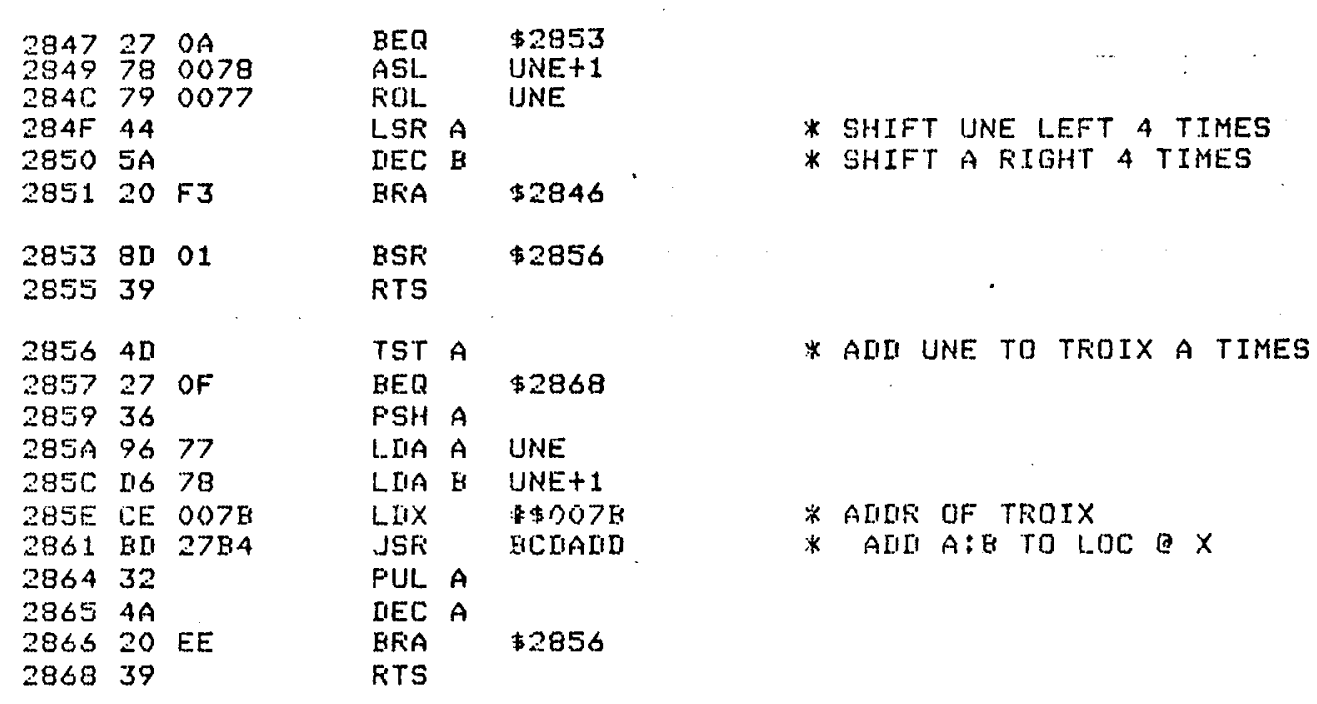

**** START OF GETANS SUBFOUTINE *****

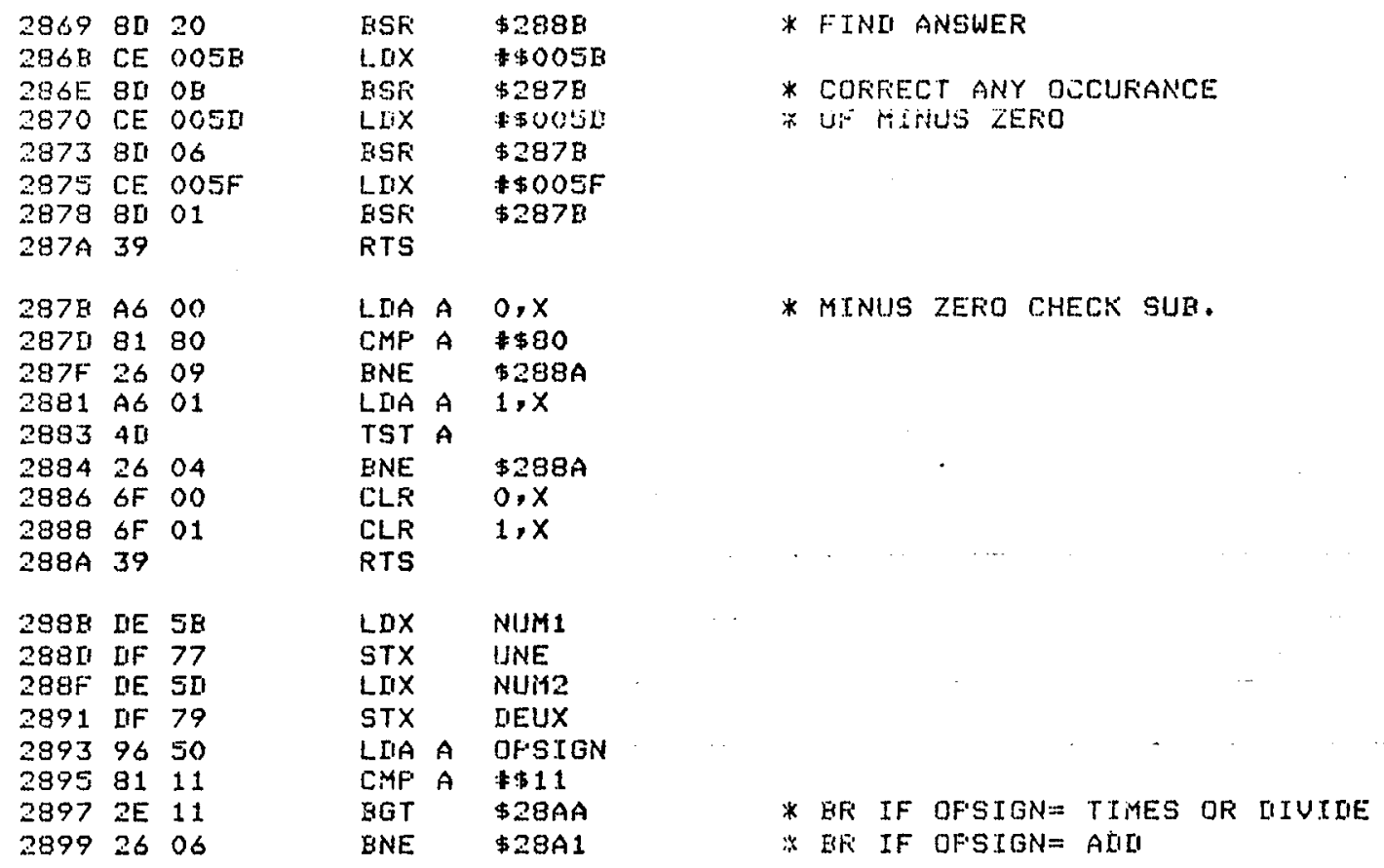




\begin{tabular}{|c|c|c|c|c|c|c|c|}
\hline $\begin{array}{l}289 \mathrm{~B} \\
289 \mathrm{II}\end{array}$ & $\begin{array}{l}20 \\
01\end{array}$ & $3 F$ & $\begin{array}{l}\text { BRA } \\
\text { NOF }\end{array}$ & & $\$ 28 D$ & & \\
\hline $289 E$ & 01 & & NOP & & & & \\
\hline $289 F$ & 01 & & NOP & & & & \\
\hline $28 \mathrm{AO}$ & 01 & & NOP & & & & \\
\hline $28 A 1$ & $\mathrm{BD}$ & 27AG & JSR & & ADIIEM & * & SIGNED BCD ADUITION ROUTINE \\
\hline $28 A 4$ & 01 & & NOP & & & & \\
\hline $28 A 5$ & IE & $7 \mathrm{~B}$ & LIXX & & TROIX & & \\
\hline $28 A 7$ & DF & $5 F$ & STX & & NUM3 & & . \\
\hline 28 A9 & 39 & & RTS & & & & 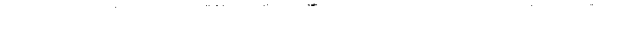 \\
\hline $28 A A$ & $\mathrm{BD}$ & $27 A 9$ & $J S F$ & & BCOMULT & $*$ & SIGNED BCD MULT, ROUTINE \\
\hline $28 \mathrm{AII}$ & 96 & 50 & LIIA & A & OFSIGN & & \\
\hline $28 \mathrm{AF}$ & 81 & 12 & CMF & A & 12 & $*$ & OFSIGN $=$ MULT.? \\
\hline $28 \mathrm{~B} 1$ & 27 & $F_{2}$ & BER & & $\$ 28 A 5$ & & \\
\hline 2383 & 20 & on & BF:A & & $\$ 2802$ & & \\
\hline $28 B 5$ & LIE & 50 & LIXX & & NUM2 & * & FOF IIUISION MOUE NUMEERS \\
\hline 28E7 & DF & SF & stX & & NUM3 & $*$ & AFTEF DOING MULT. \\
\hline $28 \mathrm{Bg}$ & DE & $5 B$ & LIIX & & NUM1 & & \\
\hline 28BE & IIF & $5 \Pi$ & STX & & NUM2 & & \\
\hline $288 \mathrm{II}$ & DE & 78 & LIIX & & TROIX & & \\
\hline $\begin{array}{l}28 \mathrm{EF} \\
28 \mathrm{C} 1\end{array}$ & $\begin{array}{l}\text { DF } \\
39\end{array}$ & $5 \mathrm{~B}$ & $\begin{array}{l}\text { STX } \\
\text { RTS }\end{array}$ & & NUM1 & & \\
\hline $28 \mathrm{C2}$ & DE & $5 B$ & $\operatorname{LIIX}$ & & NUMI & $*$ & IIUIIE BY ZERO? \\
\hline 2804 & 8c & 0000 & CFX & & $\$ \$ 0000$ & & \\
\hline 2807 & 26 & $E C$ & BNE & & $\$ 28 B 5$ & & \\
\hline $\begin{array}{l}28 C 9 \\
28 C E\end{array}$ & $\begin{array}{l}\text { TIE } \\
8 \mathrm{C}\end{array}$ & $\begin{array}{l}5 \pi \\
0000\end{array}$ & $\begin{array}{l}\operatorname{LEX} \\
\operatorname{CFX}\end{array}$ & & $\begin{array}{l}\text { NUM2 } \\
\$ \$ 0000\end{array}$ & & \\
\hline $28 \mathrm{CE}$ & 27 & 05 & $B E Q$ & & $\$ 2805$ & & \\
\hline 2350 & IE & $7 B$ & $\operatorname{LIX}$ & & TROIX & & \\
\hline $29 \pi 2$ & IF & $\mathrm{SF}$ & 3TK & & itions & & \\
\hline $28[14$ & 39 & & RTS & & & & \\
\hline 2815 & CE & 0001 & $\operatorname{LIXX}$ & & $\$ \$ 0001$ & * & CHANGE PROE TO $0 / 1=0$ \\
\hline 2808 & IfF & 50 & ETX & & NUM2 & & \\
\hline $28 I A$ & 20 & 09 & BRA & & $\$ 2885$ & & \\
\hline $28 I \mathrm{C}$ & 96 & 48 & LIIIA & & MODE & * & HEFE IF SUETFACTTION \\
\hline $\begin{array}{l}28 D E \\
28 E 0\end{array}$ & $\begin{array}{l}81 \\
26\end{array}$ & $\begin{array}{l}\text { OC } \\
16\end{array}$ & $\begin{array}{l}\text { CMP } \\
\text { BNE }\end{array}$ & A & $\begin{array}{l}\$ \$ O C \\
\$ 28 F B\end{array}$ & * & EF IF MOIE NOT EQUAL LEVEL \\
\hline $28 E 2$ & 96 & 55 & LIAA & A & FROBTYFE & & \\
\hline $28 E 4$ & 84 & 40 & ANI & $A$ & $\$ \$ 40$ & & \\
\hline $28 \mathrm{E} 6$ & 27 & 10 & BEQ & & $\$ 28 F 8$ & $*$ & BF IF EITG NOT SET (T-BIT) \\
\hline 28E8 & $\mathrm{BD}$ & $27 A 6$ & JSR & & ADIIEM & $*$ & SIGNEO BCI ADIITION ROUTINE \\
\hline 28EE & LIE & $5 \pi$ & $\operatorname{LrIX}$ & & NUM2 & & \\
\hline 28EII & [IF & $5 F$ & STX & & NUM3 & * & IF HEFE: IIO SUETFACTION BY \\
\hline 28EF & IUE & $5 B$ & LIXX & & NUM1 1 & * & MOIRG AUMITION THEN MOUE SUM \\
\hline $28 F_{1}$ & aF & 50 & STX & & NUM2 & * & TO NUM1, NUM1 TO NUM?, ANI \\
\hline $28 F 3$ & IIE & 78 & LIIX & & TFOIX & $*$ & NUM2 TO NUM3 (NOT IN THAT OFRIER) \\
\hline $28 F 5$ & DF & $5 B$ & STX & & NUM1 & & \\
\hline $28 \mathrm{~F} 7$ & 39 & & RTS & & & & \\
\hline $28 F 8$ & 96 & 79 & LIIA & A & LEUX & & \\
\hline $28 \mathrm{FA}$ & 88 & 80 & EQR & A & $\$ \$ 80$ & & · \\
\hline
\end{tabular}




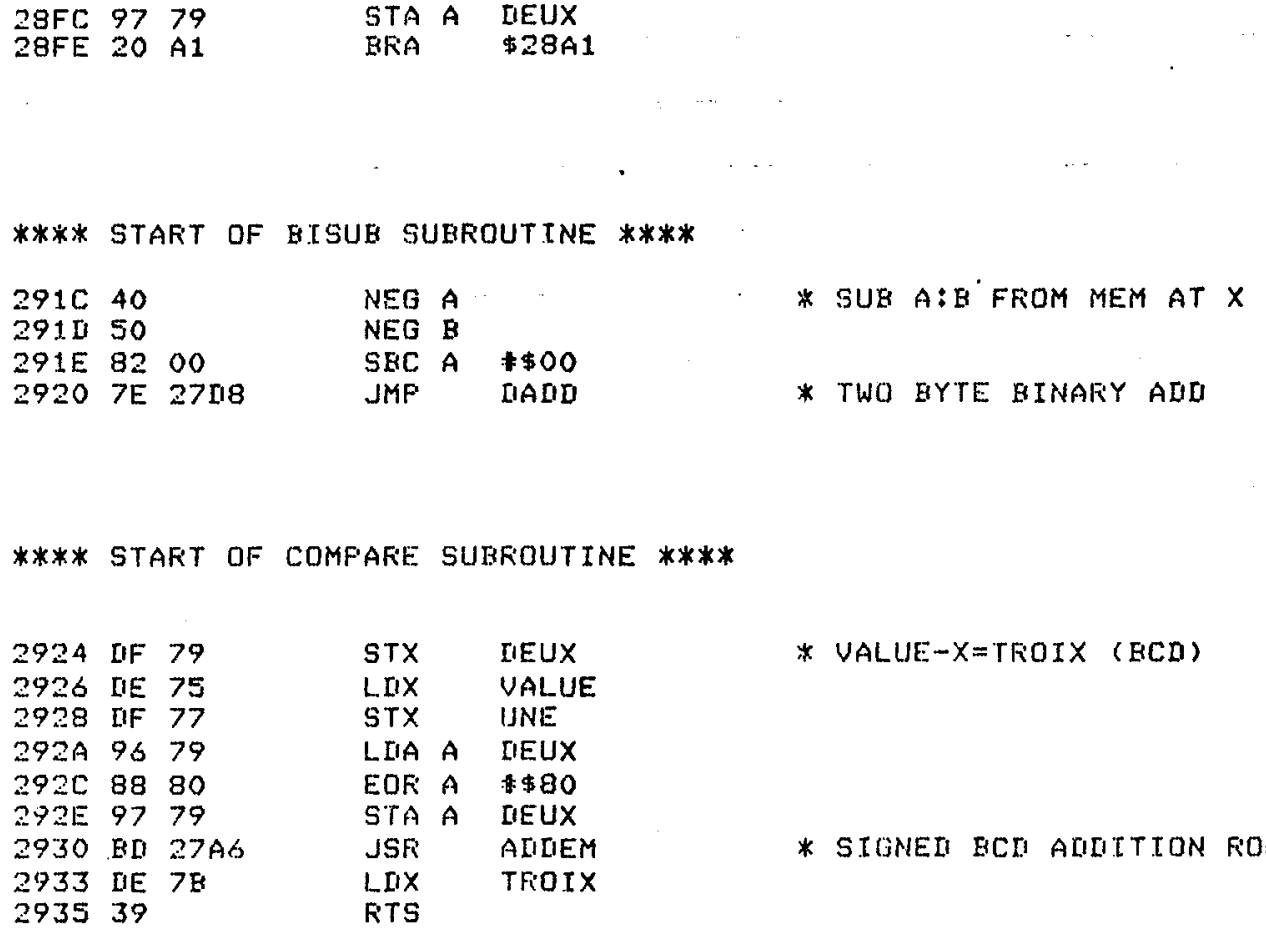

$\begin{array}{ll}\text { STX } & \text { IIEUX } \\ \text { LIIX } & \text { UALUE } \\ \text { STX } & \text { UNE } \\ \text { LIIA A } & \text { IEUX } \\ \text { EOF A } & \text { HBO } \\ \text { STA A } & \text { IEUX } \\ \text { JSF } & \text { AUUEM } \\ \text { LIX } & \text { TFOIX } \\ \text { RTS } & \end{array}$

* VALUE- $X=$ TROIX (BCD)

**** START OF GENERATE SUEROUTINE *****

\begin{tabular}{|c|c|c|c|c|c|}
\hline 2936 & 20 & $O A$ & BFA & $\$ 2942$ & * ERANCH around fatch \\
\hline 2938 & 70 & 0055 & TST & LOLIMI/FROETYP & \\
\hline $\begin{array}{l}293 \mathrm{~B} \\
2931\end{array}$ & $\begin{array}{l}28 \\
39\end{array}$ & 0.1 & $\begin{array}{l}\text { BMI } \\
\text { RTS }\end{array}$ & $\$ 293 E$ & $\begin{array}{l}\text { * IF MSH=1 CHECK THAT } \\
\text { * ABS UAL OF OFERANMS ARE }\end{array}$ \\
\hline $293 E$ & IIF. & $5 B$ & L.DX & NUM1 & * Less than ofi equal to 30 \\
\hline 2940 & 20 & 66 & BRA & $\$ 29 A 8$ & \\
\hline 2942 & 96 & 48 & LIIA A & MOUE & \\
\hline $\begin{array}{l}2944 \\
2946\end{array}$ & $\begin{array}{l}81 \\
27\end{array}$ & $\begin{array}{l}\text { OC } \\
38\end{array}$ & $\begin{array}{l}\text { CMP A } \\
\text { BEQ }\end{array}$ & $\begin{array}{l}\$ \$ 0 C \\
\$ 2980\end{array}$ & * BR IF MOLIE=LEVELS \\
\hline 2948 & $C E$ & $007 n$ & $\operatorname{Lnx}$ & $\$ \$ 0070$ & * arIDFi of seErIa \\
\hline $\begin{array}{l}294 \mathrm{~B} \\
294 \mathrm{E}\end{array}$ & $\begin{array}{l}\text { BII } \\
\text { IIE }\end{array}$ & $\begin{array}{l}27 \mathrm{AC} \\
53\end{array}$ & $\begin{array}{l}\text { JSFi } \\
\text { LDX }\end{array}$ & $\begin{array}{l}\text { FAANDOM } \\
\text { LEUEL/HILIMI }\end{array}$ & $\begin{array}{l}\text { * FIANDOM NUMEER CJENERATOR } \\
\text { * CMF. FIANIOMM NUM TO LIM }\end{array}$ \\
\hline $\begin{array}{l}2950 \\
2953\end{array}$ & 27 & $\begin{array}{l}27901 \\
02\end{array}$ & $\begin{array}{l}\text { JSR } \\
\text { BER }\end{array}$ & $\begin{array}{l}\text { COMFAFE } \\
\$ 2957\end{array}$ & $\begin{array}{l}\text { * COMPARE (ECD) UALUE \& } x \\
\text { * BF IF IN LIMITS }\end{array}$ \\
\hline 2955 & $2 A$ & $F 1$ & BFL & $\$ 2948$ & * BR IF OUT OF LIMITS \\
\hline
\end{tabular}




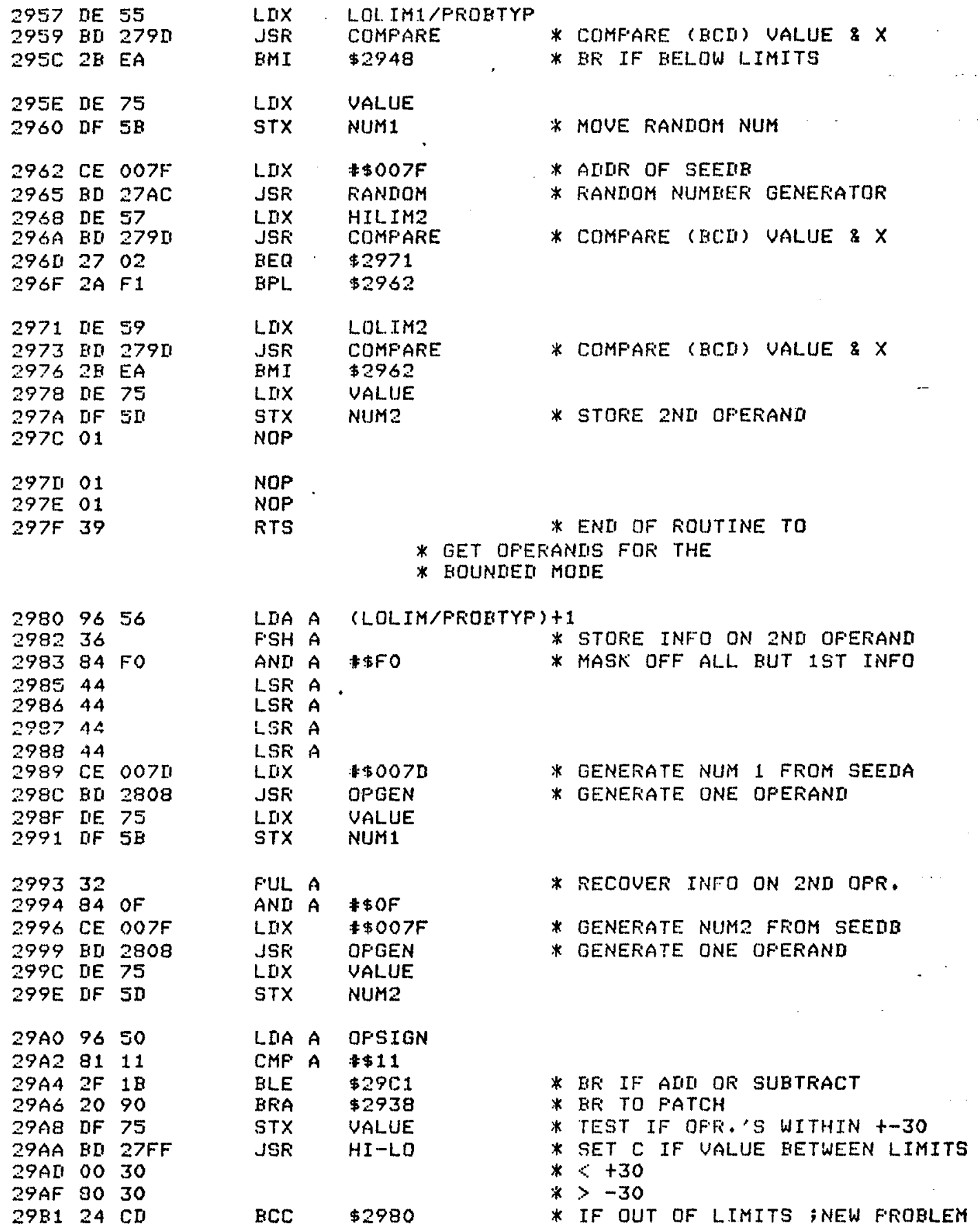




\begin{tabular}{|c|c|c|c|c|c|c|c|c|}
\hline $\begin{array}{l}29 B 3 \\
2985 \\
2987\end{array}$ & $\begin{array}{l}\text { DE } \\
\text { DF } \\
\text { BD }\end{array}$ & $\begin{array}{l}5 I 1 \\
75 \\
27+F\end{array}$ & $\begin{array}{l}\text { LIIX } \\
\text { STX } \\
\text { JSR }\end{array}$ & & $\begin{array}{l}\text { NUM2 } \\
\text { UALUE } \\
\text { HI -LO }\end{array}$ & $\begin{array}{l}* \\
*\end{array}$ & $\begin{array}{l}\text { CHECK IF NUM2=+-30 } \\
\text { SET C IF UALUE EETWEEN }\end{array}$ & LIMITS \\
\hline $29 \mathrm{BA}$ & 00 & 30 & & & & * & $<+30$ & \\
\hline $29 B C$ & 80 & 30 & & & & $*$ & $y-30$ & \\
\hline $29 \mathrm{BE}$ & 24 & $\mathrm{CO}$ & $\mathrm{BCC}$ & & $\$ 2980^{\circ}$ & & & \\
\hline 2900 & 39 & & RTS & & & & & \\
\hline $9 \mathrm{Cl}$ & 96 & 55 & LIIA & A & LOLIM1/FROBTYF & * & IF $M S B=1$ THEN IGNORE & \\
\hline $\begin{array}{l}2903 \\
2905\end{array}$ & $\begin{array}{l}84 \\
26\end{array}$ & $\begin{array}{l}80 \\
03\end{array}$ & $\begin{array}{l}\text { ANII } \\
\text { ENE }\end{array}$ & A & $\begin{array}{l}\$ \$ 80 \\
\$ 29 \mathrm{CA}\end{array}$ & * & REGROUPTNG & \\
\hline 2907 & 39 & & RTS & & - & & & \\
\hline 2908 & 20 & B6 & BFiA & & $\$ 2980$ & & & \\
\hline $29 \mathrm{CA}$ & 96 & 50 & LIIA & A & OFSIGN & $*$ & EXOF SIGN BITS WITH LSE & \\
\hline $29 \mathrm{CC}$ & 46 & & ROR & $A$ & & $*$ & OF OFSILN, IF MSE OF A & $=$ \\
\hline $29 \mathrm{CI}$ & 46 & & FIOR & $A$ & & * & O THEN ALIITION FEGFOUP & \\
\hline $29 \mathrm{CE}$ & 98 & $5 \mathrm{E}$ & EOR & A & NUM1 1 & $*$ & 1 THEN SUETRACT KEGFIOUP & \\
\hline 29110 & 98 & $5 n$ & EOR & A & NUMZ & & & \\
\hline $29[12$ & 84 & 80 & ANII & A & $\$ 80$ & & & \\
\hline $29 \Gamma 14$ & 27 & $3 \mathrm{C}$ & BEQ & & $\$ 2 A 12$ & & & \\
\hline 29116 & DE & $5 B$ & $\operatorname{LI} X$ & & NUM1 & * & HERE FOK SUETFACTION & \\
\hline 29018 & UIF & 77 & stx & & UNE & & & \\
\hline $29[1 \mathrm{~A}$ & DEE & 50 & LIXX & & NUM2 & & & \\
\hline $29[1 \mathrm{C}$ & $\mathrm{DIF}$ & 79 & STX & & LIEUX & & & \\
\hline 29 IIE & 70 & $005 \mathrm{E}$ & TST & & NUM1 1 & & & \\
\hline $29 \mathrm{E} 1$ & $2 A$ & 08 & BFL & & $\$ 29 E B$ & * & EF IF SWAF NOT NEEIIED & \\
\hline $29 E 3$ & DE & $5 \pi$ & LIIX & & NUM2 & & & \\
\hline 29E5 & $\mathrm{vF}$ & 77 & STX & & UNE & * & SWAF UNE \& TIEUX & \\
\hline 29E7 & UE & 58 & $\operatorname{Ln} D$ & & NUM1 & * & (DEUXX - UNE) & \\
\hline 29E9 & DF & 77 & $\operatorname{stx}$ & & Exist & & & \\
\hline 29EE & ID6 & $7 A$ & LIA & $\mathrm{B}$ & [IEU $X+1$ & * & TEST LS NIEELE FOR & \\
\hline $29 \mathrm{EI}$ & C4 & OF & ANII & E & $\$ \$ O F$ & * & REGROUFING & \\
\hline $29 \mathrm{EF}$ & 96 & 78 & LIIA & A & UNE+1 & & & \\
\hline $\begin{array}{l}29 F 1 \\
29 F 3\end{array}$ & $\begin{array}{l}84 \\
O C\end{array}$ & OF & $\begin{array}{l}\text { ANII } \\
\text { CLC }\end{array}$ & A & $\$ \$ O F$ & & & \\
\hline $29 F 4$ & 10 & & SEA & & & & & \\
\hline $29 F 5$ & 25 & {$[11$} & BCS & & $\$ 2908$ & & & \\
\hline $29 F ?$ & n6 & $7 A$ & LIIA & $B$ & OEUX+1 & * & TEST TENS NIEELEE & \\
\hline $29 \mathrm{~F} 9$ & $\mathrm{C} 4$ & Fo & ANI & $\mathrm{E}$ & $\$ \$ F O$ & & & \\
\hline $29 \mathrm{FB}$ & 96 & 78 & LIIA & A & UNE+1 & & & \\
\hline $29 \mathrm{FII}$ & 84 & Fo & ANI & A & $\# \$ F O$ & & & \\
\hline $29 \mathrm{FF}$ & OC & & CLC & & & & & \\
\hline $2 A 00$ & 10 & & SEA & & nonm & & & \\
\hline $2 A 01$ & 25 & $\operatorname{cs}$ & ECS & & $\$ 29 C 8$ & & & \\
\hline $2 \mathrm{AO3}$ & 106 & 79 & LIA & E & DEUX & * & TEST HUNDIFEIS NIBBLE & \\
\hline 2AOS & C4 & OF & AND & E & $\$ \$ O F$ & & & \\
\hline $2 A 07$ & 96 & 77 & LIIA & A & UNE & & .” & \\
\hline $2 A 09$ & 84 & OF & ANI & A & $\$ \$ O F$ & & & \\
\hline $\begin{array}{l}2 A O B \\
2 A O C\end{array}$ & $\begin{array}{l}\text { OC } \\
10\end{array}$ & & $\begin{array}{l}\text { CLC } \\
\text { SBA }\end{array}$ & & & & & \\
\hline 2AOD & 25 & B9 & $\mathrm{BCS}$ & & $\$ 29 C 8$ & & & \\
\hline $2 A O F$ & 39 & & RTS & & & * & IF HERE THEN NO FEGROUP & ING \\
\hline
\end{tabular}




$\begin{array}{lll}2 A 10 & 01 & \\ 2 A 11 & 01 & \\ & & \\ 2 A 12 & 06 & 5 C \\ 2 A 14 & C 4 & O F \\ 2 A 16 & 96 & 5 E \\ 2 A 18 & 84 & O F \\ 2 A 1 A & 8 A & 90 \\ 2 A 1 C & 1 B & \\ 2 A 10 & 19 & \\ 2 A 1 E & 25 & A B \\ 2 A 20 & 16 & 5 C \\ 2 A 22 & C 4 & F O \\ 2 A 24 & 96 & 5 E \\ 2 A 26 & 84 & F O \\ 2 A 28 & 1 B & \\ 2 A 29 & 19 & \\ 2 A 2 A & 25 & 9 C \\ 2 A 2 C & 116 & 5 B \\ 2 A 2 E & C 4 & O F \\ 2 A 30 & 96 & 5 D \\ 2 A 32 & 84 & O F \\ 2 A 34 & 8 A & 90 \\ 2 A 36 & 1 B & \\ 2 A 37 & 19 & \\ 2 A 38 & 25 & 8 E \\ 2 A 3 A & 39 & \end{array}$

\begin{tabular}{|c|c|c|}
\hline \multicolumn{3}{|c|}{$\begin{array}{l}\text { NOP } \\
\text { NDP }\end{array}$} \\
\hline LIIA & B & NUM $1+1$ \\
\hline ANI & $\mathrm{B}$ & $\$ O F$ \\
\hline LIAA & $A$ & NIJM2+1 \\
\hline AND & $A$ & $\$ \$ O F$ \\
\hline ORA & $A$ & $\$ \$ 90$ \\
\hline \multicolumn{3}{|c|}{$A B A$} \\
\hline \multicolumn{3}{|l|}{ DAA } \\
\hline BCS & & $\$ 29 C 8$ \\
\hline LIIA & B & NUM1+1 \\
\hline ANII & $B$ & $\neq$ A $F O$ \\
\hline LIA & A & NUM2+1 \\
\hline ANII & $A$ & $\$ \$ F O$ \\
\hline \multicolumn{3}{|l|}{$\begin{array}{l}A B A \\
\text { DAA }\end{array}$} \\
\hline \multicolumn{3}{|r|}{$\$ 29 C 8$} \\
\hline$L I I A$ & $B$ & NUM1 \\
\hline AND & $B$ & $\$ O F$ \\
\hline LIAA. & $A$ & NUM2 \\
\hline AND & $A$ & $\$ \$ O F$ \\
\hline OFIA & $A$ & $\$ \$ 90$ \\
\hline \multicolumn{3}{|l|}{ AEA } \\
\hline \multicolumn{3}{|l|}{$I M A$} \\
\hline $\operatorname{scs}$ & & $\$ 2968$ \\
\hline F'TS & & \\
\hline
\end{tabular}

* test fof alín fiegrouping

* test l.s niEBLE

* 9 profagates cakry

* test teng nieble

* test hundifiets NIERLE

* If here then NO fEgroufing

\begin{tabular}{|c|c|c|c|c|c|c|c|}
\hline $2 A 43$ & ED & 2706 & JSR & & BLANK & $*$ & ELANK ENTIFE DISFLAYY \\
\hline $2 A 46$ & $\mathrm{nE}$ & 64 & LIIX & & ATTFROES & & \\
\hline $2 A 48$ & [if & 77 & stx & & UNE & * & TOTAL_- WFONG $=$ AFIGHT \\
\hline $2 A 4 A$ & 96 & 06 & L.IIA & $A$ & WFONG & & \\
\hline $2 A 4 C$ & $8 \mathrm{~A}$ & 80 & ORA & $A$ & $\$ \$ 80$ & $*$ & CHANGE SIGN TO MINUS \\
\hline $2 A 4 E$ & 97 & 79 & STA & A & IEUUX & & \\
\hline $2 A 50$ & 96 & 67 & LDA & A & WFIONG+1 & & \\
\hline $\begin{array}{l}2 A 52 \\
2 A 54\end{array}$ & $\begin{array}{l}97 \\
\mathrm{BD}\end{array}$ & $\begin{array}{l}7 A \\
27 A 6\end{array}$ & $\begin{array}{l}\text { STA } \\
\text { JSR }\end{array}$ & A & $\begin{array}{l}\text { DEUX+1 } \\
\text { ALIIEM }\end{array}$ & * & SIGNED BCI AIIUITION FIOUTINE \\
\hline $2 A 57$ & 86 & $2 \mathbf{E}$ & LDA & A & $\$ \$ 2 \mathrm{E}$ & * & 'TOTAL" \\
\hline 2459 & $\mathrm{EDI}$ & $27 F 6$ & JSF & & SFKKWn & $*$ & LOAII WOFI INTO SFEECH EUJ. \\
\hline $2 A 5 C$ & 96 & 7E & LIIA & A & TROIX & & \\
\hline 2ASE & {$[16$} & $7 \mathrm{C}$ & LIIA & B & TFOOIX+1 & * & $A: B=A R I G H T$ \\
\hline $2 A 60$ & CE & 0006 & $\operatorname{Lax}$ & & $\$ \$ 0006$ & * & BUFFEF ADIR FOR FIRST IIISFLAY \\
\hline $2 A 63$ & BD & $27 \mathrm{cc}$ & JSR & & UNFACK & $*$ & SEFERATE NIEELES INTO EYTES \\
\hline Ac & $C E$ & 0078 & LIIX & & $\$ \$ 0078$ & $n$ & ALINE OF TFOIX \\
\hline $2 A 69$ & BD & $27 \mathrm{CF}$ & JSR & & SAYNUM & $*$ & FFONOUNCE FACKED NUA AT $(X)$ \\
\hline
\end{tabular}




\begin{tabular}{|c|c|c|c|c|c|c|c|}
\hline $\begin{array}{l}2 A G C \\
2 A B E\end{array}$ & $\begin{array}{l}86 \\
\text { ELI }\end{array}$ & $\begin{array}{l}21 \\
27 F 6\end{array}$ & $\begin{array}{l}\text { LIAA } \\
\text { JSR }\end{array}$ & A & $\begin{array}{l}+\$ 21 \\
\text { SPKWII }\end{array}$ & $\begin{array}{l}* \\
*\end{array}$ & $\begin{array}{l}\text { "QUEF" } \\
\text { LOALI WOFD INTO SFEECH ELF. }\end{array}$ \\
\hline $2 A>1$ & 96 & 64 & LLIIA & A & ATTPROES & & \\
\hline $2 A>3$ & {$[16$} & 65 & LIIA & $\mathrm{B}$ & ATTPROES+1 & & \\
\hline $\begin{array}{l}2 A>5 \\
2 A>8\end{array}$ & $\begin{array}{l}\text { CE } \\
\text { ELU }\end{array}$ & $\begin{array}{l}\text { OOOA } \\
27 \mathrm{CC}\end{array}$ & $\begin{array}{l}\operatorname{LnX} \\
\mathrm{JSR}\end{array}$ & & $\begin{array}{l}\$ \$ 0 O O A \\
\text { UNFACK }\end{array}$ & $\begin{array}{l}* \\
*\end{array}$ & $\begin{array}{l}\text { BUFFEF AIIIFI OF } 2 N I \text { OISFLAY } \\
\text { SEFEFATE NIBELES INTO BYTES }\end{array}$ \\
\hline $\begin{array}{l}2 A>B \\
2 A>I I\end{array}$ & $\begin{array}{l}86 \\
97\end{array}$ & EE & $\begin{array}{l}\text { LIIA } \\
\text { STA }\end{array}$ & $\begin{array}{l}A \\
A\end{array}$ & $\begin{array}{l}\$ \$ E E \\
\$ 0012\end{array}$ & $\begin{array}{l}* \\
*\end{array}$ & $\begin{array}{l}\text { CODE FOF IIUISION SIGN } \\
\text { PUFFER FOF OFEFATION SIGN }\end{array}$ \\
\hline $\begin{array}{l}2 A 7 F \\
2 A B 2\end{array}$ & $\begin{array}{l}C E \\
B I I\end{array}$ & $\begin{array}{l}0064 \\
27 \mathrm{CF}\end{array}$ & $\begin{array}{l}\text { LIIX } \\
\text { JSF }\end{array}$ & & $\begin{array}{l}\text { \#0064 } \\
\text { SAYNUM }\end{array}$ & $\begin{array}{l}* \\
*\end{array}$ & $\begin{array}{l}\text { AUIR OF NO. ATTEMPTED } \\
\text { FRONOUNCE PACKEI NUM AT }(X)\end{array}$ \\
\hline $\begin{array}{l}2 A 85 \\
2 A B 7\end{array}$ & $\begin{array}{l}86 \\
801\end{array}$ & $\begin{array}{l}65 \\
27 F 3\end{array}$ & $\begin{array}{l}\operatorname{LI} A A \\
J S R\end{array}$ & $A$ & $\begin{array}{l}\$ \$ 65 \\
\text { LIFAUS }\end{array}$ & $\begin{array}{l}* \\
*\end{array}$ & $\begin{array}{l}2 \text { SECOND PAUSE } \\
\text { LOAII FAUSE INTO SFEECH EIJF. }\end{array}$ \\
\hline $2 A B A$ & EII & 27EA & JSR & & WAIT & $*$ & WAIT TIL.L SFEECH-EUF EMFTY \\
\hline 2ABI & $B I$ & 2706 & JSF & & EILANK & * & ELANK ENTIRE RISFLAY \\
\hline $\begin{array}{l}2 A 90 \\
2 A 92\end{array}$ & $\begin{array}{l}96 \\
116\end{array}$ & $\begin{array}{l}\sigma A \\
6 B\end{array}$ & $\begin{array}{l}\operatorname{LLA} \\
\operatorname{LLA}\end{array}$ & $\stackrel{A}{B}$ & $\begin{array}{l}\text { MINUTES } \\
\text { MINUTES+1 }\end{array}$ & & \\
\hline 2994 & CE & 0006 & Lax & & $\$ 50006$ & $*$ & FIRST IIISF - ALIIR EUUFFER \\
\hline $2 A 97$ & $B[$ & $2>C C$ & JSK & & UNFACK & * & SEFEFATE NIHBLES INTO BYTES \\
\hline $2 A 9 A$ & CE: & OO6A & LIIX & & $\$ 006 \mathrm{~A}$ & $*$ & AIIIIF OF MINUTES \\
\hline $2 A 9 I$ & EIII & $27 \mathrm{CF}$ & JSF & & SAYNUM & $\ddot{*}$ & FFONOUNCE FACKEU NUM AT (X) \\
\hline ZAAO & 86 & 27 & LIIAA & $A$ & $\$ \$ 27$ & * & "AND" \\
\hline 2AA2 & EII & $27 F G$ & JSR & & SFKWI & * & LOAE WOFI INTO SPEECH BUF. \\
\hline IAAS & 96 & 68 & $\operatorname{LIIA}$ & $A$ & GFrñNnS & & \\
\hline $2 A A 7$ & 116 & 69 & $\operatorname{LI} A$ & $\mathbf{B}$ & SECONHS+1 & $*$ & AIIIE OF $3 N \mathrm{NI}$ UTSF BUFFER \\
\hline ZAAC & $\mathrm{BD}$ & $27 \mathrm{CC}$ & $J S R$ & & UNFACK & $\dot{*}$ & SEFERATE NIEELES INTO BYTES \\
\hline 2AAF & $C E$ & 0068 & $\operatorname{Lnx}$ & & $\$ \$ 0068$ & * & ACIUER OF SECONDS \\
\hline 2AB2 & $\mathrm{BD}$ & $2>C F$ & $J S F$ & & SAYNUM & * & FRIONOUNCE FACKER NUM AT $(X)$ \\
\hline $2 A B 5$ & 86 & 28 & LIIA & $A$ & $\$ \$ 28$ & * & "SECONOS" \\
\hline 2AB7 & BD & $27 F 6$ & JSF & & SFKWLI & $*$ & LOAAI WORI INTO SFEECH RUF. \\
\hline $\begin{array}{l}2 A B A \\
2 A B D\end{array}$ & $\begin{array}{l}311 \\
39\end{array}$ & 27EA & $\begin{array}{l}\text { JSR } \\
\text { RTS }\end{array}$ & & WAIT & * & WAIT TILL SPEECH-BIJF EMPTY \\
\hline
\end{tabular}

**** START OF TEACH SUBROUTINE ****

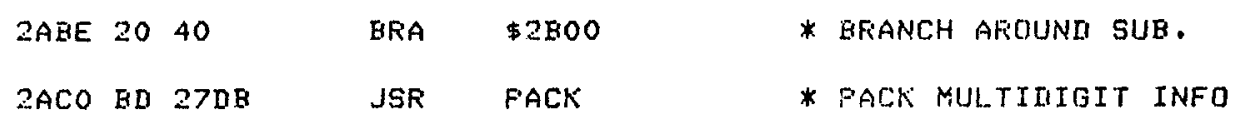




\begin{tabular}{|c|c|c|c|c|c|c|c|}
\hline $\begin{array}{l}2 A C 3 \\
2 A C 5\end{array}$ & $\begin{array}{l}96 \\
106\end{array}$ & $\begin{array}{l}44 \\
45\end{array}$ & $\begin{array}{l}\text { LIIA } \\
\text { LIA }\end{array}$ & $\begin{array}{l}A \\
B\end{array}$ & $\begin{array}{l}\text { TIMER } \\
\text { TIMEFi+1 }\end{array}$ & * & ALLOWEI-TIME LEFT $=$ \\
\hline & & & & & * TIME & TAKEN & \\
\hline $2 A C 7$ & CE & 0060 & $\operatorname{Lnx}$ & & $\$ \$ 0060$ & * & ALIER OF UISFTIM \\
\hline ZACA & BLI & $27 B \amalg$ & $J S R$ & & BISUB & * & UNSIGNEI BINARY SUBTRACTION \\
\hline ZACD & [IE & 60 & LIIX & & IISFTIM & & \\
\hline ZACF & 08 & & INX & & & * & COFFECT TIME TAKEN \\
\hline 2ADIO & DF & $6 \mathrm{D}$ & STX & & IISPTIM & & \\
\hline $2 A D 2$ & 86 & 00 & LDA & A & $\$ \$ 00$ & * & SUETFACT $50(\$ 32)$ FFOM TIME \\
\hline $\begin{array}{l}\text { 2ADIA } \\
\text { 2ALIG }\end{array}$ & $\begin{array}{l}\text { C6 } \\
\text { CE }\end{array}$ & $\begin{array}{l}32 \\
0060\end{array}$ & $\begin{array}{l}\text { LIAA } \\
\text { LIIX }\end{array}$ & $\mathrm{B}$ & $\begin{array}{l}\$ \$ 32 \\
\$ 006 n\end{array}$ & * & TAKEN TO GET SEC (IIIU, BY SO) \\
\hline ZADS & EII & $278 \square$ & JSR & & BISUB & * & UNSIGNEI EINAFY SUJETRACTION \\
\hline SADC & 24 & $1 \mathrm{~F}$ & $\mathrm{ECC}$ & & $\$ 2 A F[1$ & * & FEETUFH IF FEESLLT NEG, \\
\hline 2ADE & $C E$ & 0068 & LIIX & & $\$ 0068$ & * & AURF OF SECONOS \\
\hline $2 A E 1$ & $\mathrm{BD}$ & $27 E 7$ & JSR & & ECIINC & * & INCREMENT (ECL) AT $X \& x+1$ \\
\hline $\begin{array}{l}2 A E 4 \\
2 A E 6\end{array}$ & $\begin{array}{l}\text { IIE } \\
8 \mathrm{C}\end{array}$ & $\begin{array}{l}68 \\
0060\end{array}$ & $\underset{C F X}{\operatorname{LnX}}$ & & $\begin{array}{l}\text { SECONDS } \\
\$ \$ 0060\end{array}$ & & \\
\hline 2AE9 & 26 & $O B$ & BNE & & $\$ 2 A F 6$ & & \\
\hline $\begin{array}{l}\text { 2AEB } \\
2 A E E\end{array}$ & $\begin{array}{l}\text { CE } \\
\text { IIF }\end{array}$ & $\begin{array}{l}0000 \\
68\end{array}$ & $\begin{array}{l}\operatorname{LIXX} \\
\text { STX }\end{array}$ & & $\begin{array}{l}\text { \#\$0000 } \\
\text { SECONDS }\end{array}$ & & \\
\hline $2 A F O$ & $C E$ & OOGA & L.IIX & & $\$ \$ 006 \mathrm{~A}$ & $*$ & ALUR OF MINUTES \\
\hline 2AF3 & BII & 2787 & JSR & & ECIINC & * & TNCFEMENT (BCII) AT $X \& X+1$ \\
\hline PAFG & $\mathrm{DE}$ & 71 & LIIX & & BINSECS & & \\
\hline $2 A F B$ & 08 & & $\operatorname{INX}$ & & & & \\
\hline ZAF9 & [IF & 71 & STX & & BINSECS & & \\
\hline $2 A F B$ & 20 & 115 & BRA & & \$2AII2 & & \\
\hline $2 A F D$ & 39 & & FTS & & & & \\
\hline ZAFE & 20 & co & EFiA & & $\$ 2 A C O$ & $*$ & STEFFING STONE \\
\hline $2 B O O$ & IIE & $4 A$ & L. DXX & & SEEII & & \\
\hline 2802 & {$[I F$} & 71 & STX & & Bt:LIA & * & TRONSFEF SEEDS TO START \\
\hline $2 \mathrm{BOA}$ & DE & 62 & $\operatorname{LIXX}$ & & SEE[I2 & $\dot{*}$ & FROBLEM SETS \\
\hline $\begin{array}{l}2806 \\
2808\end{array}$ & $\underset{C E}{D F}$ & $\begin{array}{l}7 F \\
0000\end{array}$ & $\begin{array}{l}\text { STX } \\
\text { LIIX }\end{array}$ & & $\begin{array}{l}\text { SEEnR } \\
\$ \$ 0000\end{array}$ & & \\
\hline $2 B O B$ & IIF & 68 & STX & & SECONDS & $*$ & CLEAR COUNTERS \\
\hline $2 \mathrm{BOO}$ & $\mathrm{nF}$ & $6 A$ & STX & & MINUTES & & \\
\hline 2EOF & IIF & 64 & STX & & ATTFFOES & & - \\
\hline $2 B 11$ & IIF & 71 & stx & & BINSECS & & \\
\hline 2813 & IIF & 66 & $\operatorname{srx}$ & & WRONG & & \\
\hline $2 \mathrm{~B} 15$ & 86 & 01 & LIIA & A & $\$ \$ 01$ & * & SET SAY SO FFOELEMS \\
\hline $\begin{array}{l}2 B 17 \\
2 E 19\end{array}$ & $\begin{array}{l}97 \\
7 F\end{array}$ & $\begin{array}{l}61 \\
006 C\end{array}$ & $\begin{array}{l}\text { STA } \\
\text { CLF: }\end{array}$ & A & $\begin{array}{l}\text { SAY } \\
\text { EFIROR }\end{array}$ & * & WITHOUT ANSWEFS AFE SAII. \\
\hline $2 B 1 C$ & 81 & 75 & BSR & & $\$ 2893$ & * & GENERATE NEW FRIOELEM \& ANS. \\
\hline $2 B 1 E$ & 01 & & NOP & & & & \\
\hline $2 B 1 F$ & $\mathrm{BD}$ & $27 \mathrm{Co}$ & JSR & & SAYDISP & * & FFIONOUNCE FFIOELEM \\
\hline $2 \mathrm{~B} 22$ & 01 & & NOP & & & & \\
\hline $\begin{array}{l}2823 \\
2 B 24\end{array}$ & $\begin{array}{l}01 \\
01\end{array}$ & & $\begin{array}{l}\text { NOP } \\
\text { NQP }\end{array}$ & & & & \\
\hline $2 \mathrm{E} 25$ & $\mathrm{BII}$ & 2709 & $J S F$ & & DITSPLAY & * & LOAII FROB. INTO UISFLAY \\
\hline $\begin{array}{l}2 \mathrm{~B} 28 \\
2 \mathrm{E} 2 \mathrm{~B}\end{array}$ & $\begin{array}{l}\text { BII } \\
\text { CE }\end{array}$ & $\begin{array}{l}27 C 3 \\
\text { FFFE }\end{array}$ & $\begin{array}{l}\text { JSR } \\
\text { LIXX }\end{array}$ & & $\begin{array}{l}\text { BLANKIT } \\
\$ \$ F F F E\end{array}$ & $\begin{array}{l}* \\
*\end{array}$ & $\begin{array}{l}\text { BLANK MISSING NO. IN DISP. } \\
\text { IF OPTION NOT SFEEO THEN }\end{array}$ \\
\hline 2B2E & 96 & 49 & LIIA & A & DFTION & * & IISFTIM $=$ MAX ELSE TIMLIM. \\
\hline $2 \mathrm{~EB} 30$ & 81 & $O E$ & CMF & A & $\$ \$ O E$ & * & $=S F E E D ?$ \\
\hline
\end{tabular}




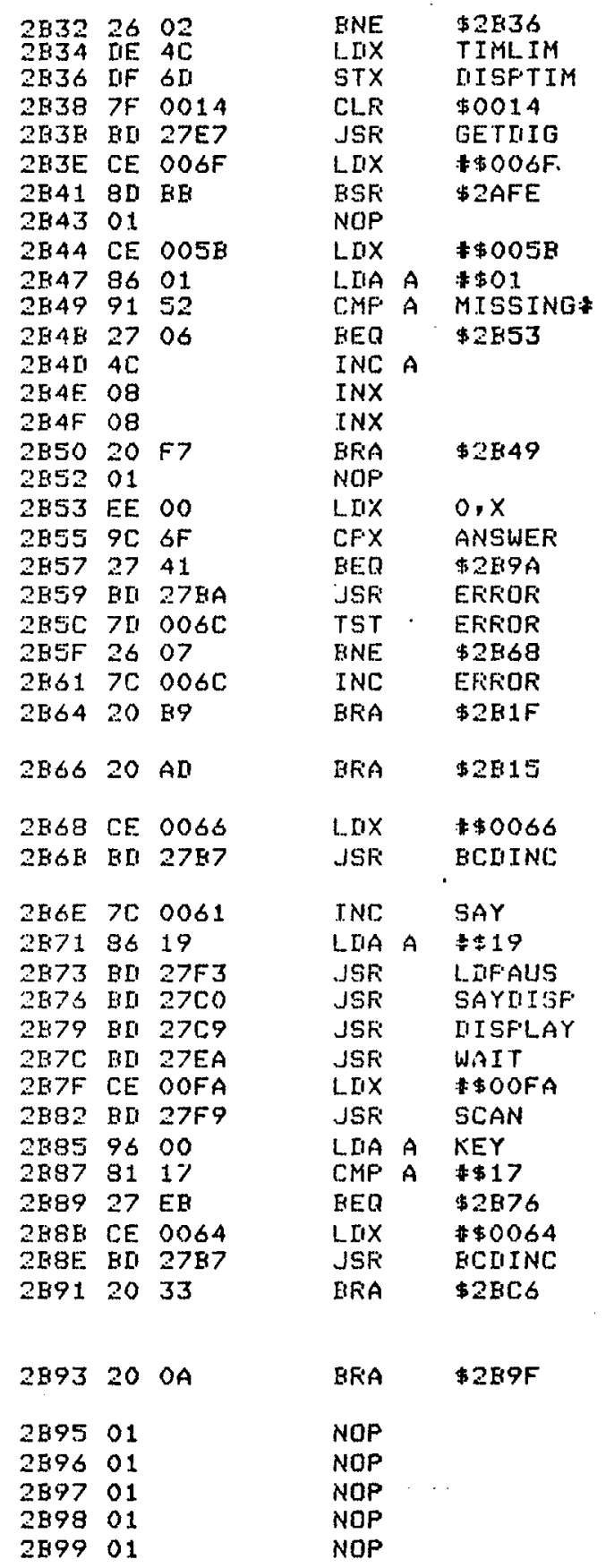

* efFompt kEyEOARD

* go get IILgITS fFom keyeroarid

* anlir dF aNSWER

* uFuate time info

* fut alirir of cofirect ans.

* IN X FEEG

* COMFAFE STULIENTS ANS. \&

* corfiect answer

* afFl. y NEg . FeEDBack

* If ERFIOR =0 THEN tFiy again

* ASK again

* stefping stone to new frogelem

* alderi of hrong

* incFement (eCD) at $x \& x+1$

* enable saying of answer

* 1/2 second fiause

* loal pause tNTU SFEech guf.

* FFONOUNCE FIFOELES

* loadi frice. into nisplay

* WAIT TILL SFEECH-EUF EMFTY

* 5 SEC faUse

* INFUT:KEYS DUTFUT:DISF, \& TALK

* KEY = REFEAT?

* atiLf of atTPFon

* INCFEMENT (ECI) at $x \& x+1$

* TEST FOF ENI CONIITIONS

* steping stone 


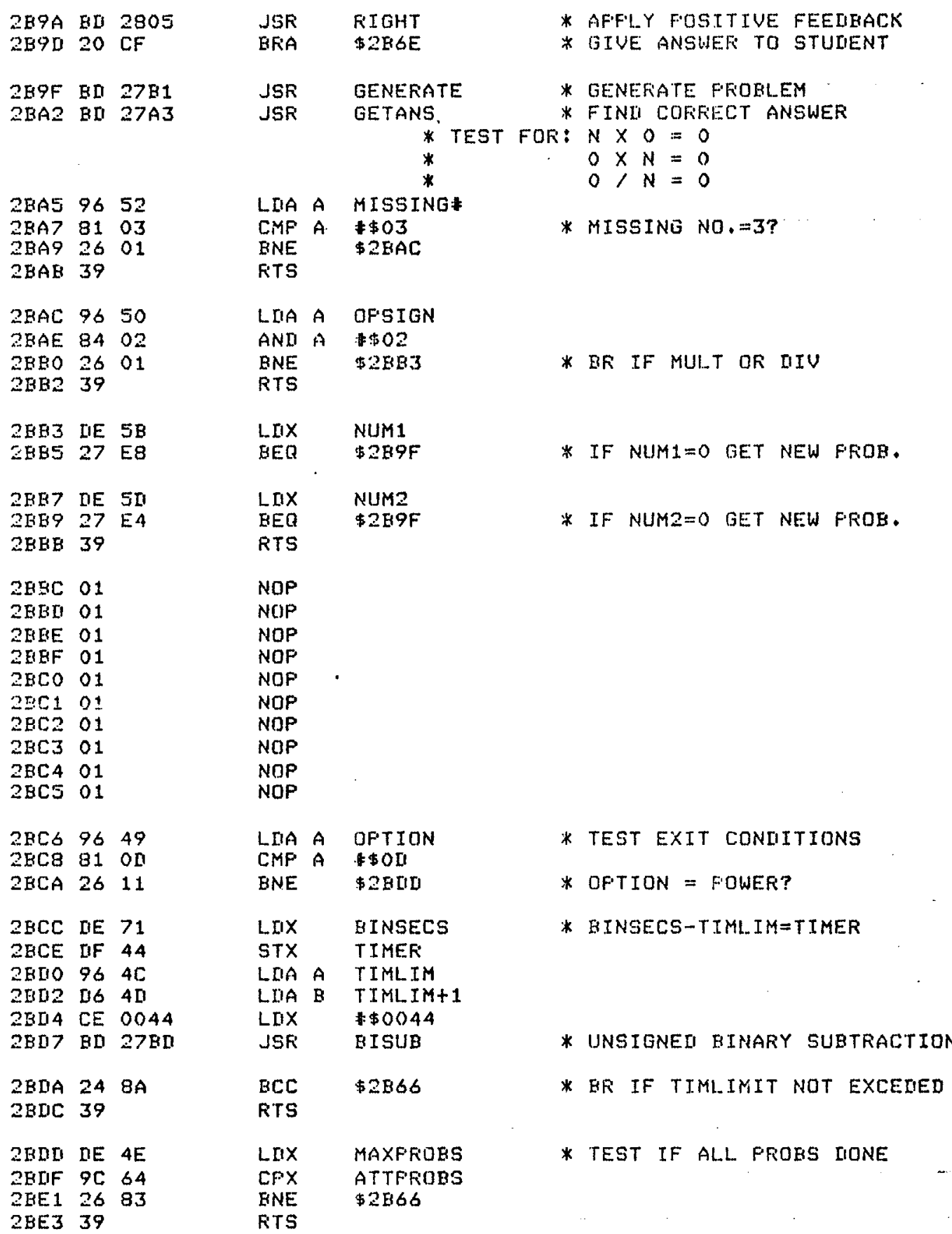


**** START OF EFROR SUBROUTINE ****

\begin{tabular}{|c|c|c|c|c|c|}
\hline 2000 & $\mathrm{BD}$ & 27EA & JSR & & WAIT \\
\hline $2 \cos$ & 86 & 01 & $\operatorname{LI} A$ & $A$ & $\$ \$ 01$ \\
\hline $2 \cos$ & 97 & 42 & STA & A & DIGS \\
\hline $\begin{array}{l}2 \mathrm{CO} 7 \\
2 \mathrm{CO} 9\end{array}$ & $\begin{array}{l}86 \\
97\end{array}$ & $\begin{array}{l}O A \\
43\end{array}$ & $\begin{array}{l}\text { LDA } \\
\text { STA }\end{array}$ & $\begin{array}{l}A \\
A\end{array}$ & $\begin{array}{l}\$ \$ O A \\
\text { DIG6 }\end{array}$ \\
\hline $2 \mathrm{COA}$ & $8 D$ & OII & ESF & & $\$ 2 C 1 A$ \\
\hline $2 \mathrm{CON}$ & $7 A$ & 0042 & DEC & & DIGS \\
\hline $2 \mathrm{C} 10$ & 26 & 00 & ENE & & $\$ 2 C 12$ \\
\hline $2 C_{12}$ & 80 & 11 & ESFi & & $\$ 2 C 25$ \\
\hline $2 \mathrm{C} 14$ & $7 A$ & 0043 & DIEC & & DIG6 \\
\hline $\begin{array}{l}2 C 17 \\
2 C 19\end{array}$ & $\begin{array}{l}26 \\
39\end{array}$ & $F 9$ & $\begin{array}{l}\text { BNE } \\
\text { RTS }\end{array}$ & & $\$ 2 C 12$ \\
\hline $2 \mathrm{C} 1 \mathrm{~A}$ & 86 & $3 E$ & LIIA & $\dot{A}$ & $\$ \$ 3 E$ \\
\hline $2 \mathrm{C} 1 \mathrm{C}$ & BU & $27 F 6$ & JSfi & & SPKWW \\
\hline 2C.1F & 86 & $3 E$ & LIIA & $A$ & $\$ 3 E$ \\
\hline $2 C 21$ & BII & $27 F 6$ & JSF & & SFK゙UI \\
\hline $2 \mathrm{C} 24$ & 39 & & RTS & & \\
\hline $2 C 25$ & BII & 2706 & JSF & & BL.ANK \\
\hline 2028 & $C E$ & 0005 & LIIX & & $\$ \$ 0005$ \\
\hline $2 \mathrm{C} 2 \mathrm{~B}$ & $\mathrm{BD}$ & $27 F 9$ & $J S F$ & & SCAN \\
\hline $2 \mathrm{C} 2 \mathrm{E}$ & EII & 2709 & JSF & & IISFLAY \\
\hline 2081 & $\mathrm{Er}$ & $2>03$ & JSF & & E! $\Delta N K I T$ \\
\hline 2034 & $C E$ & 0005 & LIIX & & $\$ \$ 0005$ \\
\hline $\begin{array}{l}2 \mathrm{C} 37 \\
2 \mathrm{C} 3 \mathrm{~A}\end{array}$ & $\frac{\mathrm{BI}}{39}$ & $27 F 9$ & $\begin{array}{l}\text { JSF } \\
\text { RTS }\end{array}$ & & SCAN \\
\hline
\end{tabular}

**** START OF AIIREM SUBFIOUTINE ****

\begin{tabular}{|c|c|c|c|c|}
\hline $2 C 40$ & LIE & 77 & $\operatorname{Lax}$ & UINE \\
\hline $2 C 42$ & $8 C$ & 8000 & $C P X$ & $\$ \$ 8000$ \\
\hline $2 \mathrm{C} 45$ & 26 & 05 & BNE & $\$ 2 C 4 C$ \\
\hline $\begin{array}{l}2 \mathrm{C} 47 \\
2 \mathrm{C} 4 \mathrm{~A}\end{array}$ & $\begin{array}{l}C E \\
\mathrm{CHF}\end{array}$ & $\begin{array}{l}0000 \\
77\end{array}$ & $\begin{array}{l}\operatorname{LIXX} \\
\text { STX }\end{array}$ & $\begin{array}{l}\text { \$00000 } \\
\text { UNE }\end{array}$ \\
\hline $2 \mathrm{C} 4 \mathrm{C}$ & $\mathrm{DE}$ & 79 & $\operatorname{LIX}$ & ¿IEUX \\
\hline $\begin{array}{l}2 \mathrm{CAE} \\
2 \mathrm{CS} 1\end{array}$ & $\begin{array}{l}8 \mathrm{C} \\
26\end{array}$ & $\begin{array}{l}8000 \\
05\end{array}$ & $\begin{array}{l}\text { CF'X } \\
\text { BNE }\end{array}$ & $\begin{array}{l}\$ \$ 8000 \\
\$ 2058\end{array}$ \\
\hline 2053 & CE & 0000 & $\operatorname{Ln} \operatorname{Lx}$ & $\$ \$ 0000$ \\
\hline 2056 & IIF & 79 & STX & DEUX \\
\hline 258 & 96 & 77 & LIA A & UNE \\
\hline $2 C 5 A$ & 98 & 79 & EOR A & IIEUX \\
\hline
\end{tabular}

* WAIT TTLL SFEECH-BUF EMPTY

* of toNe faIfis

* af IISFlay blinks

* SOUND TONES

* BLINK IIISPLAY

* "HT TONE.

* loar wofid tetro sfeech buf.

* "HI TONE"

* LOAD WOFE INTO SFEECH EUF.

* ellank entifie iIsflay

* 1/10 secorri fause

* INFUT:KEeys OUTFUT:UISF. \& talk

* LOADI FFIOB. INTO DISFLAY

* PILANK MTSSTNA MO. TN IITSP.

* 1/10 SECONI FAUSE

* INFUT:KEYS OUTFUT:DISF. \& TALK
* CHECK foR MINUS ZERO

* IN UNE ANU IIEUX 


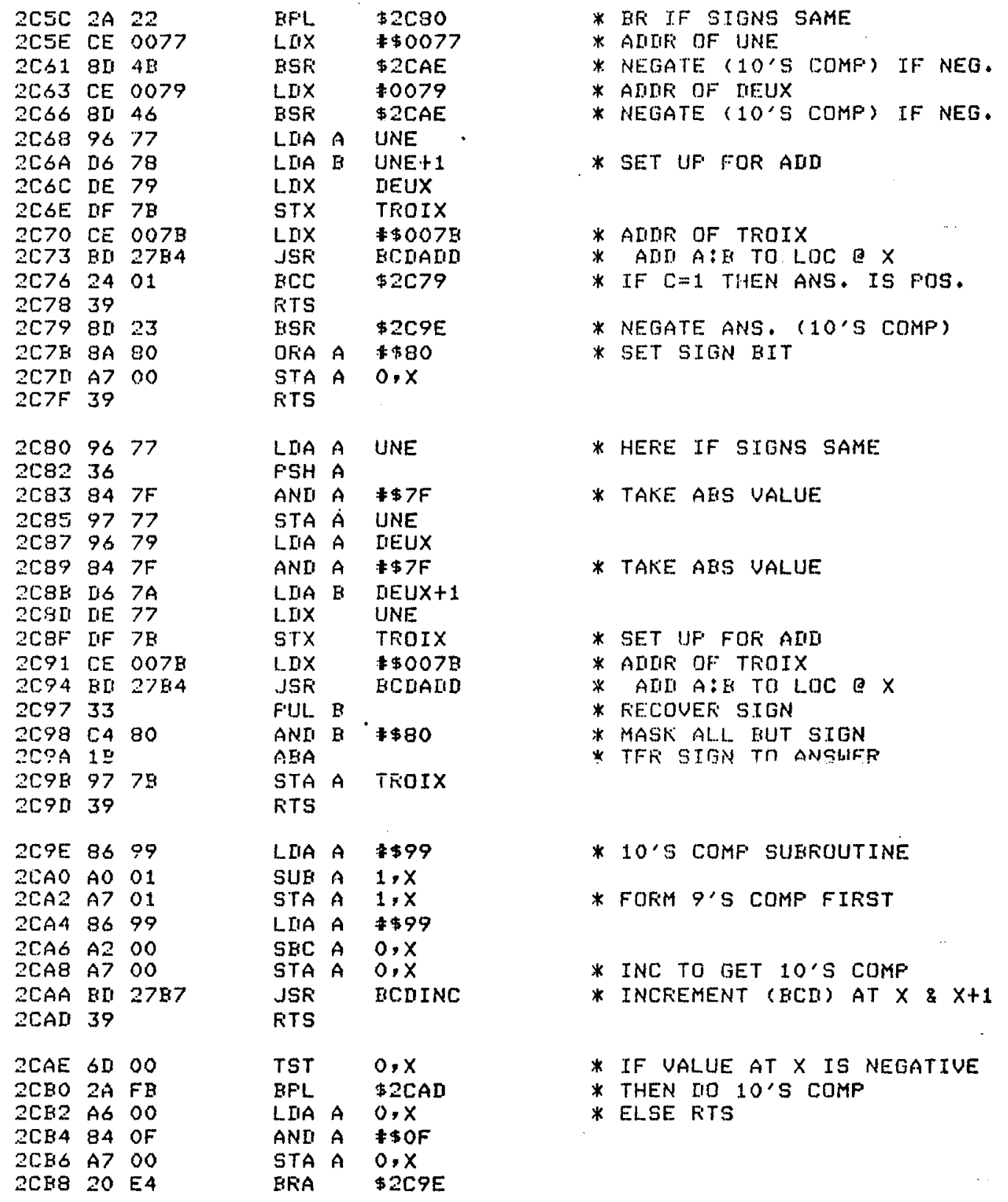




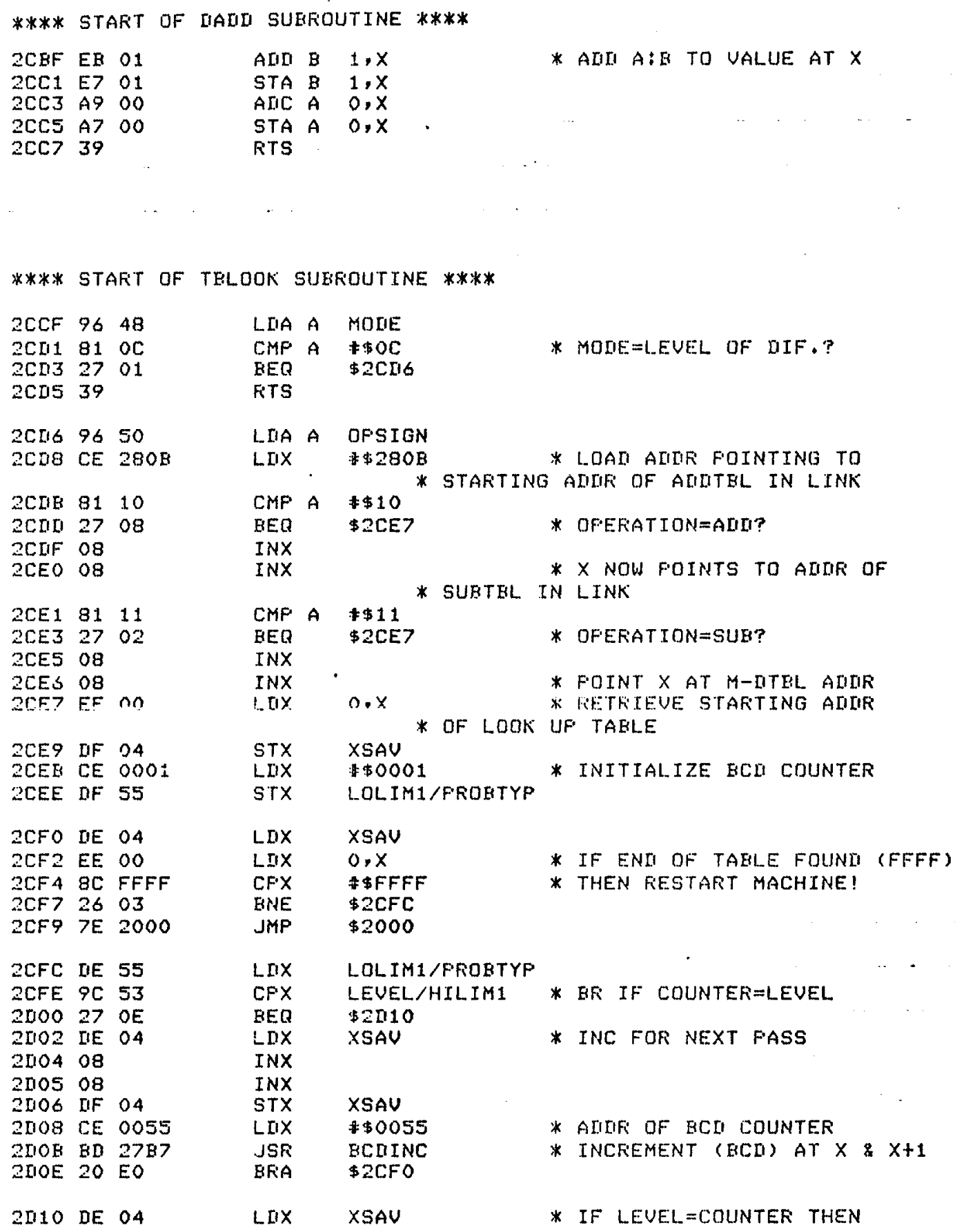

LIX XSAV

* IF LEUEL=COUNTER THEN 


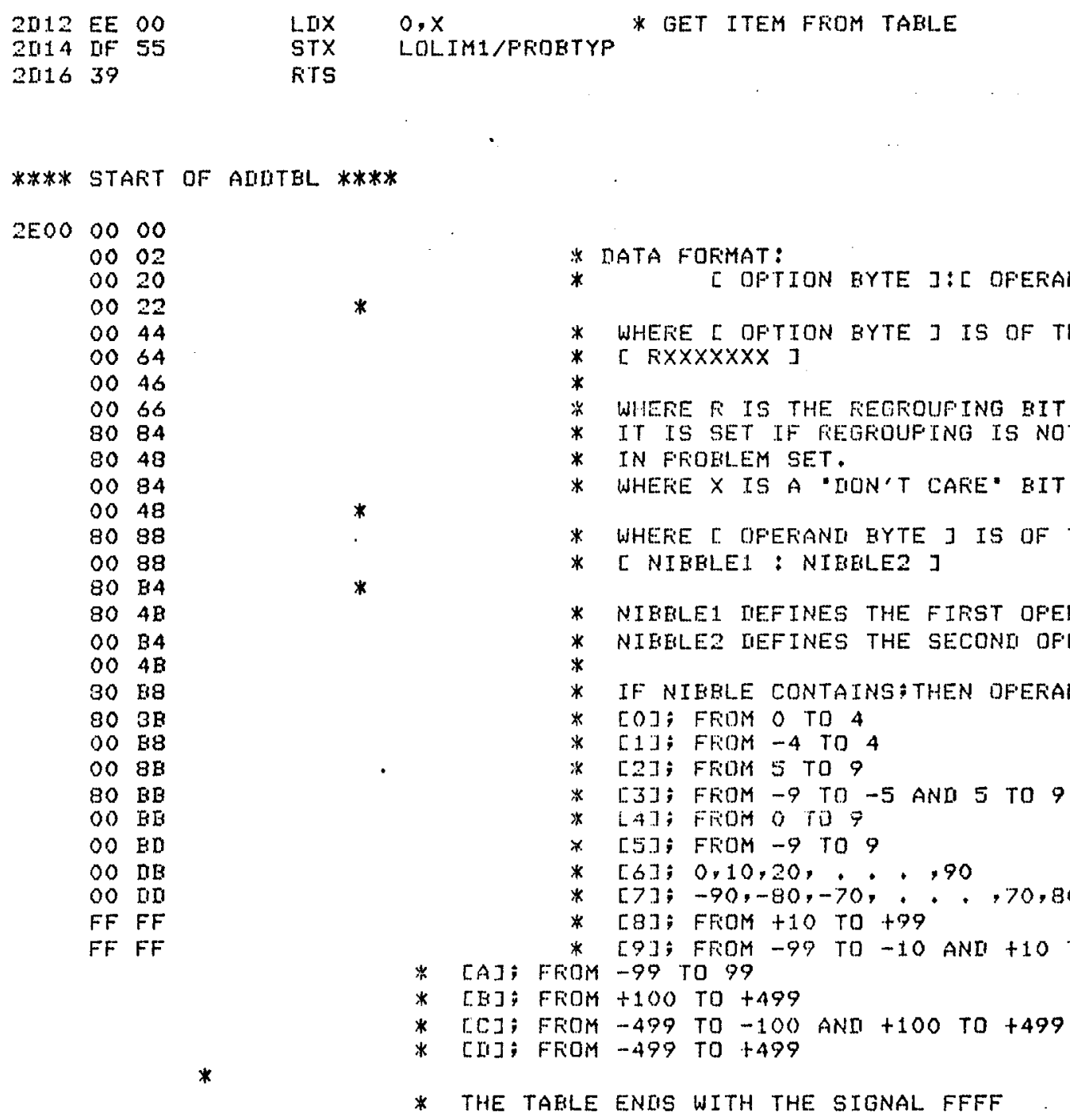

*

* the tafle endes with the signal ffFF

**** START OF SUBTBL ****

$2 E 80 \quad 40 \quad 00$

$40 \quad 02$

4020

$40 \quad 22$

$40 \quad 44$

8088
* the tiata is of the forimat:

* [ OFTION EYTE ]:[ OFEFAND BYTE ]

* WHEFE [ OFTION BYTE ] IS of THE fORMAT:

* [ FiTXX XXXX] 

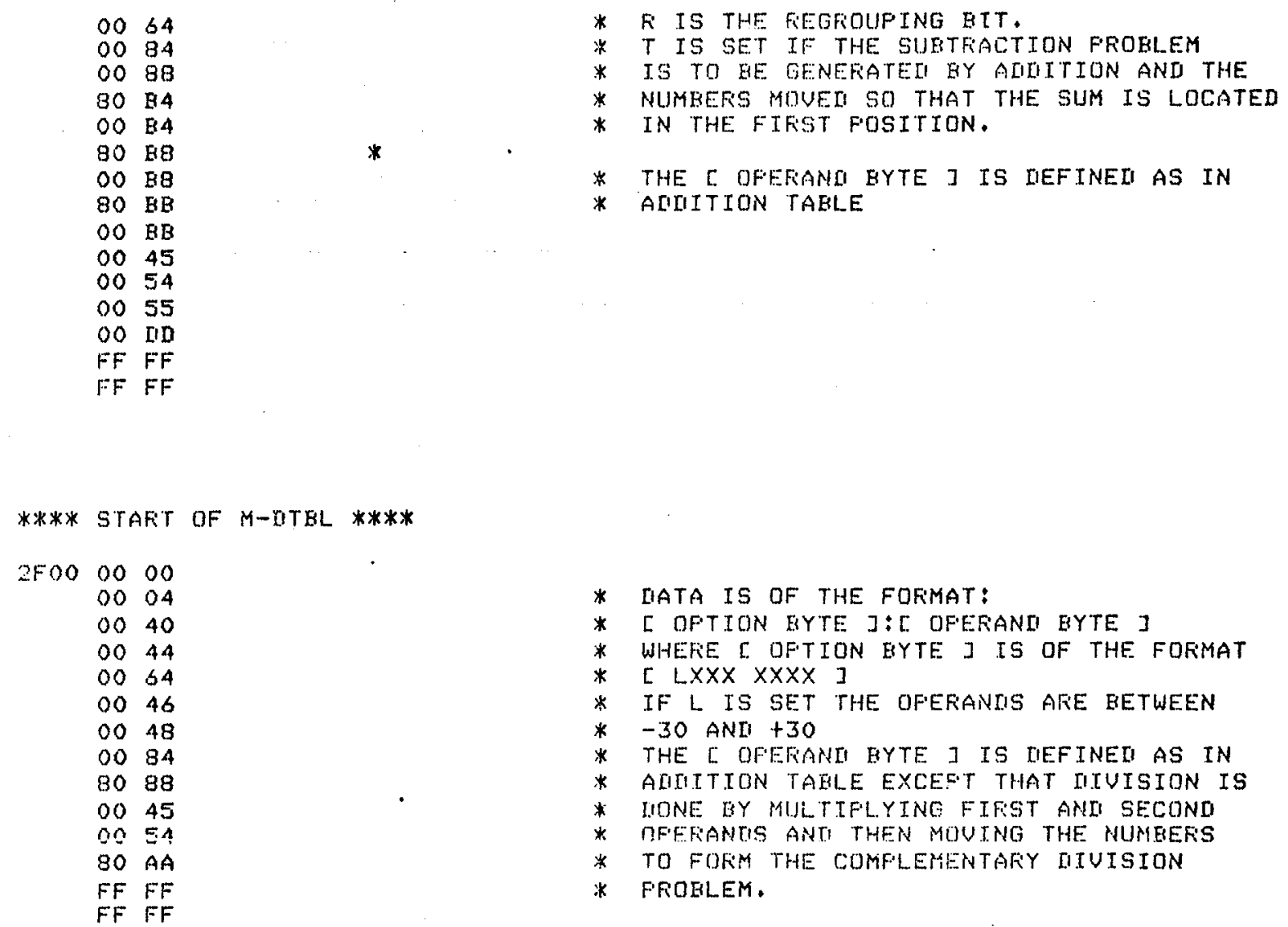

* [ oftion EYTte ]:[ oferand byte ]

* WHEFE [ OFTION EYTE ] IS OF THE FORMAT

* [ LXXX XXXX]

* IF L IS SET THE OFERANIS ARE BETWEEN

* -30 ANI t3o

* THE [ OFEFANII GYTE ] IS TIEFINED AS IN

* alimition takle except that fituision is

* IIONE bY MULTIFLy YNG FIFST AMII SECONO

* DFEFANUS ANTI THEN MOUTNG THE NUMEERS

* TO FOFM THE COMFLEMETTAFIY DIUISION

FF FF

* FROELEM.

**** STAFT OF BLANK SUEFOUTINE ****

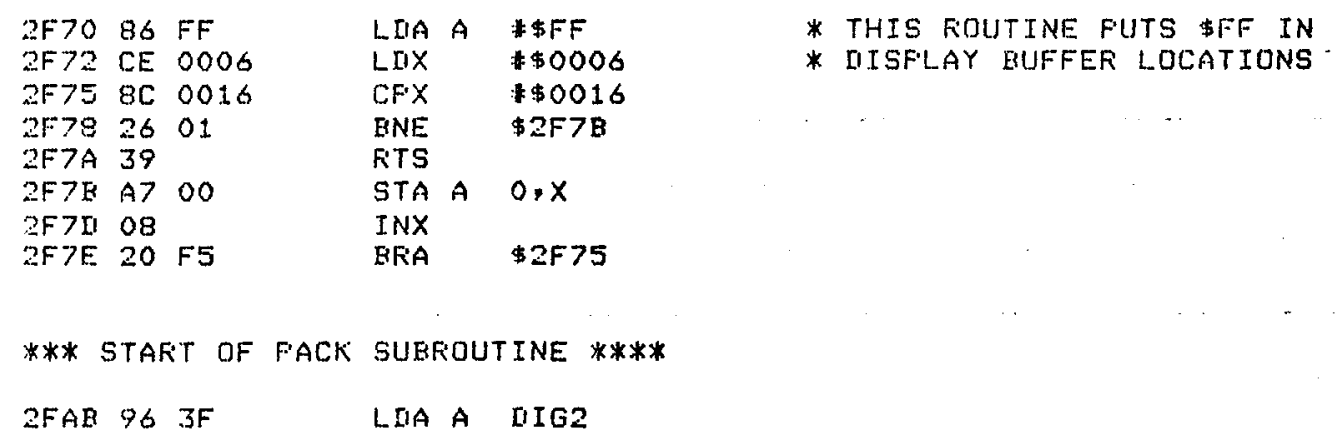




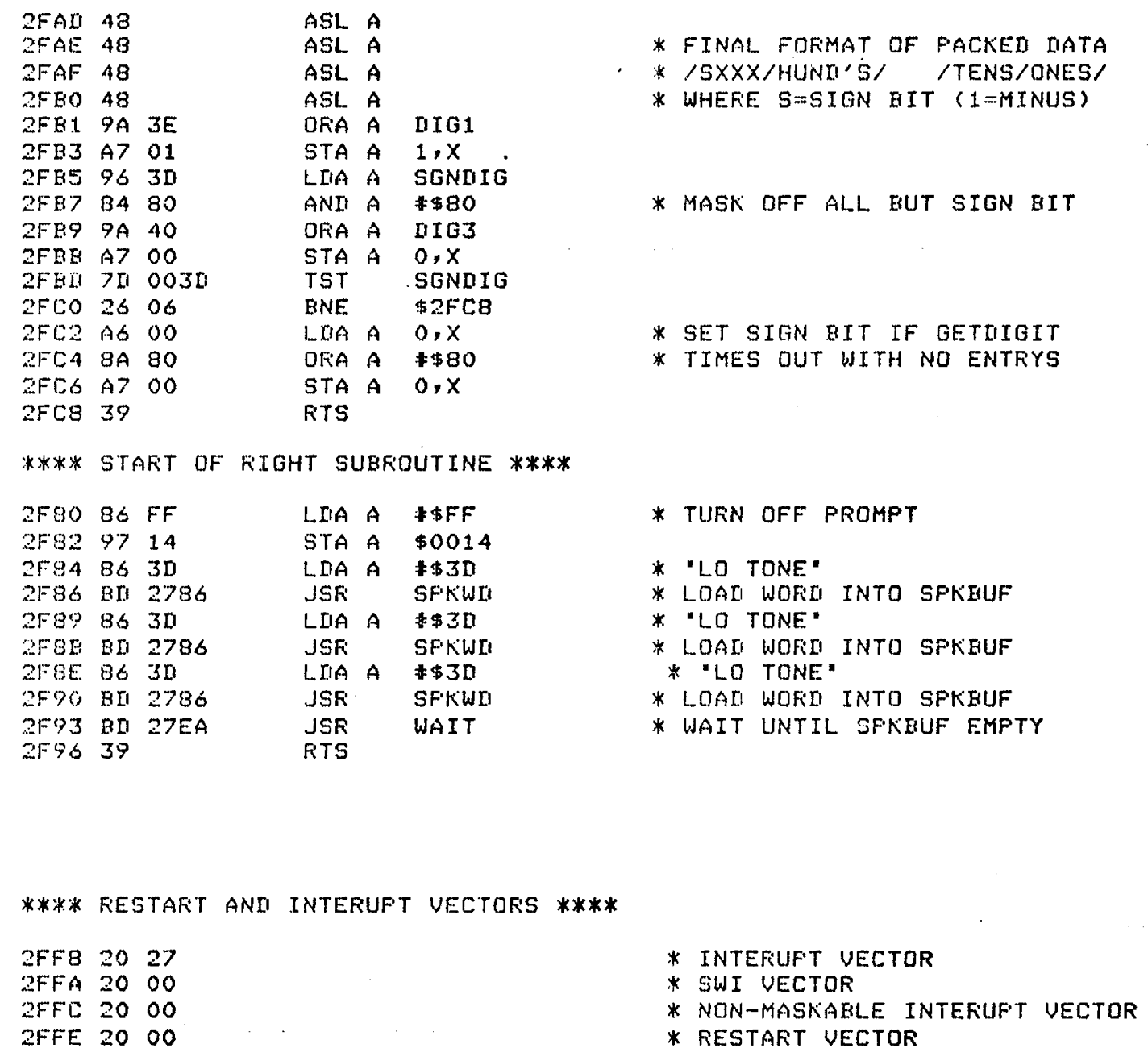

$* * * * * * * * * * * * * * * * * * * * * * * * * * * * * * * * * * * * * * * * * * * * * * * * * * * *$ ***** END OF CONTFIDL FFOGFAMS *********************************************************** 


\section{APPENDIX IV \\ PROCEDURE FOR BURNING EPROMS}

The 2708 EPROMs were programmed using a PRO-LOG M900 Universal PROM Programmer, equipped with a model 9115 RS232 interface. The programer was controlled by a D2 microcomputer having a 4K RAM board. The D2 kit was interfaced to the programmer via a standard 25 pin communications connector and the circuit shown in Fig. 1. After loading the $4 \mathrm{~K}$ RAM with the data to be programmed, the EPROM burning program, shown herein, was loaded. The addresses of the beginning and end of the data block were entered into memory at locations $\$ 0000$ $\$ 0003$. The PROLOG was reset and the program was executed starting at $\$ 0004$. 


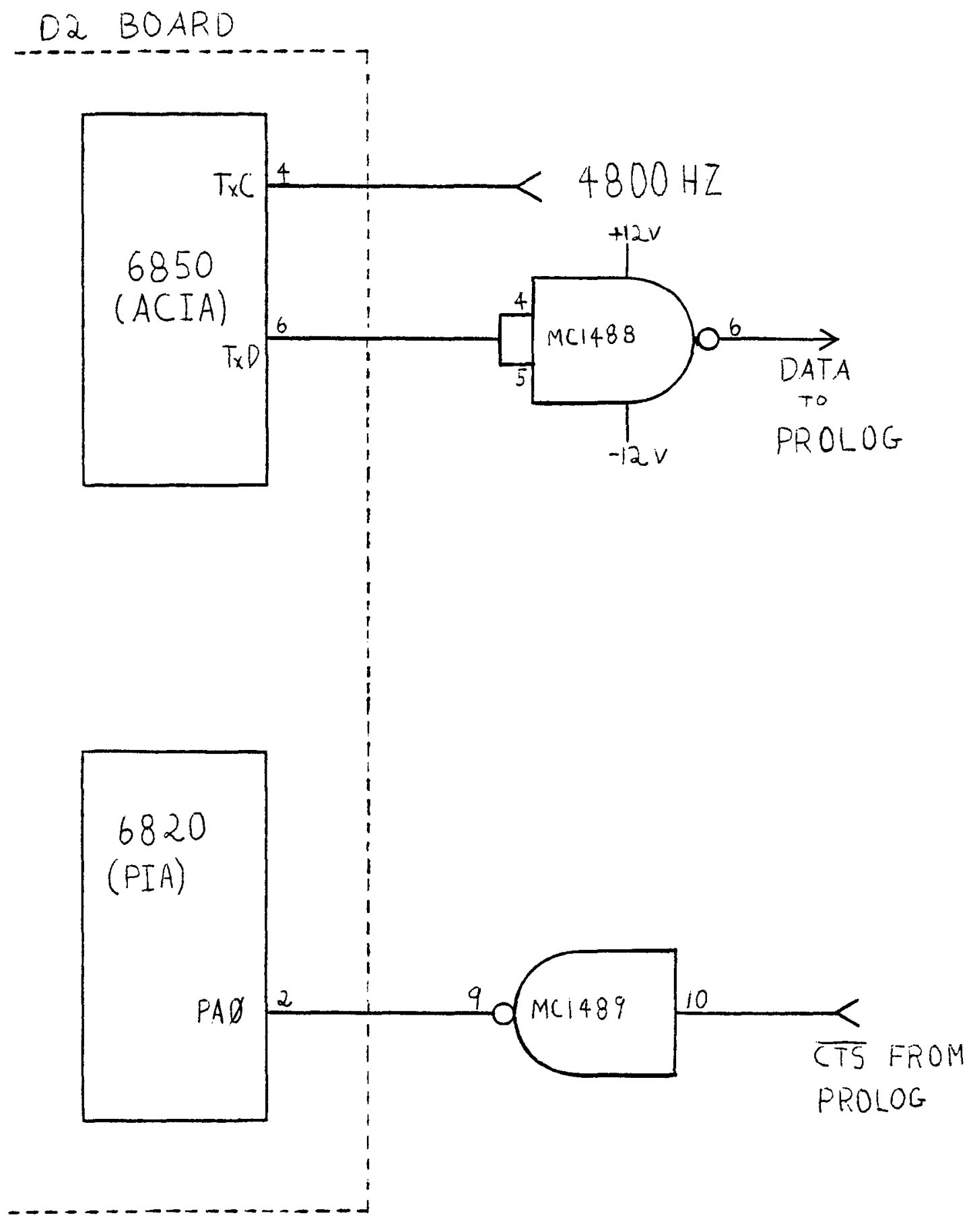

FIGURE 1 - D2 to Prolog Interface 
MAIN

\section{$\$ 0004$}

JSR INITIALIZE
LDAA, \$30
JSR OUTCR
LDA $\$ 30$
JSR OUTCR
LDA $\$ 46$
JSR OUTCR
LDA $\$ 46$
JSR OUTCR
LDA $\$ 50$
JSR OUTCR

LOOP

LDX START
LDAAX,0
JSR OUTBYTE

LDX START

CPX END

BEQ EXIT

INX

STX START

BRA LOOP

$\begin{array}{ll}\text { EXIT } & \text { LDA \$04 } \\ & \text { JSR OUTCR } \\ \text { SWI } & \text { SWI } \\ \text { CMPA } \$ 0042) & \\ & \text { BGT\{AF\} } \\ & \text { ADD A } \$ 30 \\ & \text { USR OUTCR } \\ & \text { RTS } \\ \text { (4C)AF } & \text { ADD A } \$ 47 \\ & \text { JSR OUTCR } \\ & \text { RTS }\end{array}$

(\$0052)

OUTBYTE

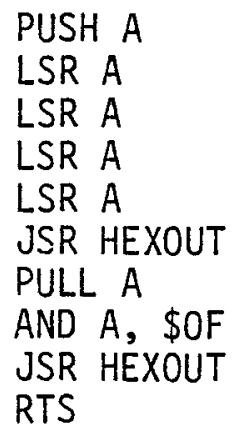

(\$0070)

OUTCH

PUSH B

JSR PATCH

ASR B

ASR B
$\mathrm{BD}, 00,92$

86,30

$\mathrm{BD}, 00,7 \mathrm{~F}$

86,33

$\mathrm{BD}, 00,7 \mathrm{~F}$

86,46

$\mathrm{BD}, 00,7 \mathrm{~F}$

86,46

$\mathrm{BD}, 00,7 \mathrm{~F}$

86,50

$\mathrm{BD}, 00,7 \mathrm{~F}$

$D E, 00$

A6, 00

$B E, 00,52$

DE, 00

$9 \mathrm{C}, 02$

27,05

08

DF, 00

20, EE

$\begin{array}{ll}86,04 & \text { "EOT" } \\ \text { BD,00,7F } & \\ 3 F(a t \$ 0041) & \\ 81,09 & \\ 2 E, 06 & \\ 8 B, 30 & \$ D+\$ 30=\$ 30=" D " \\ B D, 00,7 F & \\ 39 & \\ 8 B, 37 & \$ 37+\$ 0 A=\$ 41=" A " \\ B D, 007 F & \text { AT } \$ 0051 \\ 39 & \end{array}$

36

44

44

44

44

$B D, 00,42$

32

$84,0 \mathrm{~F}$

$\mathrm{BD}, 00,42$

39

AT $\$ 0060$

Output Data

Move Pointer

(Start Program Mode)

Supply EPROM

Address Range

Output Data

Move Pointer

NOTE: St. Addr. of Block

$\$ 0000-01$, End Addr. of

Block - \$0002-03

"F"

"F"

"p"

(a)

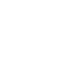




\begin{tabular}{|c|c|c|c|}
\hline$(\$ 0091)$ & $\begin{array}{l}\text { BCC } \\
\text { LDA B } \$ 8004 \\
\text { ASR B } \\
\text { BCS } \\
\text { STA A, } \$ 8009 \\
\text { PULL B } \\
\text { RTS }\end{array}$ & $\begin{array}{l}24, F 9 \\
F 6,80,04 \\
57 \\
25, F 3 \\
B 6,80,09 \\
33 \\
39\end{array}$ & $\left(i \circ e_{\circ}, \overline{C T S}=+12 \mathrm{~V}\right)$ \\
\hline $\begin{array}{l}(\$ 0092) \\
\text { INITIALIZE } \\
(\$ 00 A 1)\end{array}$ & $\begin{array}{l}\text { LD A A,\#881 } \\
\text { ST A A,\$8008 } \\
\text { LD A A\#\$00 } \\
\text { ST A A, \$8004 } \\
\text { LDA A,\#\$04 } \\
\text { STA A, } \$ 8005 \\
\text { RTS }\end{array}$ & $\begin{array}{l}86,81 \\
B 7,80,08 \\
86,00 \\
B 6,80,08 \\
86,04 \\
B 6,80,05 \\
39\end{array}$ & \\
\hline $\begin{array}{l}\text { (\$0OA4) } \\
\text { PATCH } \\
(\$ 00 A D)\end{array}$ & $\begin{array}{l}\text { LDX } \$ O F F F \\
\text { DEX } \\
\text { BNE }\{\text { PATCH }\} \\
\text { LDA B, } \$ 8008 \\
\text { RTS }\end{array}$ & $\begin{array}{l}C E, O F, F F \\
09 \\
26, F D \\
F 6,80,08 \\
39\end{array}$ & DELAY \\
\hline
\end{tabular}




\section{APPENDIX $V$}

USERS MANUAL

\section{A. Device Overview}

The Mathematics Trainer has been designed to tutor a visualiy handicapped student in the four basic arithmetic operations: addition, subtraction, multiplications, and division. The device uses speech in order to present the student with an imcomplete mathematical sentence such as "three plus two equals blank". The student will use a numeric keypad to enter the number that should be in the blank. A sketch of the Trainer is shown in Figs. 1 and 2. The device will inform the student of the responses's correctness. If the answer is incorrect, the device will repeat the problem. If the student fails to enter the correct response the second time, the device will inform the student of the response's incorrectness and will speak the entire problem with the correct answer in its proper place. If the student's answer is correct, the device will indicate that the response is correct and speak the complete mathematical sentence with the answer in place. After each problem, the device records the correctness of the student's answer and the amount of time that it took the student to respond. After the student has completed all of the problems that the teacher has assigned, the device reports the number of correct answers, the total number of problems attempted, and the total response time saying, "TOTAL[number right] OVER [number attempted]" pausing, and then saying "[number of minutes] 


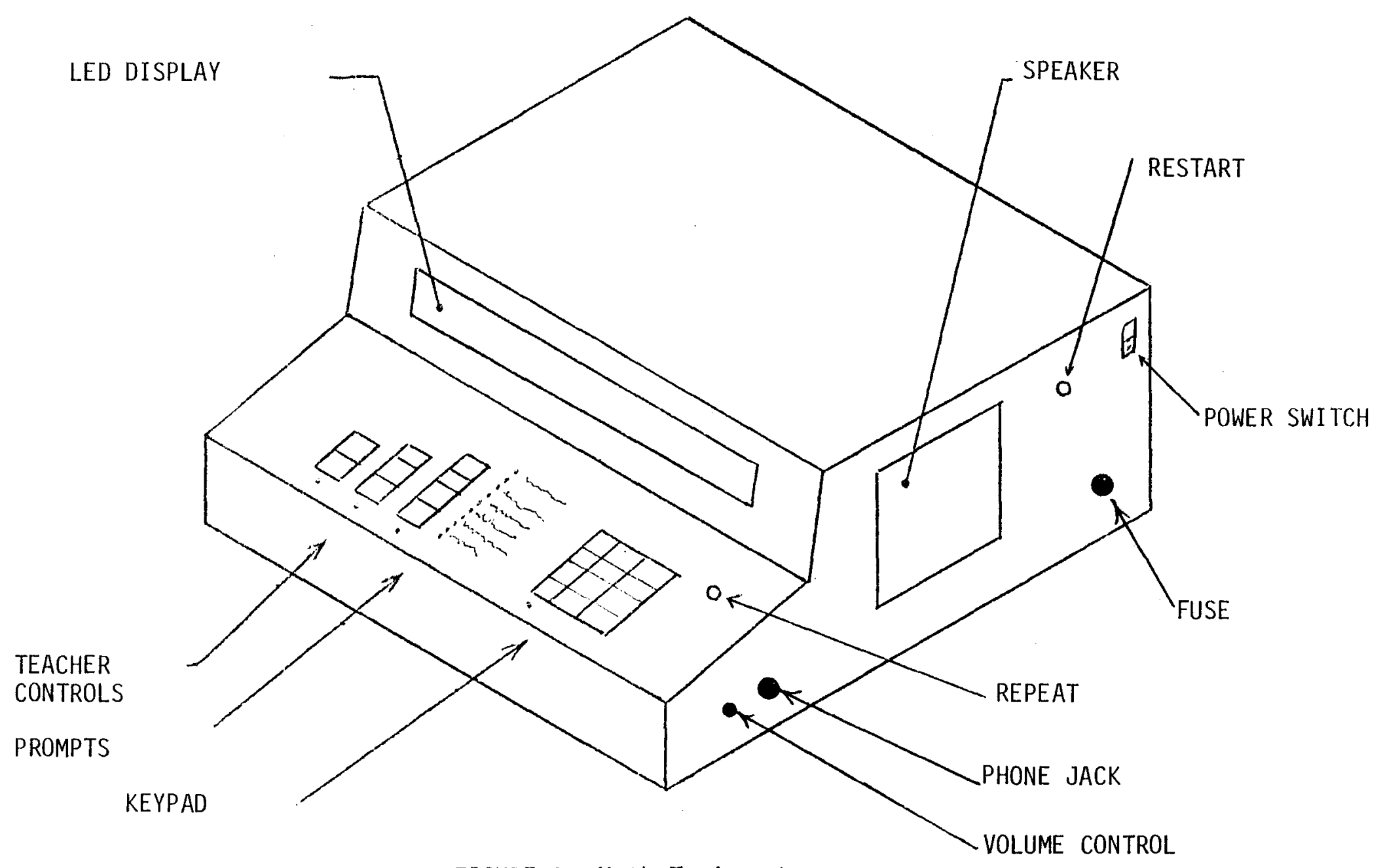

FIGURE 1 - Math Trainer Layout 
CHOICE OF METHOD

OF DEFINING PROBLEM

SETS ENTERED HERE

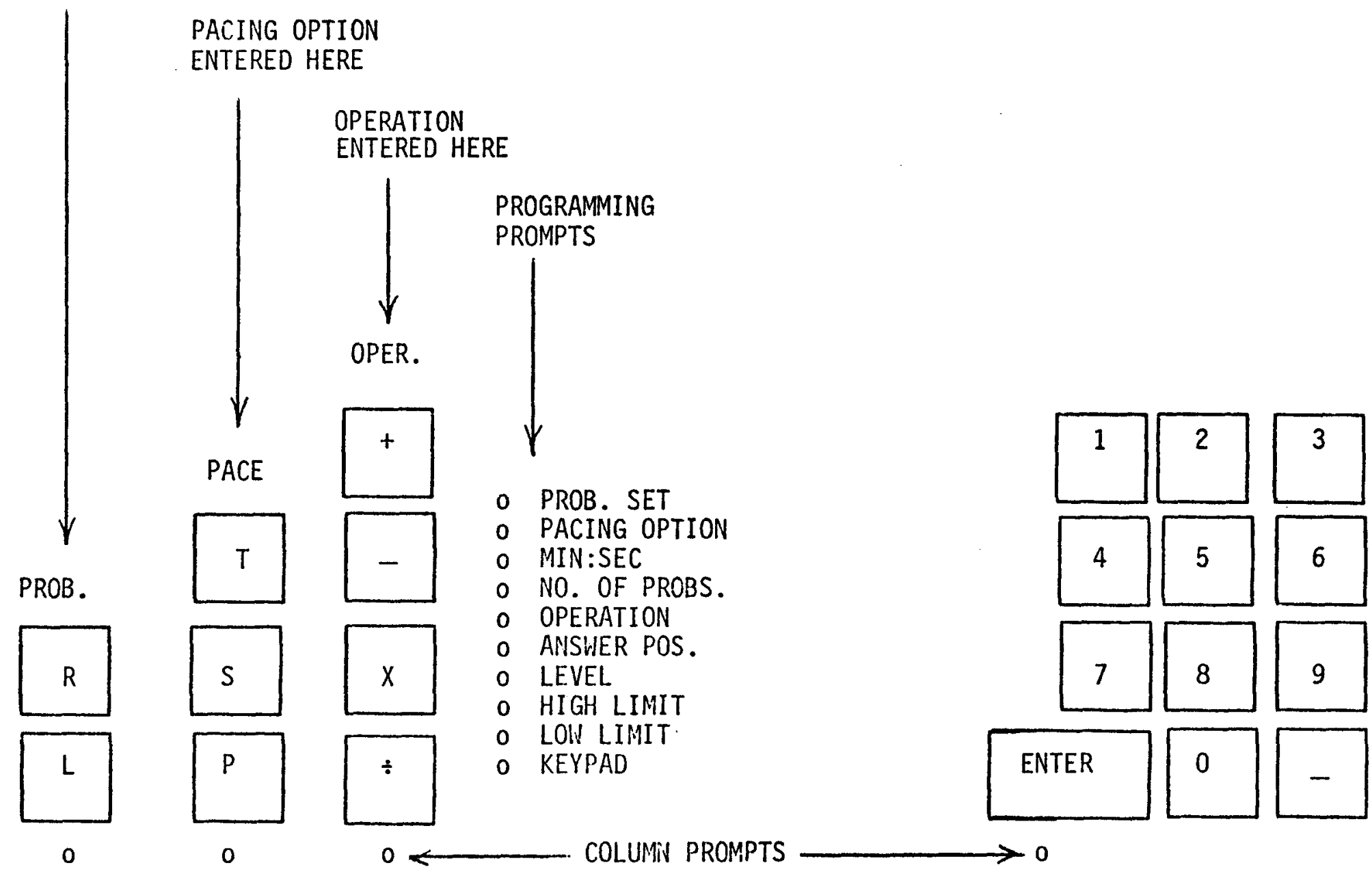

FIGURE 2 - Keyboard Detail. Prompt labels are in both print and braille. 
AND [number of seconds] SECONDS and STOP".

The teacher is able to select how the problems will be presented to the student. Problem sets may be setup on the basis of 1) a Timed mode, with a maximum total response time, 2) a Power mode, with a fixed number of problems and unlimited time, or 3) a Speed mode where the student has a fixed amount of time per problem and a fixed number of problems in the problem set.

The teacher is also able to define the contents of the problem sets. In addition to specifying the operation involved (addition, subtraction, multiplication, or division), the teacher can delimit the problem sets using two different modes. In the Level mode, ( $L$ key), the teacher supplies the device with the level of difficulty desired. In the Range mode, ( $R$ key), the teacher supplies the upper and lower bounds on the two operands needed to define the problem. The problems are generated randomly within a given problem set. In addition, each problem set is repeatable, by pushing REPEAT after the machine says "STOP"。A discussion of the choices made with regard to problem set generation, as well as Learning modes, is presented in the following sections.

\section{B. Problem Generation}

\section{Range Mode}

In the Range mode, the teacher defines the problem set by keying in the upper and lower limits for each of the first two numcers (operands) in the problem. The device randomly generates a number between or equal to these higher and lower limits. These random numbers become the actual values used in the problem. However, 
in division, the limits refer to the second and third numbers (i.e., the divisor and the quotient).

This mode allows the teacher to tailor problem sets to a student's specific needs. If, for example, a student is having trouble solving problems involving multiplications by three, the teacher could have the device present only problems that have three as the second number. This could be accomplished by setting both of the limits of the second number equal to three. 2. Level of Difficulty Mode

In the level of difficulty mode, the teacher supplies a level number to the device; that number corresponds to a specific predefined problem set. Those problem sets are arranged so that, for a given operation, they are progressively more difficult as the level number increases.

The teacher needs only to increment the level number, after the student becomes proficient in the present level, in order to proceed sequentially to the next more difficult problem set. Of course, the teacher must train the student in the mathematical mechanics necessary for each problem set.

In selecting the problem set for each level, every effort was made to present the computational concepts in the same order as is currently employed in the elementary schools. One of the major determinants of problem set difficulty is the presence of problems that involve regrouping. Regrouping is a term to denote the occurrence of a carry in addition or a borrow in subtraction. The device will discriminate between problems that have regrouping for addition and subtraction. (The problem set definitions for addition and subtraction 
are shown in TABLES 1 and 2). Because division is normally taught as the conceptual inverse of multiplication, it was decided that the divison problem sets would be the inverses of the multiplication problem sets (see TABLE 3).

\section{Problem and Answer Presentation}

This device is designed to be used by students in elementary school; therefore, the problem sets are limited to integer arithmetic. Since integers are not closed under division, only problems that have integer quotients are generated.

Often, problems that are presented in the students' text books, have the missing number in positions other than to the right of the equals sign. Because of this, the device will allow the teacher to change the position of the missing number to correspond to any of the three positions in the problem sentence. The three positions are numbered 1, 2, 3 for left, center, right, respectively. 1. Pacing Options

The teacher may choose three options that govern how the device limits problem sessions. In the first option (the Timed option), the teacher limits the time the student works on a problem set. When the time runs out, the problem session ends. In the second option (Speed), the teacher is able to limit the amount of time per problem attempt, as well as the total number of problems. If the time per attempt runs out, the device acts as if the student had entered an incorrect answer; if the maximum number of problems have been reached the problem session ends. In the third option (Power) the limiting factor is the number of problems. The teacher limits the 


\section{TABLE I}

ADDITION PROBLEM SETS

\begin{tabular}{lll}
\hline $\begin{array}{c}\text { Problem Set } \\
\text { Level }\end{array}$ & R a n g e of 0 p e r a n d s \\
\hline 1 & 0 Augend & Addend \\
\hline 2 & 0 to 4 & 0 to 4 \\
3 & 5 to 9 & 5 to 9 \\
4 & 5 to 9 & 0 to 4 \\
5 & 0 to 9 & 5 to 9 \\
6 & $0,10,20, \ldots, 90$ & 0 to 9 \\
7 & 0 to 9 & 0 to 9 \\
8 & $0,10,20, \ldots 90$ & $0,10,20, \ldots 90$ \\
$9^{*}$ & 10 to 99 & $0,10,20, \ldots 90$ \\
$10^{*}$ & 0 to 9 & 0 to 9 \\
11 & 10 to 99 & 10 to 9 \\
12 & 0 to 99 & 0 to 9 \\
$13^{*}$ & 19 to 99 & 10 to 99 \\
14 & 10 to 99 & 10 to 99 \\
$15^{*}$ & 100 to 499 & 10 to 99 \\
$16^{*}$ & 0 to 9 & 0 to 9 \\
17 & 100 to 499 & 100 to 499 \\
18 & 0 to 9 & 0 to 9 \\
$19^{*}$ & 100 to 499 & 100 to 499 \\
$20^{*}$ & 10 to 99 & 10 to 99 \\
21 & 100 to 499 & 100 to 499 \\
22 & 10 to 99 & 10 to 99 \\
$23^{*}$ & 100 to 499 & 100 to 499 \\
24 & 199 to 499 & 100 to 499 \\
25 & 100 to 499 & 100 to 499 \\
26 & -499 to 499 & -499 to 499 \\
27 & -499 to 499 & 100 to 499 \\
& -499 to 499
\end{tabular}

*NOTE: Indicates that problems containing regrouping are not members of the problem set. 
TABLE II

SUBTRACTION PROBLEM SETS

\begin{tabular}{lll}
\hline $\begin{array}{c}\text { Problem Set } \\
\text { Leve }\end{array}$ & R a $n g$ e o f 0 p e $r$ a $n$ d s \\
\hline $1^{*}$ & Minuend & Subtrahend \\
$2^{*}$ & 0 to 4 & 0 to 4 \\
$3^{*}$ & 0 to 4 & 5 to 9 \\
$4^{*}$ & 5 to 9 & 0 to 4 \\
$5^{*}$ & 5 to 9 & 5 to 9 \\
$6^{* *}$ & 0 to 9 & 0 to 9 \\
7 & 10 to 99 & 10 to 99 \\
8 & $0,10,20, \ldots, 90$ & 0 to 9 \\
$9 * *$ & 10 to 99 & 0 to 9 \\
$10^{* *}$ & 10 to 99 & 0 to 9 \\
11 & 100 to 499 & 0 to 9 \\
$12^{* *}$ & 100 to 499 & 0 to 9 \\
13 & 100 to 499 & 10 to 99 \\
$14 * *$ & 100 to 499 & 10 to 99 \\
15 & 100 to 499 & 100 to 499 \\
16 & 0 to 9 & 0 to 9 \\
17 & 19 to 99 & 10 to 99 \\
18 & 100 to 499 & 100 to 499 \\
19 & 0 to 9 & -9 to 9 \\
20 & -9 to 9 & 0 to 9 \\
$21^{*}$ & -9 to 9 & -9 to 9 \\
& -499 to 499 & -499 to 499
\end{tabular}

*NOTE: Indicates the given operand ranges are actually those of the augend and addend in the complementary addition problems.

**NOTE: Indicates that problems containing regrouping are not members of the problem set. 
TABLE III

MULTIPLICATION AND DIVISION PROBLEM SETS

\begin{tabular}{clc}
\hline $\begin{array}{c}\text { Problem Sets } \\
\text { Level }\end{array}$ & Ra $n g$ e o f & 0 pe $r$ a $n d s^{*}$ \\
\cline { 2 - 3 } & Multiplicand & Multiplier \\
1 & 0 to 4 & 0 to 4 \\
2 & 0 to 4 & 0 to 9 \\
3 & 0 to 9 & 0 to 4 \\
4 & 0 to 9 & 0 to 9 \\
5 & $0,10,20, \ldots, 90$ & 0 to 9 \\
6 & 0 to 9 & $0,10,20, \ldots, 90$ \\
7 & 0 to 9 & 10 to 99 \\
8 & 10 to 99 & 0 to 9 \\
9 & 10 to 30 & 10 to 30 \\
10 & 0 to 9 & -9 to 9 \\
11 & -9 to 9 & 0 to 9 \\
12 & -30 to 30 & -30 to 30
\end{tabular}

*NOTE: For division the problem is generated by the multiplication of numbers within the ranges in the table. The product is then placed in dividend position. 
number of problems in the session, but the student may take any amount of time in responding to each problem. When the maximum number of problems have been completed the problem sessions ends. 2. Correct/Incorrect Answers and Repeat Key

Several standard phrases were created: When a problem has been answered correctly, a string of three low tones are said by the synthesizer; An incorrect response elicits two high tones. The words "go please", serve as a general purpose audio prompt.

The device also has the capability to repeat a problem set verbatim. The major use of this feature would be if the teacher noticed that the student had difficulty with the present problem set. The teacher could then cause the problem set to be repeated, and observe the types of problems that give the student the most difficulty. If a sighted student forgets the current problem, that student can simply look at the problem again. A blind student listening to a verbal problem should have the same opportunity. For this reason a repeat problem presentation button has been incorporated into the device. Pushing the repeat button, while the trainer is waiting for the answer to a problem, causes the problem to be reread.

3. Keypad and Keypad Drill

Because many students are familiar with the Speech Plus calculator, the device's keypad is designed with the numeric keys in the same configuration as the calculator. The only difference being the presence of an enter key and a minus key (for negative number entry). 
The device also has a keypad training dri11, which begins after the teacher has completed setting up the Math Trainer. This drill will ask the student to depress the keys on the keypad in order, saying "zero please", "one please", etc. If the student hits the correct key, that key will echo its designation and sound a tone. Wrong keys will only echo their designations. Pusing the repeat button will cause the keyboard drill to end and the problem session to begin.

D. Setting Up (Programming) the Trainer for Use

Before each problem session, the teacher will have to set up (Program) the device in the desired configuration. Parameters such as teaching mode, operation to be performed, location of missing number, number of problems, level of difficulty, etc. must be supplied to the device. Verbal asking of the required questions is not possible with the limited vocabulary of the device. Therefore, a scheme using a prompt beside a written statement (in both braille and print) of the parameter to be entered is used. The prompt is an illuminated LED next to a print and braille label. The following sequence of events takes place in setting up the device for student use:

1) Teacher turns device on.

2) Teacher chooses either Range or Level mode via $R$ or $L$ keys in PROB column.

3) The Pacing Option (Timed, Speed, Power) is selected via the PACE column.

4) If the Time Option was selected the teacher enters the total time limit (via the keypad) in minutes and seconds (up to 99 minutes 
and 99 seconds) remembering to push ENTER after the last digit.

5) If the Speed Option was selected the teacher enters in the time limit per attempt in minutes and seconds (up to 20 minutes). [PUSh ENTER].

6) If the Timed Option has not been selected the teacher enters the number of problems in the problem session via the keypad. [PUSh ENTER].

7) The teacher keys in the operation $(+,-, x, \div)$.

8) If the Level Mode was selected the teacher keys in the level of difficulty number. [Push ENTER].

9) If the Range Mode was chosen the teacher enters the high and low limits of the first operand followed by the high and low limits of the second operand. [Push ENTER after each high or low limit].

The sequence of events that the student sees are shown

below:

1) The trainer begins the keyboard drill. The student should press the zero key when the device says "Zero Please". The remainder of the keys are treated in a similar fashion. [NOTE: to skip the keyboard dri11, push the REPEAT key.]

2) The trainer begins the problem session. In response to a problem, the student should enter hi (or her) answer using the keypad, followed by pushing the ENTER key. Correct responses are followed by three low tones, after which the problem and answer are spoken. An incorrect response to the first presentation of a problem is followed by two high rones and a second, and final, presentation of that problem. A second incorrect response is followed by two high tones, after which the problem and answer are spoken. 
Pushing a programing key causes the previous entries to be erased and the words "Go Please" to be said.

3) When the problem session is over the device reports the student's score and the total student response time. After the device says "STOP" the entire problem session can be repeated by pushing the Repeat button. Pushing the Restart button, at this or at any time, causes the trainer to start over at the point where the teacher chooses the Range or Level modes. Pushing any other key will cause the device to say the score again. 


\section{VITA}

The author of this thesis, Michael Joseph Linnig, was born on May 23, 1956, in Louisvil1e, Kentucky.

His elementary education was obtained at St. Clement's

School and St. Timothy's School in Louisville. His secondary education was obtained at Bishop David High School, also in Louisville. He graduate from Bishop David in May, 1974.

In August, 1974, he enrolled in the Speed Scientific School of the University of Louisville, where he majored in Electrical Engineering. He received his Bachelor of Science Degree in May, 1978, and his Master of Engineering Degree in Electrical Engineering in August, 1979. 